
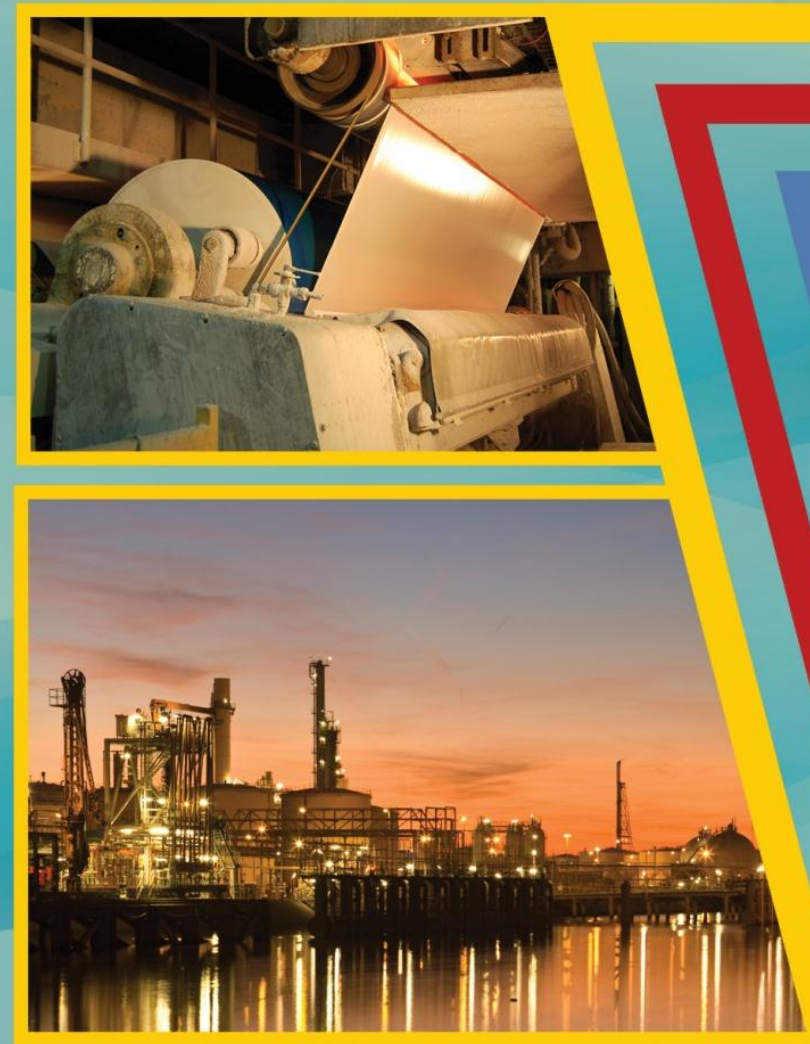

\title{
U.S. Manufacturing
}

$$
\begin{aligned}
& \text { Energy Use and } \\
& \text { Greenhouse Gas }
\end{aligned}
$$

EnjJstons Analysis

\section{November 2012}

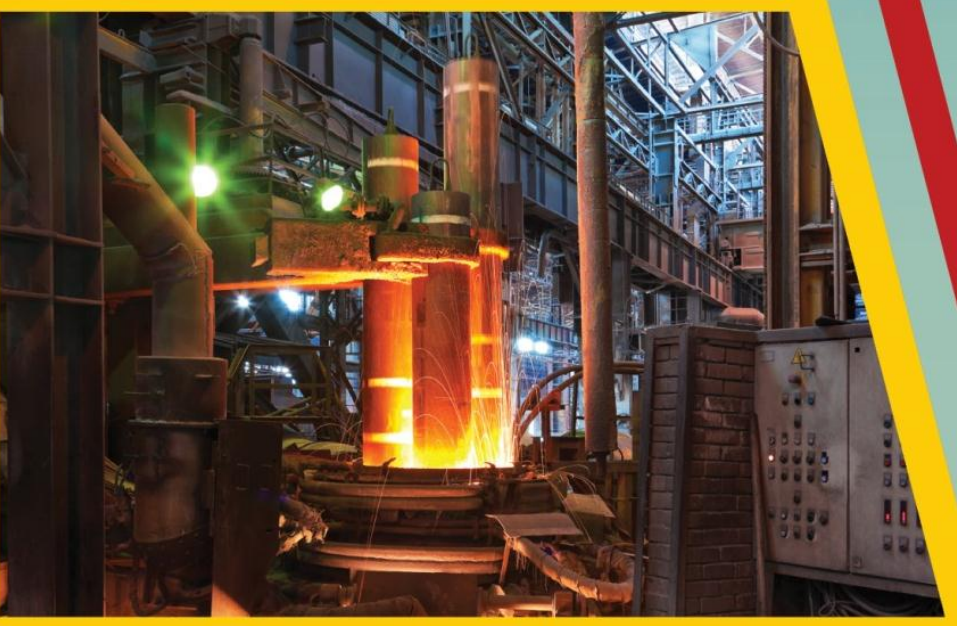

Prepared by

ENERGETICS INCORPORATED 


\title{
DOCUMENT AVAILABILITY
}

Reports produced after January 1, 1996, are generally available free via the U.S. Department of Energy (DOE) Information Bridge.

Web site http://www.osti.gov/bridge

Reports produced before January 1, 1996, may be purchased by members of the public from the following source.

\author{
National Technical Information Service \\ 5285 Port Royal Road \\ Springfield, VA 22161 \\ Telephone 703-605-6000 (1-800-553-6847) \\ TDD 703-487-4639 \\ Fax 703-605-6900 \\ E-mail info@ntis.gov \\ Web site http://www.ntis.gov/support/ordernowabout.htm
}

Reports are available to DOE employees, DOE contractors, Energy Technology Data Exchange (ETDE) representatives, and International Nuclear Information System (INIS) representatives from the following source.

Office of Scientific and Technical Information

P.O. Box 62

Oak Ridge, TN 37831

Telephone 865-576-8401

Fax 865-576-5728

E-mail reports@osti.gov

Web site http://www.osti.gov/contact.html

\begin{abstract}
This report was prepared as an account of work sponsored by an agency of the United States Government. Neither the United States Government nor any agency thereof, nor any of their employees, makes any warranty, express or implied, or assumes any legal liability or responsibility for the accuracy, completeness, or usefulness of any information, apparatus, product, or process disclosed, or represents that its use would not infringe privately owned rights. Reference herein to any specific commercial product, process, or service by trade name, trademark, manufacturer, or otherwise, does not necessarily constitute or imply its endorsement, recommendation, or favoring by the United States Government or any agency thereof. The views and opinions of authors expressed herein do not necessarily state or reflect those of the United States Government or any agency thereof.
\end{abstract}




\section{U.S. MANUFACTURING ENERGY USE AND GREENHOUSE GAS EMISSIONS ANALYSIS}

Sabine Brueske, Ridah Sabouni, Chris Zach, and Howard Andres

November 2012

Prepared by

ENERGETICS INCORPORATED

Columbia, Maryland 21046

Prepared for

OAK RIDGE NATIONAL LABORATORY

Oak Ridge, Tennessee 37831-6283

managed by

UT-BATTELLE, LLC

for the

U.S. DEPARTMENT OF ENERGY

under contract DE-AC05-00OR22725 



\section{CONTENTS}

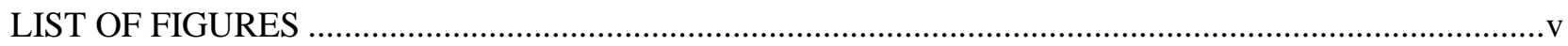

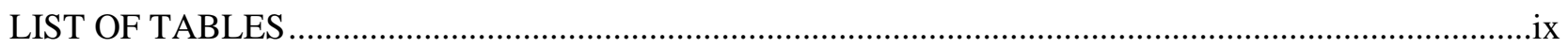

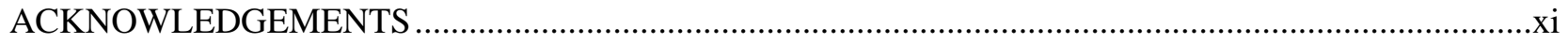

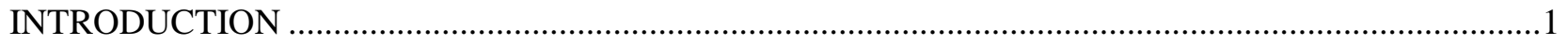

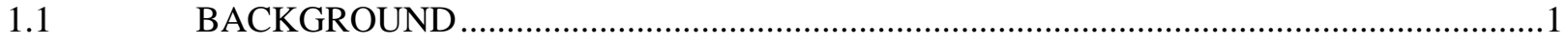

1.1.1. The Importance of Energy Efficiency in U.S. Manufacturing ............................................

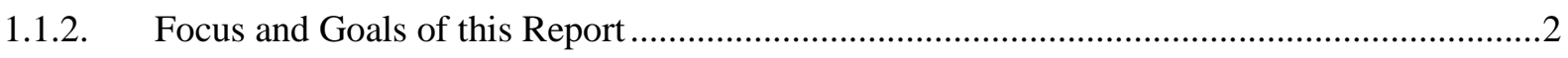

$1.2 \quad$ METHODOLOGY

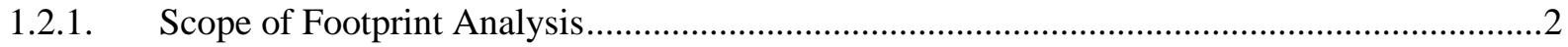

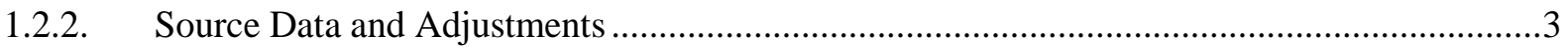

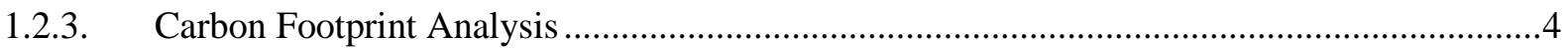

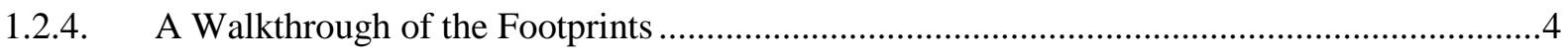

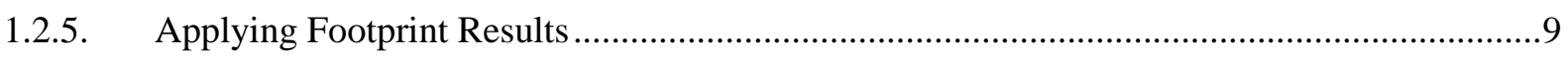

ENERGY AND GREENHOUSE GAS COMBUSTION EMISSIONS PROFILES .................................11

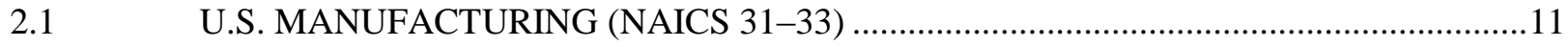

2.1.1. Overview of U.S. Manufacturing ................................................................................

2.1.2. Energy Use Profile for U.S. Manufacturing and Sector Rankings......................................11

2.1.3. Greenhouse Gas Combustion Emissions Profile for U.S. Manufacturing and Sector

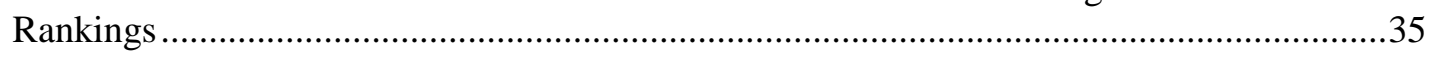

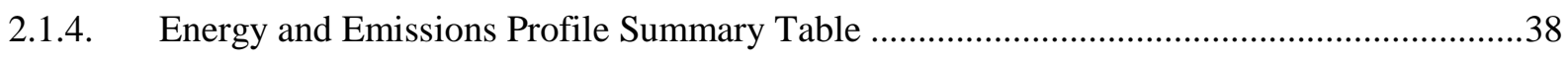

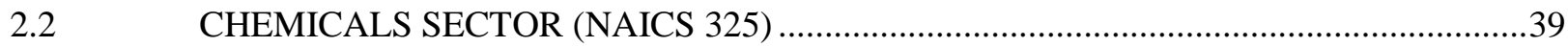

2.2.1. Overview of the Chemicals Manufacturing Sector ..............................................................39

2.2.2. Energy Use Profile for the Chemicals Sector .......................................................................

2.2.3. Greenhouse Gas Combustion Emissions Profile for the Chemicals Sector ..........................51

2.2.4. Energy and Emissions Profile Summary Table ................................................................53

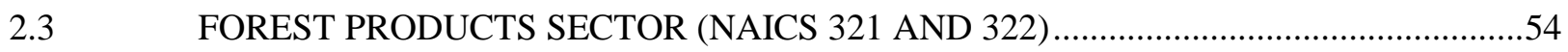

2.3.1. Overview of the Forest Products Manufacturing Sector .....................................................54

2.3.2. Energy Use Profile for the Forest Products Sector ..........................................................54

2.3.3. Greenhouse Gas Combustion Emissions Profile for the Forest Products Sector ..................66

2.3.4. Energy and Emissions Profile Summary Table .................................................................6

2.4 PETROLEUM REFINING SECTOR (NAICS 324110).............................................69

2.4.1. Overview of the Petroleum Refining Manufacturing Sector .............................................69

2.4.2. Energy Use Profile for the Petroleum Refining Sector ......................................................69

2.4.3. Greenhouse Gas Combustion Emissions Profile for the Petroleum Refining Sector.............81

2.4.4. Energy and Emissions Profile Summary Table ............................................................... 83 
2.5 FOOD AND BEVERAGE SECTOR (NAICS 311 AND 312) ....................................... 84

2.5.1. Overview of the Food and Beverage Manufacturing Sector ...............................................84

2.5.2. Energy Use Profile for the Food and Beverage Sector ...................................................... 84

2.5.3. Greenhouse Gas Combustion Emissions Profile for the Food and Beverage Sector.............96

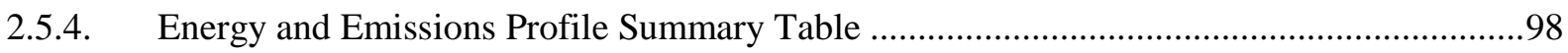

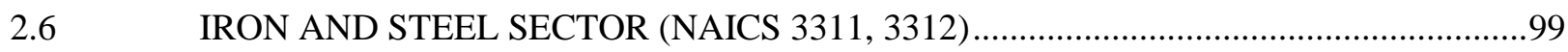

2.6.1. Overview of the Iron and Steel Manufacturing Sector ........................................................99

2.6.2. Energy Use Profile for the Iron and Steel Sector .............................................................99

2.6.3. Greenhouse Gas Combustion Emissions Profile for the Iron and Steel Sector....................111

2.6.4. Energy and Emissions Profile Summary Table ............................................................. 113

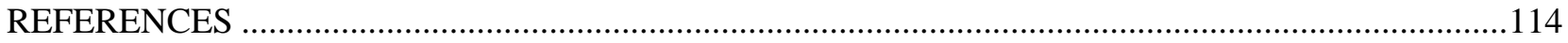

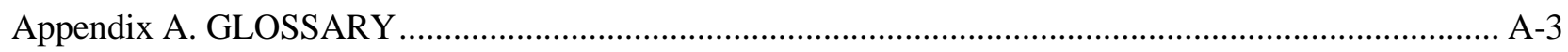

Appendix B. FOOTPRINTS SCOPE AND SECTOR DESCRIPTIONS …...............................................

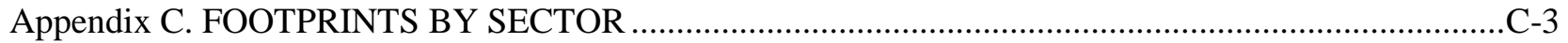

Appendix D. FOOTPRINT ASSUMPTIONS AND DATA ADJUSTMENTS …................................ D-3

Appendix E. ALLOCATION OF STEAM TO PROCESS AND NONPROCESS END USES .................. E-3

Appendix F. ESTIMATION OF PROCESS HEATING ENERGY LOSS …......................................... F-3 


\section{LIST OF FIGURES}

Figure

Page

1.1-1 2006 U.S. energy consumption [EIA 2010a] ......................................................... 1

1.2-1

1.2-2

1.2-3

1.2-4

2.1-1

2.1-2

2.1-3

2.1-4

2.1-5

2.1-6

2.1-7

2.1-8

2.1-9

2.1-10

2.1-11

2.1-12

2.1-13

2.1-14

2.1-15

2.1-16

2.1-17

2.1-18

2.1-19

2.1-20

Footprint legend 4

Total primary energy use and GHG combustion emissions for the chemicals sector ..........5

Onsite energy and carbon emissions for the chemicals sector .........................................6

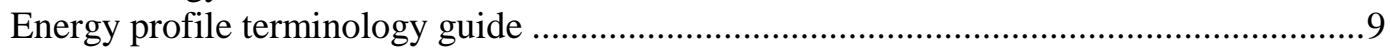

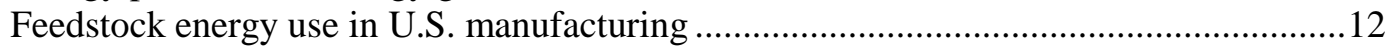

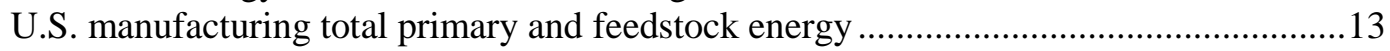

Total energy and carbon footprint for U.S. manufacturing ......................................... 14

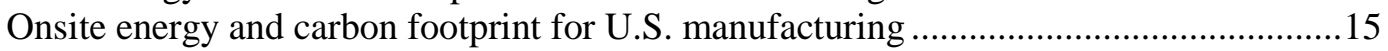

Primary energy use by energy type for U.S. manufacturing ........................................ 16

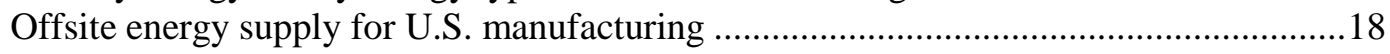

Offsite fuel, electricity, and steam supply by manufacturing sector ..............................19

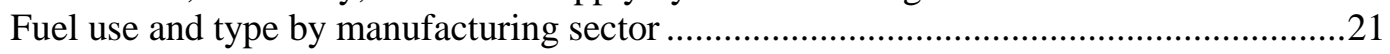

Electricity generation and direct end use in U.S. manufacturing ...................................22

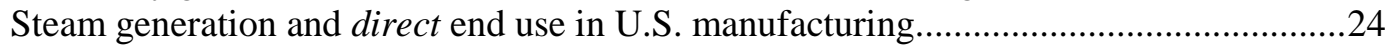

CHP fuel consumption and energy output in U.S. manufacturing ................................27

Primary energy by type at direct end use in U.S. manufacturing .................................28

Primary energy by direct end use in U.S. manufacturing ...........................................29

Primary energy use and applied energy by energy type for U.S. manufacturing ...............32

Primary energy by loss and applied energy in U.S. manufacturing .................................33

Primary applied energy by direct end use in U.S. manufacturing .....................................34

Onsite and offsite GHG combustion emissions in U.S. manufacturing ............................35

Total GHG combustion emissions in U.S. manufacturing (shown by energy supply

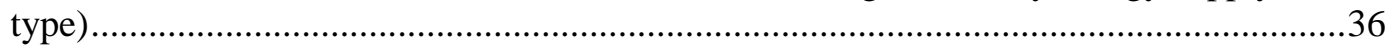

Total GHG combustion emissions in U.S. manufacturing (shown by energy end use type).

Total GHG combustion emissions in U.S. manufacturing (shown by direct energy end

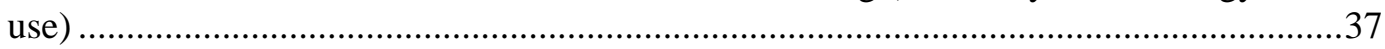

2.2-1 Feedstock energy use in the chemicals sector ...........................................................40

2.2-2 Total energy and carbon footprint for the chemicals sector ..........................................41

2.2-3 Onsite energy and carbon footprint for the chemicals sector .......................................42

2.2-4 Primary energy use by energy type in the chemicals sector...........................................43

2.2-5 Offsite energy supply in the chemicals sector .............................................................4

2.2-6 Onsite energy use in selected chemicals subsectors ......................................................4

2.2-7 Electricity generation and direct end use in the chemicals sector ...................................45

2.2-8 Steam generation and direct end use in the chemicals sector.........................................46

2.2-9 CHP fuel consumption and energy output in the chemicals sector ................................47

2.2-10 Primary energy by type at direct end use in the chemicals sector...................................47

2.2-11 Primary energy by direct end use in the chemicals sector .............................................48

2.2-12 Primary energy and applied energy by type in the chemicals sector...............................49

2.2-13 Primary energy by loss and applied energy in the chemicals sector ...............................49

2.2-14 Primary applied energy by direct end use in the chemicals sector..................................50

2.2-15 Total GHG combustion emissions in the chemicals sector (shown by energy supply

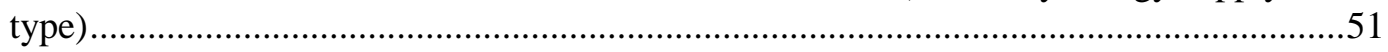

2.2-16 Total GHG combustion emissions in the chemicals sector (shown by energy end use

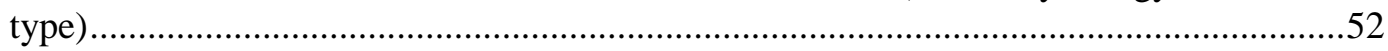

2.2-17 Total GHG combustion emissions in the chemicals sector (shown by direct energy

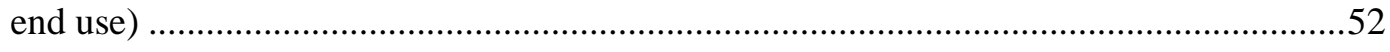

U.S. Manufacturing Energy Use and Greenhouse Gas Emissions Analysis 
2.3-1 Feedstock energy use in the forest products sector .......................................................55

2.3-2 Total energy and carbon footprint for the forest products sector ...................................56

2.3-3 Onsite energy and carbon footprint for the forest products sector ...................................57

2.3-4 Primary energy use by energy type for the forest products sector ................................58

2.3-5 Offsite energy supply in the forest products sector ....................................................58

2.3-6 Onsite energy use in selected forest products subsectors ..............................................59

2.3-7 Electricity generation and direct end use in the forest products sector ..........................60

2.3-8 Steam generation and direct end use in the forest products sector.................................61

2.3-9 CHP fuel consumption and energy output in the forest products sector ........................62

2.3-10 Primary energy by type at direct end use in the forest products sector ...........................62

2.3-11 Primary energy by direct end use in the forest products sector.......................................63

2.3-12 Primary energy use and applied energy by energy type in the forest products sector.......64

2.3-13 Primary energy by loss and applied energy in the forest products sector .......................65

2.3-14 Primary applied energy by direct end use in the forest products sector...........................65

2.3-15 Total GHG combustion emissions in the forest products sector (shown by energy supply

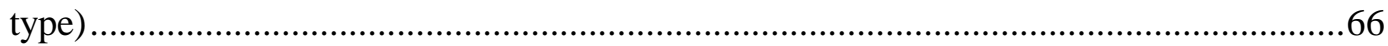

2.3-16 Total GHG combustion emissions in the forest products sector (shown by energy end

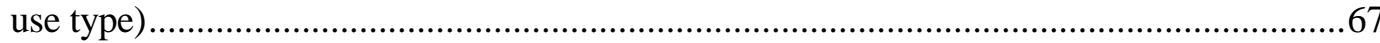

2.3-17 Total GHG combustion emissions in the forest products sector (shown by direct energy

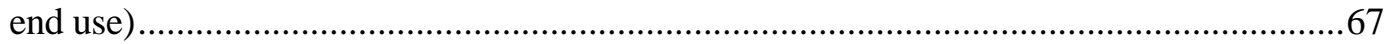

2.4-1 Feedstock energy use in the petroleum refining sector .............................................. 70

2.4-2 Total energy and carbon footprint for the petroleum refining sector .............................71

2.4-3 Onsite energy and carbon footprint for the petroleum refining sector ............................72

2.4-4 Primary energy by energy type in the petroleum refining sector ...................................73

2.4-5 Offsite energy supply in the petroleum refining sector .................................................74

2.4-6 Electricity generation and direct end use in the petroleum refining sector ......................75

2.4-7 Steam generation and direct end use in the petroleum refining sector.............................76

2.4-8 CHP fuel consumption and energy output in the petroleum refining sector .....................77

2.4-9 Primary energy by type at direct end use in the petroleum refining sector .......................77

2.4-10 Primary energy by direct end use in the petroleum refining sector..................................78

2.4-11 Primary energy and applied energy by energy type in the petroleum refining sector .......79

2.4-12 Primary energy by loss and applied energy in the petroleum refining sector ..................80

2.4-13 Primary applied energy by direct end use in the petroleum refining sector......................80

2.4-14 Total GHG combustion emissions in the petroleum refining sector (shown by energy

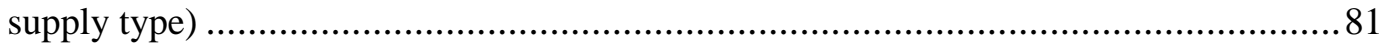

2.4-15 Total GHG combustion emissions in the petroleum refining sector (shown by energy

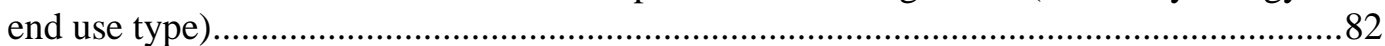

2.4-16 Total GHG combustion emissions in the petroleum refining sector (shown by direct

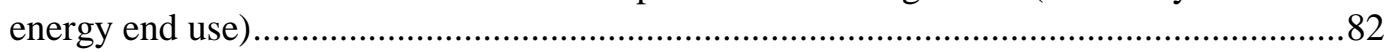

2.5-1 Feedstock energy use in the food and beverage sector................................................85

2.5-2 Total energy and carbon footprint for the food and beverage sector..............................86

2.5-3 Onsite energy and carbon footprint for the food and beverage sector............................87

2.5-4 Primary energy by energy type in the food and beverage sector.................................... 88

2.5-5 Offsite energy supply in the food and beverage sector ...............................................89

2.5-6 Onsite energy use in selected food and beverage subsectors .......................................89

2.5-7 Electricity generation and direct end use in the food and beverage sector ......................90

2.5-8 Steam generation and direct end use in the food and beverage sector .............................91

2.5-9 CHP fuel consumption and energy output in the food and beverage sector......................92

2.5-10 Primary energy by type at direct end use in the food and beverage sector ......................92

2.5-11 Primary energy by direct end use in the food and beverage sector ..................................93

2.5-12 Primary energy and applied energy by energy type in the food and beverage sector .......94

2.5-13 Primary energy by loss and applied energy in the food and beverage sector ....................95

2.5-14 Primary applied energy by direct end use in the food and beverage sector .................... 95 
2.5-15 Total GHG combustion emissions in the food and beverage sector (shown by energy

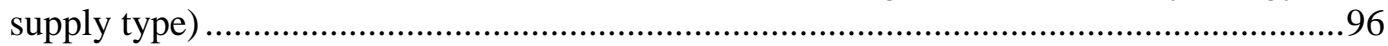

2.5-16 Total GHG combustion emissions in the food and beverage sector (shown by energy end use type).

2.5-17 Total GHG combustion emissions in the food and beverage sector (shown by direct

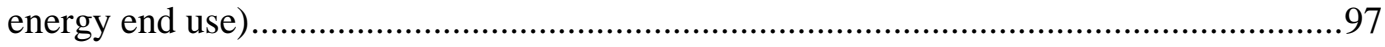

2.6-1 Feedstock energy use in the iron and steel sector.......................................................100

2.6-2 Total energy and carbon footprint for the iron and steel sector..................................... 101

2.6-3 Onsite energy and carbon footprint for the iron and steel sector....................................102

2.6-4 Primary energy by energy type in the iron and steel sector.......................................... 103

2.6-5 Offsite energy supply in the iron and steel sector ...................................................... 104

2.6-6 Onsite energy use in selected iron and steel subsectors ...........................................104

2.6-7 Electricity generation and direct end use in the iron and steel sector ...........................105

2.6-8 Steam generation and direct end use in the iron and steel sector .................................106

2.6-9 CHP fuel consumption and energy output in the iron and steel sector...........................107

2.6-10 Primary energy by type at direct end use in the iron and steel sector ...........................107

2.6-11 Primary energy by direct end use in the iron and steel sector .......................................108

2.6-12 Primary energy and applied energy by energy type in the iron and steel sector .............109

2.6-13 Primary energy by loss and applied energy in the iron and steel sector.........................109

2.6-14 Primary applied energy by direct end use in the iron and steel sector ...........................110

2.6-15 Total GHG combustion emissions in the iron and steel sector (shown by energy supply type)

2.6-16 Total GHG combustion emissions in the iron and steel sector (shown by energy end

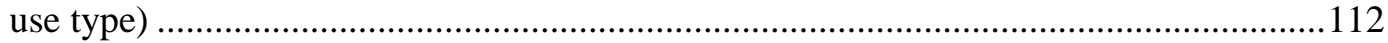

2.6-17 Total GHG combustion emissions in the iron and steel sector (shown by direct energy

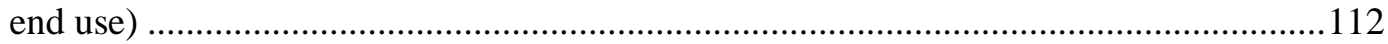

E.1 Manufacturing energy and carbon footprint for U.S. manufacturing - total energy ........E-4 E.2 Manufacturing energy and carbon footprint for U.S. manufacturing - onsite energy.....E-4 E.3 Steam end use values evaluated by steam working group.............................................. E-6

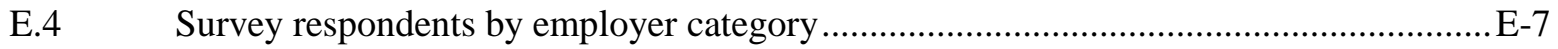

E.5 Number of survey respondents for 15 individual sectors ........................................ E-8

F.1 Manufacturing energy and carbon footprint for U.S. manufacturing - total energy ....... F-4

F.2 Manufacturing energy and carbon footprint for U.S. manufacturing - onsite energy.....F-4

F.3 Process heating energy loss value evaluated by the process heating working group ...... F-6

F.4 Simplified process heating equipment energy balance (as derived from Improving Process Heating System Performance: A Sourcebook for Industry, Figure 2, Page 13).................... F-9 



\section{LIST OF TABLES}

Table

Page

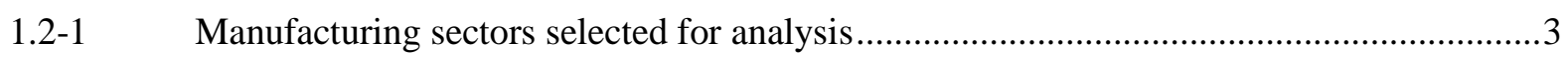

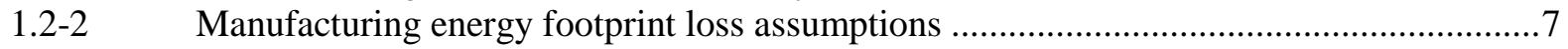

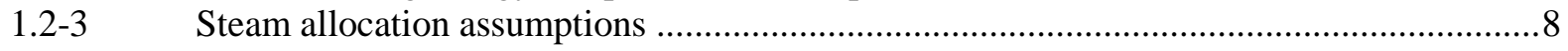

2.1-1 Snapshot of energy use and loss within U.S. manufacturing ........................................11

2.1-2 U.S. manufacturing sector rank by primary energy use ............................................ 17

2.1-3 Offsite energy supply by U.S. manufacturing sector..................................................... 19

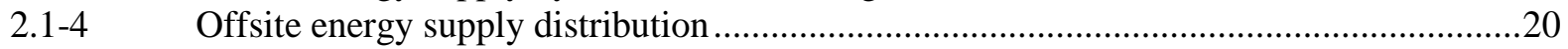

2.1-5 U.S. manufacturing sectors ranked by fuel use (indirect and direct end use) .................21

2.1-6 U.S. manufacturing sectors ranked by electricity use (direct end use) ............................23

2.1-7 U.S. manufacturing sectors ranked by steam use (direct end use) .................................25

2.1-8 Steam end-use equipment in energy-intensive industries [AMO EERE 2012b]..............26

2.1-9 U.S. manufacturing sectors ranked by onsite steam and electricity generation, TBtu ......27

2.1-10 U.S. manufacturing sectors ranked by CHP fuel use and output, TBtu ..........................28

2.1-11 U.S. manufacturing sectors ranked by process heating energy …....................................30

2.1-12 U.S. manufacturing sectors ranked by process cooling energy ….................................30

2.1-13 U.S. manufacturing sectors ranked by machine drive energy ….....................................

2.1-14 U.S. manufacturing sectors ranked by nonprocess energy …............................................

2.1-15 U.S. manufacturing sectors ranked by applied energy ….................................................33

2.1-16 U.S. manufacturing sectors ranked by total GHG combustion emissions.........................37

2.1-17 Energy use, loss, and GHG combustion emissions in U.S. manufacturing......................38

2.2-1 Chemicals subsectors with data reported in MECS ......................................................39

2.2-2 Snapshot and ranking of energy use, loss, and GHG combustion emissions in the

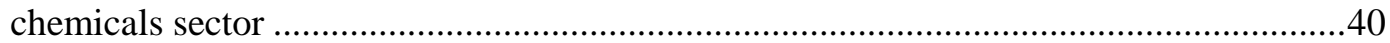

2.2-3 Energy use, loss, and GHG combustion emissions in the chemicals sector.....................53

2.3-1 Forest products subsectors with data reported in MECS...............................................54

2.3-2 Snapshot of the forest products sector: energy use and rank within U.S. manufacturing .......55

2.3-3 Energy use, loss, and GHG combustion emissions in the forest products sector ..............68

2.4-1 Snapshot of the petroleum refining sector: Energy use and rank within U.S.

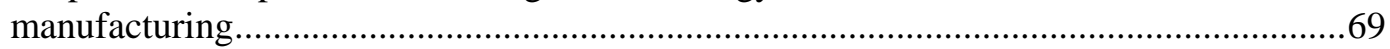

2.4-2 Energy use, loss, and GHG combustion emissions in the petroleum refining sector ........83

2.5-1 Food and beverage subsectors with data reported in MECS ..........................................84

2.5-2 Snapshot of the food and beverage sector: Energy use and rank within U.S.

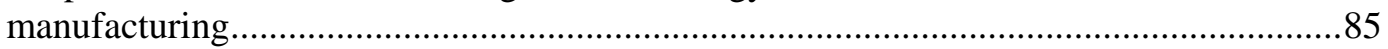

2.5-3 Energy use, loss, and GHG combustion emissions in the food and beverage sector ........98

2.6-1 Iron and steel subsectors with data reported in MECS.................................................99

2.6-2 Snapshot of the iron and steel sector: Energy use and rank within U.S. manufacturing .......100

2.6-3 Energy use, loss, and GHG combustion emissions in the iron and steel sector ..............113

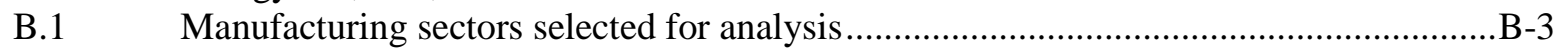

D.1 Manufacturing energy footprint loss assumptions ….......................................... D-3

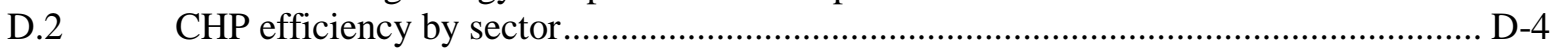

D.3 Process heating loss assumptions by sector.......................................................... D-4

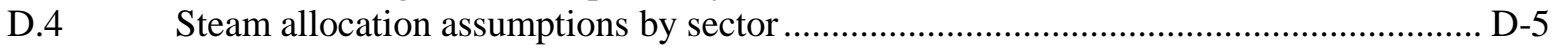

D.5 Fuel GHG combustion emission factors $\left(\mathrm{kg} \mathrm{CO}_{2} \mathrm{e}\right.$ per million Btu $)$............................ D-6

E.1 Steam end use working group organizations ......................................................... E

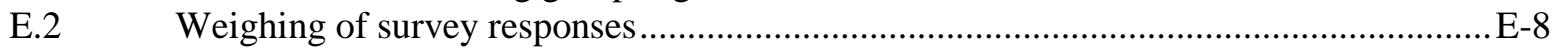

E.3 Results for steam allocation from the manufacturing steam end use working group......E-9

E.4 Manufacturing sector NAICS codes and net steam use ................................................

F.1 Process heating energy loss working group organizations ....................................... F-5

U.S. Manufacturing Energy Use and Greenhouse Gas Emissions Analysis 
F.2 Alternative analysis approaches considered by Energetics …................................... F-7

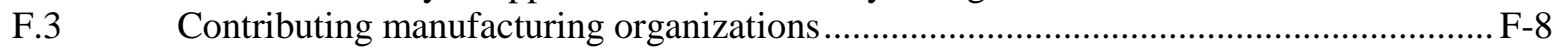

F.4 Simplified process heating energy balance loss areas explained ............................... F-9

F.5 Results for process heating energy loss from the manufacturing process heating energy loss working group .............................................................................F-11

F.6 Sources consulted in estimating process heating energy loss................................... F-11 


\section{ACKNOWLEDGEMENTS}

This report was prepared by Sabine Brueske, Ridah Sabouni, Chris Zach, and Howard Andres of Energetics Incorporated, with valuable contributions from many others. Energetics Incorporated is a consulting firm headquartered in Columbia, MD.

The authors gratefully acknowledge the many individuals and organizations that contributed to this project. In particular, we would like to express our gratitude to the following individuals, who dedicated significant time and attention to reviewing the report and/or contributing to specific analysis topics:

$\begin{array}{ll}\text { Isaac Chan } & \text { Bob Adler, } \\ \text { U.S. DOE, AMO } & \text { Energy Information Administration } \\ \text { Steve Sikirica } & \text { Tom Lorenz, } \\ \text { U.S. DOE, AMO } & \text { Energy Information Administration } \\ \text { Paul Scheihing } & \text { Sachin Nimbalkar } \\ \text { U.S. DOE, AMO } & \text { Oak Ridge National Laboratory } \\ \text { Bob Gemmer } & \text { Thomas Wenning, } \\ \text { U.S. DOE, AMO } & \text { Oak Ridge National Laboratory } \\ \text { Arvind Thekdi, } & \text { Michaela Martin, } \\ \text { E3M } & \text { Oak Ridge National Laboratory } \\ \text { Jimmy Kumana, } & \text { Patti Garland } \\ \text { Kumana and Associates } & \text { Oak Ridge National Laboratory }\end{array}$

We would also like to recognize the following organizations for their contributions to the industry peer reviews that were conducted in support of this analysis. These organizations were not asked to contribute to the report as a whole, but rather to provide insights on specific peer review topics:

$\begin{array}{lll}\text { Advanced Energy } & \text { Diamond Engineering } & \text { Lawrence Berkeley National Laboratory } \\ \text { Alcoa } & \text { Dick Reese and Associates } & \text { Northwestern University } \\ \text { Alzeta } & \text { Didion Dry Corn Milling } & \text { Oak Ridge National Laboratory } \\ \text { ArcelorMittal } & \text { Dow Chemical Company } & \text { Phillips 66 } \\ \text { Armstrong International } & \text { Duke Energy } & \text { Saint-Gobain } \\ \text { Briggs \& Stratton } & \text { E3M } & \text { Shell } \\ \text { CHT Analytics } & \text { Energy Information Administration } & \text { Southern Company } \\ \text { Carus Corporation } & \text { Foster Farms } & \text { Spreckels Sugar } \\ \text { Council of Industrial Boiler Owners } & \text { Hauck Manufacturing } & \text { Spirax Sarco } \\ \text { Darigold } & \text { Hilmar Cheese Company } & \text { Tenova Core } \\ \text { Davisco Foods } & \text { Karl Dungs Inc. } & \\ \text { Del Mar Food Products } & \text { Kumana and Associates } & \end{array}$

Sachin Nimbalkar of Oak Ridge National Laboratory provided general direction for this project, with the sponsorship of the Advanced Manufacturing Office (AMO), U.S. Department of Energy (DOE). This report provides an introduction to and analysis of the Manufacturing Energy and Carbon Footprints, which are posted on the U.S. DOE/AMO website. 



\section{INTRODUCTION}

\subsection{BACKGROUND}

\subsubsection{The Importance of Energy Efficiency in U.S. Manufacturing}

The United States (U.S.) manufacturing sector uses significant amounts of energy to convert raw materials into usable products. As shown in Fig. 1.1-1, the U.S. manufacturing sector is estimated to consume over one quarter of all U.S. energy use.

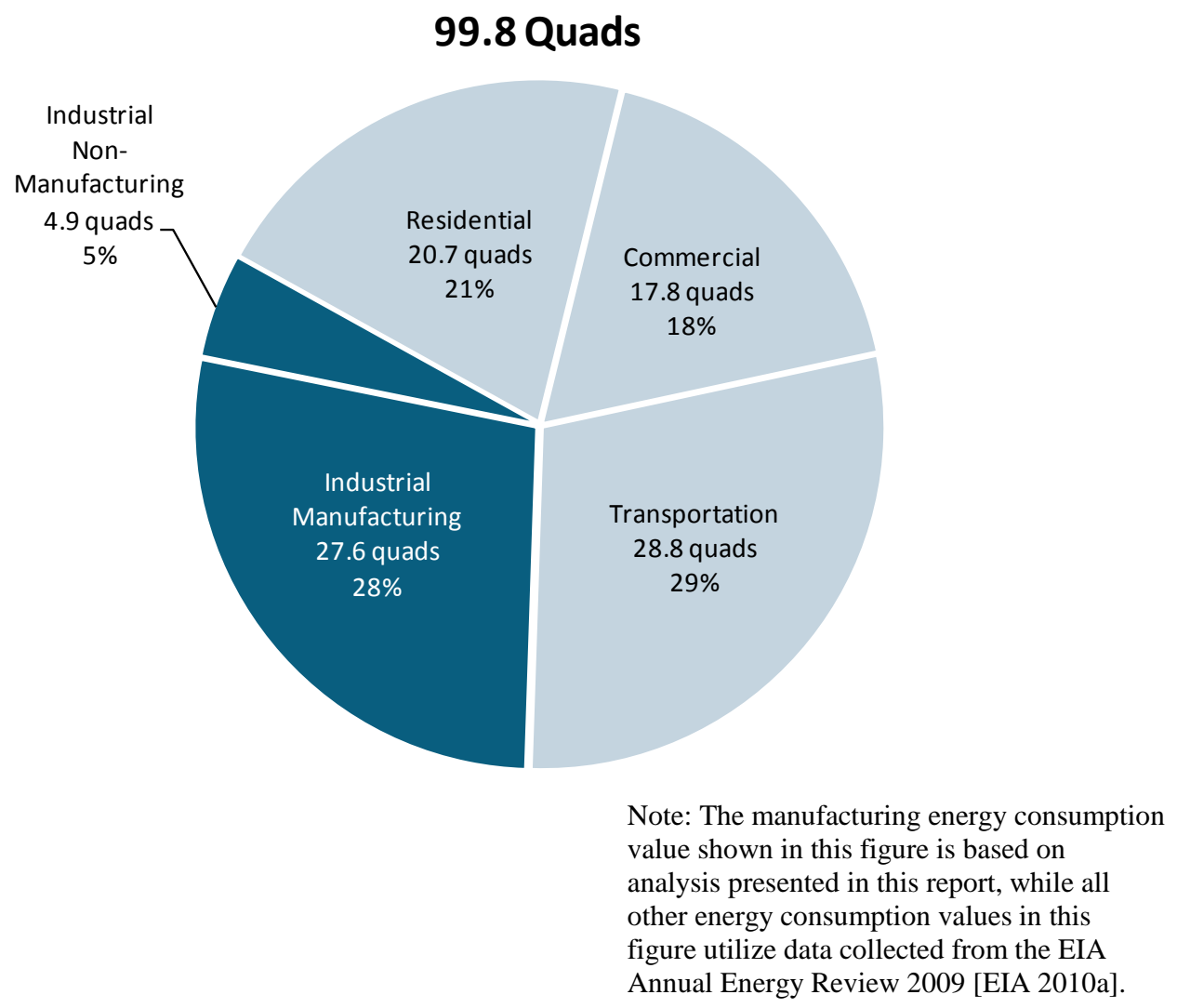

Fig. 1.1-1. 2006 U.S. energy consumption [EIA 2010a]

According to manufacturing energy use statistics from the U.S. Department of Energy's Energy Information Administration (EIA), the U.S. manufacturing sector consumed 21.1 quadrillion Btu (quads) of fuel and feedstock energy [EIA 2009] in 2006. When the estimated electricity and steam losses outside the plant (offsite) are included in this total, the primary and feedstock energy consumed by U.S. manufacturing increases to 27.6 quads. Total U.S. energy consumption for all sectors in 2006 was 99.8 quads [EIA 2010a]. Of this total, the industrial sector consumed 32.5 quads, or $33 \%$. Of this $33 \%$, manufacturing consumed approximately $28 \%$, while non-manufacturing sectors (including agriculture, mining, and construction) consumed the remaining $5 \%$ of industrial energy.

The efficiency of energy use, as well as the cost and availability of energy, have a substantial impact on the competitiveness and economic health of U.S. manufacturers. More efficient use of energy lowers production costs, conserves limited energy resources, and increases productivity. More efficient energy use also improves the environment by reducing emissions of greenhouse gases and air pollutants.

Energy efficiency measures the effectiveness with which energy is converted into usable work or heat. Efficiency is a term commonly used to measure the performance of energy conversion equipment, such as 
process heaters, boilers, and power generators; it is defined as the ratio of useful heat and/or electricity output to the heat content of the fuel consumed. The physical parameters of a process, as well as equipment design, age, and operating and maintenance practices, can lead to real-world performance that is well below the ideal efficiency. Less-than-optimal energy efficiency means that some of the input energy is lost either mechanically or as waste heat. Energy losses cost U.S. manufacturers billions of dollars each year and generate millions of metric tons of greenhouse gas emissions.

Increasing the efficiency of energy use could substantially benefit U.S. manufacturers and the nation, but the thousands of complex manufacturing processes make this a daunting task. However, significant opportunities to address energy efficiency exist in the common energy systems used across manufacturing sectors, such as boilers, onsite power systems, fired heaters, heat exchangers, compressors, motors, pumps, and others. A first step in realizing these opportunities is to identify how manufacturers are using energy. Where does this energy come from? What form is it in? Where is it used? How much is lost? This report is intended to help answer these questions for the U.S. manufacturing sector.

\subsubsection{Focus and Goals of this Report}

The U.S. Department of Energy's Advanced Manufacturing Office (DOE/AMO) conducts research, development, and deployment (RD\&D) to accelerate the development and implementation of energyefficient and environmentally sound industrial technologies and manufacturing practices. This analysis is designed to help DOE/AMO focus R\&D efforts on the most significant opportunities for reducing energy consumption.

This report documents the energy pathway, from supply through demand, for several of the most energyintensive manufacturing sectors. It captures step-by-step energy use and losses from offsite sources, onsite generation, and process and nonprocess end uses. A key output of this analysis is the "footprint" that graphically displays energy use and associated greenhouse gas (GHG) combustion emissions across U.S. manufacturing process and nonprocess end uses. Areas of high energy losses and GHG emissions represent central targets of opportunity for more advanced, efficient energy systems.

The methodology and approach used in conducting this analysis is described below. The report is organized into individual profiles of the largest energy-consuming industries (chemicals, forest products, petroleum refining, food and beverage, and iron and steel) and an aggregated energy profile for U.S. manufacturing as a whole.

\subsection{METHODOLOGY}

\subsubsection{Scope of Footprint Analysis}

This analysis examines a large subset of U.S. manufacturing to capture the bulk of energy consumption and GHG emissions. Table 1.2-1 lists the 15 manufacturing sectors selected for analysis, which together represent about $94 \%$ of U.S. manufacturing energy consumption. A footprint is created for each of the sectors selected for analysis and the U.S. manufacturing sector is also analyzed as a whole and shown in a sixteenth footprint.

Manufacturing sectors were selected on the basis of their relative energy intensities, contributions to the economy, and pertinence to existing energy efficiency programs. As shown in Table 1.2-1, the 15 manufacturing sectors are comprised of a combination of subsectors defined by their respective North American Industry Classification System (NAICS) codes. The scope of these 15 sectors is explained in Appendix B. A complete set of the two-page footprint diagrams for all sectors, including the All Manufacturing footprint, can be found in Appendix C. The footprints are also available at the DOE/AMO website, ${ }^{1}$ along with documents outlining assumptions, definition of terms, and references.

${ }^{1}$ AMO footprints website: http://www1.eere.energy.gov/manufacturing/resources/footprints.html 
Table 1.2-1. Manufacturing sectors selected for analysis

\begin{tabular}{|l|l|}
\hline Food and beverage & Iron and steel \\
NAICS 311 Food & NAICS 3311 Iron and steel mills and ferroalloys \\
NAICS 312 Beverage and tobacco products & NAICS 3312 Steel products \\
\hline $\begin{array}{l}\text { Textiles } \\
\text { NAICS } 313 \text { Textile mills } \\
\text { NAICS 314 Textile product mills } \\
\text { NAICS 315 Apparel } \\
\text { NAICS 316 Leather and allied products }\end{array}$ & Alumina and aluminum \\
\hline $\begin{array}{l}\text { Forest products } \\
\text { NAICS 321 Wood products }\end{array}$ & \\
NAICS 322 Paper & Foundries \\
\hline $\begin{array}{l}\text { Petroleum refining } \\
\text { NAICS 324110 }\end{array}$ & NAICS 3315 \\
\hline $\begin{array}{l}\text { Chemicals } \\
\text { NAICS 325 }\end{array}$ & Fabricated metals \\
\hline Plastics and rubber products & NAICS 332 \\
NAICS 326 & Machinery \\
& NAICS 333 \\
\hline Glass and glass products & Computers, electronics, and electrical equipment \\
NAICS 3272 Glass and glass products & NAICS 334 Computer and electronic products \\
NAICS 327993 Mineral wool & NAICS 335 Electrical equipment, appliances, and components \\
\hline $\begin{array}{l}\text { Cement } \\
\text { NAICS 327310 }\end{array}$ & Transportation equipment \\
\hline
\end{tabular}

\subsubsection{Source Data and Adjustments}

The analytical model for detailing sector-specific energy use and loss and associated GHG emissions reflects the latest energy-use statistics, relevant emissions guidelines, and input from industry experts. Energy-use statistics were obtained from the most recent DOE/EIA-published Manufacturing Energy Consumption Survey (MECS) results for survey year 2006 [EIA 2009]. The MECS data tables were adjusted to account for withheld data or to avoid double-counting. In addition, some assumptions were introduced when estimating energy losses and steam allocation; these are discussed later in this section. The adjustments and assumptions applied to the MECS data are outlined in Appendix D, Footprint Data Adjustments and Assumptions. Steam allocation assumptions are outlined in Appendix E, Allocation of Steam to Process and Nonprocess End Uses. Process heating loss assumptions are outlined in Appendix F, Estimation of Process Heating Energy Loss. As a result of these adjustments, the energy use and loss values in the footprints do not directly represent MECS data, and should not be cited as MECS output.

The electrical end use distribution to machine driven systems was obtained from the 2002 Oak Ridge National Laboratory study, U.S. Industrial Electric Motor Systems Market Opportunities Assessment [OIT EERE 2002b]. In this 2002 study, motor populations from 265 industrial facilities across the country were inventoried, which resulted in a motor size and motor application database by manufacturing sector. Motor applications were grouped into six system areas - pumps, fans, compressed air, materials handling, materials processing, and other systems. Machine driven system energy for refrigeration was not included as a motor application system area in the footprint analysis because it is already accounted for in MECS reported process cooling and refrigeration end use. Machine drive system allocation and assumptions are outlined in Appendix D. 


\subsubsection{Carbon Footprint Analysis}

Both the Environmental Protection Agency's (EPA) Mandatory Greenhouse Gas Reporting Rule [EPA 2009b] and the EPA's Inventory of U.S. Greenhouse Gas Emissions and Sinks [EPA 2010] were referenced in formulating the methodology and emission factors used for calculating greenhouse gas (GHG) emissions in this report. The carbon footprint calculations in this analysis conform to EPA GHG mandatory reporting requirements, referencing the same emissions calculations and fuel-specific emission factors. Unique emission factors were used for each sector based on fuel type breakdown. Emissions are reported as $\mathrm{CO}_{2}{ }^{-}$ equivalent $\left(\mathrm{CO}_{2} \mathrm{e}\right)$, as per the $\mathrm{GHG}$ reporting requirements. $\mathrm{CO}_{2} \mathrm{e}$ emissions in this report consist of combustion-related emissions of carbon dioxide $\left(\mathrm{CO}_{2}\right)$, methane $\left(\mathrm{CH}_{4}\right)$, and nitrous oxide $\left(\mathrm{N}_{2} \mathrm{O}\right)$. Process emissions are excluded from the analysis, as these are not directly related to the use of energy as fuel.

All quoted carbon emissions in this report are carbon dioxide-equivalent $\left(\mathrm{CO}_{2} \mathrm{e}\right) \mathrm{GHG}$ emissions, unless explicitly identified otherwise. Effectively, "carbon emissions" will be used interchangeably with "GHG combustion emissions" throughout this report.

\subsubsection{A Walkthrough of the Footprints}

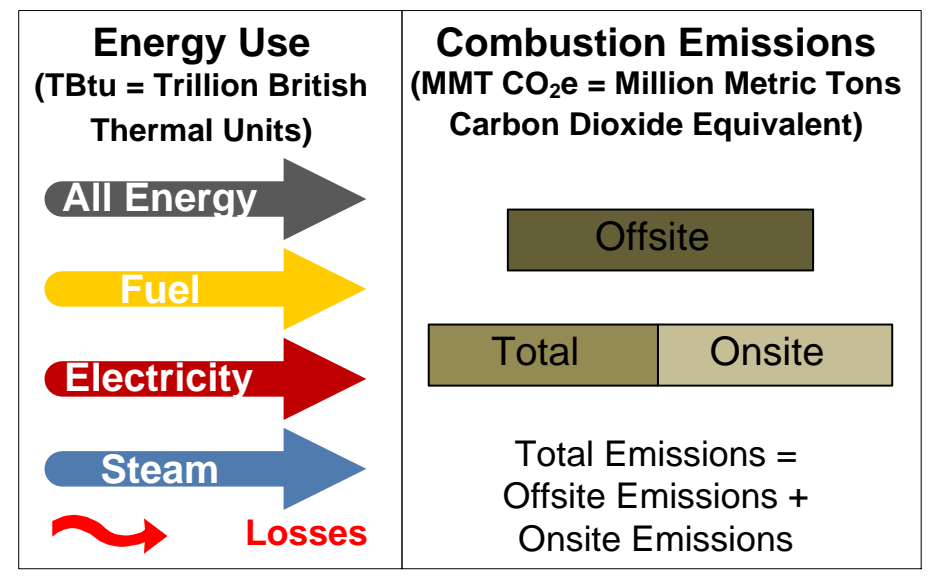

Fig. 1.2-1. Footprint legend

The output from the footprint model is presented in the form of graphical "footprints" that map the flow of energy supply, demand, and loss for selected U.S. manufacturing industries. The model and footprints can be adapted to other sectors and subsectors as needed. Fig. 1.2-1 previews the color legend used throughout this report. The chemicals sector energy and carbon footprint is provided as an example in Fig. 1.2-2 and Fig. 1.2-3. Each footprint consists of two figures; the first figure offers an overview of the sector's total primary energy flow including offsite energy and losses, while the second figure presents a more detailed breakdown of the onsite energy flow. (Note: All footprints do not include feedstock energy, which is discussed separately in section 2.1.2.). The term "Total" in the footprints refers to the total sum of offsite and onsite values. In energy terms, this is often referred to as total primary energy.

Energy use is shown as input and output flow lines to the various pathway stages; energy values appear in white font within the flow arrows. Energy use is broken down by energy type and distinguished by color (as shown in Fig. 1.2-1): dark gray = all energy, yellow = fuel, dark red = electricity, and blue = steam . Energy losses are represented as wavy red arrows. GHG emissions are shown in the boxes along the bottom of each pathway stage. Offsite, onsite, and total GHG emissions are distinguished by color as shown in the legend: dark brown $=$ offsite emissions, light brown $=$ onsite emissions, and medium brown $=$ total emissions (offsite + onsite). 
The footprint pathway captures both energy supply and demand. On the supply side, the footprints provide details on energy purchases and transfers in to a plant site (including fuels derived from byproducts), and onsite generation of steam and electricity. On the demand side, the footprints illustrate the end use of energy within a given sector, from process energy uses such as heaters and motors, to nonprocess uses such as heating, ventilation, and air conditioning (HVAC) and lighting. Fuel and electricity end use allocations in each sector are based on MECS data, while sector-specific steam end use allocations are summarized in Table 1.2-3 and detailed in Appendix E. The footprints also identify where energy is lost due to generation and distribution losses and system inefficiencies, both inside and outside the plant boundary. Losses are critical, as they represent immediate opportunities to improve efficiency and reduce energy consumption through best energy management practices and technologies.

The energy footprint shown in Fig. 1.2-2 shows primary energy, beginning with the fuel, electricity, and steam supplied to the plant boundary from offsite sources (power plants, fuel and gas distributors, etc.). Many industries generate byproduct fuels that are also part of the energy supply. Notable examples include black liquor and wood byproducts used in pulp and paper mills and waste gas from petroleum refineries.

The energy footprint shown in Fig. 1.2-3 shows onsite energy demand by energy type and end use. The onsite energy that reaches the plant boundary is used either indirectly for onsite generation or directly for process and nonprocess end uses. Onsite energy generation, consisting of conventional boilers, combined heat and power (CHP)/cogeneration systems controlled by a manufacturing establishment, and other electricity generation such as renewable energy sources, contributes to the electricity and steam demands of process and nonprocess end uses. A percentage breakdown of energy use by fuel type, including fuels derived from byproducts, is presented as a yellow call out box at the beginning of the onsite fuel pathway.

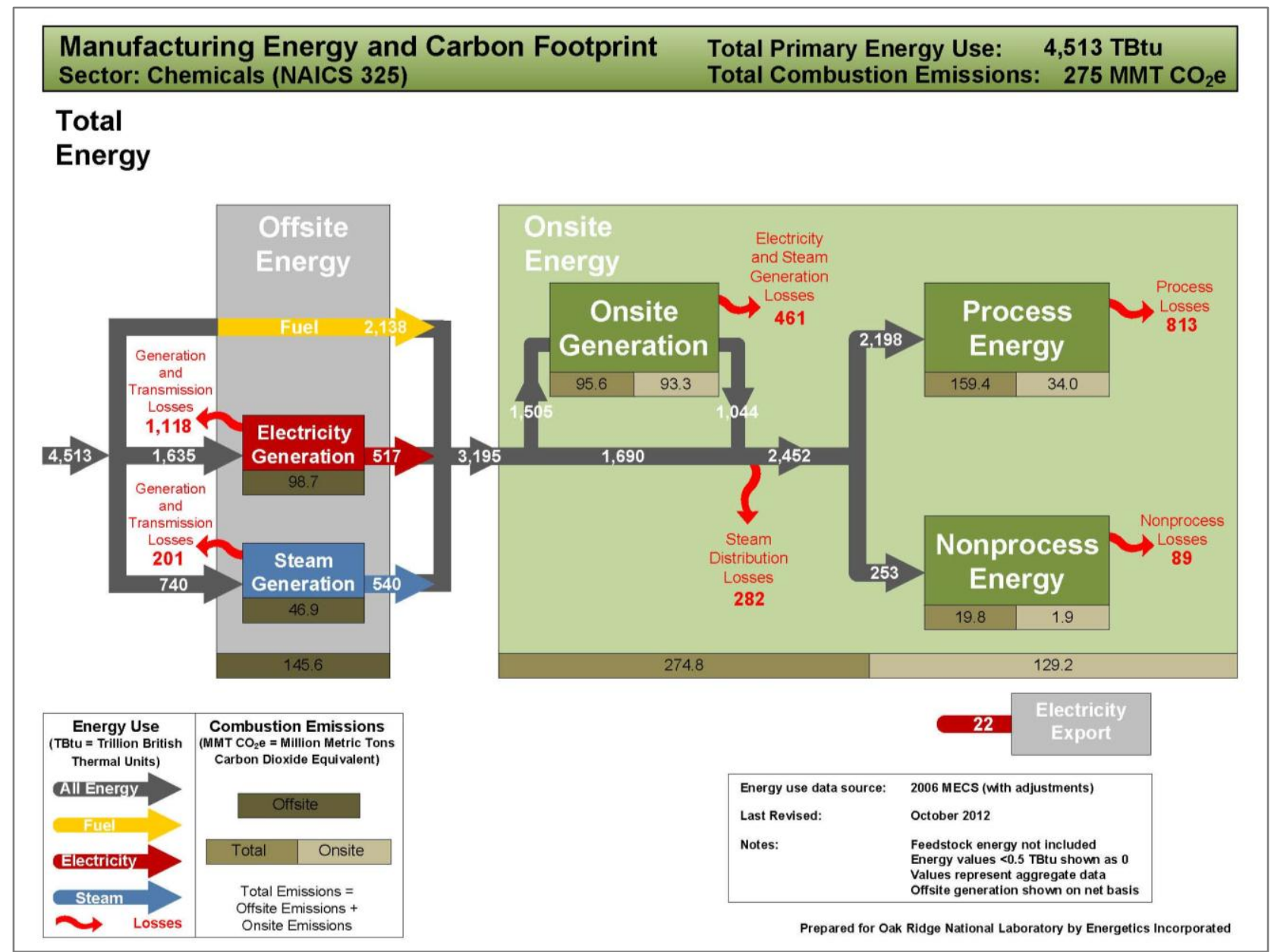

Fig. 1.2-2 Total primary energy use and GHG combustion emissions for the chemicals sector 


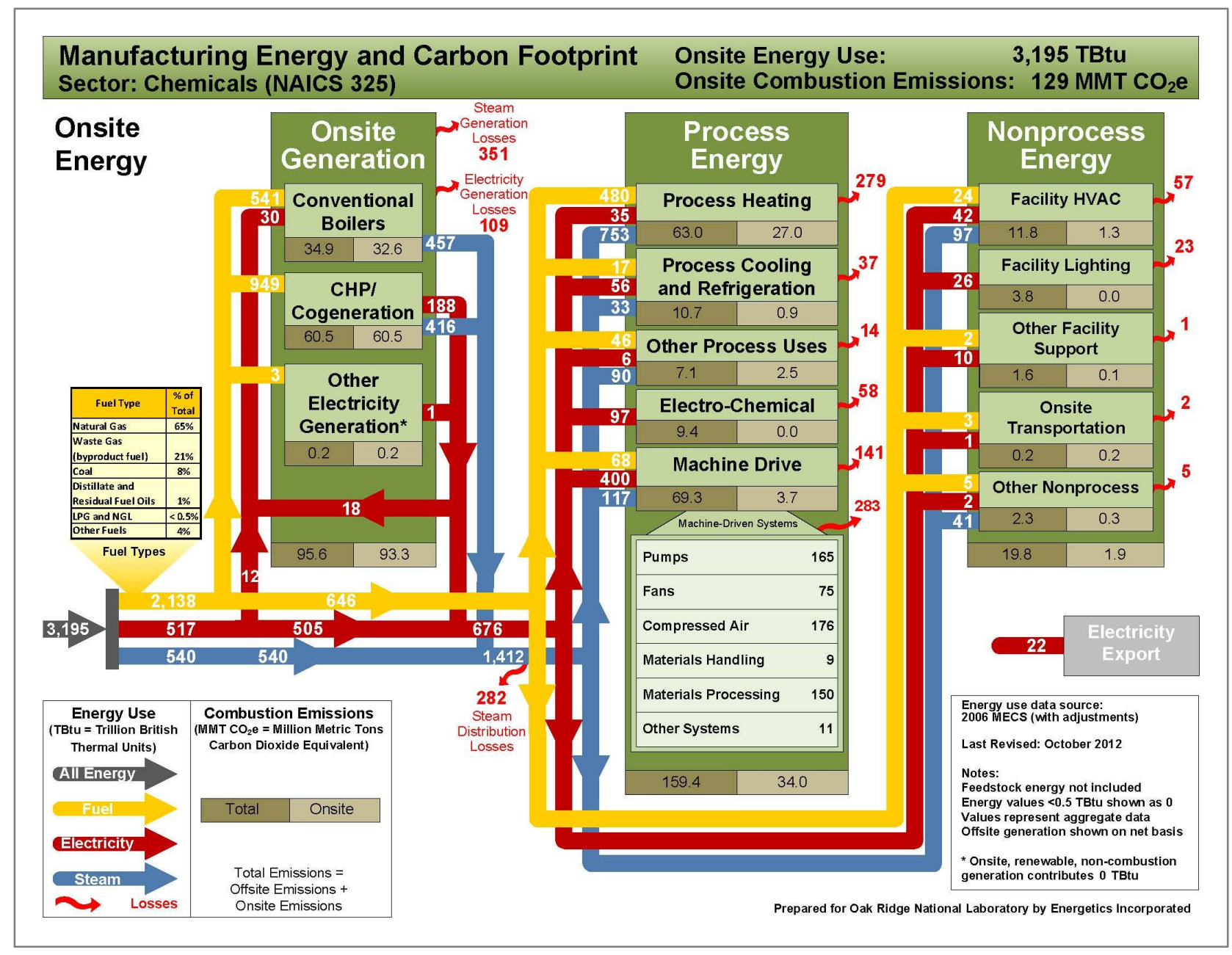

Fig. 1.2-3. Onsite energy and carbon emissions for the chemicals sector

Often, onsite generation of electricity creates more energy than is needed at the plant site. When this occurs, the excess electricity is exported offsite to the local grid or other nearby plants. Total primary and onsite energy use values in the footprint are based on net electricity and do not include exported electricity (though the value of electricity exports is provided on the footprint for reference). Steam can also be generated onsite and exported to other nearby plants; however, exported steam is accounted for in the MECS net steam data, and thus is not explicitly shown in the footprint.

Process energy systems consist of the equipment necessary for process heating (e.g., kilns, ovens, furnaces, strip heaters), process cooling and refrigeration, electro-chemical processes (e.g., reduction processes), machine drive (e.g., motors and pumps associated with process equipment), and other direct process uses. Another step in the energy pathway is the energy that is distributed to nonprocess end uses. This involves the use of energy for facility HVAC, facility lighting, other facility support (e.g., water heating and office equipment), onsite transportation, and other nonprocess use.

Energy losses occur along the entire energy pathway from generation and delivery to end use. Energy is lost in generating power and steam, in transmitting power and steam, and in process and nonprocess end use of power, steam, and fuel. In the footprint analysis these energy loss values are estimated. Energy losses vary greatly by industry and by facility, so conservative sector-wide energy loss estimates are assumed with the understanding that these estimates are highly dependent on the specific manufacturing 
plant site. A summary of footprint loss assumptions is presented in Table 1.2-2 and in Appendix D. In addition, process heating loss assumptions are detailed in Appendix F.

Energy losses do not equate to recoverable energy. While a portion of energy losses are recoverable, this report does not attempt to identify and distinguish between recoverable and non-recoverable losses.

Identifying the portion of losses that is recoverable through use of more efficient technologies and practices is a worthwhile subject that requires further study. Some examples of non-recoverable energy losses include a) heat storage in a batch furnace where losses are not economically recoverable; b) transmission losses where low quality energy loss is impractical to recover over a long distance, c) frictional losses. The recovery of waste heat depends on many factors, including waste heat temperature, quantity, accessibility, quality/cleanliness, corrosiveness, and intended use. The distinction between recoverable and nonrecoverable waste heat losses are discussed in more detail in the 2008 DOE ITP publication, Waste Heat Recovery: Technology and Opportunities in U.S. Industry [ITP EERE 2008b].

Table 1.2-2. Manufacturing energy footprint loss assumptions

\begin{tabular}{|c|c|}
\hline Energy system & Percent energy lost \\
\hline \multicolumn{2}{|c|}{ Energy generation, transmission, and distribution losses } \\
\hline Offsite generation & $\begin{array}{l}\text { Offsite electricity generation and transmission (grid) }-68.4 \% \\
\text { Offsite steam generation }-19 \% \\
\text { Offsite steam transmission }-10 \%\end{array}$ \\
\hline Onsite generation & $\begin{array}{l}\text { Onsite steam generation (conventional boiler) }-20 \% \\
\text { Onsite CHP/cogeneration }-24.4 \%-36.3 \% \text {, see Table D.2 } \\
\text { Onsite steam distribution }-20 \%\end{array}$ \\
\hline \multicolumn{2}{|c|}{ Onsite process and nonprocess losses } \\
\hline Process energy & $\begin{array}{l}\text { Process heating - } 18 \%-68 \% \text {, see Table D. } 3 \\
\text { Process cooling and refrigeration }-35 \% \\
\text { Electro-chemical }-60 \% \\
\text { Other processes }-10 \% \\
\text { Machine drive (shaft energy) - electric } 7 \% \text {, fuel } 60 \% \text {, steam } 50 \% \\
\text { Machine driven systems } \\
\quad \text { Pumps }-40 \% \\
\quad \text { Fans }-40 \% \\
\text { Compressed air }-80 \% \\
\text { Materials handling - 5\% } \\
\text { Materials processing (e.g., grinders) }-90 \% \\
\text { Other systems }-5 \%\end{array}$ \\
\hline Nonprocess energy & $\begin{array}{l}\text { Facility HVAC }-35 \% \\
\text { Facility lighting }-88 \% \\
\text { Other facility support }-10 \% \\
\text { Onsite transportation }-60 \% \\
\text { Other nonprocesses }-10 \%\end{array}$ \\
\hline
\end{tabular}

Note: The values in this table are gross assumptions used to generate order-of-magnitude energy loss estimates. Energy generation and transmission loss assumptions are based on EIA data. Process and nonprocess loss assumptions are drawn from discussion with industry experts and have been substantiated where possible with review of relevant studies. In practice, these energy loss assumptions are heavily dependent on specific operating equipment and conditions and vary greatly within and across manufacturing sectors. 
Table 1.2-3. Steam allocation assumptions

\begin{tabular}{|l|c|c|c|c|c|c|}
\hline \multicolumn{1}{|c|}{ Sector } & \multicolumn{7}{|c|}{ Steam end use allocation } \\
\cline { 2 - 6 } & $\begin{array}{c}\text { Process } \\
\text { heating }\end{array}$ & $\begin{array}{c}\text { Machine } \\
\text { drive }\end{array}$ & $\begin{array}{c}\text { Process } \\
\text { cooling/ } \\
\text { refrigeration }\end{array}$ & $\begin{array}{c}\text { Other } \\
\text { process uses }\end{array}$ & $\begin{array}{c}\text { Facility } \\
\text { HVAC }\end{array}$ & $\begin{array}{c}\text { Other } \\
\text { nonprocess } \\
\text { uses }\end{array}$ \\
\hline Alumina and aluminum & $31 \%$ & $13 \%$ & $0 \%$ & $27 \%$ & $21 \%$ & $7 \%$ \\
Cement & $45 \%$ & $6 \%$ & $1 \%$ & $16 \%$ & $27 \%$ & $6 \%$ \\
Chemicals & $67 \%$ & $10 \%$ & $3 \%$ & $8 \%$ & $9 \%$ & $4 \%$ \\
Computers, electronics and & $16 \%$ & $0 \%$ & $1 \%$ & $7 \%$ & $73 \%$ & $4 \%$ \\
electrical equipment & $35 \%$ & $1 \%$ & $1 \%$ & $16 \%$ & $46 \%$ & $2 \%$ \\
Fabricated metals & $69 \%$ & $4 \%$ & $5 \%$ & $8 \%$ & $10 \%$ & $3 \%$ \\
Food and beverage & $70 \%$ & $9 \%$ & $2 \%$ & $5 \%$ & $9 \%$ & $4 \%$ \\
Forest products & $13 \%$ & $15 \%$ & $0 \%$ & $9 \%$ & $60 \%$ & $3 \%$ \\
Foundries & $5 \%$ & $5 \%$ & $0 \%$ & $22 \%$ & $63 \%$ & $5 \%$ \\
Glass & $46 \%$ & $7 \%$ & $0 \%$ & $8 \%$ & $38 \%$ & $1 \%$ \\
Iron and steel & $24 \%$ & $29 \%$ & $1 \%$ & $7 \%$ & $37 \%$ & $1 \%$ \\
Machinery & $66 \%$ & $16 \%$ & $2 \%$ & $10 \%$ & $4 \%$ & $2 \%$ \\
Petroleum refining & $71 \%$ & $1 \%$ & $0 \%$ & $7 \%$ & $18 \%$ & $3 \%$ \\
Plastics & $63 \%$ & $2 \%$ & $2 \%$ & $10 \%$ & $21 \%$ & $2 \%$ \\
Textiles & $27 \%$ & $2 \%$ & $7 \%$ & $9 \%$ & $53 \%$ & $2 \%$ \\
Transportation equipment & $66 \%$ & $10 \%$ & $3 \%$ & $8 \%$ & $11 \%$ & $3 \%$ \\
\hline All manufacturing & & & & & & \\
\hline
\end{tabular}

\subsubsection{Direct vs. indirect end use}

In the MECS data, purchased energy and end use energy are reported by NAICS sector, in addition to a number of other energy use measures. The resulting energy balance is complicated by a number of factors, ${ }^{2}$ one of which is the indirect energy use and loss associated with boilers, CHP units, and other onsite generation equipment. The term "indirect" here means that energy is converted in to another form (e.g., steam or electricity) prior to direct use in process or nonprocess applications. Indirect end use is shown as Onsite Generation in the energy footprint and includes associated onsite generation losses.

EIA does not report the indirect generation of steam, nor does EIA report the end use of steam onsite. In the footprint model, the onsite energy generated in the form of steam and electricity is taken into account and distributed to process and nonprocess end uses. As shown in the onsite energy footprint (second page of the footprint), the indirect energy use for onsite generation (which is primarily fuel) is used to generate steam and electricity that is applied towards direct process and nonprocess end uses. Taken as a whole, the onsite energy footprint presents indirect end use, direct end use, and the intermediate onsite generation losses that complete the energy balance.

In the sector profiles herein, onsite steam and electricity is typically not equal to the direct end use of steam and electricity due to the conversion of indirect energy. Onsite steam and electricity is a lesser value as it does not include onsite generation, and instead represents only the offsite supply entering the plant boundary. The distinction between the terms primary energy, onsite energy, indirect end use, and direct end use has been clarified in Fig. 1.2-4 to avoid misinterpretation of the results.

\footnotetext{
${ }^{2}$ There are a number of adjustments that were made to the EIA-reported data in the footprint model, including adjustments for unreported energy, which are necessary in balancing the energy model.
} 


\section{Manufacturing Energy and Carbon Footprint $\quad$ Total Primary Energy Use: 21,972 TBtu Sector: All Manufacturing (NAICS 31-33)

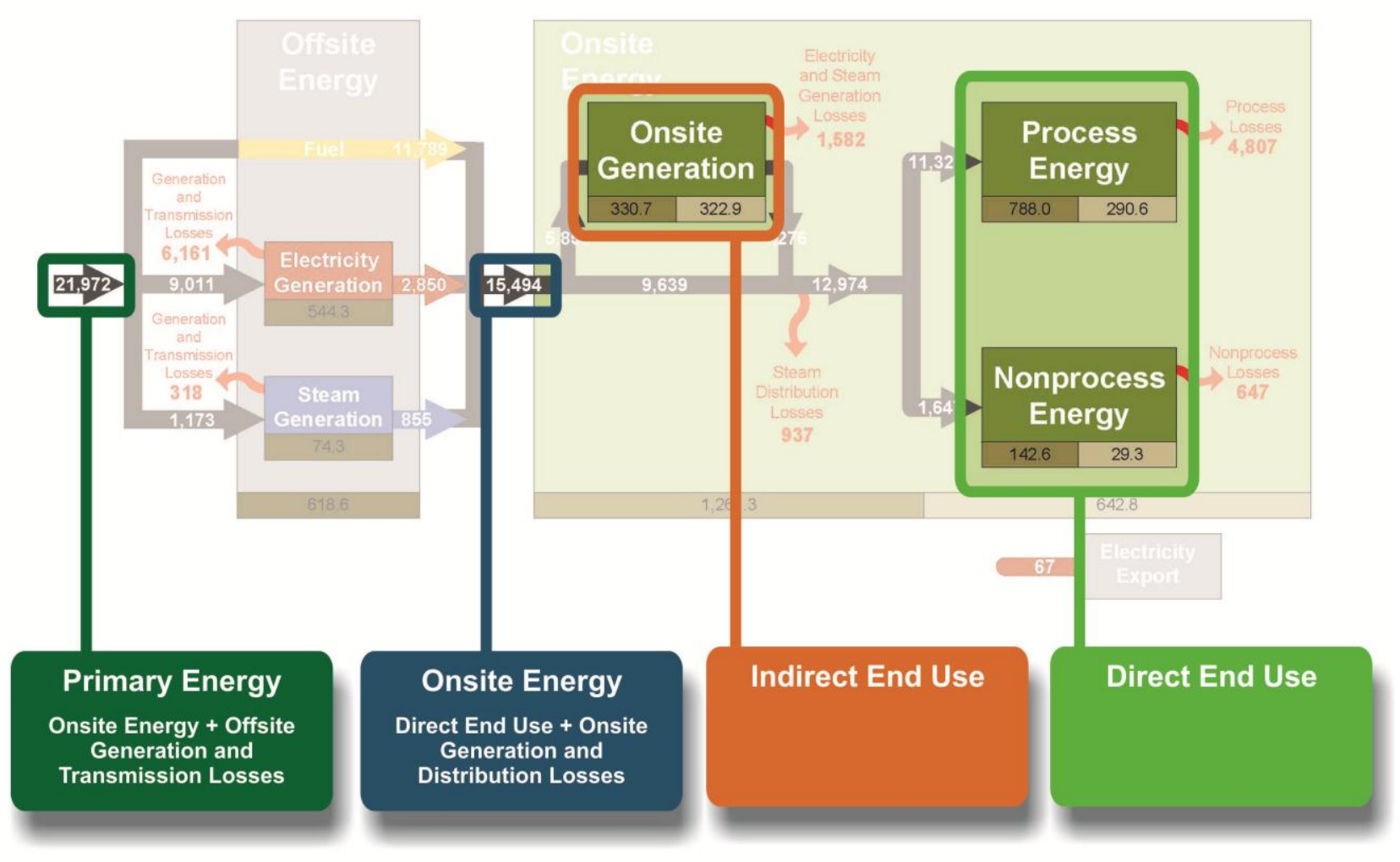

Fig. 1.2-4. Energy profile terminology guide

\subsubsection{Applying Footprint Results}

The energy and carbon footprints are based on actual plant survey data; therefore, they represent a genuine distribution of energy use and losses across the manufacturing sector as a whole. Through them, the magnitude of energy consumption and losses can begin to be assessed, both by end use and fuel type. They also provide a baseline from which to calculate the benefits of improving energy efficiency. The carbon values in the footprint can be used to support carbon management planning and analysis.

In this report, the results of the footprint analysis are presented from various perspectives to help guide the top energy consumers by energy type or energy application area, and propensity for onsite versus offsite power and steam generation. Section 2.1 examines the U.S. manufacturing sector and ranks sectors by energy consumption in key energy use areas.

These rankings also reveal a select subset of the U.S. manufacturing sectors that warrant further study and analysis. Five manufacturing sectors, each of which utilizes over 1 quad of primary energy, were the chosen focus for the remainder of Chapter 2 in this report: chemicals, forest products, petroleum refining, food and beverage, and iron and steel. Profiles of primary energy; fuel, electricity, and steam use; onsite generation; direct and applied end use; and emissions are highlighted in each sector. 



\section{ENERGY AND GREENHOUSE GAS COMBUSTION EMISSIONS PROFILES}

\subsection{U.S. MANUFACTURING (NAICS 31-33)}

\subsubsection{Overview of U.S. Manufacturing}

U.S. manufacturing is highly diverse, using thousands of processes to manufacture countless different products. Manufacturing is a complex composite of many sectors - some convert raw materials into intermediate and final products, while other sectors form, forge, fabricate, and assemble final products.

There are integral links between the "heavy industry" sectors (e.g., chemicals, steel, pulp and paper) that convert raw materials and the sectors that create finished products. For example, steel mills produce intermediate steel products that are sent to forgers and fabricators and supplied to the transportation industry where they become automotive components. Similarly, changes in energy use patterns in the heavy industries can ripple through the sectors they supply goods to, affecting not just product costs, but the life cycle energy embodied in the final product.

This section looks at the energy and emissions profiles for all of U.S. manufacturing, which includes NAICS codes 31 through 33. More in-depth profiles of the top five energy consuming sectors are also detailed later in this chapter. In this section the 15 manufacturing sectors are ranked in the areas of: primary energy use, onsite energy use, energy type, energy end use, applied energy, and GHG emissions.

\subsubsection{Energy Use Profile for U.S. Manufacturing and Sector Rankings}

A snapshot of total energy use for U.S. manufacturing is shown in Table 2.1-1, along with total and onsite combustions emissions. Energy losses are shown in red font. All values are based on the most currently available complete set of manufacturing energy use statistics, representing annual energy use and loss values for calendar year 2006.

Table 2.1-1. Snapshot of energy use and loss within U.S. manufacturing

\begin{tabular}{|l|r|}
\hline \multicolumn{1}{|c|}{ Category } & Energy (TBtu) \\
\hline Total primary energy & 21,972 \\
Offsite losses & 6,479 \\
Onsite energy & 15,494 \\
Onsite losses & 7,974 \\
Steam generation and distribution & 2,292 \\
Electricity generation & 227 \\
Process energy & 4,807 \\
Nonprocess energy & 647 \\
Feedstock energy & 6,962 \\
Total primary and feedstock energy ${ }^{\text {a }}$ & 27,568 \\
\hline GHG combustion emissions & $\mathbf{M M T ~ C O}_{\mathbf{2}} \mathbf{e}$ \\
Total & 1,261 \\
Onsite & 643 \\
\hline When total primary energy and feedstock energy are summed, the energy value of byproduct fuels derived from \\
feedstock energy sources is excluded to avoid double counting of feedstock energy
\end{tabular}


Although outside of the scope of the footprint analysis, it is worth noting that a substantial amount of energy is consumed as non-fuel feedstock in manufacturing. As shown in Fig. 2.1-1, U.S. manufacturing consumed nearly 7 quads of feedstock energy in 2006. Liquefied petroleum gas (LPG) and natural gas liquid (NGL) fuels comprise about one-third of feedstock energy consumption, while other feedstocks make up the majority of feedstock energy consumption. The petroleum refining sector (NAICS 324110, feedstock energy consumption equal to 3.4 quads) ${ }^{3}$ and the chemicals sector (NAICS 325, feedstock energy consumption equal to 2.8 quads) are the top feedstock energy consuming sectors. In this report, feedstock energy composition is discussed separately at the beginning of each sector's respective chapter.

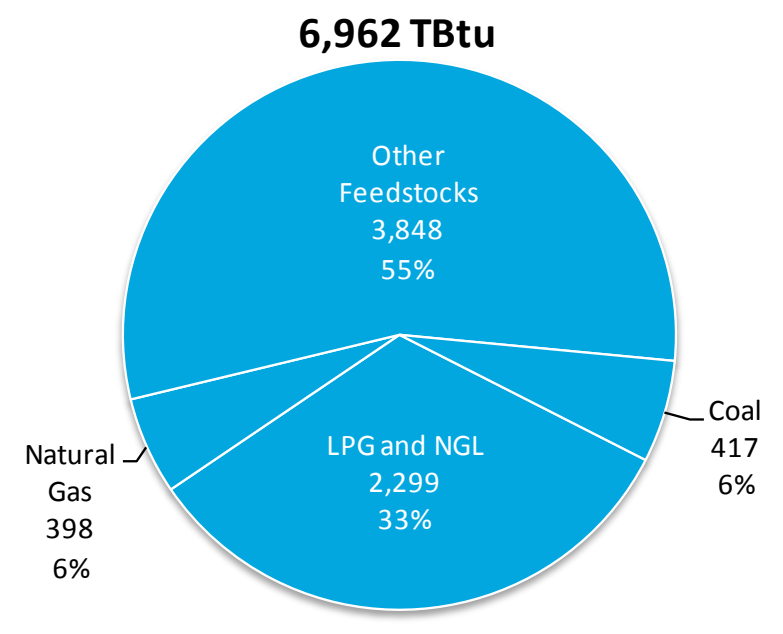

Fig. 2.1-1. Feedstock energy use in U.S. manufacturing

Total energy consumption, by sector, including primary and feedstock energy is shown in Fig. 2.1-2. The primary and feedstock energy profile is the most complete picture of energy consumption in U.S.

manufacturing. The combined energy consumption for the fifteen manufacturing sectors considered in Fig. 2.1-2 is 26.1 quads. The total primary and feedstock energy for all U.S. manufacturing (NAICS 31-33) sectors is 27.6 quads.

\footnotetext{
${ }^{3}$ The reported petroleum feedstock value does not include energy feedstocks that are converted to energy products (e.g., crude oil converted to fuel oil). The actual petroleum feedstock value would be much greater than the value reported by EIA.
} 


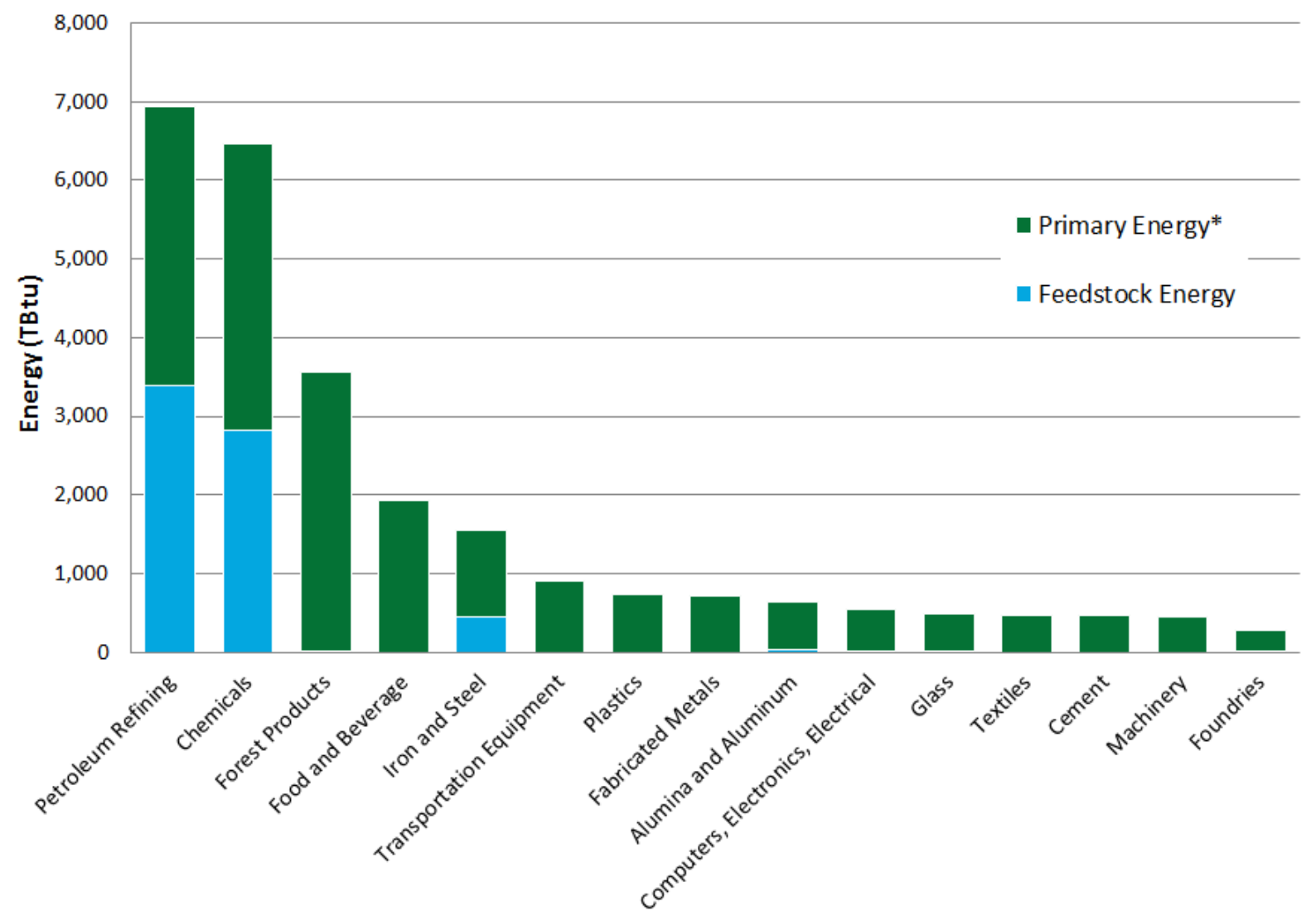

*Primary energy use has been adjusted to exclude the energy value of byproduct fuels derived from feedstock energy sources (e.g., waste gas from LPG feedstock in the chemicals sector); this exclusion avoids double counting feedstock energy. In the case of the petroleum refining sector, the feedstock energy includes energy feedstock used for the production of non-energy products (such as asphalt), it does not include energy feedstock that is converted to other energy products. Therefore, for petroleum refining only, there is no adjustment to the primary energy use for byproducts derived from feedstock energy sources.

Fig. 2.1-2. U.S. manufacturing total primary and feedstock energy

For the purposes of this report, primary energy use and onsite energy use in the manufacturing sector are of the most interest in the evaluation of energy use, loss and energy saving opportunities. Thus, the focus of the analysis that follows excludes feedstock energy use.

\subsubsection{1. $\quad$ Energy and carbon footprint}

The U.S. manufacturing sector footprint is shown in Fig. 2.1-3 and Fig. 2.1-4. The footprint serves as the basis for characterizing the offsite and onsite flow of energy, as well as carbon emissions, from generation through end use in the sector. Data is presented in two levels of detail. The first page (Fig. 2.1-3) provides a primary energy perspective including offsite and onsite energy flow, while the second page (Fig. 2.1-4) shows detail for the onsite generation and end use of energy. Chapter 1 presents a more detailed walkthrough of the footprints. 


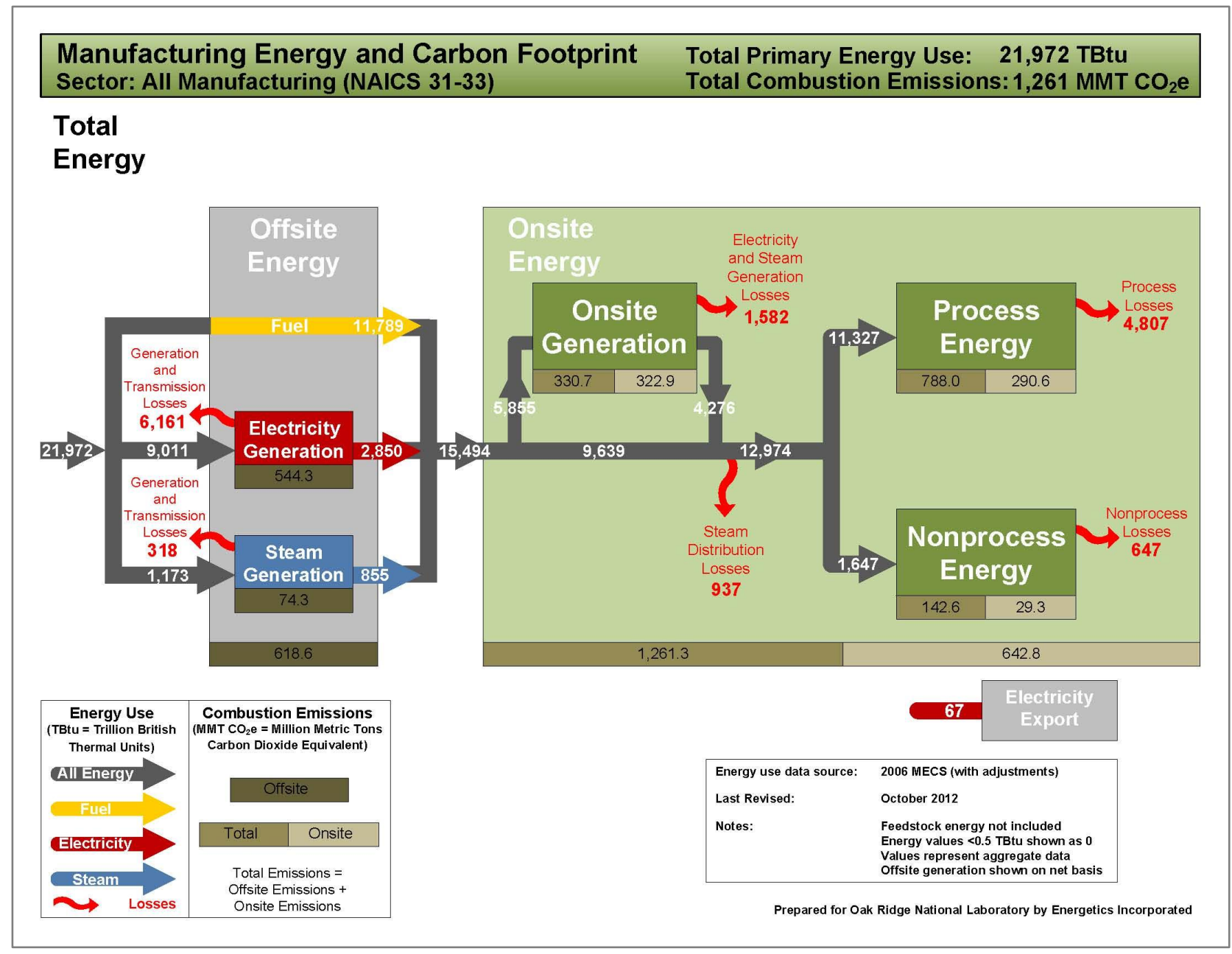

Fig. 2.1-3. Total energy and carbon footprint for U.S. manufacturing 


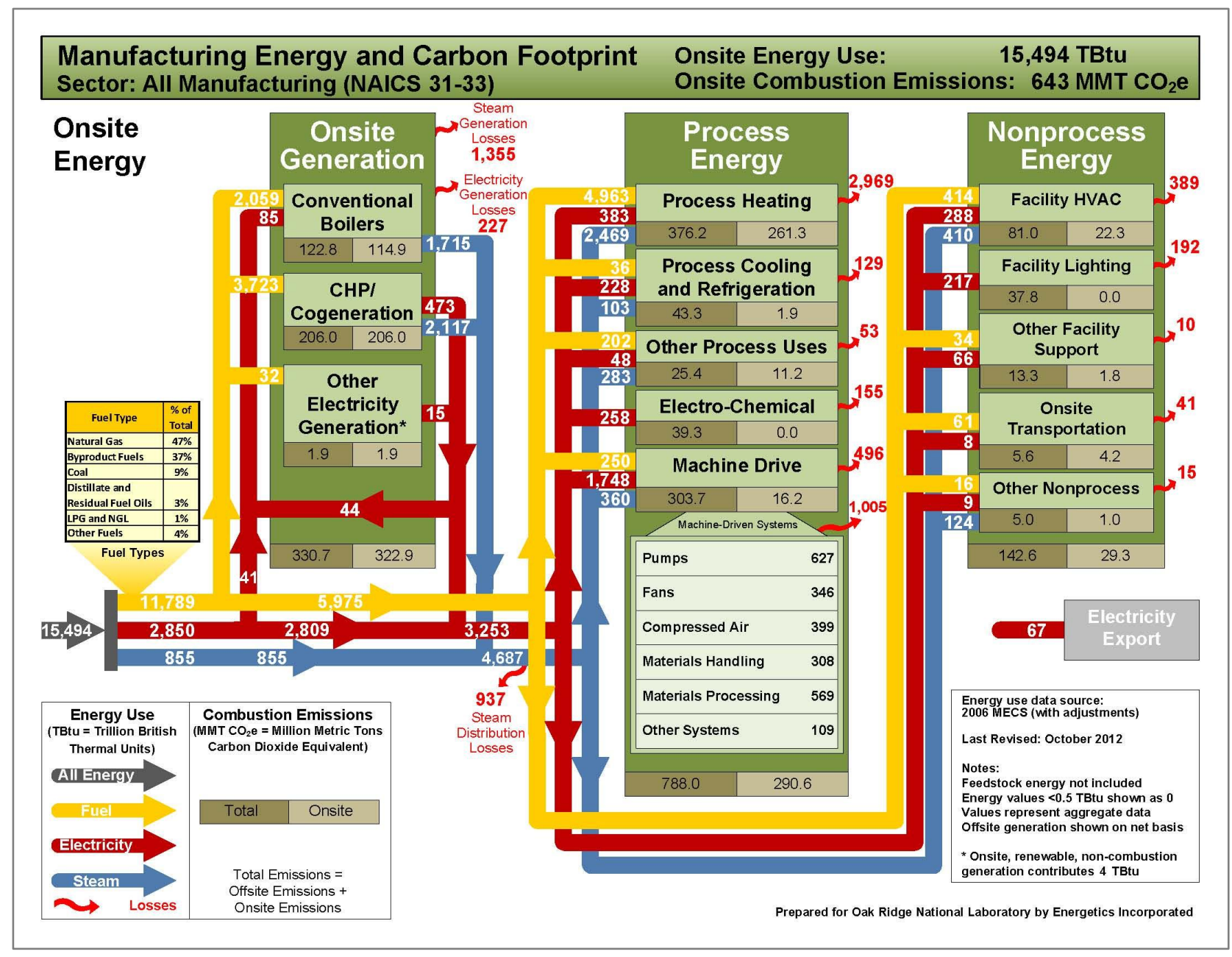

Fig. 2.1-4. Onsite energy and carbon footprint for U.S. manufacturing

\subsubsection{Primary energy}

Primary energy use includes fuels, electricity, and steam consumed, both external and internal to the plant boundary. This does not include feedstock energy. Primary energy use is depicted in Fig. 2.1-5, where energy use and loss is shown separately by energy type (steam, electricity, and fuel). Consistent with the footprints, the color blue represents steam energy, red represents electric energy, and yellow represents fuel energy. This same energy coloring scheme is used throughout this report.

The U.S. manufacturing sector consumed 21,972 TBtu of primary energy in 2006. Energy used to generate electricity is the largest category of primary energy use - comprising 9,638 TBtu (44\%) of primary energy. Over $93 \%$ of primary electricity energy use is attributable to offsite generation and associated losses. The electricity generated offsite that is not lost during generation or transmission accounts for 2,809 TBtu, ${ }^{4}$ while onsite electricity generation accounts for $441 \mathrm{TBtu}$. Overall, manufacturing primary electricity generation is $34 \%$ efficient, with $64 \%$ of primary energy lost in offsite generation and $2 \%$ lost in onsite generation.

\footnotetext{
${ }^{4}$ The offsite electricity generation value $(2,809 \mathrm{TBtu})$ is slightly lower than the total onsite electricity value $(2,850 \mathrm{TBtu})$ entering the plant boundary in the energy footprint. This difference is due to the 41 TBtu of offsite electricity that is used in onsite generation.
} 
Energy used to generate steam is the next largest category of primary energy use, consuming 6,360 TBtu (29\%) of total primary energy. Unlike electricity, the majority, $84 \%$, of primary steam energy use is from onsite generation and associated losses, and only $16 \%$ is attributed to offsite steam. Onsite generation of steam is estimated to be 3,066 $\mathrm{TBtu}^{5}$; this estimate is dependent on the boiler efficiency assumption explained in Appendix D.

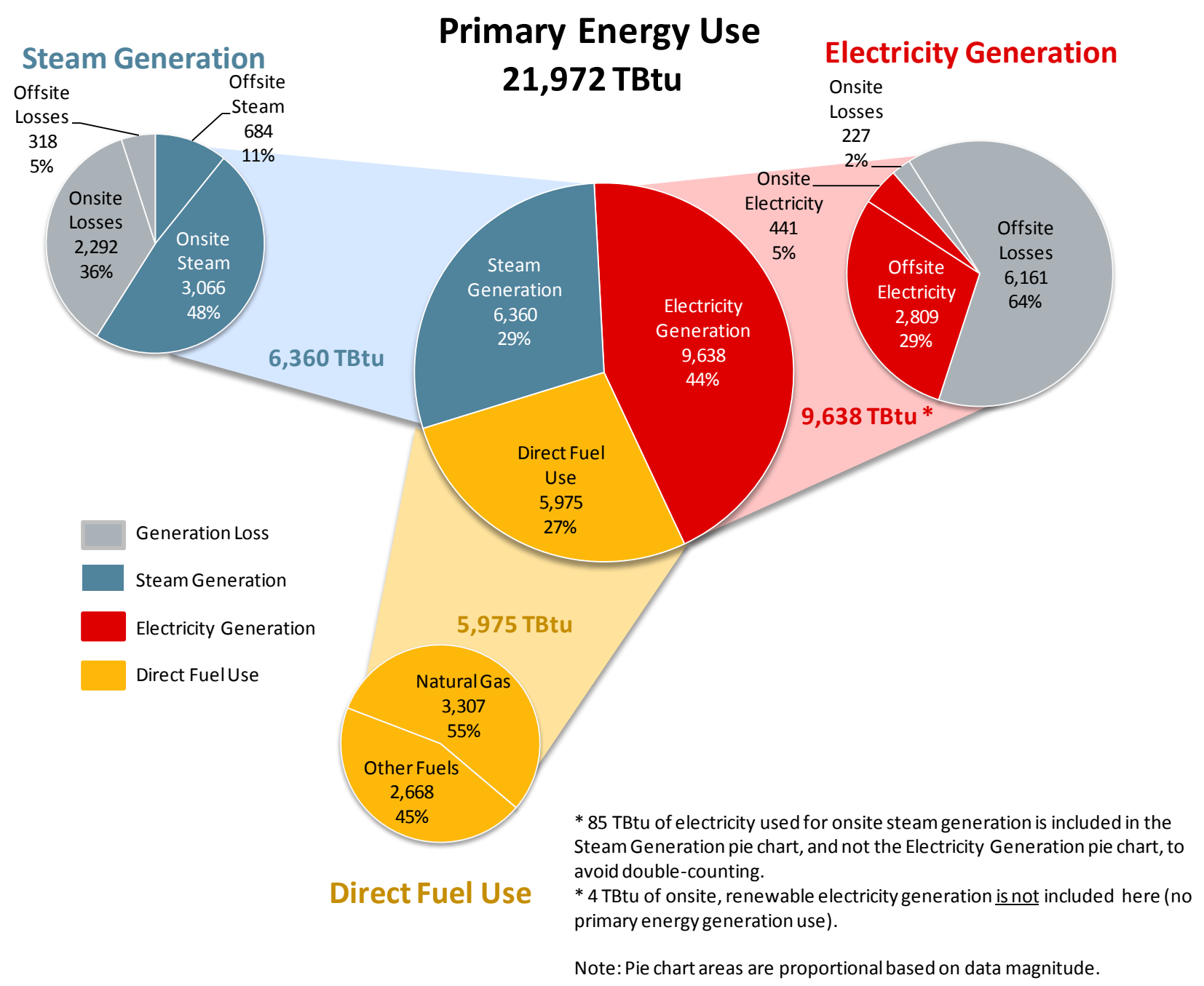

Fig. 2.1-5. Primary energy use by energy type for U.S. manufacturing

Fuel that is directly used by process or nonprocess uses (i.e., not including fuel used to generate electricity or steam onsite) totals $5,975 \mathrm{TBtu}$, or $27 \%$ of total primary energy consumption. Natural gas accounts for over half of direct fuel consumption at 3,307 TBtu, while other fuels - coal, fuel oils, byproduct fuels, and other petroleum-based fuels - account for the remaining 2,668 TBtu of direct fuel energy.

Primary energy use breakdown figures, similar to Fig. 2.1-5, are provided for five of the most energyintensive manufacturing sectors later in this chapter. It is important to note that in these figures the small amount of electrical energy used for steam generation is included only in the steam generation pie chart to avoid double-counting when both steam and electricity are shown together. The primary energy use for electricity generation increases to 9,727 TBtu when the electrical energy for onsite steam generation is included. Another note to point out is that the onsite electricity generation value includes 4 TBtu of

\footnotetext{
${ }^{5}$ The onsite steam generation value (1,694 TBtu from CHP and 1,372 TBtu from boilers) includes 20\% distribution losses. These values do not match the steam output values shown in the footprint (2,117 from CHP and 1,715 from boilers), as the steam distribution losses are shown further downstream in the footprint.
} 
renewable, non-combustion electricity generation. The forest products sector contributes the majority (3 $\mathrm{TBtu})$ of this renewable electricity generation.

In Table 2.1-2, manufacturing sectors are ranked by primary energy use. When offsite and onsite energy generation is considered, the chemicals sector is clearly the greatest user of primary energy, followed closely by the forest products and petroleum refining sectors. Other large energy consuming sectors, with primary energy use over one quad per year, include the food and beverage sector and the iron and steel sector. Transportation equipment manufacturing consumes close to one quad of primary energy, at 904 TBtu, but has a substantially lower share of onsite energy use than the five aforementioned sectors that each consume more than one quad of energy.

Table 2.1-2. U.S. manufacturing sector rank by primary energy use

\begin{tabular}{|l|c|c|c|c|}
\hline \multicolumn{1}{|c|}{ Sector } & $\begin{array}{c}\text { Primary } \\
\text { energy use } \\
\text { (TBtu) }\end{array}$ & Rank & $\begin{array}{c}\text { Percent of } \\
\text { primary energy } \\
\text { consumed onsite }\end{array}$ & $\begin{array}{c}\text { Percent of } \\
\text { primary energy } \\
\text { consumed ofisite }\end{array}$ \\
\hline Chemicals & 4,513 & 1 & $71 \%$ & $29 \%$ \\
Forest products & 3,559 & 2 & $79 \%$ & $21 \%$ \\
Petroleum refining & 3,546 & 3 & $91 \%$ & $9 \%$ \\
Food and beverage & 1,934 & 4 & $67 \%$ & $33 \%$ \\
Iron and steel & 1,481 & 5 & $70 \%$ & $30 \%$ \\
Transportation equipment & 904 & 6 & $53 \%$ & $47 \%$ \\
Plastics & 729 & 7 & $46 \%$ & $54 \%$ \\
Fabricated metals & 708 & 8 & $56 \%$ & $44 \%$ \\
Alumina and aluminum & 603 & 9 & $45 \%$ & $55 \%$ \\
Computers, electronics, and & 527 & 10 & $43 \%$ & $57 \%$ \\
electrical equipment & 472 & 11 & $56 \%$ & $44 \%$ \\
Textiles & 471 & 12 & $81 \%$ & $19 \%$ \\
Cement & 466 & 13 & $71 \%$ & $29 \%$ \\
Glass & 444 & 14 & $46 \%$ & $54 \%$ \\
Machinery & 281 & 15 & $56 \%$ & $29 \%$ \\
Foundries & 21,972 & N/A & $71 \%$ & \\
\hline All manufacturing & & & \\
\hline
\end{tabular}

The top three sectors share several characteristics that contribute to their high energy consumption. First, the core processes used to convert raw materials in these industries operate at high temperatures and pressures. Second, each consumes vast amounts of steam energy. Third, the energy efficiency of some core processes is below optimal, for a variety of reasons. In the chemicals and petroleum refining industries, for example, distillation columns play a key role in producing chemicals and fuels. The thermal efficiency of these energy-intensive columns is typically low (approximately $10 \%{ }^{6}$ ). To some degree, these same characteristics - high temperatures and pressures, steam intensity, and "thermal inefficiency" - elevate energy use in all energy-intensive industries.

\subsubsection{Onsite energy}

Onsite energy differs from primary energy in that only the fuel energy consumed within the plant boundary, or onsite, is reported. This includes both purchases and transfers-in of energy, and energy generated onsite; it does not include losses incurred at offsite utilities. Differentiating between inside or

${ }^{6}$ ITP (Industrial Technologies Program), EERE (Energy Efficiency and Renewable Energy). 2009. Heat Integrated Distillation through Use of Microchannel Technology. U.S. Department of Energy. 
outside the plant boundary is important when evaluating technology options for improving energy efficiency. Within the plant boundary, a plant has control over its energy consumption. Outside the plant boundary, where energy is generated by or provided by utilities, a plant has little or no control over technology efficiency. However, a plant can reduce energy losses associated with external energy supply by adopting technologies that allow it to generate more energy onsite, more efficiently than the utility (e.g., cogeneration). The end uses of onsite energy are further described herein as either indirect or direct end use. The distinction stems from the inclusion or exclusion of energy used for onsite generation.

Onsite energy use for all of U.S. manufacturing totaled 15,494 TBtu in 2006. This onsite energy use enters the plant boundary in the form of three offsite energy types: fuel, steam, and electricity. A large portion of this fuel is consumed onsite in order to generate additional steam and electricity. Fig. 2.1-6 shows a breakdown of total fuel, electricity, and steam supply from offsite sources; the yellow fuel use portion of the pie chart is further divided by fuel type. Offsite electricity accounts for $18 \%$ of this total, while natural gas accounts for 5,512 TBtu, or 36\% of this energy. Offsite steam comprises only $855 \mathrm{TBtu}$, or $5 \%$ of total offsite energy supply; the majority of direct steam use is produced onsite. Byproducts fuels (mostly derived from non-fuel feedstock) including byproduct waste gases (still gas, blast furnace gas, or coke oven gas), waste oils, petroleum coke, wood chips/bark, agricultural waste, and pulping/black liquor contribute almost a third (4,385 TBtu) of total offsite energy supply. The remaining $876 \mathrm{TBtu}$ of offsite energy supply consists of other fuels including coke and breeze and other miscellaneous fuels.

\section{5,494 TBtu}

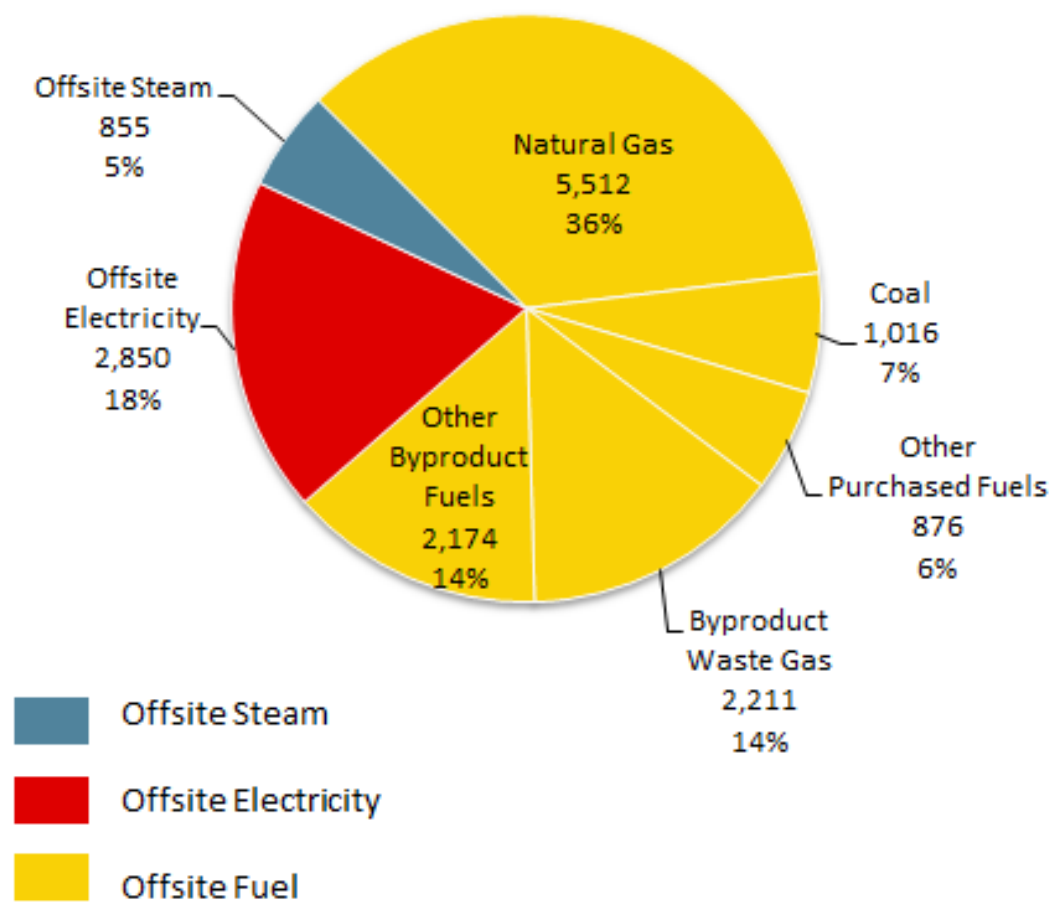

Fig. 2.1-6. Offsite energy supply for U.S. manufacturing

U.S. manufacturers create a diversity of products with many different production processes and technologies, so energy use patterns vary across sectors. A breakdown of offsite fuel, electricity, and steam supply by sector is shown in Fig. 2.1-7, and ranked by order of magnitude from left to right. The fuel category includes byproduct fuels generated at the plant site, as well as the onsite use of renewable sources such as solar, wind, or geothermal energy. Coinciding with the sectors of focus in this report, the top consumers of purchased fuel, electricity, and steam by sector are petroleum refining, chemicals, forest products, food and beverage, and iron and steel. 


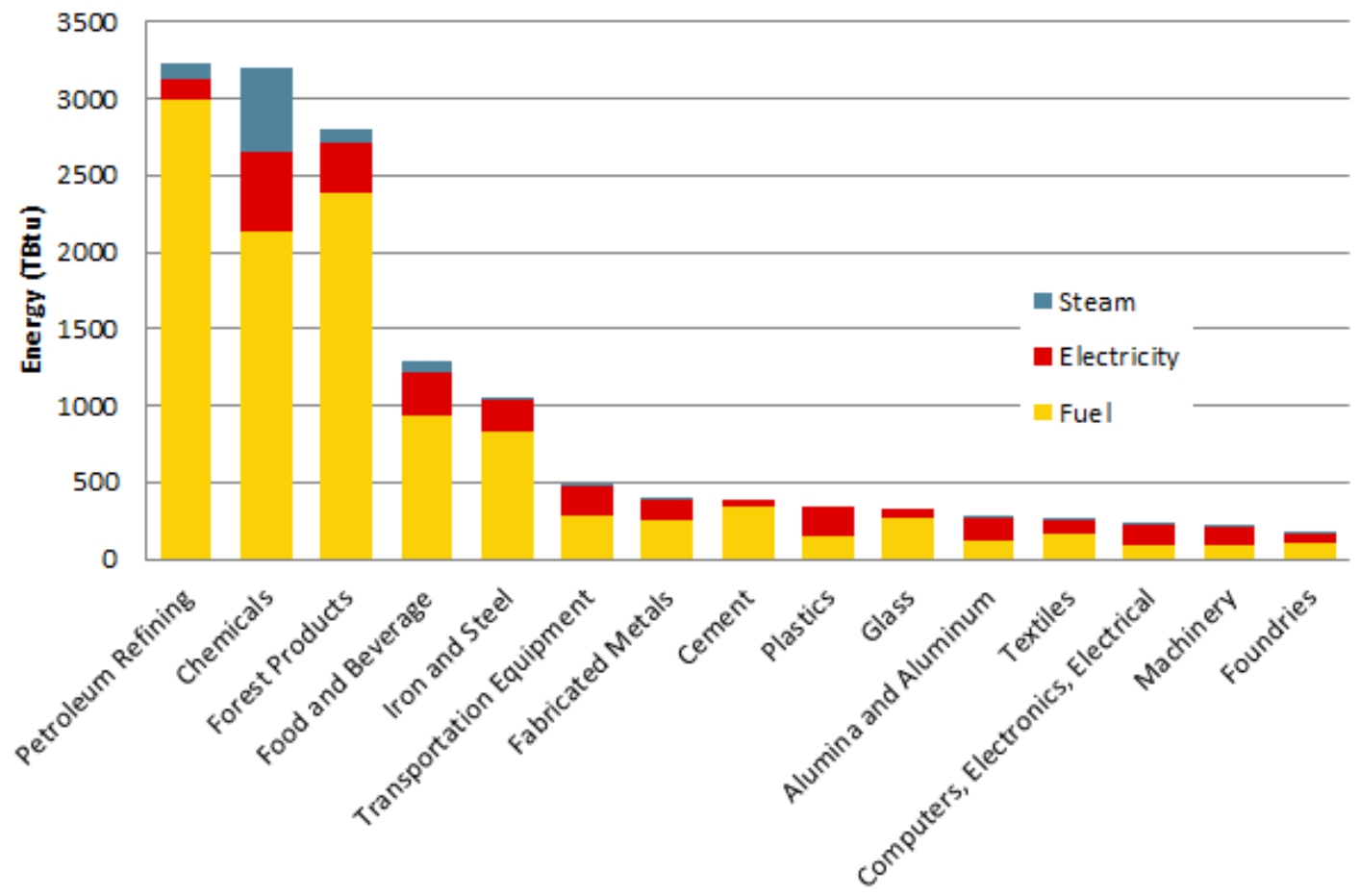

Manufacturing Sector

Fig. 2.1-7. Offsite fuel, electricity, and steam supply by manufacturing sector

Similar to Fig. 2.1-7, Table 2.1-3 and Table 2.1-4 compare and rank the offsite supply of fuel, electricity, and steam among the different manufacturing sectors. This comparison provides a means of identifying those sectors that are highly dependent on purchased fuel and electricity. It also helps to identify those sectors that could benefit from the use (or increased use) of efficient onsite cogeneration technology.

Table 2.1-3. Offsite energy supply by U.S. manufacturing sector

\begin{tabular}{|l|c|c|c|c|c|c|c|c|}
\hline \multirow{2}{*}{\multicolumn{1}{|c}{ Sector }} & \multicolumn{2}{c}{ Total } & \multicolumn{2}{c}{ Fuel } & \multicolumn{2}{c|}{ Electricity } & \multicolumn{2}{c|}{ Steam } \\
\cline { 2 - 8 } & TBtu & Rank & TBtu & Rank & TBtu & Rank & TBtu & Rank \\
\hline Petroleum refining & 3,231 & 1 & 2,994 & 1 & 127 & 10 & 110 & 2 \\
Chemicals & 3,195 & 2 & 2,138 & 3 & 517 & 1 & 540 & 1 \\
Forest products & 2,799 & 3 & 2,381 & 2 & 338 & 2 & 80 & 4 \\
Food and beverage & 1,295 & 4 & 928 & 4 & 281 & 3 & 86 & 3 \\
Iron and steel & 1,043 & 5 & 831 & 5 & 201 & 4 & 11 & 5 \\
Transportation equipment & 480 & 6 & 278 & 7 & 195 & 5 & 7 & 7 \\
Fabricated metals & 397 & 7 & 248 & 9 & 143 & 8 & 6 & 8 \\
Cement & 382 & 8 & 341 & 6 & 41 & 15 & 0 & - \\
Plastics & 336 & 9 & 154 & 11 & 182 & 6 & 0 & - \\
Glass & 330 & 10 & 267 & 8 & 63 & 13 & 0 & - \\
Alumina and aluminum & 273 & 11 & 118 & 12 & 152 & 7 & 3 & 9 \\
Textiles & 265 & 12 & 162 & 10 & 94 & 12 & 9 & 6 \\
Computers, electronics, and & 228 & 13 & 89 & 15 & 138 & 9 & 1 & 10 \\
electrical equipment & 204 & 14 & 92 & 14 & 111 & 11 & 1 & 11 \\
Machinery & 158 & 15 & 101 & 13 & 57 & 14 & 0 & - \\
Foundries & 15,494 & N/A & 11,789 & N/A & 2,850 & N/A & 855 & N/A \\
\hline All manufacturing & & & & & \\
\hline
\end{tabular}


Table 2.1-4. Offsite energy supply distribution

\begin{tabular}{|l|c|c|c|}
\hline \multicolumn{1}{|c|}{ Sector } & $\begin{array}{c}\text { Percent } \\
\text { fuel }\end{array}$ & $\begin{array}{c}\text { Percent } \\
\text { electricity }\end{array}$ & $\begin{array}{c}\text { Percent } \\
\text { steam }\end{array}$ \\
\hline Petroleum refining & $93 \%$ & $4 \%$ & $3 \%$ \\
Cement & $89 \%$ & $11 \%$ & $0 \%$ \\
Forest products & $85 \%$ & $12 \%$ & $3 \%$ \\
Glass & $81 \%$ & $19 \%$ & $0 \%$ \\
Iron and steel & $80 \%$ & $19 \%$ & $1 \%$ \\
Food and beverage & $72 \%$ & $22 \%$ & $7 \%$ \\
Chemicals & $67 \%$ & $16 \%$ & $17 \%$ \\
Fabricated metals & $62 \%$ & $36 \%$ & $2 \%$ \\
Foundries & $64 \%$ & $36 \%$ & $0 \%$ \\
Textiles & $61 \%$ & $35 \%$ & $3 \%$ \\
Transportation equipment & $58 \%$ & $41 \%$ & $1 \%$ \\
Plastics & $46 \%$ & $54 \%$ & $0 \%$ \\
Machinery & $45 \%$ & $54 \%$ & $0 \%$ \\
Alumina and aluminum & $43 \%$ & $56 \%$ & $1 \%$ \\
Computers, electronics, and electrical equipment & $39 \%$ & $61 \%$ & $0 \%$ \\
\hline All manufacturing & $76 \%$ & $18 \%$ & $6 \%$ \\
\hline
\end{tabular}

Understanding the relative reliance on purchased fuels, electricity, and steam for each sector is important when assessing the vulnerability of individual sectors to volatility for energy price or supply. A majority of manufacturing sectors do not purchase steam (notwithstanding the chemicals sector, which imports steam to supply $17 \%$ of its primary energy use). Rather, most sectors produce steam onsite, consuming fuel in the process. The tables identify five sectors that are most heavily reliant on electricity: computers, electronics and electrical equipment, alumina and aluminum, machinery, plastics, and transportation equipment. Electricity accounts for $41 \%$ or more of energy requirements in these sectors.

In terms of fuel, five sectors are most reliant on fuel use: petroleum refining, cement, forest products, glass, and iron and steel. Fuel use accounts for about $80 \%$ or more of energy use in these sectors. Natural gas is of particular interest, since it comprises the largest share of purchased fuel use. Other relatively heavy fuel users include food and beverage, chemicals, fabricated metals, foundries, and textiles.

Equally as important as onsite energy use is onsite energy loss. Onsite losses take various forms; many onsite losses are typical across all sectors, such as those incurred in steam systems, cogeneration units, energy distribution lines, motors, pumps, compressors, and other commonly used equipment. In other cases, onsite losses are highly specific to the manufacturing processes employed. This report provides a macro view of sector-wide energy use and loss, and for this reason average loss estimates are applied (e.g., $20 \%$ conventional boiler loss). Average system area loss estimates are provided in Table 1.2-2 and explained in Appendix D. Specific process loss detail (e.g., mechanical pulping efficiency, cement kiln efficiency) is not included in the energy footprint model.

\subsubsection{Fuel energy}

Table 2.1-5 presents the sector ranking for onsite fuel use, while Fig. 2.1-8 illustrates the breakdown of types of fuels used by each sector. As shown, the top five sectors collectively consumed over 9 quads of energy as fuel, with petroleum refining, forest products, and chemicals each reaching over 2 quads. Natural gas is the most commonly used fuel type for most industries, with coal serving as a large fuel source in cement. Byproduct fuels such as waste gases, black liquor, and petroleum coke are also commonly used manufacturing fuels; these are discussed in further detail in the corresponding sector profiles. 
Table 2.1-5. U.S. manufacturing sectors ranked by fuel use (indirect and direct end use)

\begin{tabular}{|l|c|c|c|c|}
\hline \multicolumn{1}{|c|}{ Sector } & $\begin{array}{c}\text { Fuel use } \\
\text { (TBtu) }\end{array}$ & Rank & $\begin{array}{c}\text { Percent of } \\
\text { fuel for direct } \\
\text { end use }\end{array}$ & $\begin{array}{c}\text { Percent of fuel } \\
\text { for indirect end } \\
\text { use }\end{array}$ \\
\hline Petroleum refining & 2,994 & 1 & $69 \%$ & $31 \%$ \\
Forest products & 2,381 & 2 & $13 \%$ & $87 \%$ \\
Chemicals & 2,138 & 3 & $30 \%$ & $70 \%$ \\
Food and beverage & 928 & 4 & $34 \%$ & $66 \%$ \\
Iron and steel & 831 & 5 & $75 \%$ & $25 \%$ \\
Cement & 341 & 6 & $89 \%$ & $11 \%$ \\
Transportation equipment & 278 & 7 & $77 \%$ & $23 \%$ \\
Glass & 267 & 8 & $91 \%$ & $9 \%$ \\
Fabricated metals & 248 & 9 & $84 \%$ & $16 \%$ \\
Textiles & 162 & 10 & $40 \%$ & $60 \%$ \\
Plastics & 154 & 11 & $48 \%$ & $52 \%$ \\
Alumina and aluminum & 118 & 12 & $84 \%$ & $16 \%$ \\
Foundries & 101 & 13 & $97 \%$ & $3 \%$ \\
Machinery & 92 & 14 & $73 \%$ & $27 \%$ \\
Computers, electronics, and electrical equipment & 89 & 15 & $69 \%$ & $31 \%$ \\
\hline All manufacturing & 11,789 & N/A & $51 \%$ & $49 \%$ \\
\hline
\end{tabular}

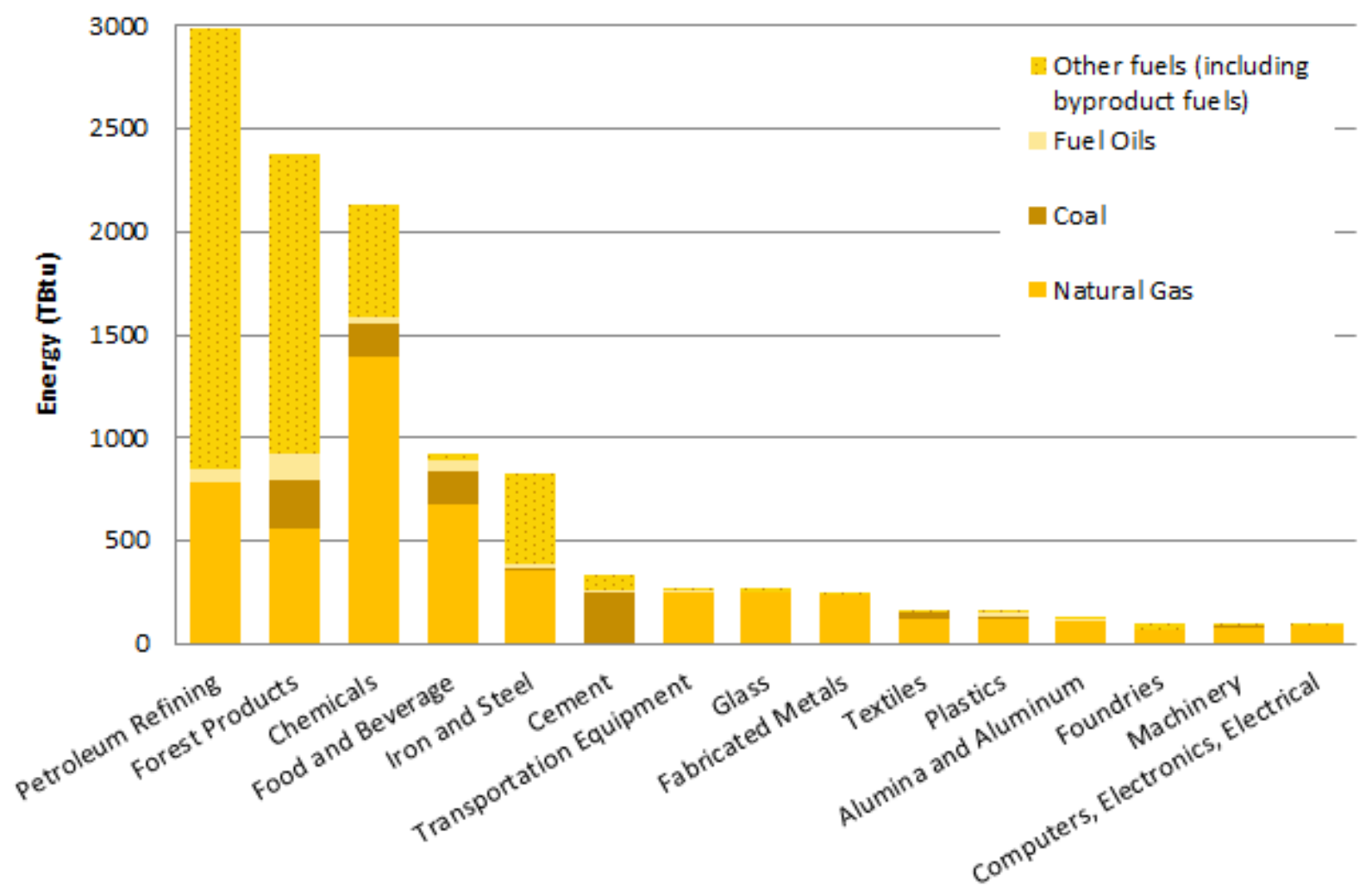

Manufacturing Sector

Fig. 2.1-8. Fuel use and type by manufacturing sector 
The onsite fuel use totals in Table 2.1-5 and Fig. 2.1-8 include indirect and direct fuel use. The proportion of indirect versus direct fuel use varies widely by sector depending on specific process energy needs and onsite generation capabilities. In Table 2.1-5, the percent of fuel that is used by direct end uses is shown to vary from $13 \%$ in Forest Products (where a great deal of fuel is used in CHP systems) to 97\% in Foundries (where there is minimal onsite generation).

\subsubsection{5. $\quad$ Electrical energy}

Onsite electricity demand has two components: offsite electricity and electricity generated onsite. As was shown in Fig. 2.1-5, electricity use accounts for the largest portion of primary energy use across U.S. manufacturing at about $44 \%$. Some of the sectors that are most dependent on electricity (i.e., greater than $40 \%$ of primary energy use) rely almost entirely on purchased electricity. As was shown in Table 2.1-4, these industries include computers, electronics and electrical equipment, alumina and aluminum, machinery, plastics, and transportation equipment.

Figure 2.1-9 shows that a large portion of the primary energy consumed for electricity use is associated with generation, transmission and distribution (T\&D) losses, taking place mostly offsite. The efficiency of offsite utility power generation, transmission, and distribution is assumed to be $31.6 \%$ on average [EIA 2010b], generating 6,161 TBtu of energy losses in order to produce 2,809 TBtu of electricity that is used in U.S. manufacturing. ${ }^{7}$ The overall efficiency of electricity generation and transmission, including onsite generation, is $34 \%$. The onsite energy pie chart shows how generated electricity is used by various direct end uses.

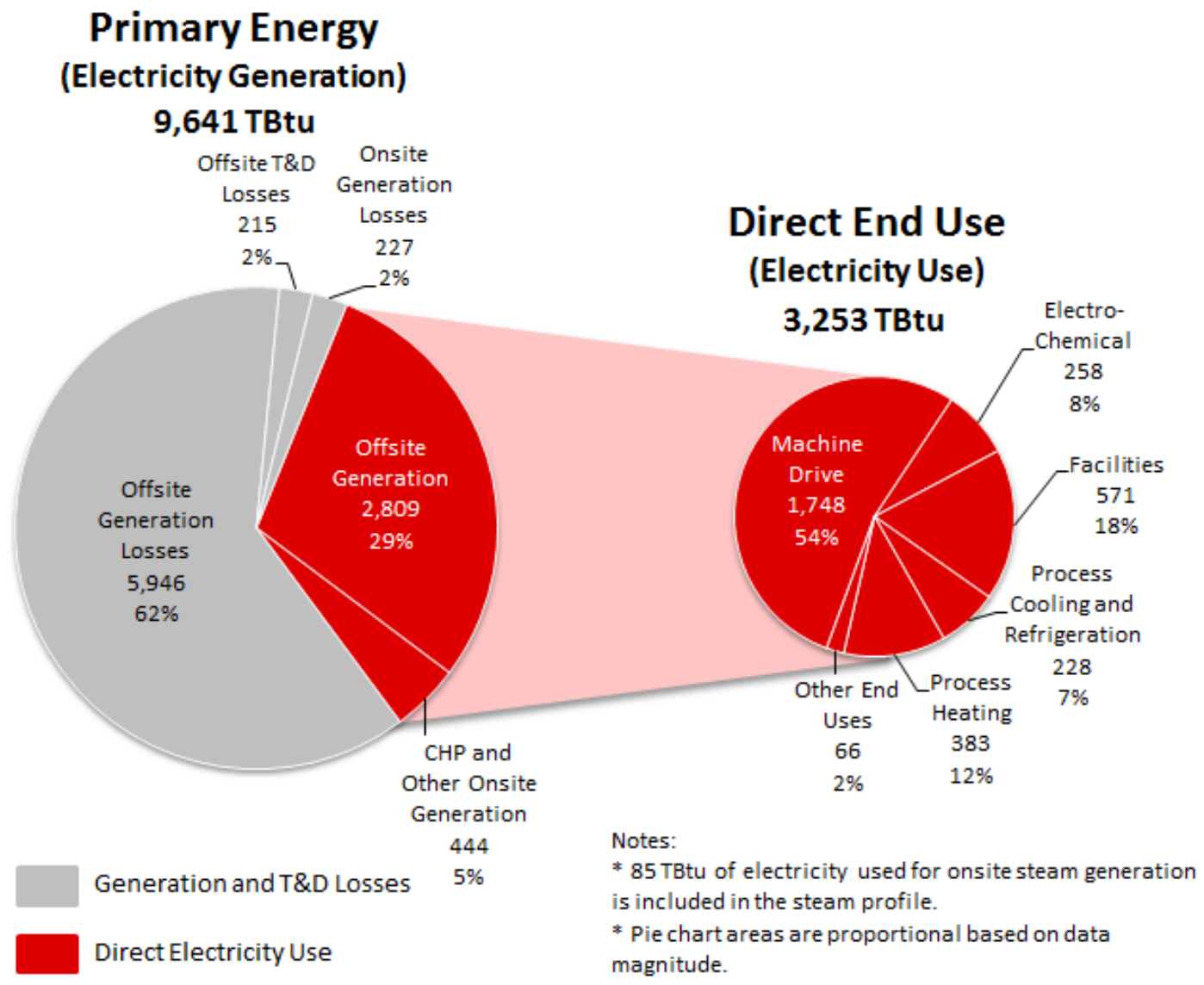

Fig. 2.1-9. Electricity generation and direct end use in U.S. manufacturing

\footnotetext{
${ }^{7}$ Offsite electricity generation $(2,809 \mathrm{TBtu})$ shown in this chart is lower than the value of offsite energy entering the plant boundary shown in the energy and carbon footprint for U.S. manufacturing (2,850 TBtu). This difference is due to the small portion of offsite electricity (41 TBtu) that is used by conventional boilers to generate steam.
} 
Manufacturers do meet a moderate portion of their electricity demand through onsite generation.

Approximately $444 \mathrm{TBtu}$ of direct electricity use is produced from onsite generation. Most of the electricity produced onsite comes from cogeneration, or CHP units, with only a small percentage of onsite generation originating from other generation methods such as the use of generators running on combustible energy sources or electricity from renewable resources. Renewable energy generation itself contributes about 4 TBtu to onsite electricity generation in U.S. manufacturing.

Approximately $54 \%$ of the electricity use in manufacturing is consumed by machine-driven systems such as pumps, conveyors, compressors, fans, mixers, grinders, and other materials handling or processing equipment. Facility energy use, such as HVAC and lighting, is the next largest category, encompassing $17 \%$ of electricity use. Process heating follows at $12 \%$ of electricity use. The remaining $17 \%$ of electricity use is consumed by other process uses such as electrochemical processes and process cooling and refrigeration.

Onsite electricity end use is shown by sector in Table 2.1-6, along with the percent of this electricity end use that is generated onsite. The electricity values listed in Table 2.1-6 are direct electricity use, which includes onsite generated electricity. Total offsite electricity supply, shown in Table 2.1-3, is slightly lower for most sectors given that electricity generated onsite is not included.

Table 2.1-6. U.S. manufacturing sectors ranked by electricity use (direct end use)

\begin{tabular}{|l|c|c|c|}
\hline \multicolumn{1}{|c|}{ Sector } & $\begin{array}{c}\text { Electricity } \\
\text { use } \\
\text { (TBtu) }\end{array}$ & $\begin{array}{c}\text { Percent } \\
\text { Rank }\end{array}$ & $\begin{array}{c}\text { generated } \\
\text { onsite }\end{array}$ \\
\hline Chemicals & 676 & 1 & $28 \%$ \\
Forest products & 484 & 2 & $37 \%$ \\
Food and beverage & 292 & 3 & $6 \%$ \\
Iron and steel & 214 & 4 & $7 \%$ \\
Transportation equipment & 195 & 5 & $1 \%$ \\
Petroleum refining & 191 & 6 & $35 \%$ \\
Plastics & 181 & 7 & $0 \%$ \\
Alumina and aluminum & 153 & 8 & $1 \%$ \\
Fabricated metals & 143 & 9 & $1 \%$ \\
Computers, electronics, and electrical equipment & 137 & 10 & $0 \%$ \\
Machinery & 111 & 11 & $1 \%$ \\
Textiles & 96 & 12 & $3 \%$ \\
Glass & 63 & 13 & $0 \%$ \\
Foundries & 57 & 14 & $0 \%$ \\
Cement & 46 & 15 & $10 \%$ \\
\hline All manufacturing & 3,253 & $\mathrm{~N} / \mathrm{A}$ & $15 \%$ \\
\hline
\end{tabular}

The chemicals and forest product sectors have the largest onsite electricity demand. These sectors also are among the largest indirect generators of electricity. The petroleum refining sector is also a large onsite generator (35\% of direct electricity demand is generated onsite), but it is ranked lower because overall electricity demand is much lower for the sector.

\subsubsection{Steam energy}

A profile of onsite steam demand from generation and associated losses to end uses is shown in Fig. 2.1-10. About $40 \%$ of primary energy inputs are assumed to be lost due to system inefficiencies in steam generation and transmission, both offsite and onsite; see Appendix D for explanation of steam generation 
and distribution loss assumptions. CHP generation serves as a principal source of steam energy in the manufacturing sector, comprising over a quarter $(27 \%, 1,694 \mathrm{TBtu})$ of steam generated. Conventional boilers are the next largest source of steam, providing about $22 \%(1,372 \mathrm{TBtu})$ of primary energy for end use, followed by steam generated offsite at $11 \%$ (684 TBtu) ${ }^{8}$

Of the 6,360 TBtu of primary energy used for steam, 3,750 TBtu of energy is applied to process and nonprocess end uses. Steam end use is not reported in the EIA MECS data, so the direct end use of steam was estimated based results from a peer review effort described in Appendix E. For all manufacturing, it was determined that $66 \%$ of steam energy is applied towards process heating $(2,469 \mathrm{TBtu}), 11 \%$ to facility HVAC (410 TBtu), $10 \%$ to machine drive (360 TBtu), $8 \%$ to other process uses (283 TBtu), $3 \%$ to other nonprocess uses (124 TBtu), and the remaining 3\% to process cooling and refrigeration (103 TBtu)

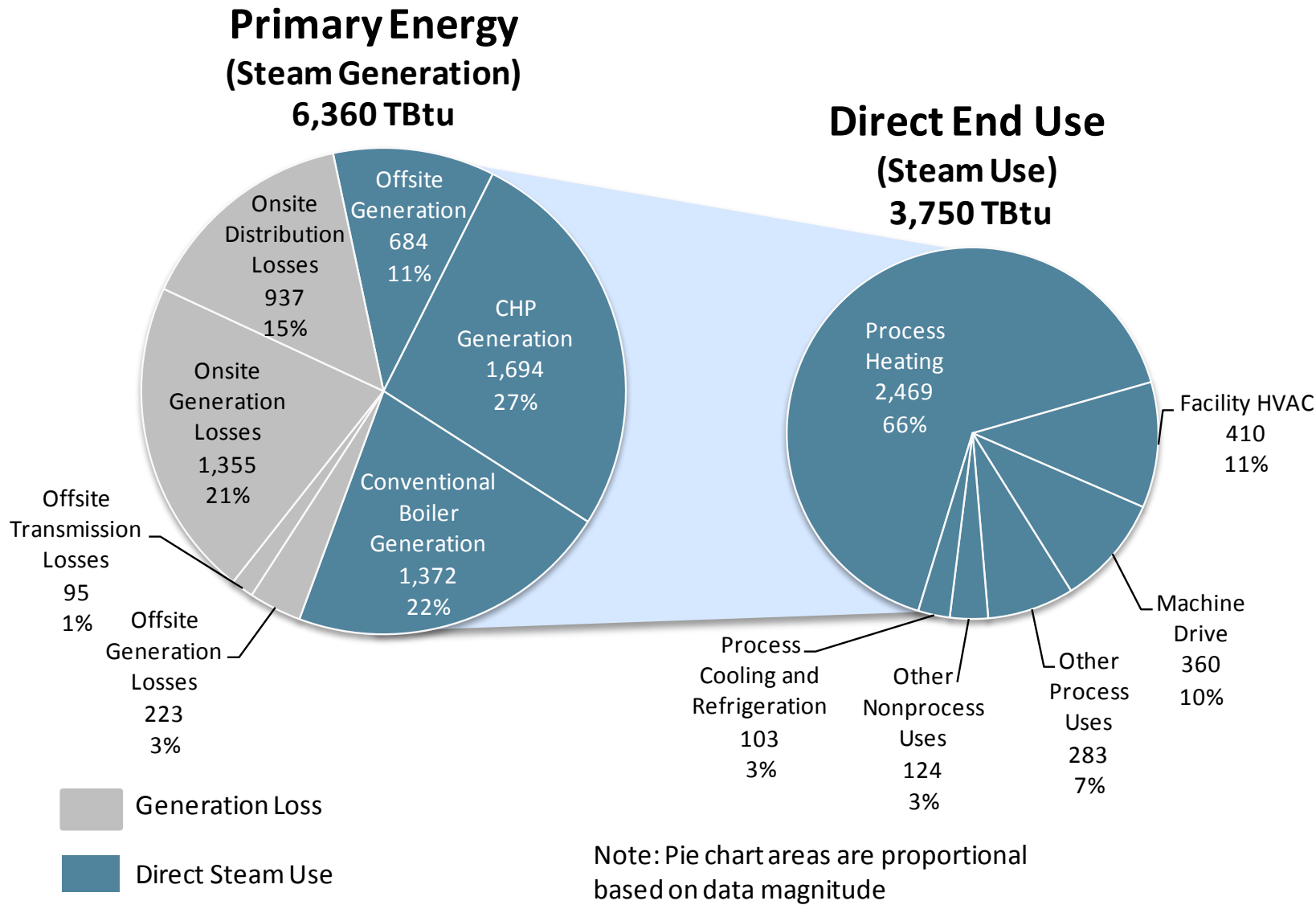

Fig. 2.1-10. Steam generation and direct end use in U.S. manufacturing

Manufacturing sector steam use is shown in Table 2.1-7, with sectors ranked by magnitude. The top five sectors - forest products, chemicals, petroleum refining, food and beverage, and iron and steel—all consume over $100 \mathrm{TBtu}$ of steam. The energy conversion component of steam systems (e.g., heat exchangers, injectors, mechanical drives) varies substantially among industries and is generally processand site-specific. The chemicals sector, for example, uses steam mostly for fluid heating (steam stripping, steam reforming). Other sectors may use steam for direct heating of parts or components, for cleaning, or for other process heating (e.g., sterilization). Common steam direct and indirect end uses in select energyintensive industries are listed in Table 2.1-8 and described in more detail in the 2012 DOE AMO publication, Improving Steam System Performance: A Sourcebook for Industry [AMO EERE 2012b].

\footnotetext{
${ }^{8}$ The onsite steam generation values (1,679 TBtu from CHP and 1,372 TBtu from boilers) include 20\% distribution losses. These values do not match the steam output values shown in the footprint (2,099 TBtu from CHP and 1,715 TBtu from boilers), as the steam distribution losses are shown further downstream in the footprint.
} 
Table 2.1-7. U.S. manufacturing sectors ranked by steam use (direct end use)

\begin{tabular}{|l|c|c|c|}
\hline \multicolumn{1}{|c|}{ Sector } & $\begin{array}{c}\text { Steam use } \\
(\text { TBtu })\end{array}$ & Rank & $\begin{array}{c}\text { Percent } \\
\text { generated onsite }\end{array}$ \\
\hline Forest products & 1,202 & 1 & $95 \%$ \\
Chemicals & 1,130 & 2 & $62 \%$ \\
Petroleum refining & 581 & 3 & $85 \%$ \\
Food and beverage & 443 & 4 & $84 \%$ \\
Iron and steel & 118 & 5 & $92 \%$ \\
Textiles & 66 & 6 & $89 \%$ \\
Plastics & 52 & 7 & $100 \%$ \\
Transportation equipment & 45 & 8 & $88 \%$ \\
Fabricated metals & 30 & 9 & $84 \%$ \\
Computers, electronics, and & 19 & 10 & $98 \%$ \\
electrical equipment & 17 & 11 & $100 \%$ \\
Cement & 16 & 12 & $100 \%$ \\
Glass & 15 & 13 & $97 \%$ \\
Machinery & 12 & 14 & $80 \%$ \\
Alumina and aluminum & 2 & 15 & $96 \%$ \\
Foundries & 3,750 & N/A & $82 \%$ \\
\hline All manufacturing & & & \\
\hline
\end{tabular}

The steam values listed in Table 2.1-7 encompass all of onsite steam use which includes onsite generated steam and steam from offsite sources. For all sectors, a majority of steam is generated onsite through CHP and conventional boiler systems. 
Table 2.1-8. Steam end use equipment in energy-intensive industries [AMO EERE 2012b]

\begin{tabular}{|c|c|c|}
\hline Equipment & Process application & Industry \\
\hline Condenser & Steam turbine operation & $\begin{array}{l}\text { Aluminum, chemicals, forest } \\
\text { products, glass, metal casting, } \\
\text { petroleum refining, steel }\end{array}$ \\
\hline $\begin{array}{l}\text { Distillation } \\
\text { tower }\end{array}$ & Distillation, fractionation & Chemicals, petroleum refining \\
\hline Dryer & Drying & Forest products \\
\hline Evaporator & Evaporation/concentration & $\begin{array}{l}\text { Chemicals, forest products, } \\
\text { petroleum refining }\end{array}$ \\
\hline $\begin{array}{l}\text { Process heat } \\
\text { exchanger }\end{array}$ & $\begin{array}{l}\text { Alkylation, process air heating, process water heating, } \\
\text { gas recovery/light ends distillation, isomerization, } \\
\text { storage tank heating, visbreaking/coking }\end{array}$ & $\begin{array}{l}\text { Aluminum, chemicals, forest } \\
\text { products, glass, metal casting, } \\
\text { petroleum refining, steel }\end{array}$ \\
\hline Reboiler & Fractionation & Petroleum refining \\
\hline Reformer & Hydrogen generation & Chemicals, petroleum refining \\
\hline Separator & Component separation & $\begin{array}{l}\text { Chemicals, forest products, } \\
\text { petroleum refining }\end{array}$ \\
\hline $\begin{array}{l}\text { Steam } \\
\text { ejector }\end{array}$ & Condenser operation, vacuum distillation & $\begin{array}{l}\text { Aluminum, chemicals, forest } \\
\text { products, glass, metal casting, } \\
\text { petroleum refining, steel }\end{array}$ \\
\hline $\begin{array}{l}\text { Steam } \\
\text { injector }\end{array}$ & Agitation/blending, heating & $\begin{array}{l}\text { Chemicals, forest products, } \\
\text { petroleum refining }\end{array}$ \\
\hline $\begin{array}{l}\text { Steam } \\
\text { turbine }\end{array}$ & $\begin{array}{l}\text { Power generation, compressor mechanical drive, } \\
\text { hydrocracking, naphtha reforming, pump mechanical } \\
\text { drive, feed pump mechanical drive }\end{array}$ & $\begin{array}{l}\text { Aluminum, chemicals, forest } \\
\text { products, glass, metal casting, } \\
\text { petroleum refining, steel }\end{array}$ \\
\hline Stripper & $\begin{array}{l}\text { Distillation (crude and vacuum units), catalytic } \\
\text { cracking, asphalt processing, catalytic reforming, } \\
\text { component removal, component separation, } \\
\text { fractionation, hydrogen treatment lube oil processing }\end{array}$ & Chemicals, petroleum refining \\
\hline $\begin{array}{l}\text { Thermo- } \\
\text { compressor }\end{array}$ & Drying, steam pressure amplification & Forest products \\
\hline
\end{tabular}

\subsubsection{Onsite generation/CHP energy}

Onsite electricity and steam generation is a significant provider of end use energy in U.S. manufacturing; approximately a third of all process and nonprocess energy is generated onsite and over $80 \%$ of steam is generated onsite. The (indirect) energy used for onsite generation is primarily fuel (99\%), with only $1 \%$ of energy in the form of electricity for boilers. Approximately half of all purchased fuel (Table 2.1-5, 49\%) is used indirectly for onsite generation $(5,814 \mathrm{TBtu})$. Direct process and nonprocess end uses are shown in more detail in Fig. 2.1-13.

Sector rankings for onsite generation of steam and electricity are presented in Table 2.1-9. The forest products, chemicals, and petroleum refining sectors generate the most onsite steam. In the forest products sector, almost all of the steam is generated in CHP units with black liquor as a contributing fuel source. In the chemicals and petroleum refining sectors, the split between CHP and boiler steam generation is closer to $50 / 50$. 
Table 2.1-9. U.S. manufacturing sectors ranked by onsite steam and electricity generation, TBtu

\begin{tabular}{|l|r|r|r|c|c|c|c|c|}
\hline \multirow{2}{*}{ Sector } & \multicolumn{3}{|c|}{ Onsite steam generation } & \multicolumn{3}{c|}{ Onsite electricity generation } \\
\cline { 2 - 8 } & CHP & Boilers & Total steam & Rank & CHP & Other & Total electricity & Rank \\
\hline Forest products & 1,250 & 173 & 1,422 & 1 & 174 & 6 & 180 & 2 \\
Chemicals & 416 & 457 & 873 & 2 & 188 & 1 & 189 & 1 \\
Petroleum refining & 255 & 361 & 616 & 3 & 65 & 1 & 66 & 3 \\
Food and beverage & 105 & 363 & 468 & 4 & 17 & 1 & 18 & 4 \\
Iron and steel & 71 & 66 & 137 & 5 & 12 & 2 & 14 & 5 \\
Textiles & 10 & 64 & 74 & 6 & 3 & 0 & 3 & 7 \\
Plastics & 0 & 65 & 65 & 7 & 0 & 0 & 0 & - \\
Transportation equipment & 10 & 39 & 49 & 8 & 2 & 0 & 2 & 8 \\
Fabricated metals & 2 & 30 & 32 & 9 & 1 & 0 & 1 & 11 \\
Computers, electronics, & 0 & 23 & 23 & 10 & 0 & 0 & 0 & - \\
electrical & 22 & 0 & 22 & 11 & 5 & 0 & 5 & 6 \\
Cement & 4 & 15 & 19 & 12 & 1 & 0 & 1 & 10 \\
Machinery & 0 & 19 & 19 & 13 & 0 & 0 & 0 & - \\
Glass & 9 & 3 & 12 & 14 & 1 & 0 & 1 & 9 \\
Alumina and aluminum & 0 & 3 & 3 & 15 & 0 & 0 & 0 & - \\
Foundries & 2,117 & 1,715 & 3,832 & N/A & 473 & 15 & 488 & N/A \\
\hline All manufacturing & & &
\end{tabular}

Onsite electricity generation takes place primarily in CHP units; only 3\% of onsite electricity is generated from other electricity generation sources, including renewable sources. Three sectors make up the bulk of onsite electricity generation: chemicals (39\%), forest products (37\%), and petroleum refining (14\%). The proportion of CHP generated electricity vs. steam is higher in the chemicals sector than other sectors as dictated by demand, so although the forest products industry used twice as much fuel for CHP, electricity generation output for the forest products industry is still less than that of the chemicals sector.

About $60 \%$ of onsite electricity and steam generation is from CHP units. As shown in Fig. 2.1-11, CHP systems produce nearly 4 quads of energy output; steam accounts for $57 \%(2,117 \mathrm{TBtu})$ and electricity $13 \%$ (473 TBtu). The remaining 30\% of CHP energy is energy losses (1,133 TBtu); proportionally distributed between steam and electricity based on useful output when needed. Natural gas is the most widely used fuel at $864 \mathrm{TBtu}$, followed by pulping/black liquor, which consumes $440 \mathrm{TBtu}$ exclusively in the forest products sector. Waste gases and biomass are also significant sources of fuel, followed by coal, and other fuels including residual fuel oil and blast furnace/coke oven gases used in the iron and steel sector.

\section{CHP Indirect Fuel Use}

CHP Energy Output

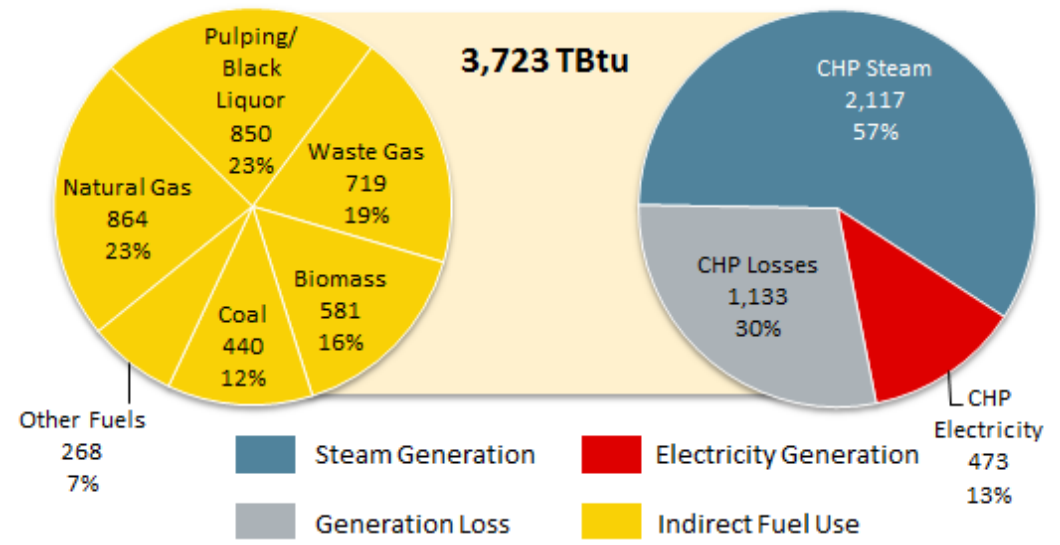

Fig. 2.1-11. CHP fuel consumption and energy output in U.S. manufacturing 
Sector rank for CHP output is presented in Table 2.1-10. The forest products sector ranks highest with over twice the output of the chemicals sector, due to heavy use of pulping/black liquor and biomass fuel. Petroleum refining (320 TBtu) and food and beverage (122 TBtu) are also top users of CHP energy. CHP electricity output is derived from 2006 EIA MECS data, while steam output is estimated using CHP efficiency data published by DOE [EIA 2006]. Refer to Appendix D for boiler and CHP efficiency details.

Table 2.1-10. U.S. manufacturing sectors ranked by CHP fuel use and output, TBtu

\begin{tabular}{|l|r|r|r|r|c|}
\hline \multicolumn{1}{|c|}{ Sector } & Fuel use & Steam output & Electricity output & Total output & Rank \\
\hline Forest products & 1,884 & 1,250 & 174 & 1,424 & 1 \\
Chemicals & 949 & 416 & 188 & 604 & 2 \\
Petroleum refining & 464 & 255 & 65 & 320 & 3 \\
Food and beverage & 163 & 105 & 17 & 122 & 4 \\
Iron and steel & 120 & 71 & 12 & 83 & 5 \\
Cement & 37 & 22 & 5 & 26 & 6 \\
Textiles & 18 & 10 & 3 & 13 & 7 \\
Transportation equipment & 16 & 10 & 2 & 12 & 8 \\
Alumina and aluminum & 14 & 9 & 1 & 10 & 9 \\
Machinery & 7 & 4 & 1 & 5 & 10 \\
Fabricated metals & 4 & 1 & 1 & 3 & 11 \\
Plastics & 1 & 0 & 0 & 0 & 12 \\
Foundries & 0 & 0 & 0 & 0 & - \\
Glass & 0 & 0 & 0 & 0 & - \\
Computers, electronics, and & 0 & 0 & 0 & 2,590 & N/A \\
\hline electrical equipment & 3,723 & 2,117 & 473 & & 0 \\
\hline All manufacturing & & & & & \\
\hline
\end{tabular}

\subsubsection{Direct end use energy}

Often analysts are particularly interested in the direct end use of energy, as this is where investment in research and development in new process technology is most prevalent. The direct end use of energy is the best measure of process energy because this includes both offsite and onsite generated energy sources. Further illustration of direct end use is presented in Fig. 2.1-12.

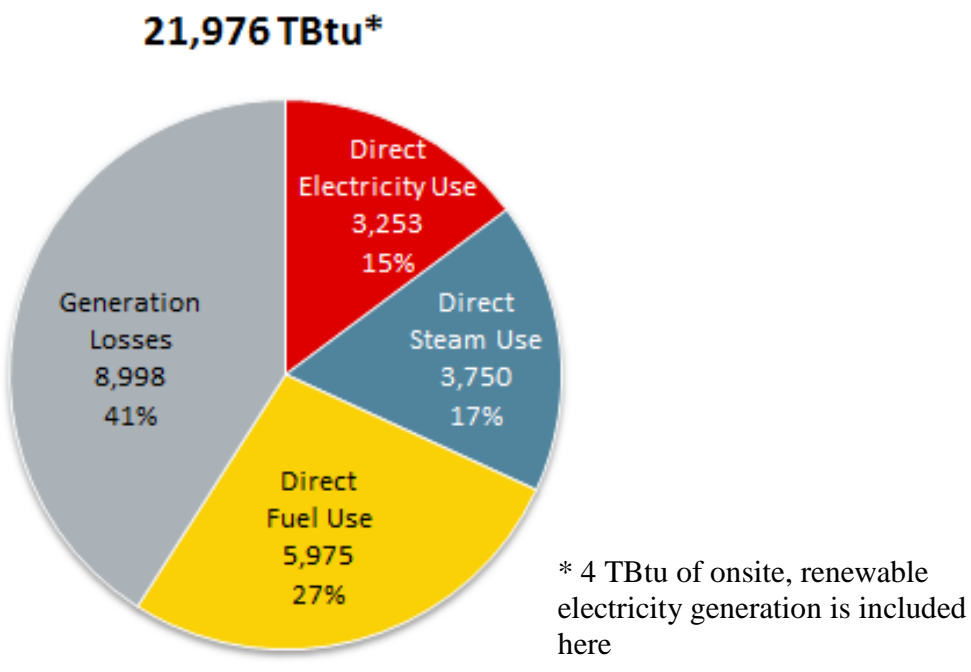

Fig. 2.1-12 Primary energy by type at direct end use in U.S. manufacturing 
The direct process end use categories are based on the EIA-MECS categories of data and include process heating, process cooling and refrigeration, machine drive, electrochemical, and other process uses. Direct nonprocess end use categories include facility HVAC, facility lighting, other facility, onsite transportation, and other nonprocess uses.

The breakdown of primary energy by type at direct end use is shown in Fig. 2.1-12. When offsite and onsite generation losses are excluded, 12,978 TBtu of onsite electricity, fuel, and steam is used for process and nonprocess end uses. The major end uses of this energy are shown in Fig. 2.1-13. Process heating, machine drive, and facility HVAC combined consume almost $90 \%$ of direct end use energy.

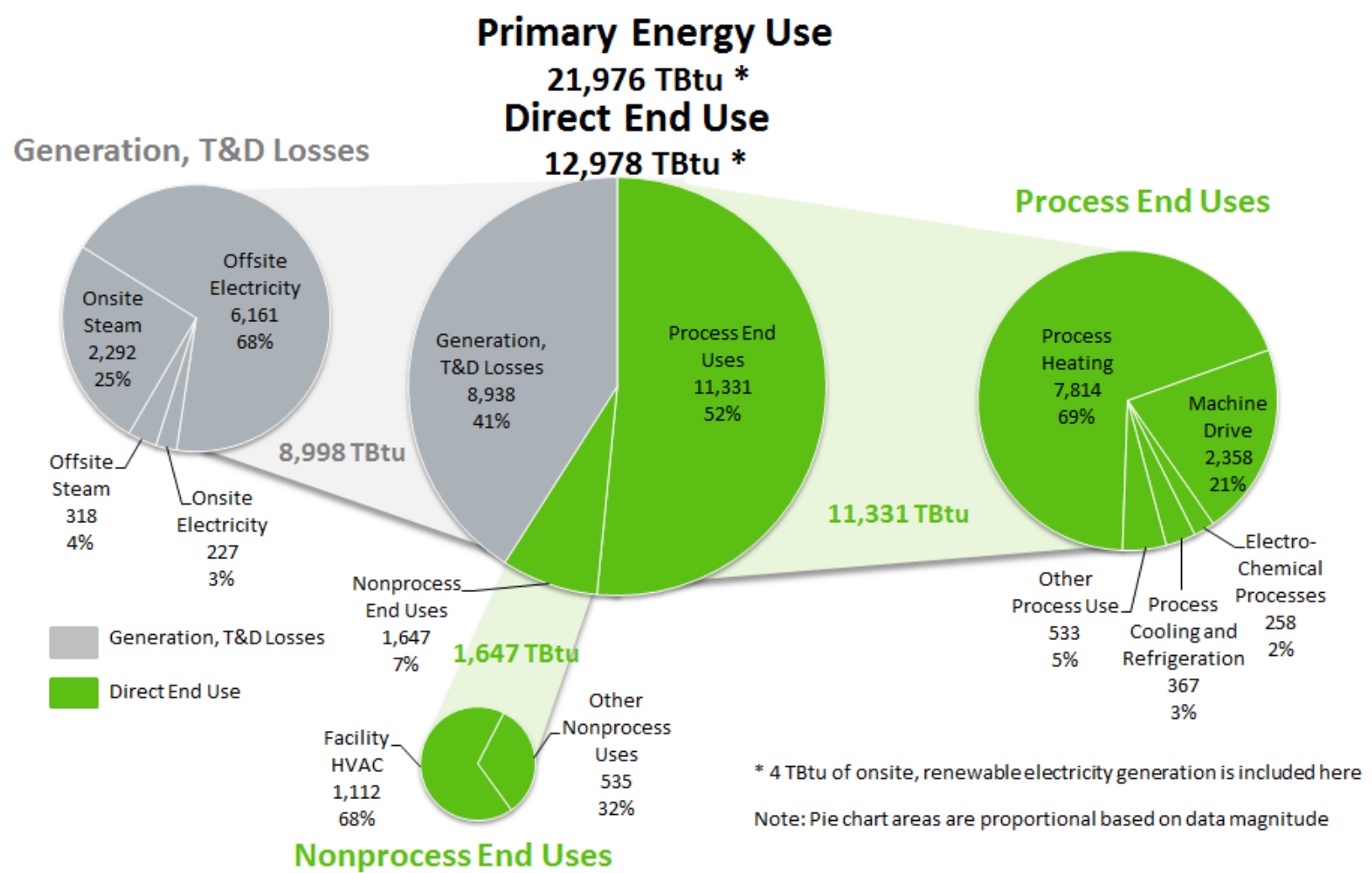

Fig. 2.1-13. Primary energy by direct end use in U.S. manufacturing

Fig. 2.1-13 shows primary energy end use equal to 21,976 TBtu, while Fig. 2.1-5 shows primary energy input equal to $21,972 \mathrm{TBtu}$. The primary end use includes $4 \mathrm{TBtu}$ of onsite renewable electricity that is generated onsite and used in direct end use. Since there is no energy input for this renewable energy source, the primary energy input for electricity generation is 4 TBtu lower.

For the nonprocess end use pie chart, facility lighting, other facility support, onsite transportation, and other nonprocess end uses are combined as "Other Nonprocess Uses" totaling 535 TBtu. The detailed breakdown of this end use is shown in the energy footprints in Appendix C.

Process heating serves as the single largest end use, consuming over 69\% of direct end use energy and approximately $36 \%$ of all primary energy use. Process heating systems are widely used across many sectors for the direct and indirect heating and cooling of gases, fluids, and solids (e.g., metals). As Table 2.1-11 illustrates, energy use attributed to process heating systems is significant (greater than 1 quad) in three industries (petroleum refining, chemicals, and forest products) and is above $200 \mathrm{~TB}$ tu in five other industries. Table 2.1-12 shows that process cooling systems energy use is only above $100 \mathrm{TBtu}$ for the chemicals and food and beverage industries. 
Table 2.1-11. U.S. manufacturing sectors ranked by process heating energy

\begin{tabular}{|l|r|c|}
\hline \multicolumn{1}{|c|}{ Sector } & TBtu & Rank \\
\hline Petroleum refining & 2,346 & 1 \\
Chemicals & 1,268 & 2 \\
Forest products & 1,102 & 3 \\
Iron and steel & 723 & 4 \\
Food and beverage & 555 & 5 \\
Cement & 311 & 6 \\
Glass & 255 & 7 \\
Fabricated metals & 201 & 8 \\
Transportation equipment & 117 & 9 \\
Foundries & 106 & 10 \\
Plastics & 101 & 11 \\
Alumina and aluminum & 100 & 12 \\
Textiles & 100 & 13 \\
Computers, electronics, and & 51 & 14 \\
electrical equipment & 37 & 15 \\
Machinery &
\end{tabular}

Table 2.1-12. U.S. manufacturing sectors ranked by process cooling energy

\begin{tabular}{|l|r|c|}
\hline \multicolumn{1}{|c|}{ Sector } & TBtu & Rank \\
\hline Chemicals & 107 & 1 \\
Food and beverage & 106 & 2 \\
Forest products & 40 & 3 \\
Petroleum refining & 24 & 4 \\
Transportation equipment & 17 & 5 \\
Plastics & 16 & 6 \\
Computers, electronics, and & 13 & 7 \\
electrical equipment & 12 & 8 \\
Textiles & 6 & 9 \\
Fabricated metals & 3 & 10 \\
Machinery & 3 & 11 \\
Alumina and aluminum & 2 & 12 \\
Glass & 1 & 13 \\
Iron and steel & 1 & 14 \\
Foundries & 0 & 15 \\
Cement & & \\
\hline
\end{tabular}

Table 2.1-13 shows the primary energy used for motor-driven equipment, the second largest process end use of energy. Chemicals and forest products are the largest users of machine drive energy, followed by petroleum refining and food and beverage. 
Table 2.1-13. U.S. manufacturing sectors ranked by machine drive energy

\begin{tabular}{|l|c|c|}
\hline \multicolumn{1}{|c|}{ Sector } & TBtu & Rank \\
\hline Chemicals & 586 & 1 \\
Forest products & 524 & 2 \\
Petroleum refining & 301 & 3 \\
Food and beverage & 169 & 4 \\
Iron and steel & 112 & 5 \\
Plastics & 96 & 6 \\
Transportation equipment & 78 & 7 \\
Fabricated metals & 73 & 8 \\
Machinery & 56 & 9 \\
Textiles & 54 & 10 \\
Cement & 39 & 11 \\
Computers, electronics, and & 36 & 12 \\
electrical equipment & 29 & 13 \\
Glass & 22 & 14 \\
Alumina and aluminum & 19 & 15 \\
Foundries & & \\
\hline
\end{tabular}

The sector ranking of nonprocess energy use is shown in Table 2.1-14. The forest products, chemicals, transportation equipment, food and beverage, and computers, electronics, and electrical equipment sectors each consume over 100 TBtu for nonprocess energy end uses; primarily due to facility HVAC and lighting, and onsite transportation systems for moving products within the plant boundary and other facility support.

Table 2.1-14. U.S. manufacturing sectors ranked by nonprocess energy

\begin{tabular}{|l|c|c|}
\hline \multicolumn{1}{|c|}{ Sector } & TBtu & Rank \\
\hline Forest products & 256 & 1 \\
Chemicals & 253 & 2 \\
Transportation equipment & 196 & 3 \\
Food and beverage & 166 & 4 \\
Computers, electronics, and & 103 & 5 \\
electrical equipment & 91 & 6 \\
Machinery & 88 & 7 \\
Fabricated metals & 84 & 8 \\
Plastics & 82 & 9 \\
Iron and steel & 62 & 10 \\
Petroleum refining & 52 & 11 \\
Textiles & 30 & 12 \\
Glass & 26 & 13 \\
Foundries & 16 & 14 \\
Alumina and aluminum & 14 & 15 \\
Cement & & \\
\hline
\end{tabular}




\subsubsection{Applied end use energy}

Up until this point in the analysis, energy losses have only been estimated for offsite and onsite generation of electricity and steam. However, there is another form of energy loss that is important to include in an overall manufacturing energy use balance - direct energy end use losses. Direct end uses refer to process and nonprocess end uses, with energy consumption shown in Fig. 2.1-13.

End use losses are the system and equipment losses that occur in process and nonprocess energy end use, e.g., electric motor shaft losses, or process heating insulation and exhaust losses. End use efficiency has been estimated for each direct end use, as shown by the wavy red arrows in originating from end uses in the manufacturing energy footprints Fig. 2.1-3 and Fig. 2.1-4. The energy that is not lost to system and equipment inefficiencies (end use losses) is applied to the end use.

When both generation and end use losses are accounted for, the energy that remains is referred to herein as applied energy. Applied energy is best illustrated by re-examining Fig. 2.1-5, which shows primary energy by energy type for U.S. manufacturing. Each of the energy types (i.e., fuel, electricity, or steam) shown in this figure have associated onsite and offsite generation losses (shown with onsite and offsite losses combined in light gray) that are incurred during energy generation (and transmission and distribution). While the majority of electricity generation losses take place offsite (as shown in Fig. 2.1-9), the majority of steam generation losses are onsite (as shown in Fig. 2.1-10), while direct fuel use is assumed to have no associated generation losses. After taking into account these generation losses, a further portion of the remaining energy is lost at direct end uses, due to process and nonprocess system and equipment inefficiencies, shown in dark gray in the figure below. The remaining energy is applied to end uses, shown in light green as "Applied Energy" in Fig. 2.1-14 below.

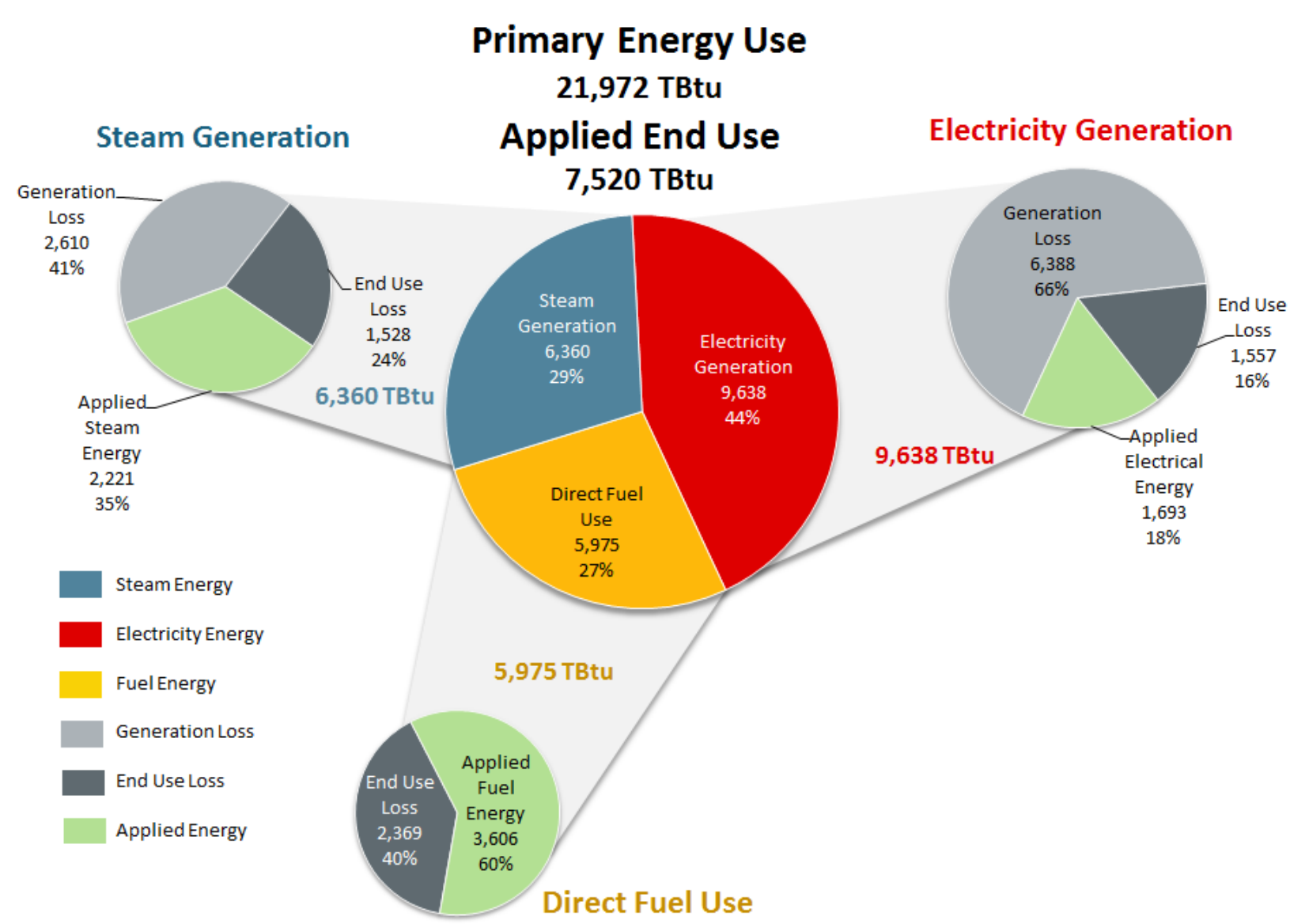

Fig. 2.1-14. Primary energy use and applied energy by energy type for U.S. manufacturing 
U.S. manufacturing primary energy generation losses, end uses losses, and applied energy is shown in Fig. 2.1-15, which shows that $34 \%$ of all primary energy input is applied to process and nonprocess end uses. Generation losses account for $41 \%$ of primary energy input and end use losses account for the remaining $25 \%$ of primary energy input.

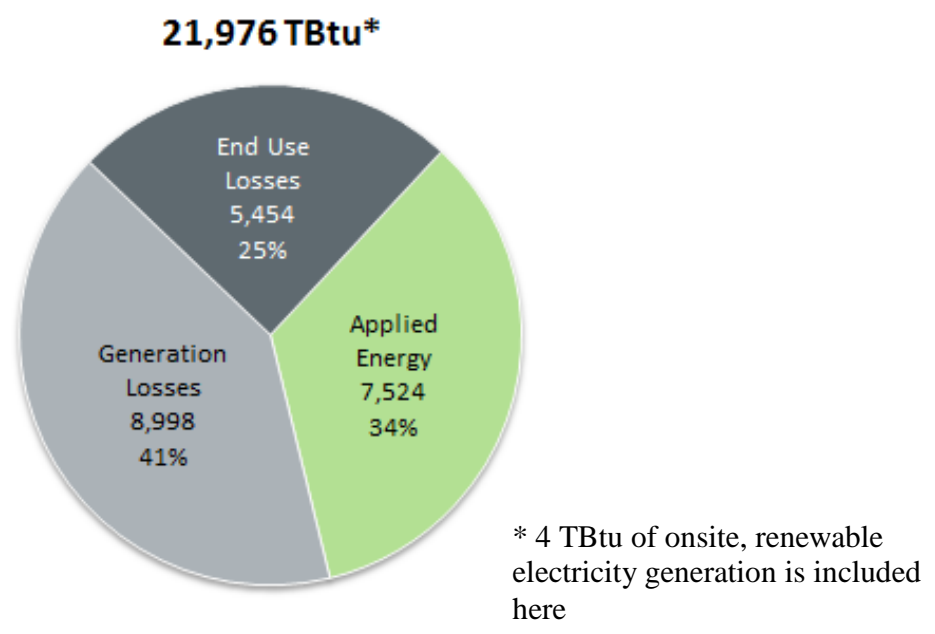

Fig. 2.1-15. Primary energy by loss and applied energy in U.S. manufacturing

Table 2.1-15 provides a sector ranking for applied energy and the percent of the primary energy that is applied to end use. In five of these industries (glass, cement, forest products, iron and steel, food and beverage), direct end use losses are over $30 \%$ of primary energy input energy. In seven out of 15 sectors, over $70 \%$ of primary energy is lost to generation, transmission, and distribution loss or direct end use loss.

Table 2.1-15. U.S. manufacturing sectors ranked by applied energy

\begin{tabular}{|c|c|c|c|c|c|c|c|c|}
\hline \multirow{2}{*}{ Sector } & \multirow{2}{*}{$\begin{array}{c}\text { Primary } \\
\text { energy } \\
\text { use } \\
\text { (TBtu) }\end{array}$} & \multicolumn{2}{|c|}{$\begin{array}{l}\text { Generation, } \\
\text { transmission, and } \\
\text { distribution loss }\end{array}$} & \multicolumn{2}{|c|}{$\begin{array}{l}\text { Direct end use } \\
\text { loss }\end{array}$} & \multirow{2}{*}{$\begin{array}{l}\text { Overall } \% \\
\text { of primary } \\
\text { energy lost }\end{array}$} & \multirow{2}{*}{$\begin{array}{l}\text { Applied } \\
\text { energy }\end{array}$} & \multirow{2}{*}{ Rank } \\
\hline & & TBtu & $\begin{array}{c}\% \text { of } \\
\text { primary } \\
\text { energy }\end{array}$ & TBtu & $\begin{array}{c}\% \text { of } \\
\text { primary } \\
\text { energy }\end{array}$ & & & \\
\hline Petroleum refining & 3,546 & 706 & $20 \%$ & 661 & $19 \%$ & $39 \%$ & 2,179 & 1 \\
\hline Chemicals & 4,513 & 2,062 & $46 \%$ & 902 & $20 \%$ & $66 \%$ & 1,550 & 2 \\
\hline Forest products & 3,559 & 1,005 & $28 \%$ & 1,173 & $33 \%$ & $61 \%$ & 1,382 & 3 \\
\hline Food and beverage & 1,934 & 647 & $33 \%$ & 587 & $30 \%$ & $64 \%$ & 700 & 4 \\
\hline Iron and steel & 1,481 & 525 & $35 \%$ & 464 & $31 \%$ & $67 \%$ & 493 & 5 \\
\hline Transportation equipment & 904 & 450 & $50 \%$ & 188 & $21 \%$ & $71 \%$ & 267 & 6 \\
\hline Fabricated metals & 708 & 328 & $46 \%$ & 164 & $23 \%$ & $69 \%$ & 217 & 7 \\
\hline Cement & 471 & 103 & $22 \%$ & 160 & $34 \%$ & $56 \%$ & 208 & 8 \\
\hline Plastics & 729 & 423 & $58 \%$ & 125 & $17 \%$ & $75 \%$ & 181 & 9 \\
\hline Glass & 466 & 145 & $31 \%$ & 174 & $37 \%$ & $68 \%$ & 147 & 10 \\
\hline $\begin{array}{l}\text { Computers, electronics, } \\
\text { and electrical equipment }\end{array}$ & 527 & 309 & $59 \%$ & 91 & $17 \%$ & $76 \%$ & 126 & 11 \\
\hline Alumina and aluminum & 603 & 338 & $56 \%$ & 141 & $23 \%$ & $79 \%$ & 124 & 12 \\
\hline Machinery & 444 & 250 & $56 \%$ & 90 & $20 \%$ & $77 \%$ & 104 & 13 \\
\hline Textiles & 472 & 244 & $52 \%$ & 129 & $27 \%$ & $79 \%$ & 98 & 14 \\
\hline Foundries & 281 & 125 & $44 \%$ & 75 & $27 \%$ & $71 \%$ & 81 & 15 \\
\hline All manufacturing & 21,972 & 8,998 & $41 \%$ & 5,454 & $25 \%$ & $66 \%$ & 7,520 & N/A \\
\hline
\end{tabular}


Applied energy can also be calculated for specific end uses, as shown in Fig. 2.1-16. In this figure, generation losses are labeled as either steam or electricity losses. End use losses are labeled as process or nonprocess losses; in the case of machine drive end use, process losses are further defined as machine drive, or machine driven system losses.

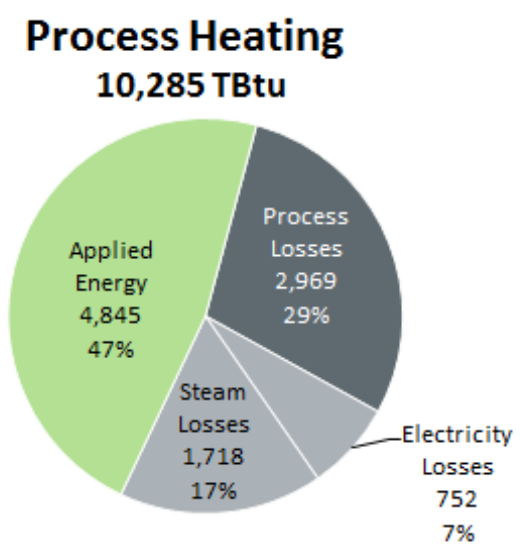

All Other Process End Use 2,476 TBtu

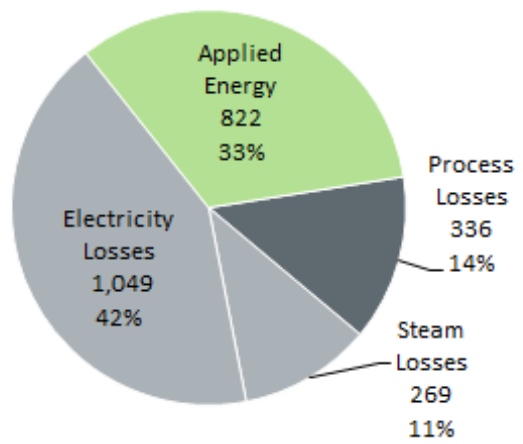

Machine Drive 6,042 TBtu

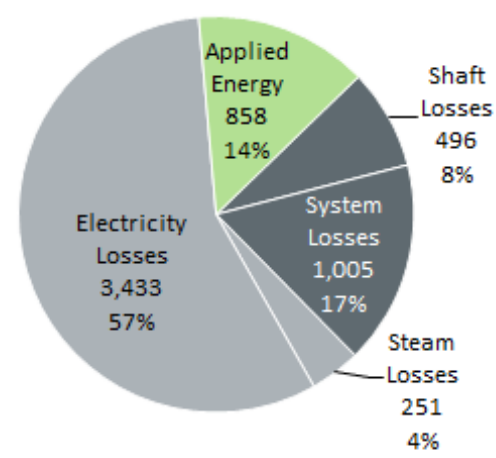

Nonprocess End Uses 3,173 TBtu

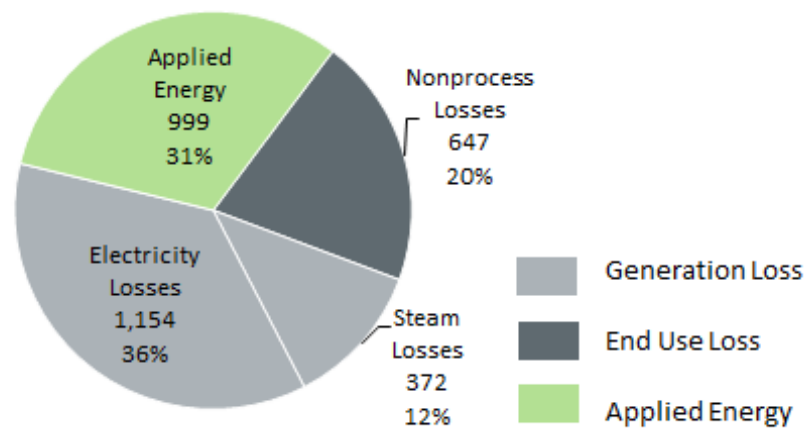

Note: Pie chart areas are not proportional to magnitude of energy consumption

Fig. 2.1-16. Primary applied energy by direct end use in U.S. manufacturing

For process heating applications, $47 \%$ of primary energy is applied to the process. Process heating applied energy is relatively high compared to other end uses, because the majority of process heating energy is consumed in the form of fuel or steam. Process heating losses do vary greatly by sector. An explanation of the methodology used in estimating process heating loss is provided in Appendix F, while loss estimates for all end uses are shown in Appendix D.

In machine-driven systems, only $14 \%$ of primary energy is applied, primarily because of the inefficiency in electricity generation. Electricity losses are the result of turbine and power system efficiencies which are as low as $25 \%$ for older steam-based systems, but as high as $50-60 \% \%$ for state-of-the-art combined cycle gas turbines. On average, this means every kilowatt hour of electricity generated by a utility requires three kilowatt hour equivalents of fuel. Although the manufacturing facility does not incur these losses, including them in the loss analysis provides a total (primary) picture of the energy associated with the use of electricity.

The machine drive, or shaft losses represent the inefficiency of converting fuel (in engines), steam (in turbines), or electricity (in motors) into rotating, kinetic energy. The machine driven system losses represent the inefficiency of applying this kinetic energy as effective work, such as compressing air in a rotary screw compressor. Machine-driven system losses total 1,005 TBtu and shaft losses comprise 499 $\mathrm{TBtu}$, for a combined total of 1,504 TBtu, or $25 \%$ of machine driven primary energy use. 


\subsubsection{Greenhouse Gas Combustion Emissions Profile for U.S. Manufacturing and Sector Rankings}

This analysis considers GHG combustion emissions released during the combustion of fuels for energy use, including carbon dioxide $\left(\mathrm{CO}_{2}\right)$, methane $\left(\mathrm{CH}_{4}\right)$, and nitrous oxide $\left(\mathrm{N}_{2} \mathrm{O}\right)$, since these are the most common greenhouse gases released during the combustion of fuel (further detail on fuel emission factors is provided in Appendix D). The GHG combustion emission profiles shown here are similar to the energy profiles in that emissions are reported either with or without emissions released during offsite energy generation. As labeled in the sector footprints, "Total" emissions include emissions from offsite steam and electricity generation, which is equivalent to primary energy use in the energy profiles. "Onsite" GHG combustion emissions are the result of either indirect (e.g., CHP systems or boilers) or direct (e.g., process or nonprocess end uses) fuel use within the plant boundary. As discussed in Chapter 1, the GHG emissions shown in the energy and carbon footprint represent combustion emissions; process emissions (e.g., $\mathrm{CO}_{2}$ emissions released during iron and steel production and the calcination reaction during cement manufacturing, perfluorocarbon emissions emitted during aluminum smelting) are not included in this analysis. GHG emissions should not be interpreted as life cycle emissions.

Total U.S. manufacturing GHG combustion emissions were equal to 1,261 million metric ton of $\mathrm{CO}_{2}$ equivalent $\left(\mathrm{MMT} \mathrm{CO}_{2} \mathrm{e}\right)$ in 2006 as shown in Fig. 2.1-17. Onsite emissions, which result from fuel consumption for all onsite end uses (including onsite steam and electricity generation and process and nonprocess end uses), contribute $51 \%$ of total emissions. Offsite emissions, which are produced during the offsite generation of electricity and steam, contribute the remaining $49 \%$ of total emissions.

\section{1,261 MMTCO2e}

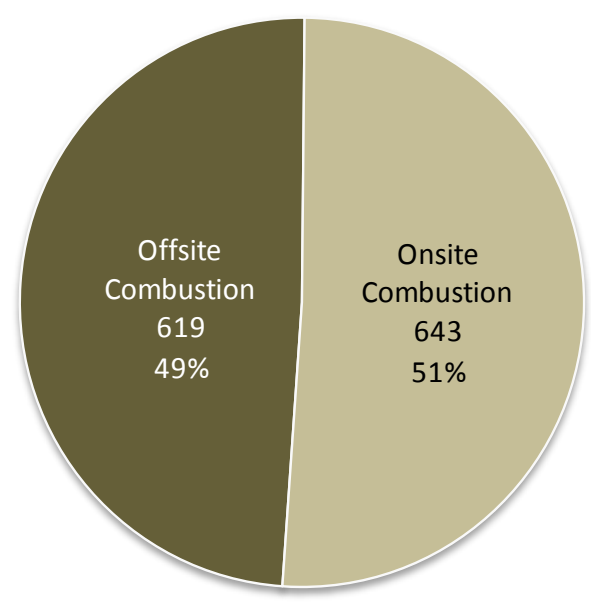

Fig. 2.1-17. Onsite and offsite GHG combustion emissions in U.S. manufacturing

A more detailed breakdown of emissions in shown in Fig. 2.1-18, which shows total emissions by energy type. Onsite consumption of fuels (shown in yellow in the pie chart), including natural gas, fuels derived from byproducts, coal, and other fuels account for $51 \%$ of total emissions. Emissions released during the offsite production of electricity account for $43 \%$ of emissions, while the remaining $6 \%$ of emissions are released during offsite steam production. 


\section{1,261 MMT CO2e}

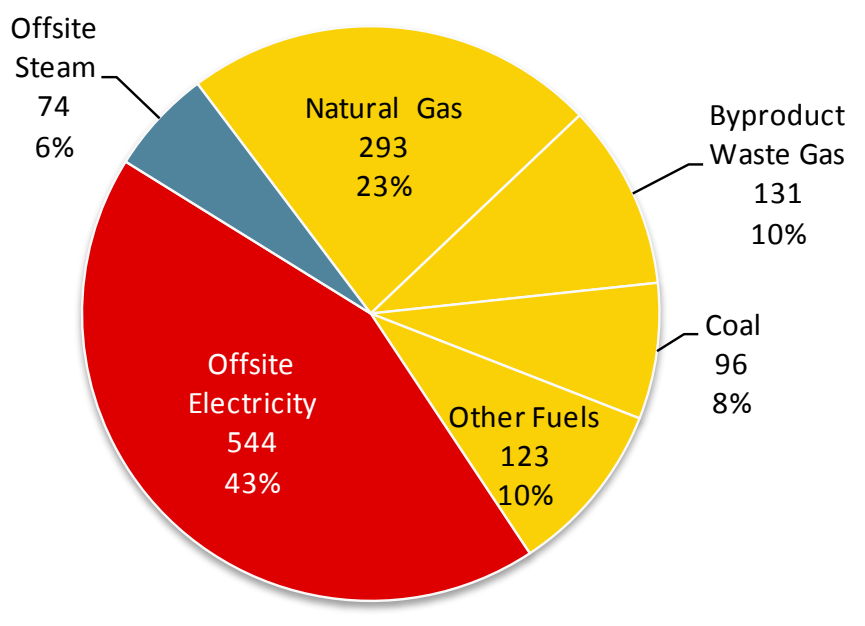

Fig. 2.1-18. Total GHG combustion emissions in U.S. manufacturing (shown by energy supply type)

An alternate view of emissions is shown in Fig. 2.1-19, which also shows emissions by energy type, but this figure assigns emissions to onsite electricity and steam production (as opposed to assigning emissions strictly to offsite supplied fuels). All emissions associated with electricity production are shown in red, including emissions released during offsite electricity generation and emissions released during onsite generation of electricity. All emissions associated with steam production are shown in blue, including emissions released during offsite steam generation and emissions released during onsite generation of steam in boilers or CHP systems. Lastly, all emissions associated with fuel combustion at process and nonprocess end uses are shown in yellow. Electricity generation (offsite and onsite) contributes about $43 \%$ of all emissions. Steam generation (offsite or onsite) contributes a further $29 \%$ of emissions, while the remaining $25 \%$ of emissions are released during fuel combustion for process and nonprocess end uses.

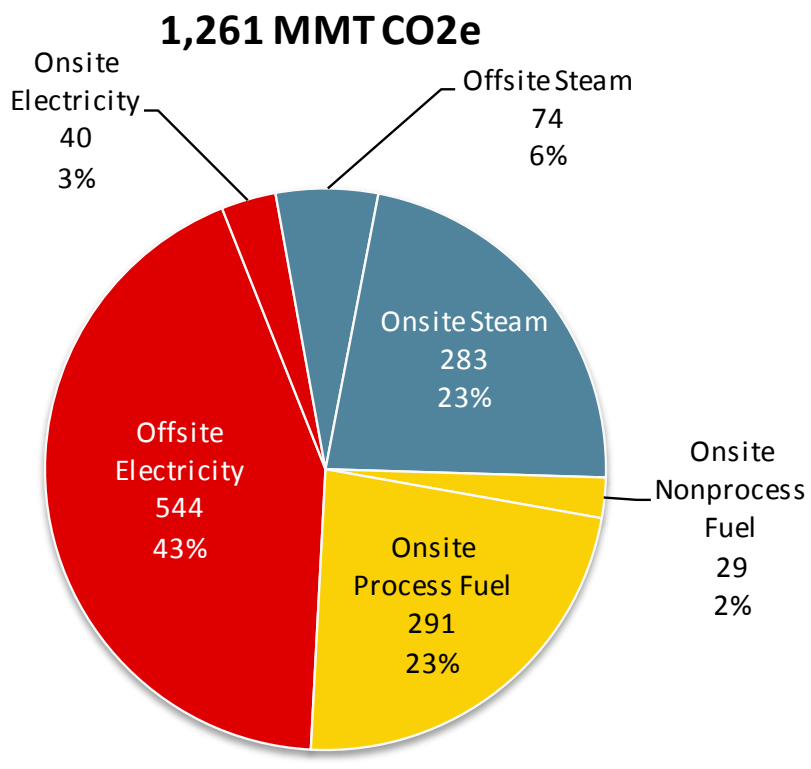

Fig. 2.1-19. Total GHG combustion emissions in U.S. manufacturing (shown by energy end use type)

Emissions can also be attributed to direct end uses, as shown in Fig. 2.1-20. In this figure, the emissions released from both offsite and onsite electricity and steam generation are distributed to direct end uses, along with emissions released when fuel is consumed at direct end uses. This pie chart allows for a direct comparison of the emissions resulting from different process and nonprocess direct end uses. Almost half 
of manufacturing sector end use emissions result from process heating applications. The next highest contributor of emissions is machine-driven uses (which include a large proportion of offsite electricity emissions). The emissions associated other process and nonprocess uses are also shown in the figure.

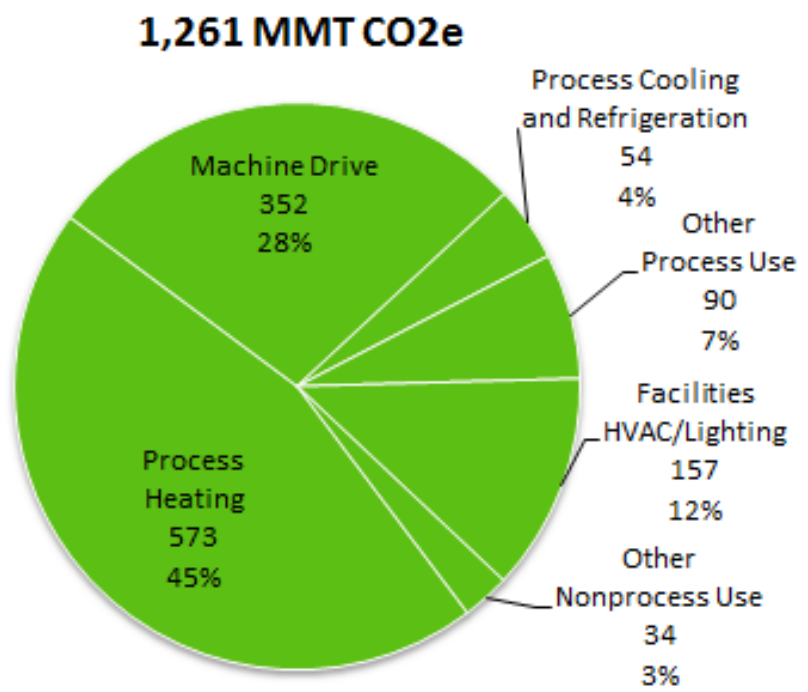

Fig. 2.1-20. Total GHG combustion emissions in U.S. manufacturing (shown by direct energy end use)

Table 2.1-16 shows manufacturing sector rankings by total and onsite emissions, respectively. In terms of total emissions, chemicals, petroleum refining, forest products, and food and beverage produce the highest emissions, each emitting over $100 \mathrm{MMT} \mathrm{CO}_{2} \mathrm{e}$. Focusing on onsite emissions, petroleum refining, with its heavy onsite use of fossil fuels, contributes the most towards emissions at a value of $210 \mathrm{MMT} \mathrm{CO}_{2} \mathrm{e}$, almost double the emissions of the next-largest onsite emitting sector, chemicals. Forest products and food and beverage follow with onsite emissions in each sector totaling over $50 \mathrm{MMT} \mathrm{CO}_{2} \mathrm{e}$.

Table 2.1-16. U.S. manufacturing sectors ranked by total GHG combustion emissions

\begin{tabular}{|c|c|c|c|c|}
\hline Sector & $\begin{array}{l}\text { Total emissions } \\
\left(\mathrm{MMT} \mathrm{CO}_{2} \mathrm{e}\right)\end{array}$ & Rank & 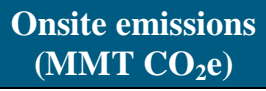 & Rank \\
\hline Chemicals & 275 & 1 & 129 & 2 \\
\hline Petroleum refining & 244 & 2 & 210 & 1 \\
\hline Forest products & 140 & 3 & 68 & 3 \\
\hline Food and beverage & 117 & 4 & 56 & 4 \\
\hline Iron and steel & 62 & 5 & 23 & 6 \\
\hline Transportation equipment & 53 & 6 & 15 & 7 \\
\hline Plastics & 44 & 7 & 9 & 11 \\
\hline Fabricated metals & 41 & 8 & 13 & 9 \\
\hline Cement & 39 & 9 & 31 & 5 \\
\hline Alumina and aluminum & 36 & 10 & 6 & 12 \\
\hline $\begin{array}{l}\text { Computers, electronics, electrical } \\
\text { equipment }\end{array}$ & 31 & 11 & 5 & 15 \\
\hline Textiles & 29 & 12 & 10 & 10 \\
\hline Machinery & 26 & 13 & 5 & 14 \\
\hline Glass & 26 & 14 & 14 & 8 \\
\hline Foundries & 16 & 15 & 5 & 13 \\
\hline All manufacturing & 1,261 & N/A & 643 & N/A \\
\hline
\end{tabular}

Note: $\mathrm{CO}_{2}$ emissions from biomass fuel combustion (also known as biogenic $\mathrm{CO}_{2}$ ) are not included in the total emission factor because the uptake of $\mathrm{CO}_{2}$ during biomass growth results in zero net emissions over time 


\subsubsection{Energy and Emissions Profile Summary Table}

The energy and emissions profiles for U.S. manufacturing are summarized in Fig. 2.1-17 below. Offsite and onsite contributions to energy supply, use and loss are shown separately in this table, along with GHG combustion emissions. "Applied energy" is calculated for each direct energy use area by subtracting associated offsite and onsite energy losses. For GHG combustion emissions, emissions from the point of use, whether offsite or onsite, are depicted in the first GHG emissions column; offsite emissions are combined with onsite emissions in the total emissions columns. The values in this table correspond to the energy and carbon footprints, which show two carbon values associated with each onsite end use: at point of use and the total based on onsite use.

Table 2.1-17. Energy use, loss, and GHG combustion emissions in U.S. manufacturing

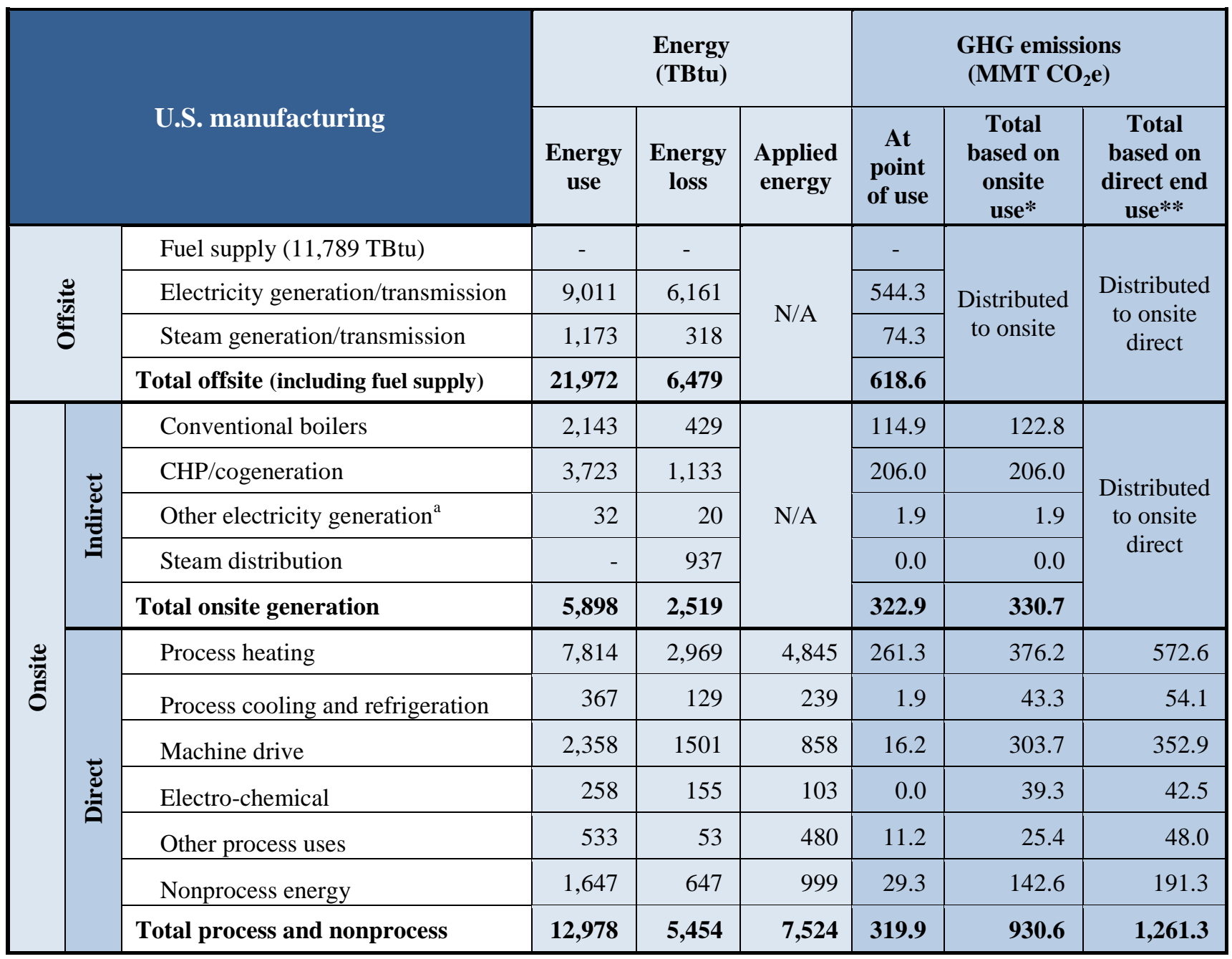

* These values are referenced as "Total" emissions in the footprints, Total emissions $=$ onsite emissions + offsite emissions (i.e., emissions associated with offsite generation are distributed to indirect and direct onsite end uses)

** These values represent direct end use carbon emissions only (i.e., emissions associated with offsite and onsite generation are distributed to direct (and final) end use)

${ }^{a}$ Onsite, renewable, non-combustion generation contributes 4 TBtu 


\subsection{CHEMICALS SECTOR (NAICS 325)}

\subsubsection{Overview of the Chemicals Manufacturing Sector}

The chemicals manufacturing sector is an integral component of the U.S. economy, converting raw materials such as petroleum, natural gas, minerals, coal, air, and water into more than 70,000 diverse products. Chemical products are critical components of consumer goods and are found in everything from automobiles to plastics to electronics.

This sector creates its diverse output from raw materials of two general types: organic (oil, natural gas, coal) and inorganic (minerals, metals, air, water). Table 2.2-1 shows the subsector categories in the chemicals sector with data reported in the 2006 EIA Manufacturing Energy Consumption Survey (MECS).

Table 2.2-1. Chemicals subsectors with data reported in MECS

\begin{tabular}{|l|l|}
\hline \multicolumn{1}{|c|}{ NAICS code } & \multicolumn{1}{c|}{ Chemicals subsector } \\
\hline 325 & Chemicals \\
\hline 325110 & Petrochemicals \\
\hline 325120 & Industrial gases \\
\hline 325181 & Alkalines and chlorine \\
\hline 325182 & Carbon black \\
\hline 325188 & Other basic inorganic chemicals \\
\hline 325192 & Cyclic crudes and intermediates \\
\hline 325193 & Ethyl alcohol \\
\hline 325199 & Other basic organic chemicals \\
\hline 325211 & Plastics materials and resins \\
\hline 325212 & Synthetic rubber \\
\hline 325222 & Noncellulosic organic fibers \\
\hline 325311 & Nitrogenous fertilizers \\
\hline 325312 & Phosphatic fertilizers \\
\hline 3254 & Pharmaceuticals and medicines \\
\hline 325412 & Pharmaceutical preparation \\
\hline 325992 & Photographic film, paper, plate, and chemicals \\
\hline
\end{tabular}

The chemicals sector is the largest consumer of primary energy in U.S. manufacturing. The manufacture of chemicals is complex and energy-intensive, often requiring large quantities of thermal energy to convert raw materials into useful products. The efficiency of the processes and equipment used to produce chemicals are constrained by thermodynamic, kinetic, and transport limitations, and operating conditions may be severe, comprising high temperatures, high pressures, and corrosive environments. These operational factors contribute to relatively high energy use per pound of product compared to other sectors.

\subsubsection{Energy Use Profile for the Chemicals Sector}

A snapshot of how the chemicals sector ranks in terms of energy use and losses within manufacturing is shown in Table 2.2-2, along with total and onsite GHG combustion emissions. Energy losses are shown in red font. All values represent annual energy use and loss for calendar year 2006, and are based on the most currently available manufacturing energy use statistics. The chemicals sector ranks among the top two sectors in nearly all energy use or loss categories. The sector is the largest user of primary energy and the 
second largest user of onsite energy. The chemicals sector also releases more carbon emissions than any other sector, while ranking second in terms of onsite emissions.

Table 2.2-2. Snapshot and ranking of energy use, loss, and GHG combustion emissions in the chemicals sector

\begin{tabular}{|l|c|c|}
\hline \multicolumn{1}{|c|}{ Category } & Rank & $\begin{array}{c}\text { Energy } \\
\text { (TBtu) }\end{array}$ \\
\hline Total primary energy use & 1 & 4,513 \\
Offsite losses & 1 & 1,318 \\
Onsite energy use & 2 & 3,195 \\
Onsite losses & 2 & 1,645 \\
$\quad$ Steam generation and distribution & 2 & 634 \\
$\quad$ Electricity generation & 1 & 109 \\
$\quad$ Process energy & 2 & 813 \\
$\quad$ Nonprocess energy & 2 & 89 \\
Feedstock energy & 2 & 2,812 \\
Total primary and feedstock energy ${ }^{\mathrm{a}}$ & \multicolumn{2}{|c|}{6,467} \\
\hline GHG combustion emissions & 1 & MMT CO$_{\mathbf{2}} \mathbf{e}$ \\
Total & 2 & 275 \\
Onsite & 2 & 129 \\
\hline${ }^{a}$ When total primary energy and feedstock energy are summed, the energy value of byproduct fuels \\
derived from feedstock energy sources is excluded to avoid double counting of feedstock energy
\end{tabular}

Although outside the scope of the footprint analysis, it is worth noting that a significant amount of non-fuel feedstock is consumed as raw materials, primarily for the production of petrochemicals, plastic materials and resin, and other basic organic chemicals. As shown in Fig. 2.2-1, the total feedstock energy consumed by the chemicals sector is 2.8 quads. When feedstock and fuel energy are summed, total primary fuel and feedstock energy used is about 6.5 quads. The focus of the energy use and loss analysis that follows excludes all feedstock energy use.

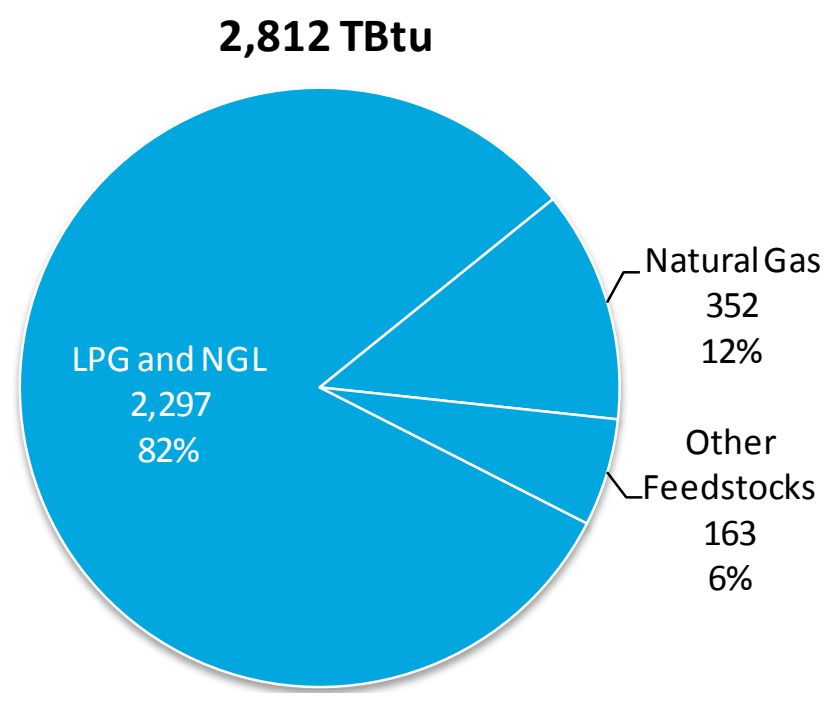

Fig. 2.2-1. Feedstock energy use in the chemicals sector 


\subsubsection{Energy and carbon footprint}

The chemicals sector Manufacturing Energy and Carbon Footprint is shown in Fig. 2.2-2 and Fig. 2.2-3. The footprints serve as the basis for characterizing the offsite and onsite flow of energy, as well as carbon emissions, from generation through end use in the sector.

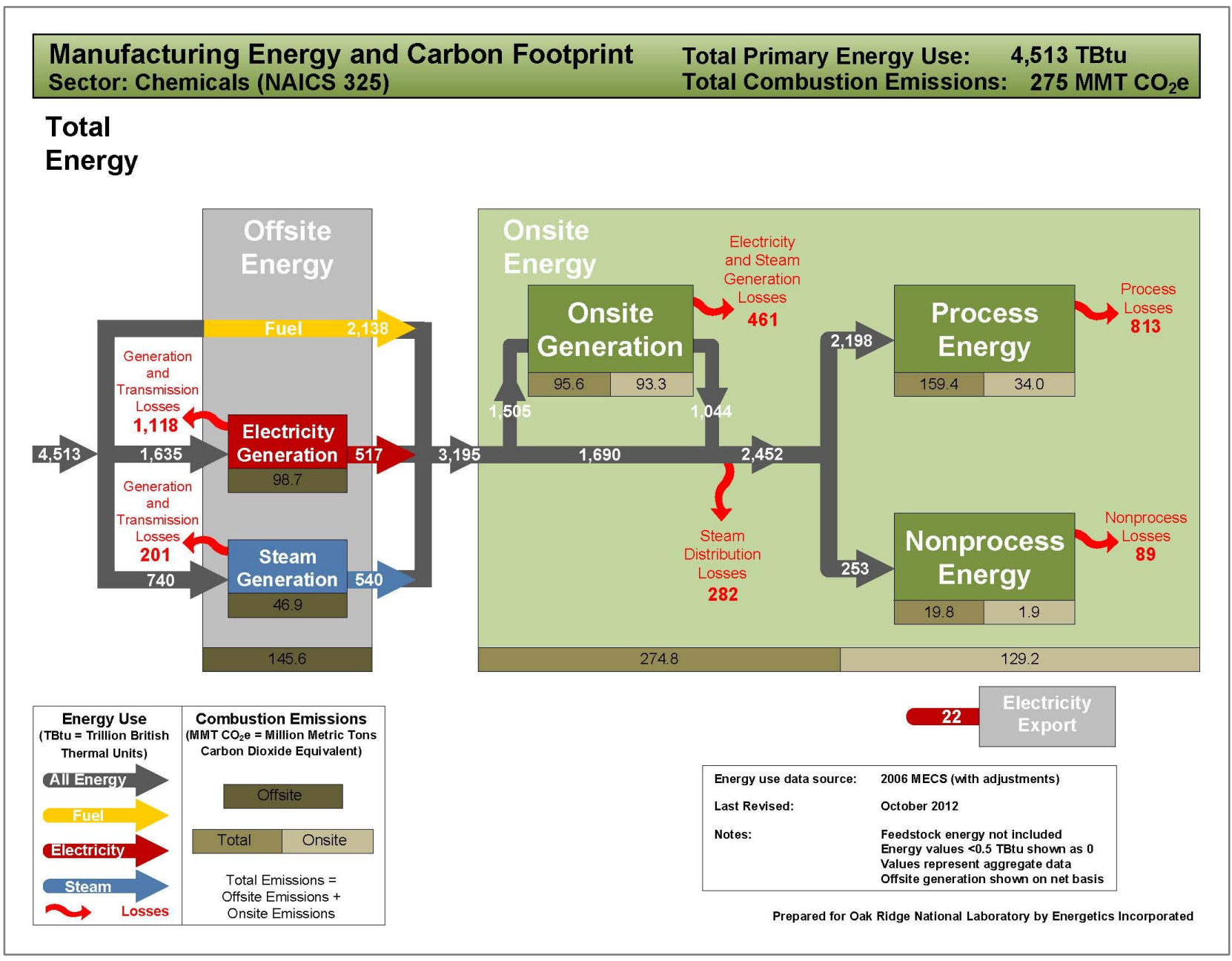

Fig. 2.2-2. Total energy and carbon footprint for the chemicals sector 


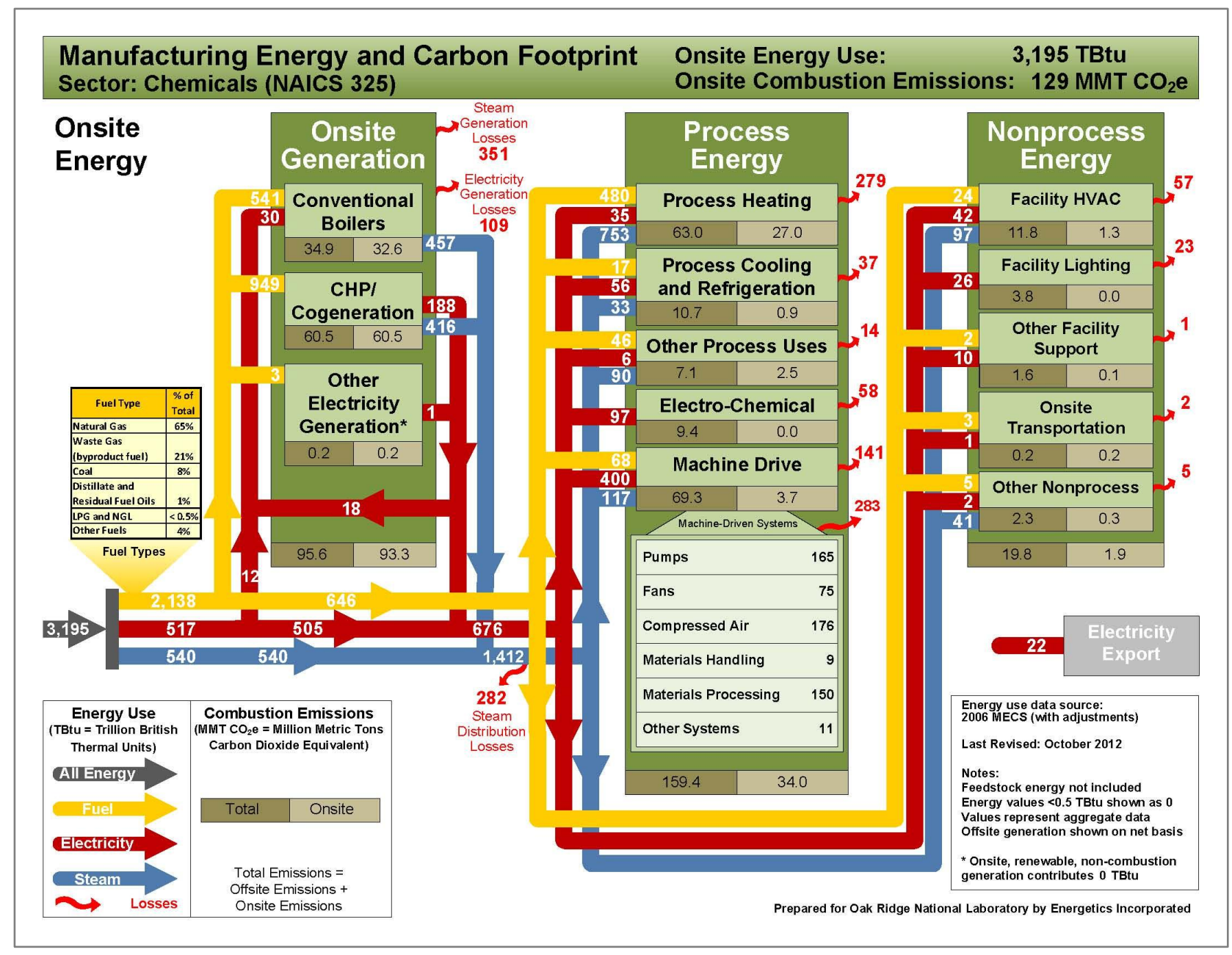

Fig. 2.2-3. Onsite energy and carbon footprint for the chemicals sector

\subsubsection{Primary energy}

Primary energy use includes fuels, electricity, and steam consumed in manufacturing, including the generation and distribution/transmission losses associated with offsite and onsite electricity and steam generation. In 2006, the chemicals sector used 4,513 TBtu of primary energy. The distribution of primary energy by energy type is shown in Fig. 2.2-4. Steam and electricity generation are roughly equal, consuming $44 \%$ and $42 \%$ of primary energy, respectively. Direct fuel use comprises the remaining $14 \%$ of primary energy consumption. Consistent with the footprints, blue represents steam energy, red represents electric energy, and yellow represents fuel energy. This same energy coloring scheme is used throughout this report. 


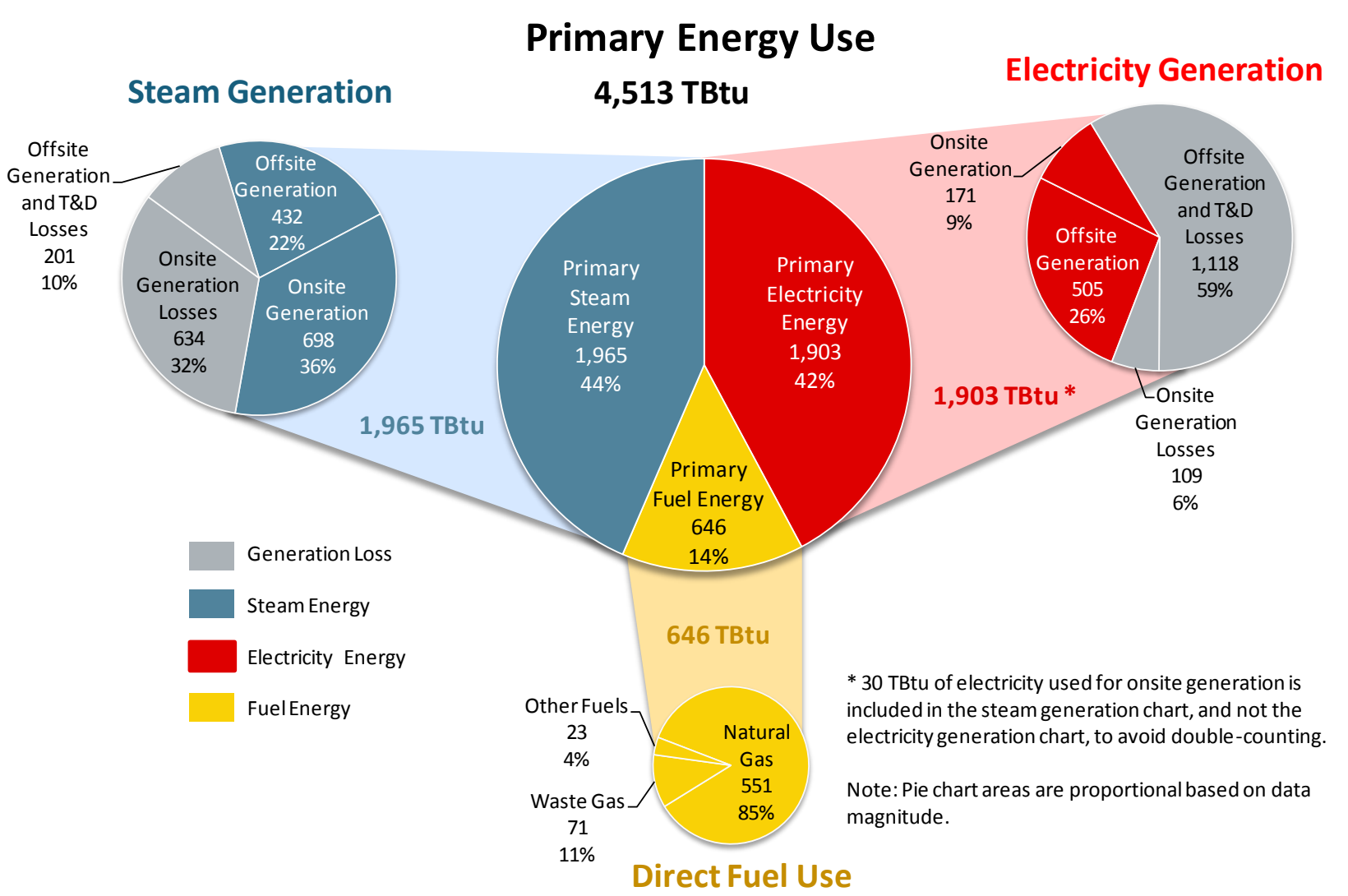

Fig. 2.2-4. Primary energy use by energy type in the chemicals sector

A considerable portion (46\%) of the primary energy used in chemicals manufacturing is lost during offsite and onsite generation and distribution of energy. Electricity generation and distribution losses account for $60 \%$ of these losses, with the remaining $40 \%$ associated with steam generation and distribution. For electricity, the great majority $(91 \%)$ of electricity losses occur during offsite generation and distribution. Conversely, the majority of steam losses $(76 \%)$ occur through onsite generation and distribution of steam.

\subsubsection{Onsite energy}

Onsite energy is a measure of the energy entering the plant boundary in the form of three offsite energy types: fuel, electricity, and steam. This onsite energy is then used by processes and nonprocess end uses. Additionally, a large portion of the fuel is consumed onsite in order to generate additional electricity and steam for the manufacturing end uses. The amount of energy that entered chemical plants in 2006 was about 3.2 quads, or $71 \%$ of primary energy.

The offsite energy supply, shown in Fig. 2.2-5, is composed of $67 \%$ fuel (or feedstock that would later produce a byproduct fuel), $16 \%$ offsite electricity, and $17 \%$ offsite steam. The chemicals industry relies on hundreds of different chemical processes, and as a result, energy use patterns vary dramatically across subsectors. Processes used to produce petrochemicals, for example, are distillation and steam cracking, resulting in substantial fuel consumption, while chlorine production depends heavily on electricity used in electrolytic cells. Although the energy values presented here represent total energy use for the entire chemicals manufacturing sector, the breakdown by energy type is the average for the sector. As is clarified later in this chapter, a large portion of the offsite fuel use shown in this figure is used to generate a significant amount of steam and electricity onsite. 


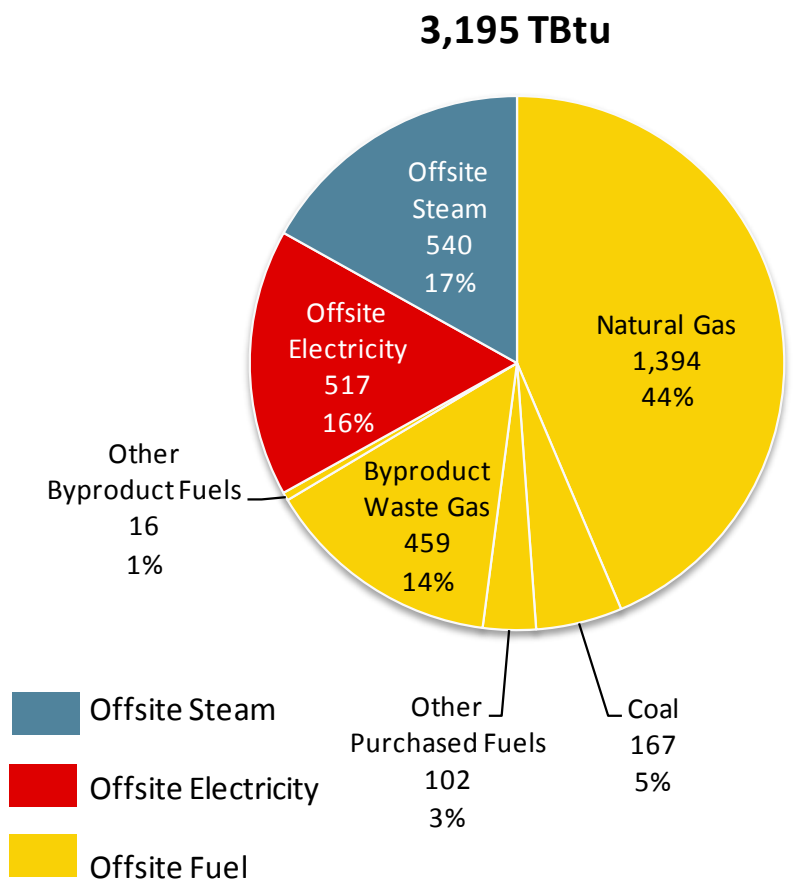

Fig. 2.2-5. Offsite energy supply in the chemicals sector

Fig. 2.2-6 shows the onsite energy use by the largest ten energy-consuming subsectors in chemicals manufacturing (the sum of onsite energy use across these subsectors is equal to $88 \%$ of sector-wide onsite energy use). The largest energy using subsectors are petrochemicals, other basic organic chemicals, and plastics materials and resins.

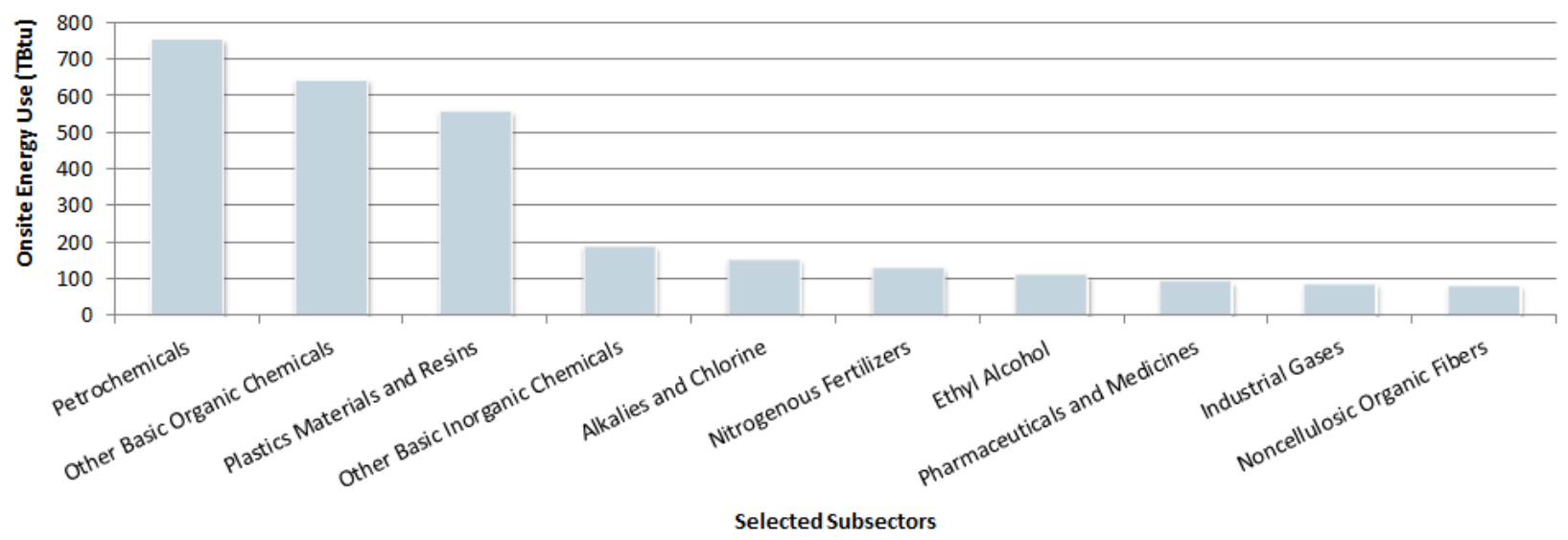

Fig. 2.2-6. Onsite energy use in selected chemicals subsectors

\subsubsection{Fuel energy}

Onsite fuel use in the chemicals sector was 2,138 TBtu in 2006, as can be seen by summing the energy consumption of the fuels shown in Fig. 2.2-5. Fuel use accounts for 47\% of primary energy use, and $67 \%$ of onsite energy use. A significant proportion of fuel use, $70 \%$, is used to generate onsite steam and electricity in this sector. Chemical sector manufacturing demands a great deal of electricity, ranking first in direct electricity demand (see Table 2.1-6); $28 \%$ of this onsite electricity demand is generated onsite using purchased and byproduct fuels, primarily in CHP units. 
The dominant fuel used in the chemicals sector is natural gas, consuming 1,394 TBtu, thus making the sector particularly susceptible to fluctuations in natural gas prices. Byproduct gases and fuels are the next largest fuel use category, consuming 459 TBtu. Waste gas, or still gas, is the most commonly used byproduct fuel. Waste gas is produced and captured in the off-gases from distillation and reaction processes and is typically made up of methane, ethane, and other light end gases.

\subsubsection{Electrical energy}

In 2006, direct electricity use in the chemicals sector was $676 \mathrm{TBtu}$; this excludes $30 \mathrm{TBtu}$ of indirect electricity input to onsite boilers, and includes $171 \mathrm{TBtu}$ of electricity generated onsite. ${ }^{9}$ Energy used to generate electricity accounts for $42 \%$ of primary energy use (as was shown in Fig. 2.2-4), but electricity accounts for only $15 \%$ of direct end use energy (Fig. 2.2-10). This discrepancy is due to the relative inefficiency of generation and distributing electricity compared to direct fuel use.

Figure 2.2-7 shows the large portion of primary energy consumed for electricity use is associated with generation, transmission, and distribution (T\&D) losses, taking place mostly offsite. The smaller chart on the right shows the direct process and nonprocess end uses of electricity. Virtually all onsite electricity production is derived from CHP units. When considering electricity generation and T\&D losses, CHP units are $64 \%$ efficient while the offsite electricity grid is assumed to be only $31.6 \%$ efficient. This near-doubling in efficiency is due to the greater efficiency of CHP and the elimination of transmission and distribution (T\&D) losses. The overall efficiency of electricity production is $36 \%$.

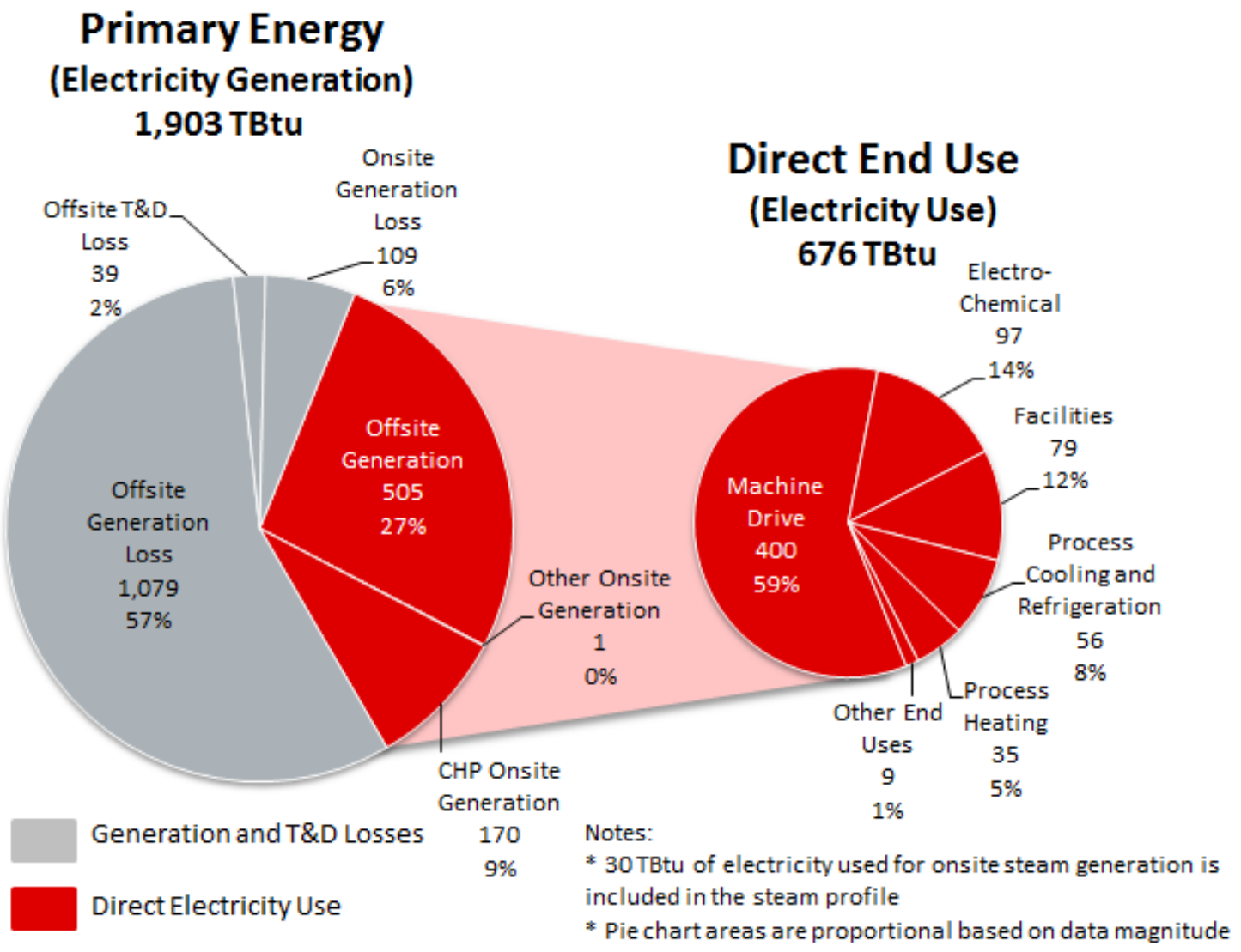

Fig. 2.2-7. Electricity generation and direct end use in the chemicals sector

\footnotetext{
${ }^{9}$ Onsite electricity generation consists of 188 TBtu of electricity from CHP units and 1 TBtu from other onsite sources; 18 TBtu of this onsite generated electricity does not end up as direct end use and is used as energy input to onsite boilers.
} 


\subsubsection{Steam energy}

Figure 2.2-8 shows the primary energy use and losses that occur in steam generation and the direct end uses of steam. Steam generation is roughly evenly distributed among offsite sources, onsite CHP, and onsite conventional boilers. When taking into account steam generation, as well as transmission and distribution, efficiency ranges from a low of $51 \%$ for CHP systems to a high of $64 \%$ for conventional boilers, with offsite plants at $58 \%$. (The low figure for CHP systems is misleading, however, because it does not capture the increased overall efficiency due to the cogeneration of steam and electricity.) The overall efficiency of steam production is $58 \%$.

Most steam production losses occur in boilers, where thermal efficiencies range between $55 \%-85 \%,{ }^{10}$ depending on the age of the boiler and type of fuel used. The chemicals sector has the largest amount of steam output from CHP units of any of the manufacturing sectors, $416 \mathrm{TBtu}$. Overall, the forest products sector has twice the CHP energy output as the chemicals sector (see Table 2.1-9); however, the proportion of steam generation is significantly lower than that of the chemicals sector.

\section{Primary Energy (Steam Generation) 1,965 TBtu}

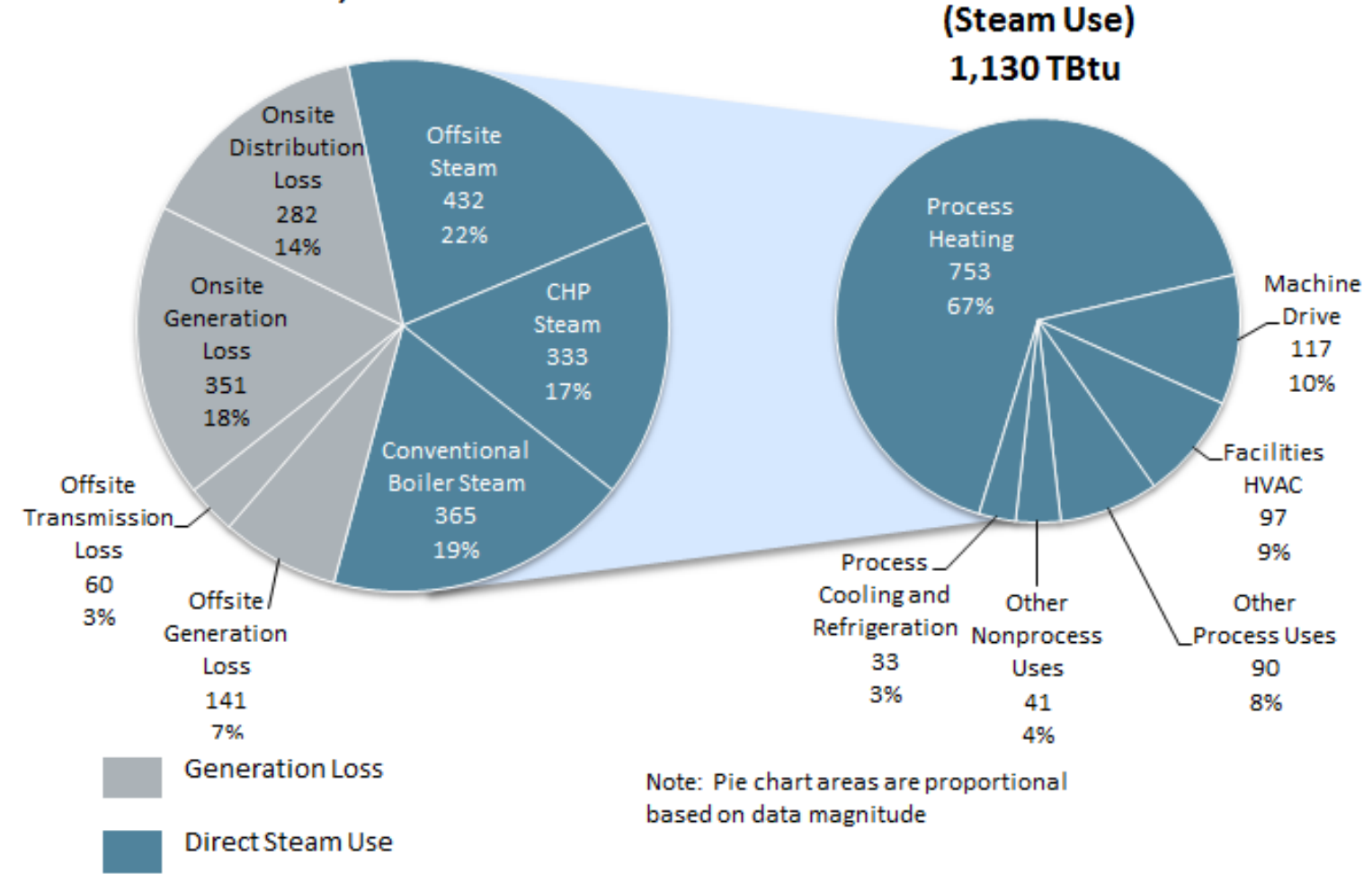

Fig. 2.2-8. Steam generation and direct end use in the chemicals sector

\subsubsection{Combined heat and power energy}

The chemicals sector meets a significant amount of energy demand through onsite generation, ranking first on onsite electricity generation, second in onsite steam generation, and second in CHP output across U.S. manufacturing. As shown in Fig. 2.2-9, 949 TBtu of fuel use for combined heat and power systems produces 604 TBtu of energy output, with about two-thirds in the form of steam (416 TBtu) and about onethird in the form of electricity (188 TBtu). CHP generation losses constitute $36 \%$ of CHP fuel use; CHP

${ }^{10}$ This report assumes $80 \%$ efficiency in boilers and $20 \%$ losses in onsite steam distribution. 
efficiency estimates are referenced in Appendix D, Table D.2. Over 80\% of CHP fuel use in the chemicals sector is in the form of natural gas or fuel.

\section{CHP Indirect Fuel Use}

\section{CHP Energy Output}

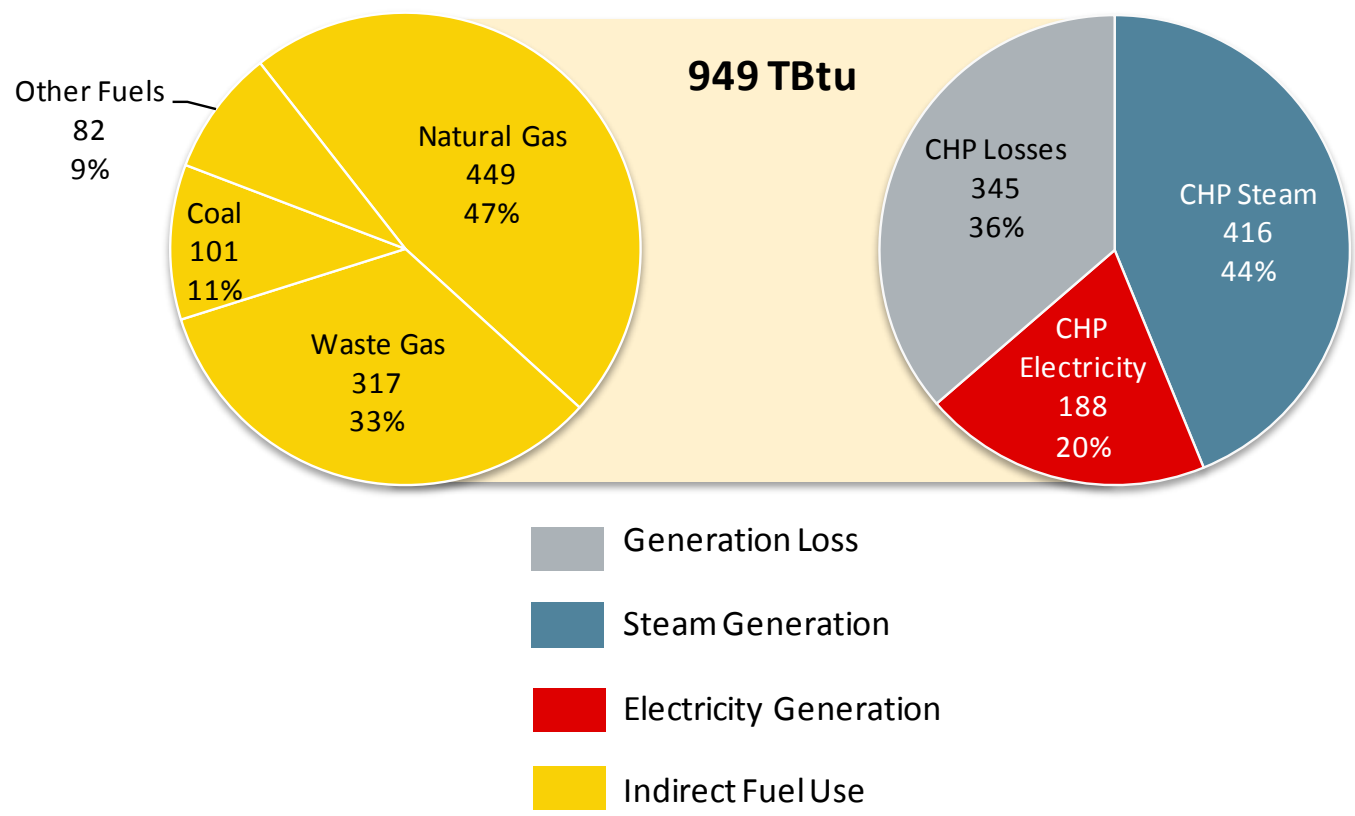

Fig. 2.2-9. CHP fuel consumption and energy output in the chemicals sector

\subsubsection{Direct end use energy}

Figure 2.2-10 shows the breakdown of primary energy by type (fuel, electricity, steam) at its direct end use. Steam is the most significant share of useful energy, with $25 \%$, while electricity accounts for $15 \%$ and fuel accounts for $14 \%$ of primary energy use. The remaining $46 \%$ of primary energy is lost during steam and electricity generation and distribution.

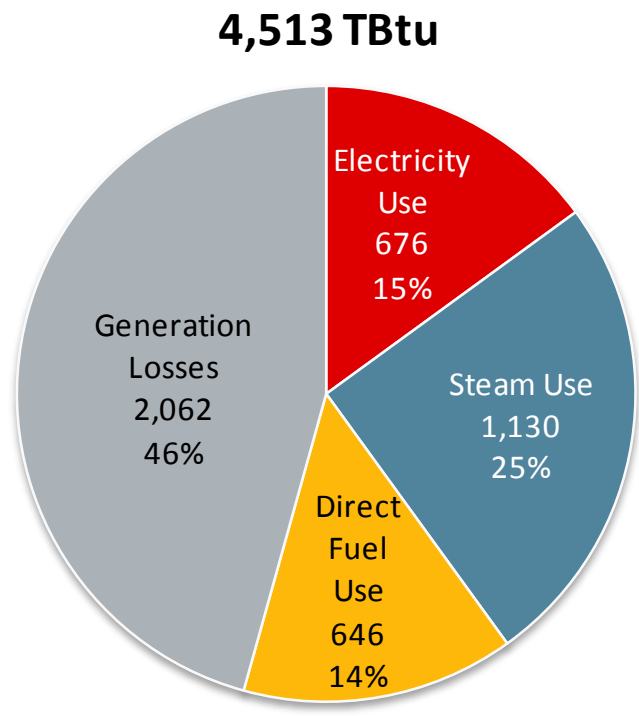

Fig. 2.2-10. Primary energy by type at direct end use in the chemicals sector 
Direct end uses consume 54\% of primary energy, primarily in process heating and machine-driven systems. Nonprocess end uses account for only $5 \%$ of direct end use energy. A breakdown of primary energy by all direct end uses is shown in Fig. 2.2-11.

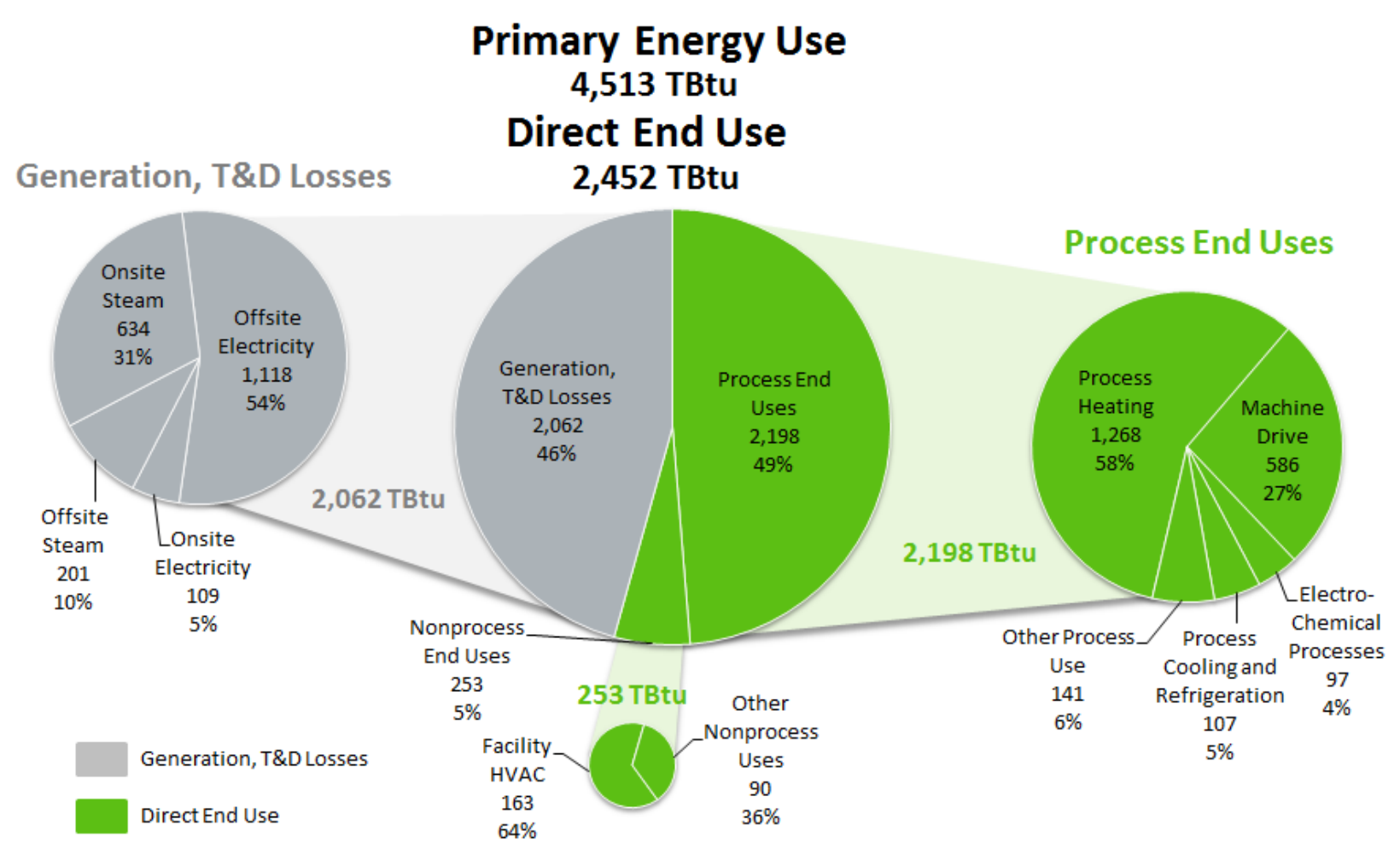

Nonprocess End Uses

Fig. 2.2-11. Primary energy by direct end use in the chemicals sector

Process heating systems represent the bulk of energy use in chemicals manufacturing, consuming 58\% of end use energy (28\% of primary energy). These include steam-based systems and fired systems such as furnaces and reboilers. Machine-driven systems, including pumps, conveyors, compressors, fans, mixers, grinders, and other materials handling or processing equipment, rank second with $27 \%$ of end use energy (13\% of primary energy). Facilities HVAC accounts for $7 \%$ of end use energy (4\% of primary energy).

\subsubsection{Applied end use energy}

In addition to the energy generation losses identified above, direct end use losses have also been calculated in the energy footprint model. When both generation and end use losses are accounted for, the energy that remains is the applied energy. Applied energy can be illustrated by re-examining Fig. 2.2-4, which shows primary energy by energy type for chemicals manufacturing. Each of the energy types (i.e., fuel, electricity, or steam) shown in this figure have associated onsite and offsite generation losses (shown with onsite and offsite losses combined in light gray) that are incurred during energy generation (and transmission and distribution). While the majority of electricity generation losses take place offsite (shown in Fig. 2.2-7), the majority of steam generation losses are onsite (shown in Fig. 2.2-8), and direct fuel use is assumed to have no associated generation losses. After taking into account these generation losses, a further portion of the remaining energy is lost at direct end uses, due to process and nonprocess system and equipment inefficiencies, shown in dark gray. The remaining energy is applied to end uses, shown in light green as "Applied Energy" in Fig. 2.2-12. 


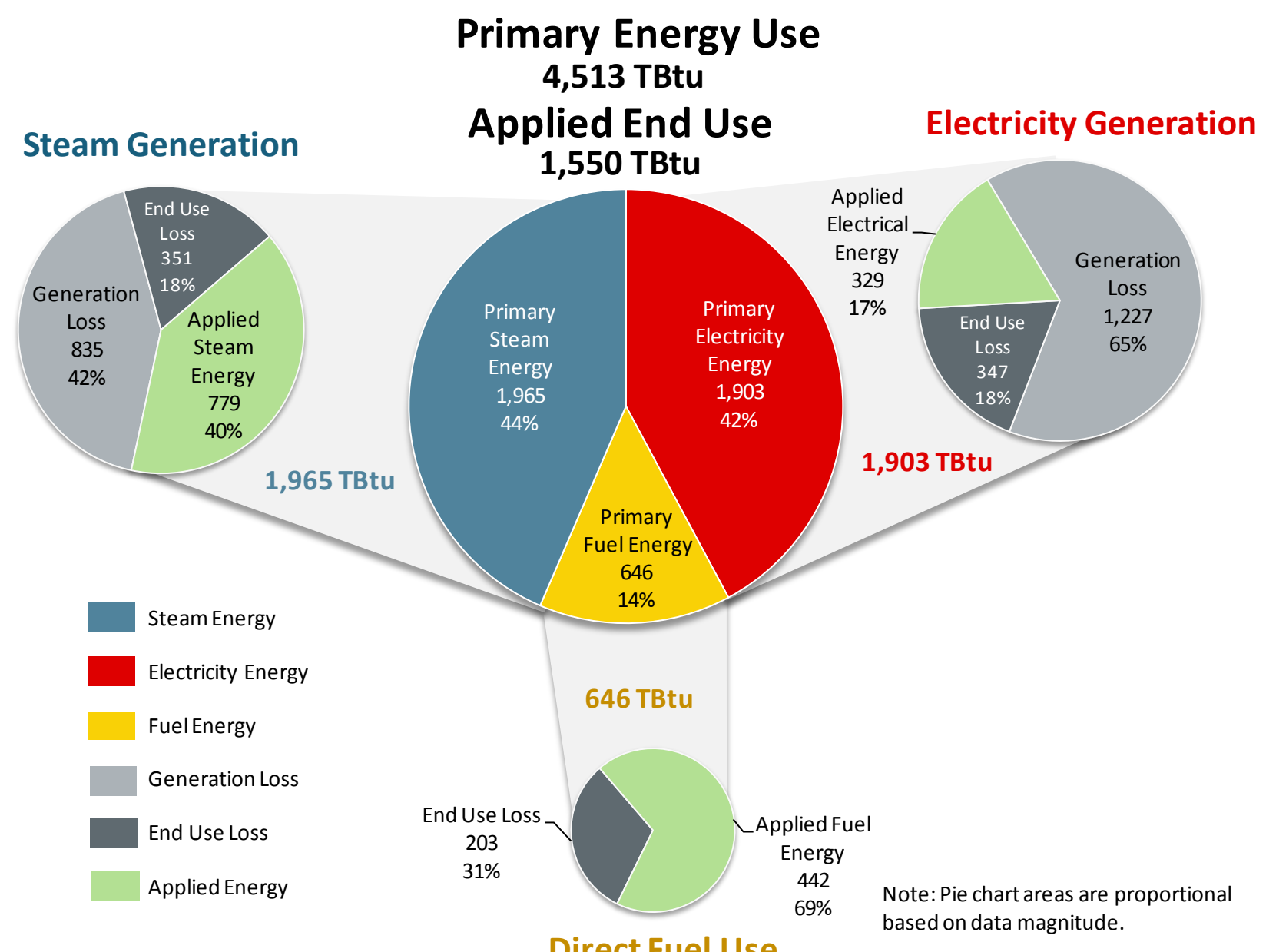

Fig. 2.2-12. Primary energy and applied energy by type in the chemicals sector

Figure 2.2-13 shows the breakdown of all primary energy by energy loss and applied energy. As for the manufacturing as a whole, $34 \%$ of primary energy input is applied to process and nonprocess end uses in the chemicals sector. Generation losses account for $46 \%$ of primary energy input and end use losses account for the remaining $20 \%$ of primary energy input.

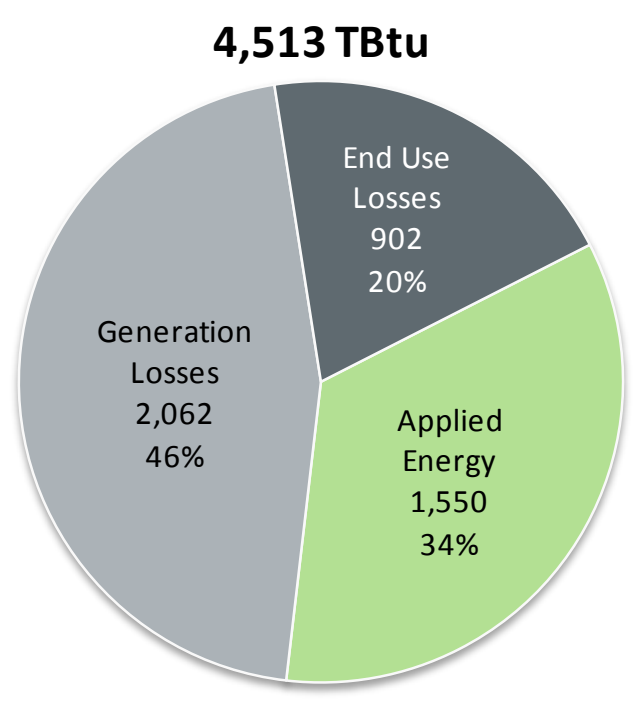

Fig. 2.2-13. Primary energy by loss and applied energy in the chemicals sector 
Applied energy can also be calculated for specific end uses, as shown in Fig. 2.2-14. In this figure, generation losses are labeled as either steam or electricity losses. End use losses are labeled as process or nonprocess losses; in the case of machine drive end use, process losses are further defined as machine drive, or machine driven system losses. For process heating, $52 \%$ of primary energy is applied to the process. Process heating applied energy is relatively high compared to other end uses, because most process heating energy is consumed in the form of fuel or steam. In machine-driven systems, only $12 \%$ of primary energy is applied, primarily because of the inefficiency in electricity generation.
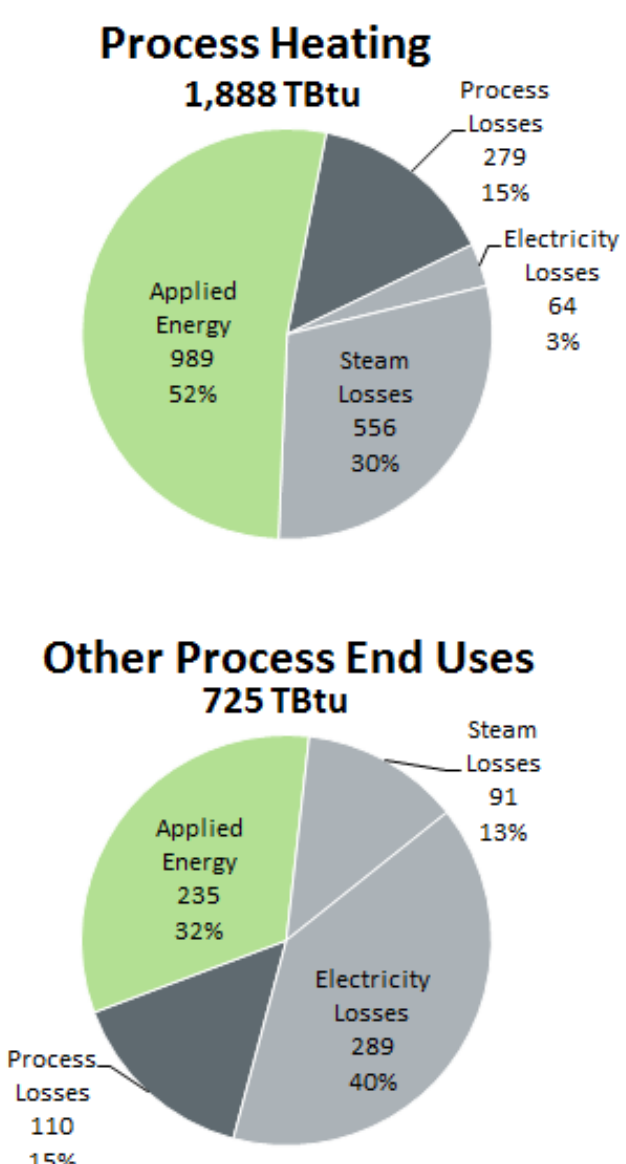

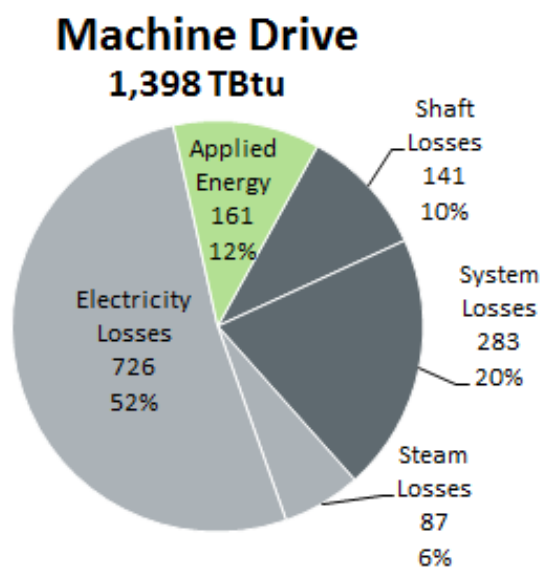

\section{Nonprocess End Uses 503 TBtu}

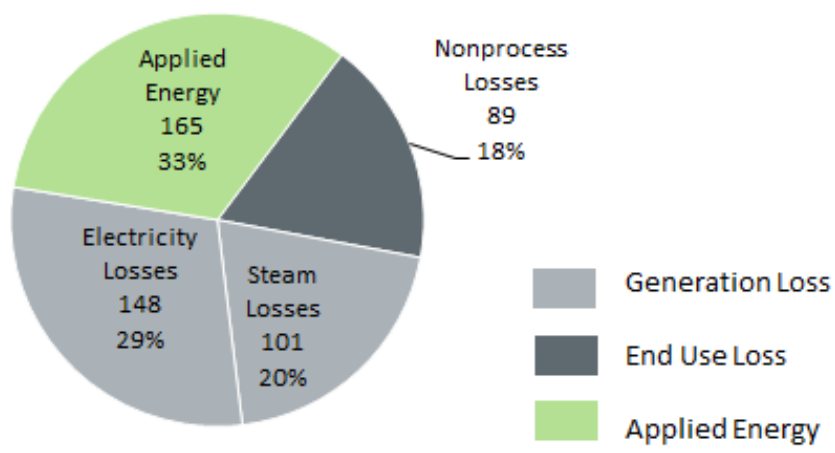

Note: Pie chart areas are not proportional to magnitude of energy consumption

Fig. 2.2-14. Primary applied energy by direct end use in the chemicals sector

The machine drive, or shaft losses represent the inefficiency of converting fuel (in engines), steam (in turbines), or electricity (in motors) into rotating, kinetic energy. The machine driven system losses represent the inefficiency of applying this kinetic energy as effective work, such as compressing air in a rotary screw compressor. Machine-driven system losses total 283 TBtu and shaft losses comprise 141 TBtu, for a combined total of $424 \mathrm{TBtu}$, or $9 \%$ of primary energy. 


\subsubsection{Greenhouse Gas Combustion Emissions Profile for the Chemicals Sector}

In 2006, GHG combustion emissions in the chemicals sector totaled $275 \mathrm{MMT} \mathrm{CO}_{2} \mathrm{e}$, contributing more emissions than any other manufacturing sector. Figure 2.2-15 shows total emissions by offsite energy supply type. Emissions released during offsite production of electricity contribute $36 \%$ of sector emissions, while $17 \%$ of emissions are attributed to the production of offsite steam. The onsite consumption of fuels (shown in yellow), including natural gas, byproduct fuels, coal, and other fuels accounts for nearly half of total emissions. These fuels are used for both direct (e.g., process or nonprocess) and indirect (e.g., fuel for CHP units or boilers) end uses. Table D.5 shows fuel GHG combustion emission factors associated with fuel combustion, as well as electricity and steam generation.

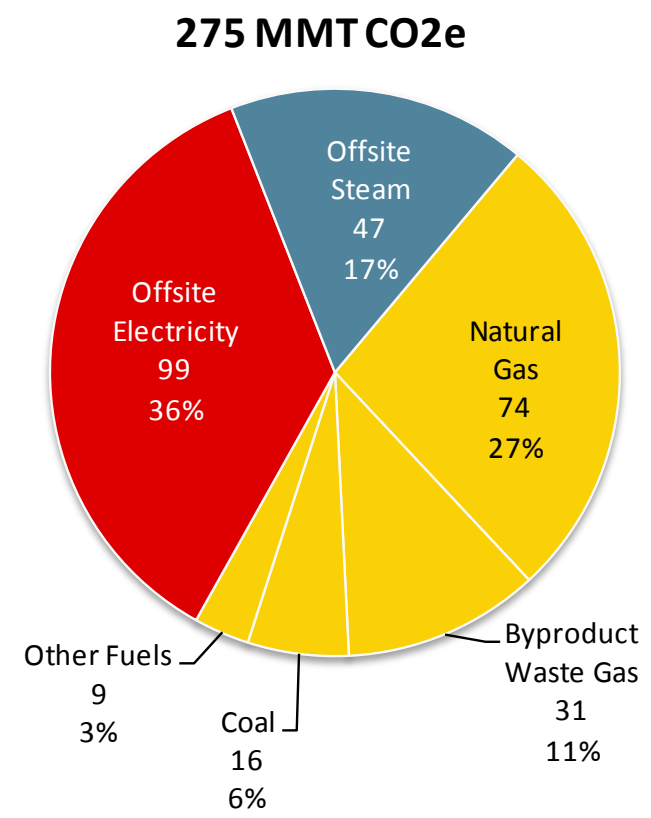

Fig. 2.2-15. Total GHG combustion emissions in the chemicals sector (shown by energy supply type)

An alternative view of emissions is shown in Fig. 2.2-16, which also shows total emissions by energy type, but this figure assigns emissions to onsite electricity and steam production (as opposed to assigning emissions strictly to offsite supplied fuels). All emissions associated with electricity production are shown in red, including emissions released during offsite electricity generation and emissions released during onsite generation of electricity. All emissions associated with steam production are shown in blue, including emissions released during offsite steam generation and emissions released to generate steam onsite in boilers and CHP systems. Lastly, all emissions associated with fuel combustion at process and nonprocess end uses are shown in yellow. Electricity generation (offsite and onsite) contributes about $43 \%$ of all emissions. Steam generation (offsite or onsite) contributes a further $44 \%$ of emissions, while the remaining $13 \%$ of emissions are released during fuel combustion for process and nonprocess end uses. 


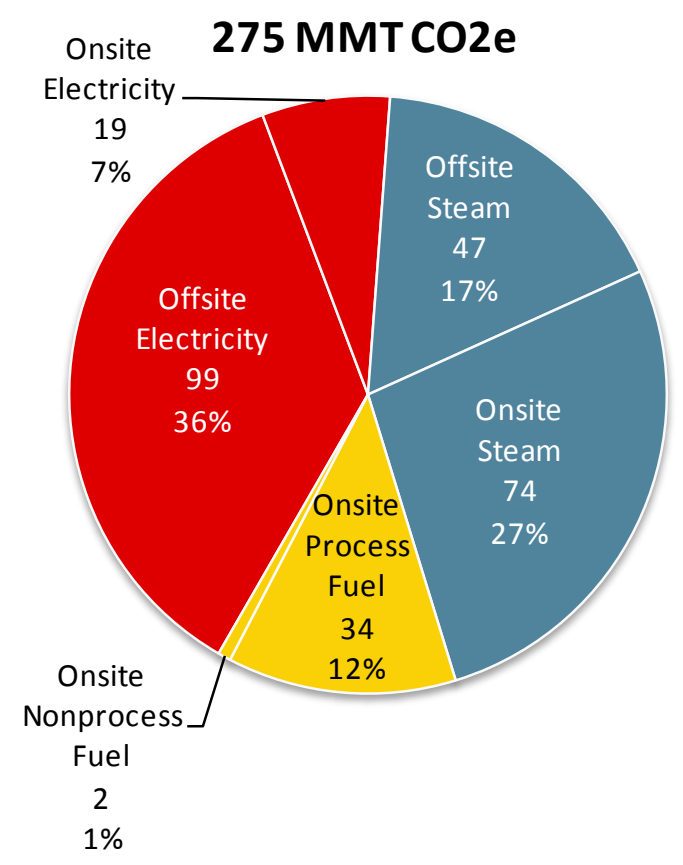

Fig. 2.2-16. Total GHG combustion emissions in the chemicals sector (shown by energy end use type)

Emissions can also be associated with the direct end uses of energy, as is shown in Fig. 2.2-17. In this figure, the emissions released from offsite both offsite and onsite electricity and steam generation are distributed to direct end uses, along with emissions resulting from fuel consumed at the direct end uses. This pie chart allows for a direct comparison of the emissions resulting from individual direct process and nonprocess end uses. Almost half of manufacturing sector end use emissions is the result of process heating applications. Machine-driven processes, which include a large proportion of offsite electricity emissions, are the next highest contributor of emissions. The emissions associated other process and nonprocess uses are also shown in the figure.

\section{MMT CO2e}

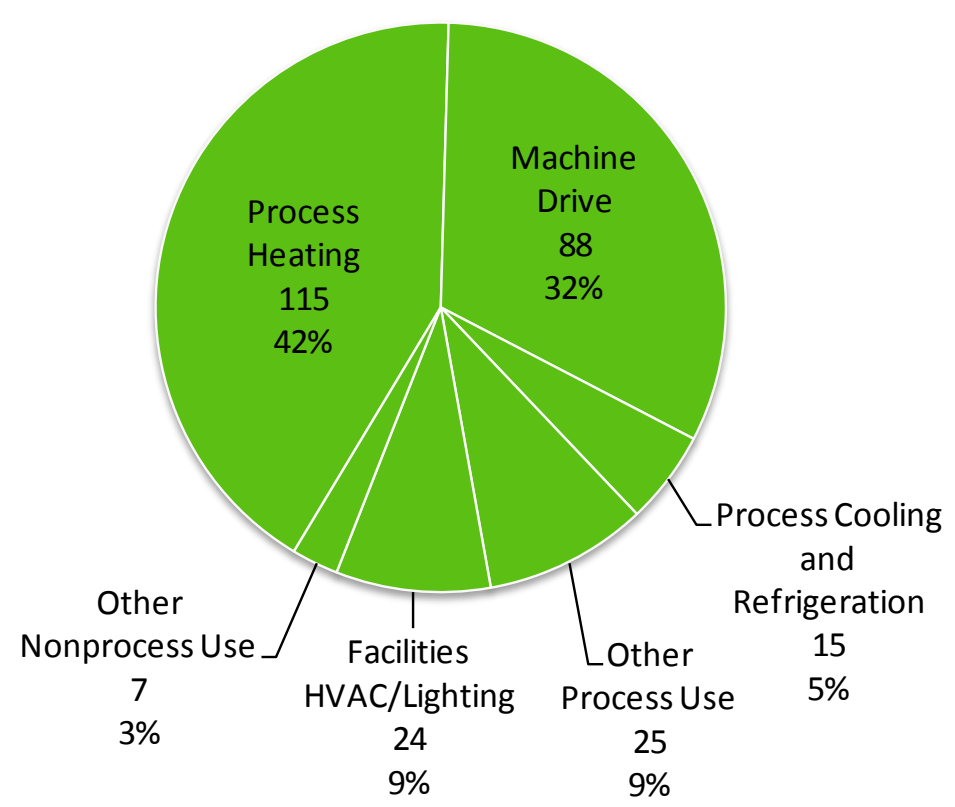

Fig. 2.2-17. Total GHG combustion emissions in the chemicals sector (shown by direct energy end use) 


\subsubsection{Energy and Emissions Profile Summary Table}

The energy and emissions profiles for the chemicals sector discussed in this section are summarized in Table 2.2-3 below. Offsite and onsite contributions to energy supply, use and loss are shown separately in this table, along with GHG combustion emissions. "Applied energy" is calculated for each direct energy use area by subtracting associated offsite and onsite energy losses. For GHG combustion emissions, emissions from the point of use, whether offsite or onsite, are depicted in the first emissions column; offsite emissions are combined with onsite emissions in the total emissions columns. The values in this table correspond to the energy and carbon footprints, which show two carbon values associated with each onsite end use: at point of use and the total based on onsite use.

Table 2.2-3. Energy use, loss, and GHG combustion emissions in the chemicals sector

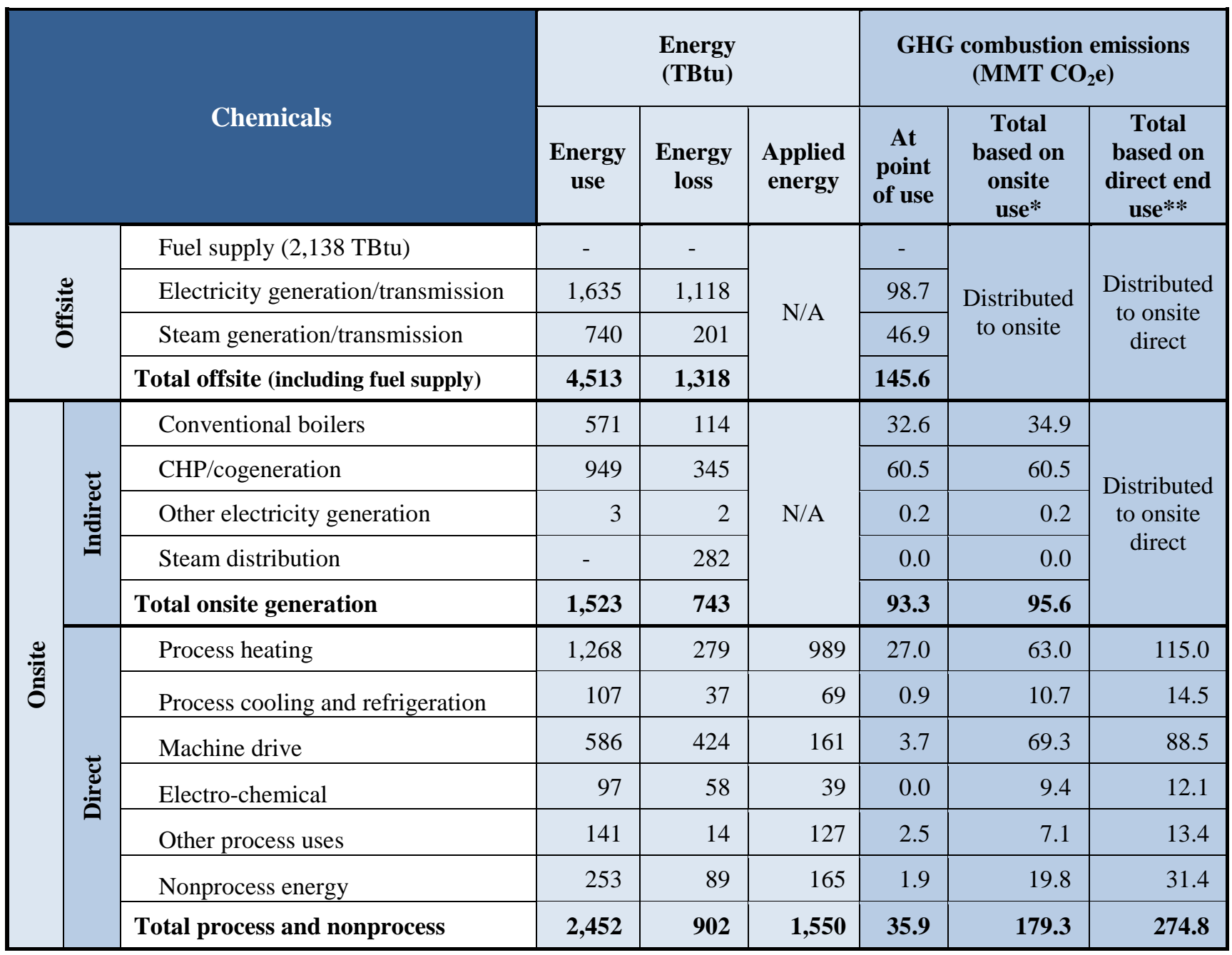

* These values are referenced as "Total" emissions in the footprints, Total emissions $=$ onsite emissions + offsite emissions (i.e., emissions associated with offsite generation are distributed to indirect and direct onsite end uses)

** These values represent direct end use carbon emissions only (i.e., emissions associated with offsite and onsite generation are distributed to direct (and final) end use) 


\subsection{FOREST PRODUCTS SECTOR (NAICS 321 AND 322)}

\subsubsection{Overview of the Forest Products Manufacturing Sector}

The forest products sector produces thousands of products from renewable raw materials (wood) that are essential for communication, packaging, consumer goods, and construction.

The sector is divided into two major categories: Wood Product Manufacturing (NAICS 321) and Paper Manufacturing (NAICS 322). These industries are often grouped together because both rely on the nation's vast forest resources for raw material. In addition, many companies that produce pulp and paper also produce lumber and wood products in integrated operations. Table 2.3-1 presents the subsectors in forest products with data reported in the 2006 EIA Manufacturing Energy Consumption Survey (MECS).

Table 2.3-1. Forest products subsectors with data reported in MECS

\begin{tabular}{|l|l|}
\hline \multicolumn{1}{|c|}{ NAICS code } & \multicolumn{1}{c|}{ Forest products subsector } \\
\hline 321 & Wood product manufacturing \\
\hline 321113 & Sawmills \\
\hline 3212 & Veneer, plywood, and engineered woods \\
\hline 3219 & Other wood products \\
\hline 322 & Paper manufacturing \\
\hline 322110 & Pulp mills \\
\hline 322121 & Paper mills, except newsprint \\
\hline 322122 & Newsprint mills \\
\hline 322130 & Paperboard mills \\
\hline
\end{tabular}

Based on total primary energy use, the forest products sector is the second largest consumer of fuels and power in U.S. manufacturing. The manufacture of wood and paper products is highly energy-intensive, requiring large quantities of thermal energy to convert raw materials to useful products. In addition to fossil fuels, the forest products sector uses wood residues and byproducts (black liquor) to self-generate almost half of its energy needs.

\subsection{2. $\quad$ Energy Use Profile for the Forest Products Sector}

Differentiating between inside or outside the plant boundary is important when evaluating technology options for improving energy efficiency. Within the plant boundary, companies have control over plant energy consumption. Outside the plant boundary, where energy is generated by or provided by utilities, companies have little or no control over technology efficiency. However, companies can reduce energy losses associated with external energy supply by adopting technologies that allow facilities to generate more energy onsite, more efficiently than the utility (e.g., cogeneration).

A snapshot of where the forest products sector ranks in terms of energy use, losses, and emissions within U.S. manufacturing is shown in Table 2.3-2. Energy losses are shown in red font. All values are based on the most currently available complete set of manufacturing energy use statistics, representing annual energy use and loss values for calendar year 2006. The forest products sector ranks among the top three in U.S. manufacturing in nearly every energy end use category. The sector ranks first in onsite generation output, and second only to chemicals in primary energy use. 
Table 2.3-2. Snapshot of the forest products sector: energy use and rank within U.S. manufacturing

\begin{tabular}{|l|r|r|}
\hline \multicolumn{1}{|c|}{ Category } & Rank & \multicolumn{2}{c|}{$\begin{array}{c}\text { Energy } \\
\text { (TBtu) }\end{array}$} \\
\hline Total primary energy use & 2 & 3,559 \\
Offsite losses & 2 & 760 \\
Onsite energy use & 3 & 2,799 \\
Onsite losses & 1 & 1,977 \\
Steam generation and distribution & 1 & 748 \\
Electricity generation & 2 & 57 \\
Process energy & 1 & 1,079 \\
Nonprocess energy & 1 & 94 \\
Feedstock energy & 6 & 8 \\
Total primary and feedstock energy* & 3 & 3,565 \\
\hline GHG combustion emissions & 3 & MMT CO $_{\mathbf{2}} \mathbf{e}$ \\
Total & 3 & 140 \\
Onsite & 3 & 68 \\
\hline * When total primary energy and feedstock energy are summed, the energy value of byproduct fuels \\
derived from feedstock energy sources is excluded to avoid double counting of feedstock energy \\
\hline
\end{tabular}

Although outside the scope of the footprint analysis, it is worth noting that a small amount of energy is consumed as non-fuel feedstock in this sector. As shown in Fig. 2.3-1, the total feedstock energy consumed by the forest products sector is $8 \mathrm{TBtu}$. This amount is minimal in comparison with the greater feedstock energy use in the petroleum refining sector (NAICS 324110, feedstock energy consumption equal to 3.4 quads) and the chemicals sector (NAICS 325, feedstock energy consumption equal to 2.8 quads). When feedstock and primary energy are summed, total primary and feedstock energy is about 3.6 quads for the forest products sector.

The focus of the energy use and loss analysis that follows excludes all feedstock energy use.

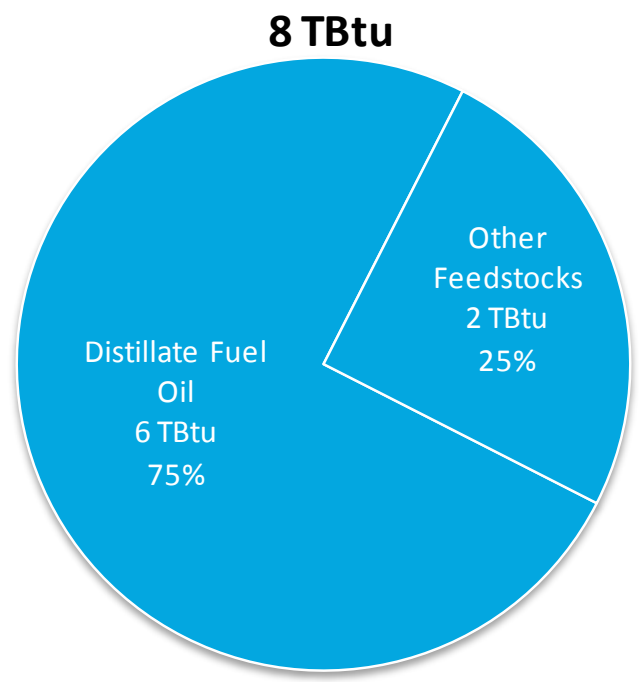

Fig. 2.3-1. Feedstock energy use in the forest products sector 


\subsubsection{1. $\quad$ Energy and carbon footprint}

The Manufacturing Energy and Carbon Footprint for the forest products sector is shown in Fig. 2.3-2 and Fig. 2.3-3. The footprints serve as the basis for characterizing the offsite and onsite flow of energy, as well as carbon emissions, from generation through end use in the sector.

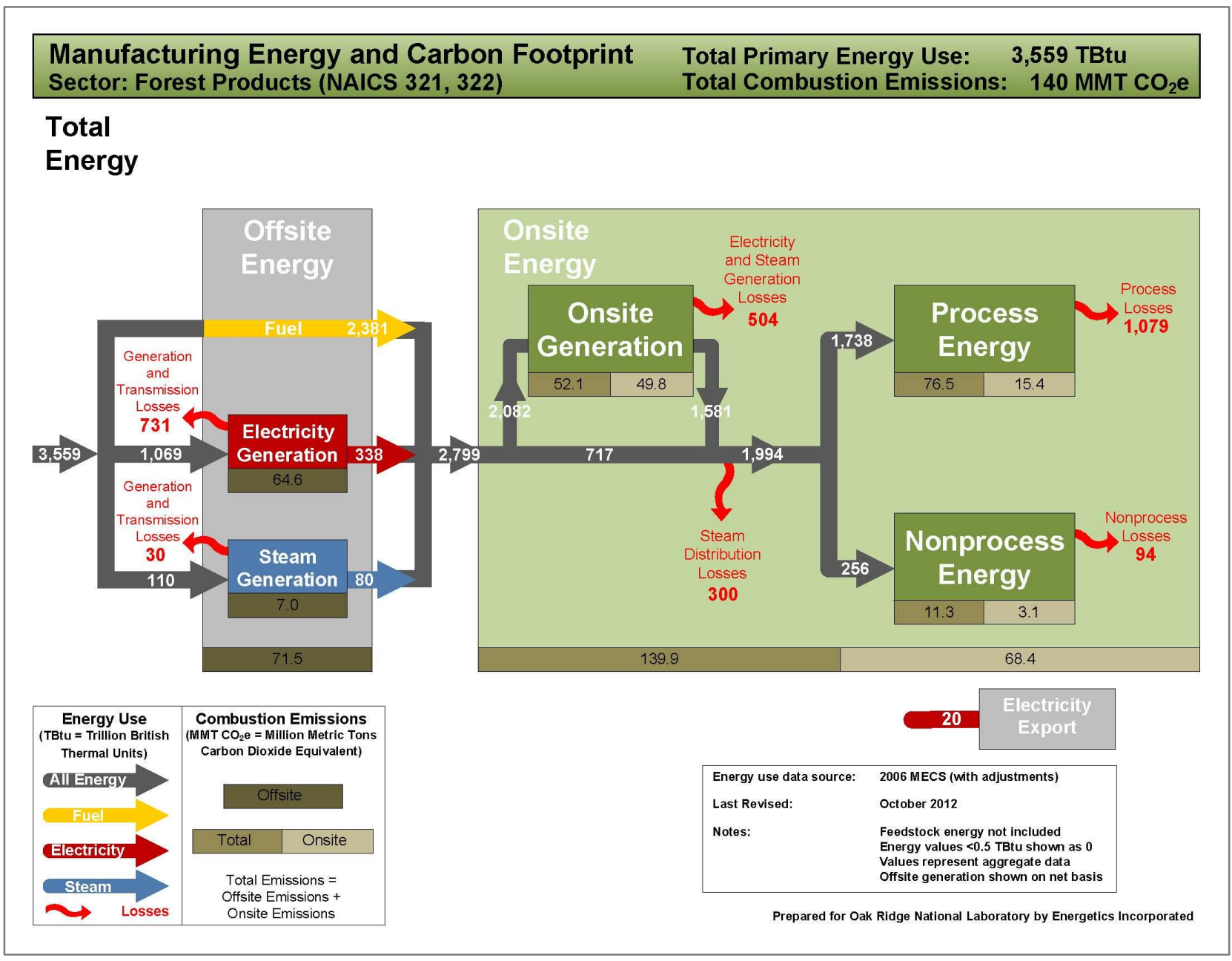

Fig. 2.3-2. Total energy and carbon footprint for the forest products sector 


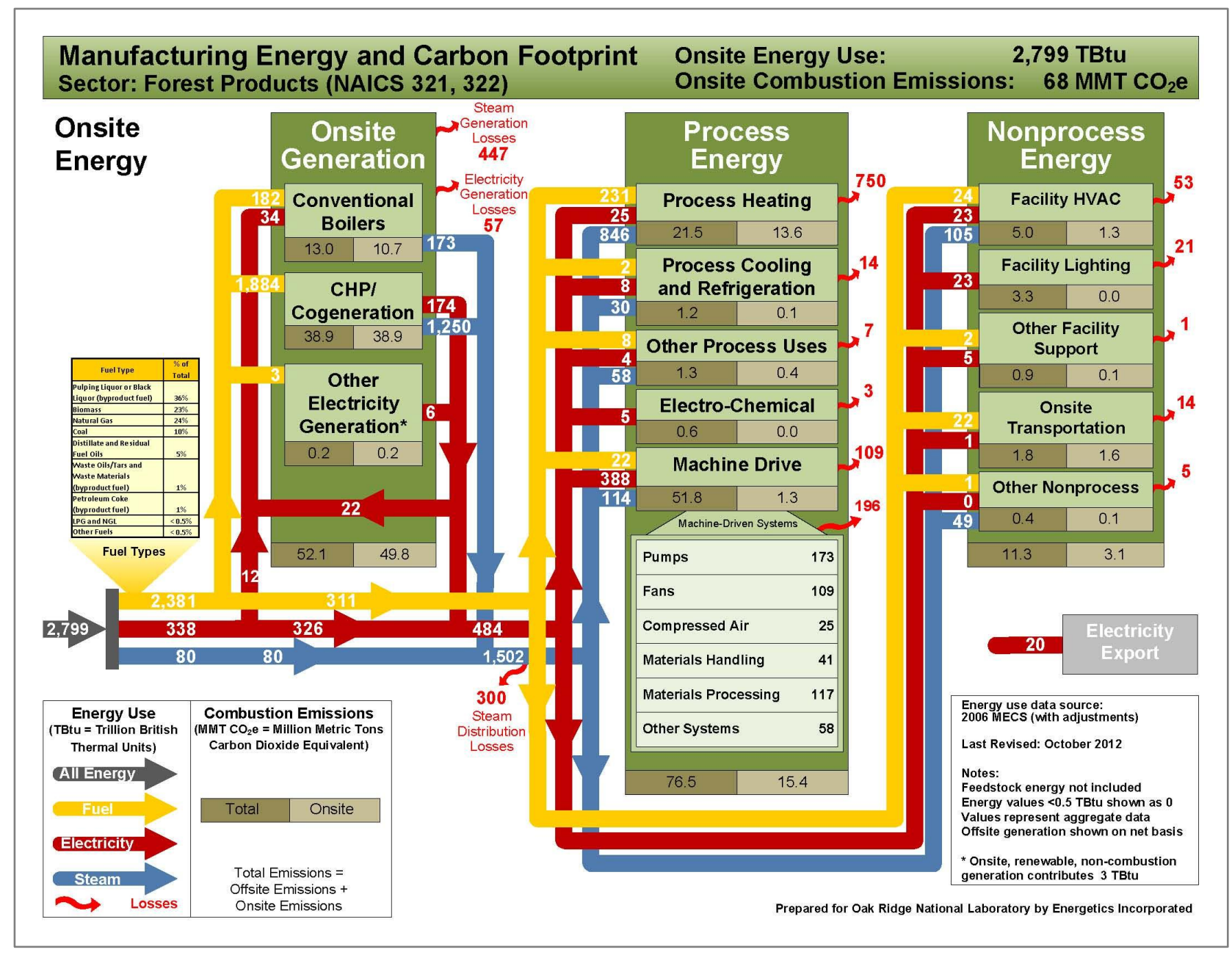

Fig. 2.3-3. Onsite energy and carbon footprint for the forest products sector

\subsubsection{Primary energy}

Primary energy use includes fuels, electricity, and steam consumed in manufacturing, including the generation and distribution/transmission losses associated with offsite and onsite electricity and steam generation. The primary energy use by energy type for the forest products sector is depicted in Fig. 2.3-4. The forest products sector consumes 3,559 TBtu of primary energy, ranking second across U.S. manufacturing. Steam and electricity generation consume $55 \%$ and $36 \%$ of primary energy, respectively. Direct fuel use comprises the remaining $9 \%$ of primary energy consumption. Consistent with the footprints, blue represents steam energy, red represents electric energy, and yellow represents fuel energy.

Steam is the largest category of primary energy - consuming 1,979 TBtu (55\%) of total primary energy. Onsite generation of steam accounts for 1,138 TBtu of this total, while losses from this onsite generation and steam distribution losses account for a further $748 \mathrm{TBtu}$ of this total. Together, onsite steam and associated losses account for $95 \%$ of total steam generation, with the remaining steam due to offsite steam and associated generation and distribution losses.

Electricity is the second largest category of primary energy, using 1,269 TBtu (36\%) of primary energy consumption. Offsite electricity (including losses) accounts for $84 \%$ of electricity generation, with the remaining $16 \%$ of electricity generation from onsite generation. Offsite electricity losses account for $58 \%$ of electricity generation energy consumption (731 TBtu). Offsite generated electricity provides 326 TBtu to direct end uses (excludes electricity used to generate steam onsite), while onsite electricity generation provides an additional $155 \mathrm{~TB}$ tu to direct end uses. Onsite electricity losses account for $57 \mathrm{TBtu}$ of energy. 


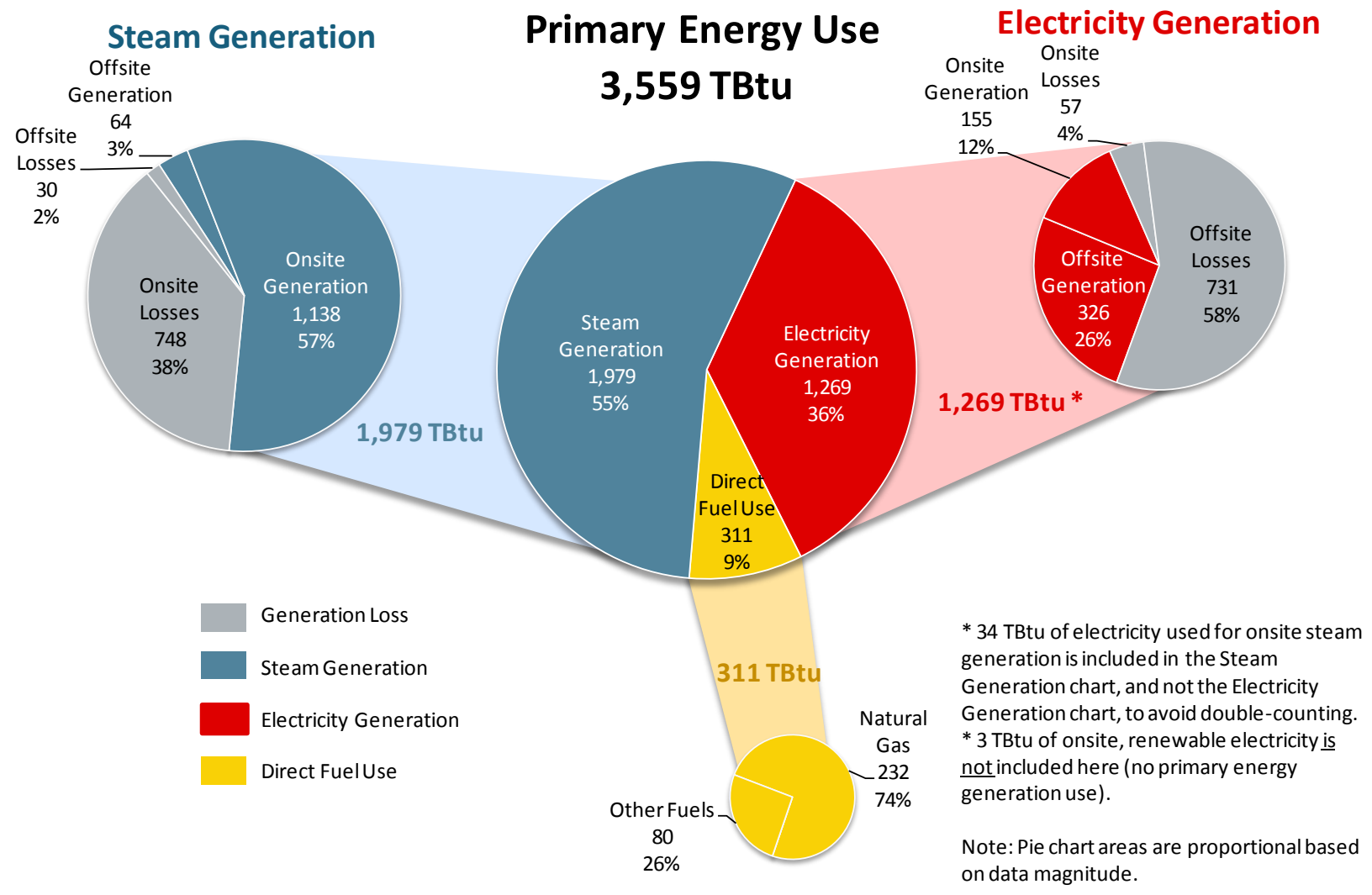

\section{Direct Fuel Use}

Fig. 2.3-4. Primary energy use by energy type for the forest products sector

\subsubsection{Onsite energy}

About 2.8 quads, or $79 \%$ of primary energy, were consumed onsite by the forest products sector in 2006. This onsite energy enters the plant boundary in the form of three offsite energy types: fuel, steam, and electricity. As shown in Fig. 2.3-5, this energy is composed of $85 \%$ fuel (or feedstock that becomes a byproduct fuel), $12 \%$ offsite electricity, and $3 \%$ offsite steam. Onsite fuel use is further broken down by fuel type in the yellow portion of the chart.

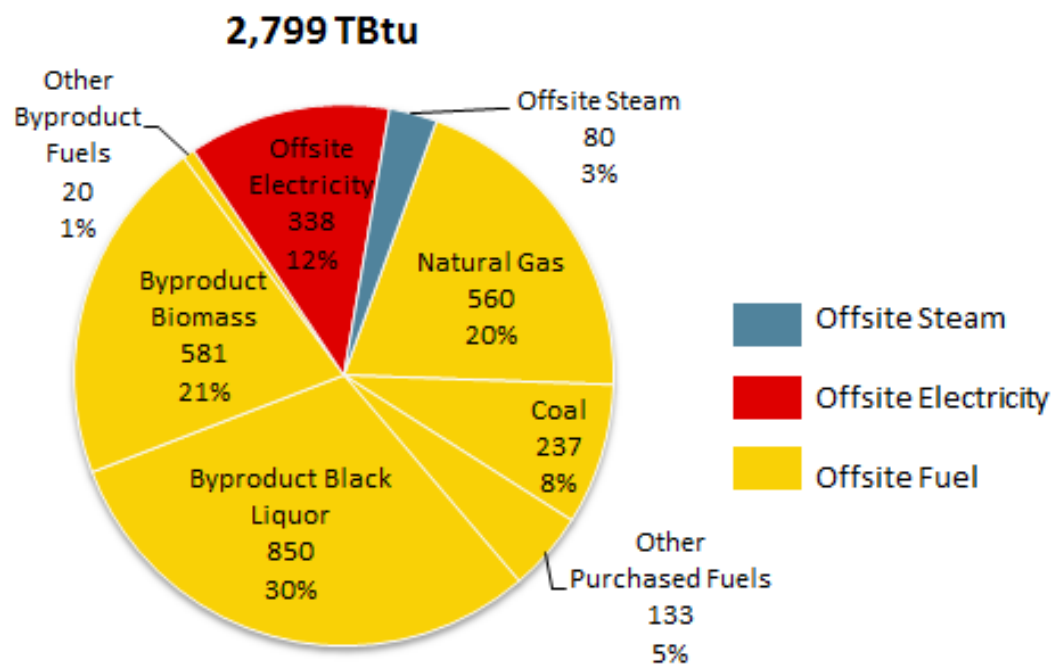

Fig. 2.3-5. Offsite energy supply in the forest products sector 
Figure 2.3-6 illustrates the onsite energy consumption patterns across major subsectors of the forest products sector (the sum of onsite energy use across these subsectors is equal to $88 \%$ of sector-side onsite energy use). Overall, paper mills (except newsprint) and paperboard mills consume more energy than any other subsector in 2006 at $939 \mathrm{TBtu}$ and $827 \mathrm{TBtu}$, respectively. The remaining other subsectors of veneer, plywood, and engineered woods; other wood products; sawmills, pulp mills, and newsprint mills each use about 200 TBtu or less of fuel energy.

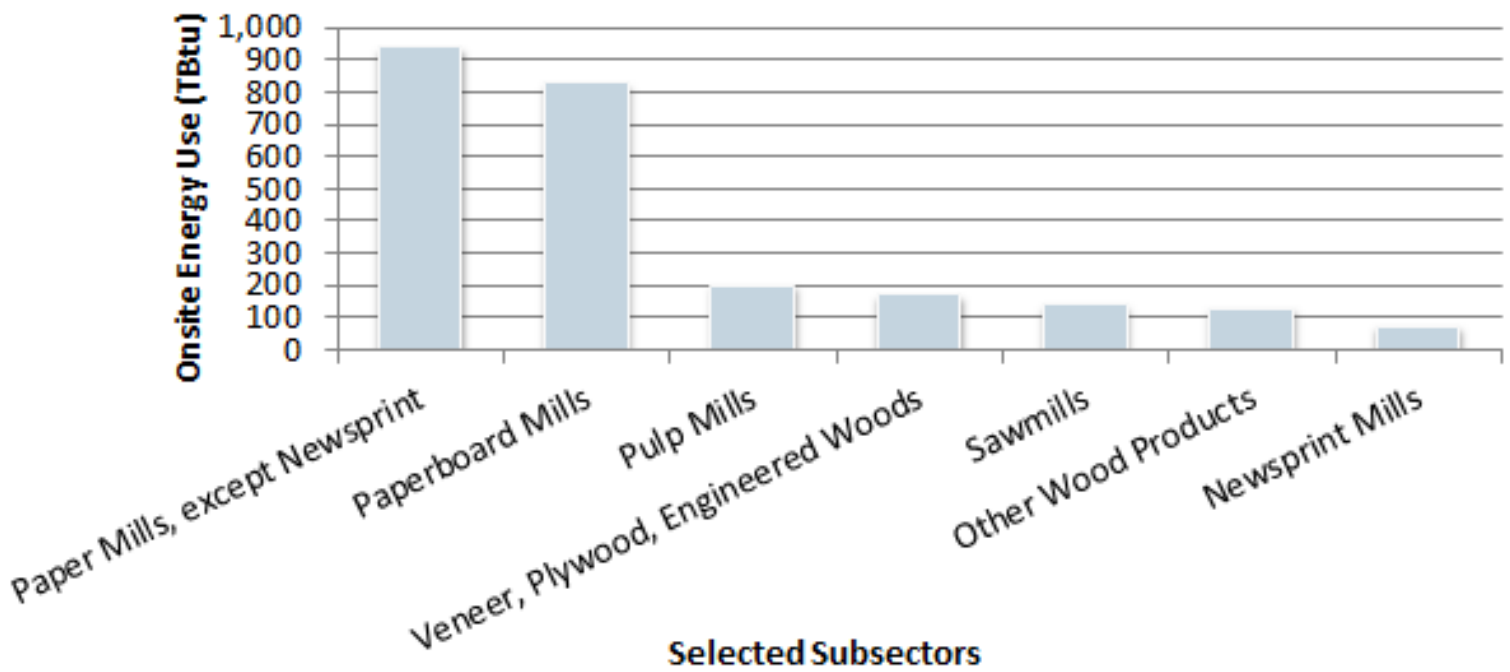

Fig. 2.3-6. Onsite energy use in selected forest products subsectors

However, it should be noted that the data reported may be somewhat misleading due to how sectors are categorized by NAICS. Paper and Paperboard Mills, for example, include operations where pulping is done at the same facility (integrated pulp/paper mills). Subsequently, in those cases, energy reported includes energy for pulping as well as papermaking. Energy shown for pulp mills only includes mills that do not make paper.

\subsubsection{Fuel energy}

Onsite fuel use in the forest products sector is 2,381 TBtu. The forest products sector is the second largest user of fuel behind the petroleum refining sector and almost $80 \%$ of this fuel is used for onsite CHP generation, making forest products the largest user of CHP, with almost two and half times as much CHP output as the second-ranked chemicals sector.

Forest products manufacturing constitutes the largest manufacturing use of biomass. Biomass resources utilized by the industry include black liquor produced by kraft pulping processes and wood residues collected from wood handling and manufacturing processes. These wood byproducts are burned by the forest products industry to generate steam and electricity. As shown in Fig. 2.3-5, pulping/black liquor itself provides $850 \mathrm{TBtu}$, or $30 \%$ of offsite energy supply. Combined with other forms of biomass such as wood residues, biomass comprises about $51 \%$ (1,431 TBtu) of offsite energy supply. Coal, fuel oils, and other petroleum-based fuels make up the remainder of fuel use.

Improvements in the efficiency of energy systems impact fuel use distribution directly in forest products. The forest products industry is steam intensive, so increasing boiler and process heat transfer efficiencies can have a significant impact. Much of boiler fuel, however, comes from process byproducts. There is subsequently a trade-off between increased yield and process efficiency (producing less byproducts), the biomass available for boiler fuel, and the use of more costly fossil fuels. 


\subsubsection{Electrical energy}

The forest products sector ranks second among U.S. manufacturing sectors in electricity demand at 518 TBtu. Electricity demand, equal to the sum of net purchased electricity and electricity generated onsite, provides the most complete picture of facility electricity use. Electricity only accounts for less than $15 \%$ of energy consumption across the sector. The sector creates a diversity of products with many different production processes, so energy use patterns do vary across subsectors. Within the same product subsector, processes (and associated energy demand) can also differ depending on the technology used. For example, pulp can be made by chemical pulping, mechanical pulping, or a combination of the two pulping processes.

As shown in Fig. 2.3-7, the forest products sector used 484 TBtu of electricity for direct ${ }^{11}$ process uses. A large portion of the primary energy consumed for electricity end use is associated with generation, transmission and distribution (T\&D) losses, taking place mostly offsite. On average, the efficiency of utility power generation and transmission is assumed to be $31.6 \%$, generating over 705 TBtu of energy losses in order to produce $326 \mathrm{TBtu}$ of electricity that is used in the sector. The forest products sector also does meet a moderate portion of its electricity demand through onsite generation. Approximately $158 \mathrm{TBtu}$ of energy use is associated with the production of onsite electricity. Most of the onsite produced electricity is generated using CHP units, with only a small percentage originating from other generation methods such as the use of generators running on combustible energy sources or electricity from renewable resources. Renewable electricity generation contributes about 3 TBtu to onsite electricity generation in forest products, more than any other sector.

Approximately $80 \%$ of the electricity is consumed by machine-driven systems such as pumps, conveyors, compressors, fans, mixers, grinders, and other materials handling or processing equipment. Facilities use, such as HVAC and lighting, is the next largest category of electricity consumption within the sector, consuming $11 \%$ of electricity use. The remaining $9 \%$ of sector electricity use is consumed by other process uses including process heating, process cooling and refrigeration, and electro-chemical processes.

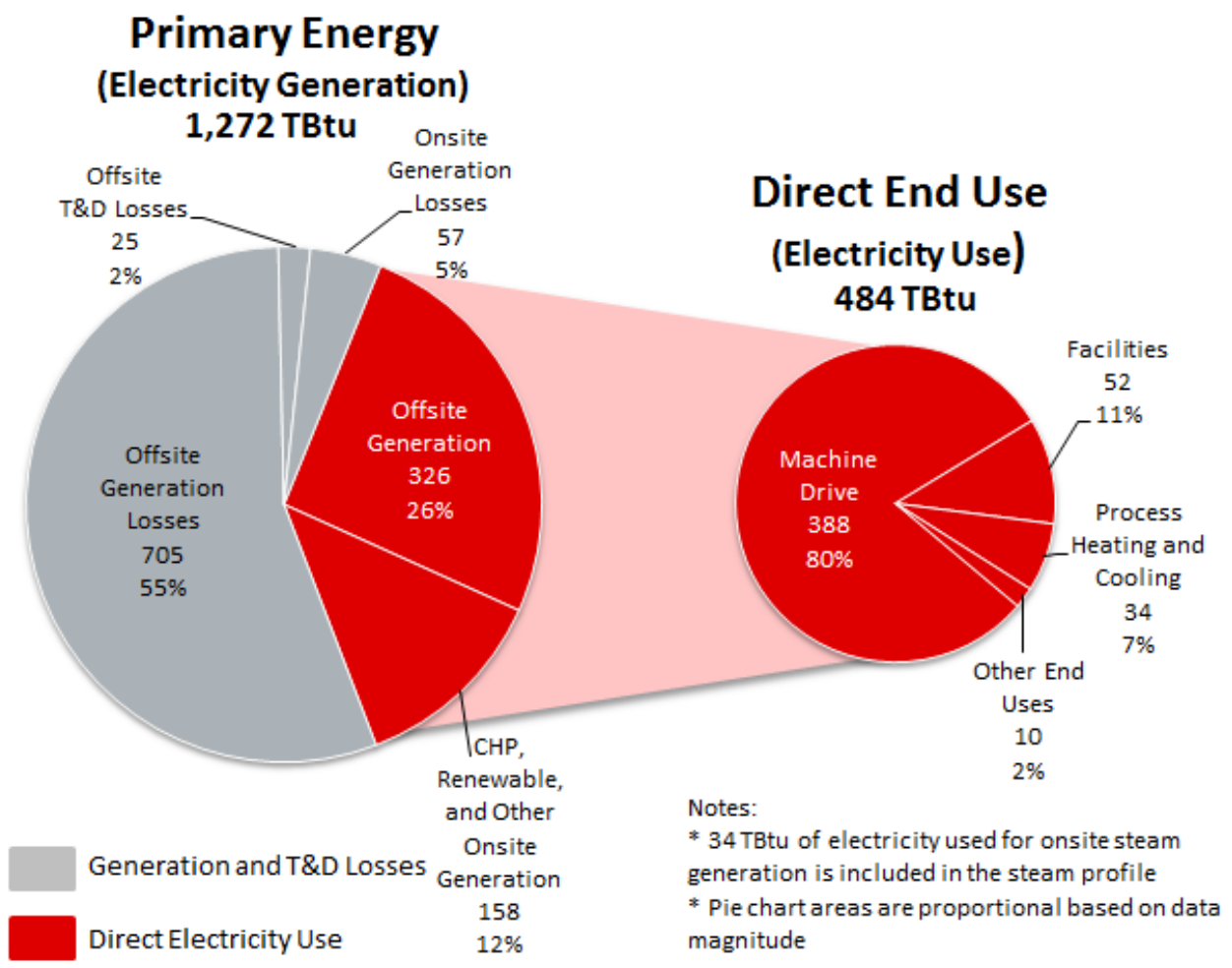

Fig. 2.3-7. Electricity generation and direct end use in the forest products sector

\footnotetext{
${ }^{11}$ Offsite electricity generation (326 TBtu) shown in this chart is lower than the value of offsite energy entering the plant boundary shown in the energy and carbon footprint for this sector (338 TBtu). This difference is due to the small portion of offsite electricity (12 TBtu) that is used by conventional boilers to generate steam.
} 


\subsubsection{Steam energy}

The forest products sector ranks first across U.S. manufacturing in steam usage. A profile of the forest products sector steam use from primary energy and associated losses is shown in Fig. 2.3-8. About 39\% of primary energy inputs are lost due to system inefficiencies in steam generation and transmission, both offsite and onsite. CHP generation comprises just over half $(51 \%, 1,000 \mathrm{TBtu})$ of primary energy, serving as the principal source of energy to be applied towards end use. Conventional boiler steam provides for about $7 \%$ (138 TBtu) of the energy for end use, followed by steam generated offsite at 3\% (64 TBtu). Of the 1,979 TBtu of primary energy made available for steam, 1,202 TBtu of energy is applied to end use. Process heating systems, particularly those used for drying or evaporation, receive the bulk of the energy at $70 \%$ (846 TBtu), followed by machine drive and facility HVAC uses each at 9\% (114 and $109 \mathrm{TBtu}$ respectively), $5 \%$ to other process uses (58 TBtu), $4 \%$ to other nonprocess uses ( $49 \mathrm{TBtu}$ ), and the remaining $3 \%$ going to process cooling and refrigeration $(30 \mathrm{TBtu})$.

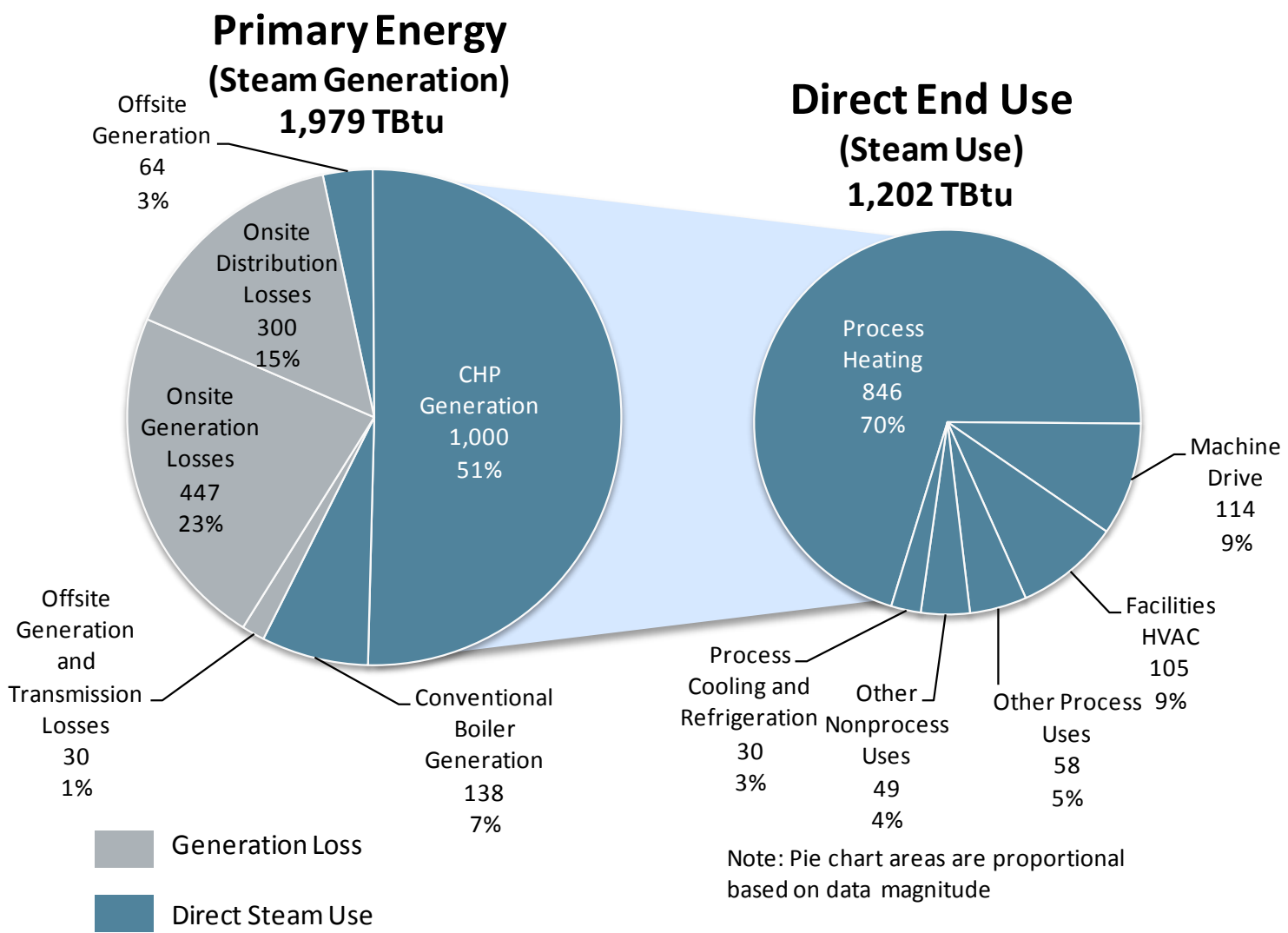

Fig. 2.3-8. Steam generation and direct end use in the forest products sector

\subsubsection{Combined heat and power energy}

The forest products sector meets a significant amount of energy demand through onsite generation, especially steam, ranking first in CHP output across U.S. manufacturing. As shown Fig. 2.3-9, fuel use for combined heat and power systems produces 1,884 TBtu of energy output, with about two-thirds in the form of steam $(1,250 \mathrm{TBtu}, 66 \%)$. Electricity encompasses about $9 \%$ of CHP output (174 TBtu), with the remaining $25 \%$ of energy composed of losses (461 TBtu). Three-fourths of fuels entering CHP units are biomass-related, consisting of pulping/black liquor (45\%, $850 \mathrm{TBtu})$ and other biomass sources such as wood residues $(31 \%, 581 \mathrm{TBtu})$. Coal comprises $11 \%$ of fuel used for CHP at $204 \mathrm{TBtu}$, followed by $9 \%$ (179 TBtu) from natural gas, with the remaining 4\% (71 TBtu) composed of other fuels such as distillate and residual fuel oils. 


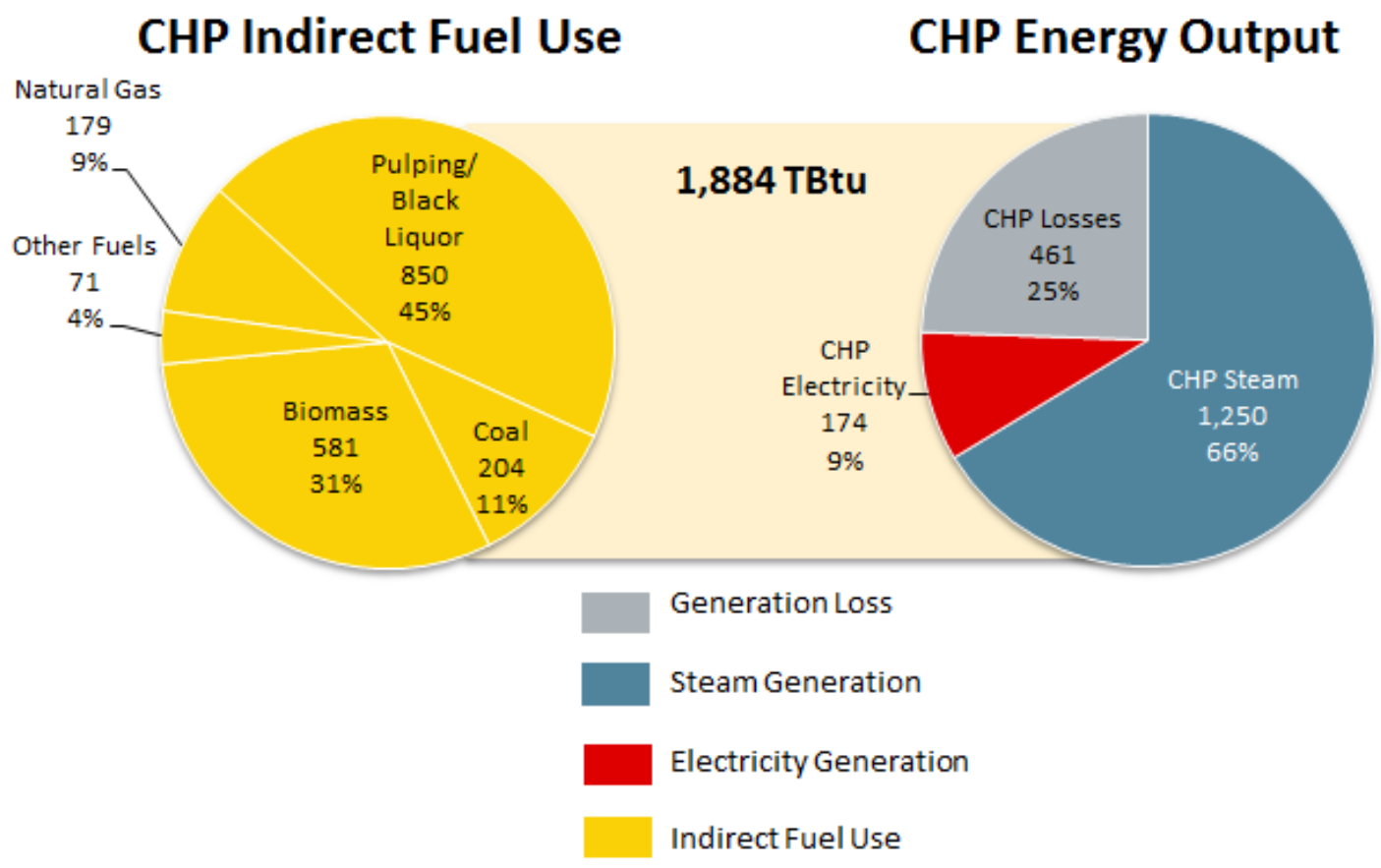

Fig. 2.3-9. CHP fuel consumption and energy output in the forest products sector

\subsubsection{Direct end use energy}

Energy is consumed in forest product manufacturing to provide process heating and cooling, to power motor-driven systems, and for various other purposes. A simple breakdown of primary energy by type at its direct end use is shown in Fig. 2.3-10.

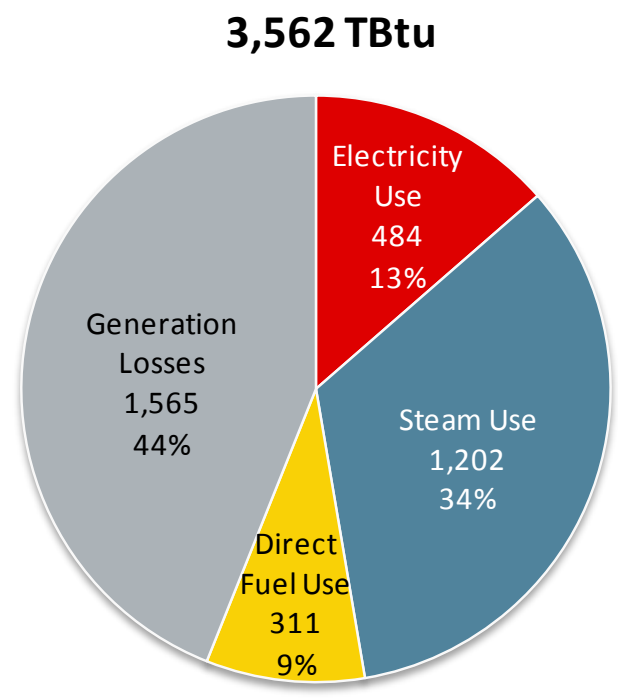

Fig. 2.3-10. Primary energy by type at direct end use in the forest products sector

A breakdown of primary energy by all direct end uses is shown in Fig. 2.3-11, which shows $49 \%$ of primary energy used for process used (49\%, 1,741 TBtu). Losses incurred during the generation of electricity and steam at accounts for a further $44 \%(1,565 \mathrm{TBtu})$ of primary energy and nonprocess uses account for only about $7 \%$ (256 TBtu) of sector primary energy use. 


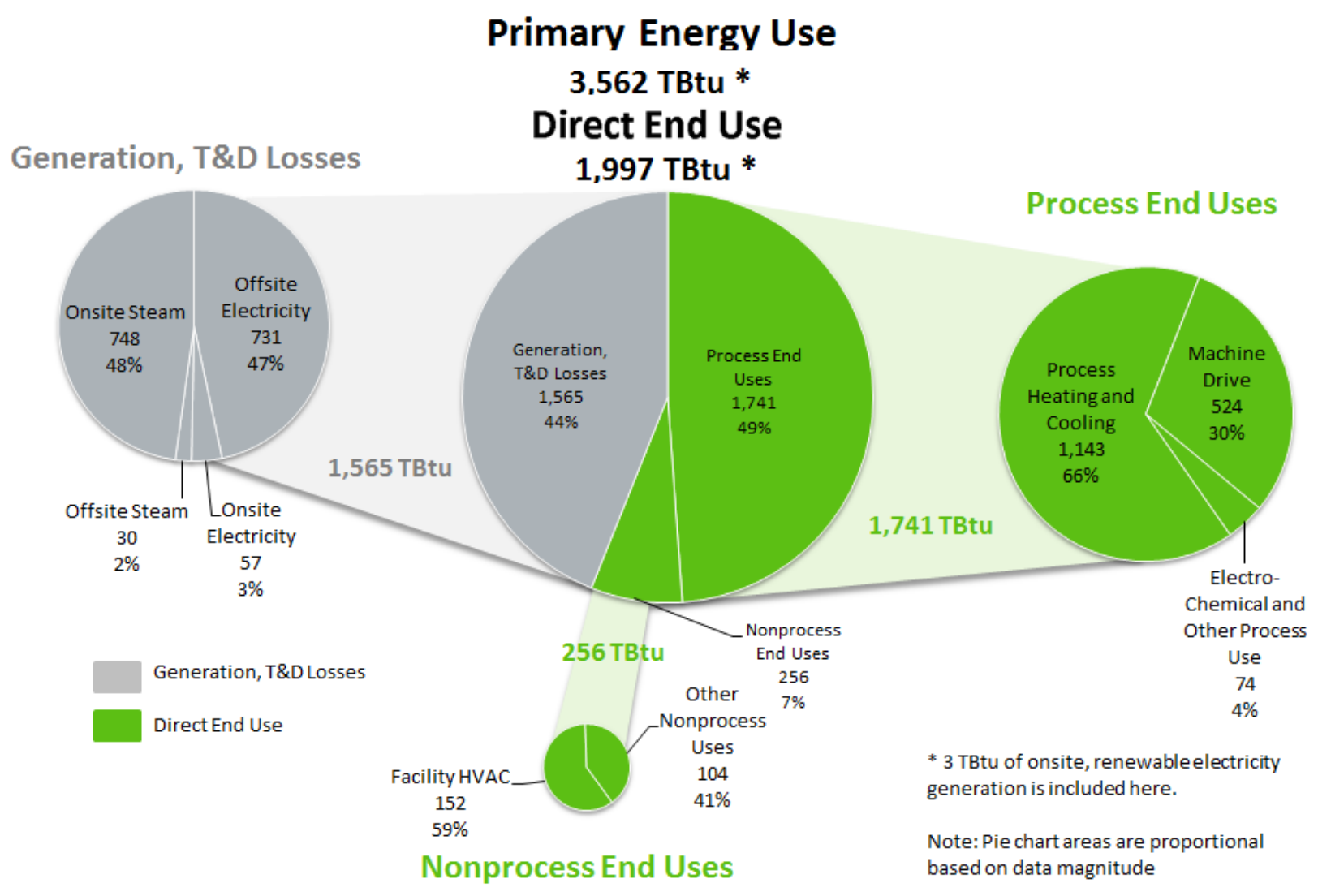

Fig. 2.3-11. Primary energy by direct end use in the forest products sector

The forest products sector ranks third across U.S. manufacturing in the use of process heating and cooling systems, and second in the use of machine-driven systems. Heating and cooling processes consume 1,143 TBtu out of the 1,741 TBtu (66\%) total delivered to process end uses. These include steam systems and fired systems such as furnaces and reboilers. Machine-driven systems are the next largest use of process energy in the sector at $524 \mathrm{TBtu}(30 \%)$. As shown in Fig. 2.3-8, steam serves as the primary energy source for process heating systems, while electricity is the main source of energy for the largely electric-based, machine-driven systems. Further, the majority of other fuels are primarily comprised of biomass sources such as pulping/black liquor and wood residues, as described in the combined heat and power section.

The forest products sector also ranks first across U.S. manufacturing in nonprocess energy end uses.

Facility HVAC is the largest user of nonprocess energy, followed by other nonprocess energy uses such as facility lighting, onsite transportation, and other facility support. 


\subsubsection{Applied end use energy}

In addition to the energy generation losses identified above, direct end use losses have also been calculated in the energy footprint model. When both generation and end use losses are accounted for, the energy that remains is the applied energy. Applied energy can be illustrated by re-examining Fig. 2.3-4, which shows primary energy by energy type for the forest products sector. Each of the energy types (i.e., fuel, electricity, or steam) shown in this figure have associated onsite and offsite generation losses (shown with onsite and offsite losses combined in light gray) that are incurred during energy generation (and transmission and distribution). While the majority of electricity generation losses take place offsite (as shown in Fig. 2.3-7), the majority of steam generation losses are onsite (as shown in Fig. 2.3-8), and direct fuel use is assumed to have no associated generation losses. After taking into account these generation losses, a further portion of the remaining energy is lost at direct end uses, due to process and nonprocess system and equipment inefficiencies, shown in dark gray. The remaining energy is applied to end uses, shown in light green as "Applied Energy" in Fig. 2.3-12.

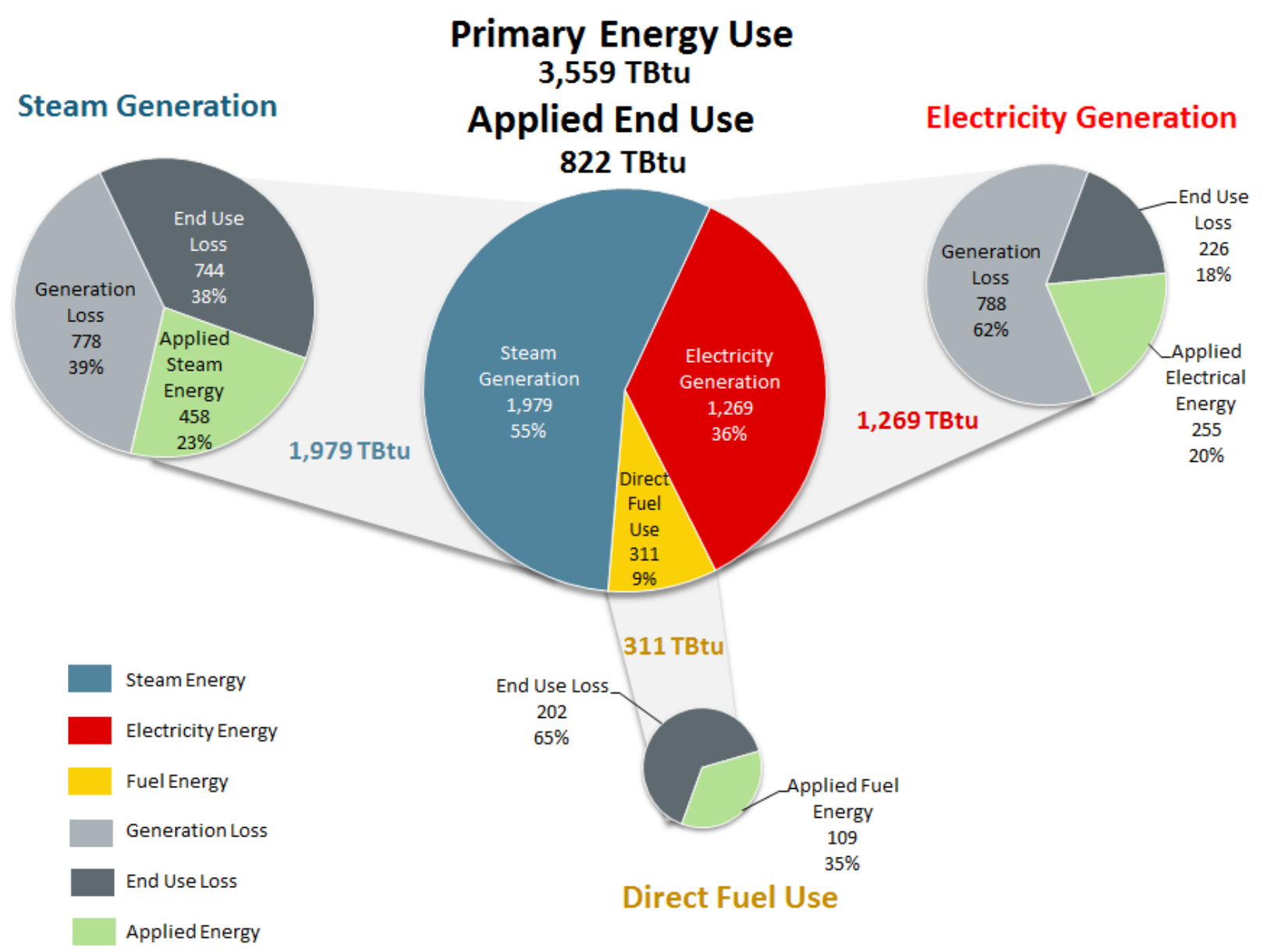

Fig. 2.3-12. Primary energy use and applied energy by energy type in the forest products sector

Fig. 2.3-13 shows the breakdown of primary energy by energy loss and applied energy. In this sector, only $23 \%$ of primary energy input is applied to process and nonprocess end uses, significantly less than the manufacturing average of $34 \%$. Generation losses account for $44 \%$ of primary energy input and end use losses account for the remaining $33 \%$ of primary energy input. 


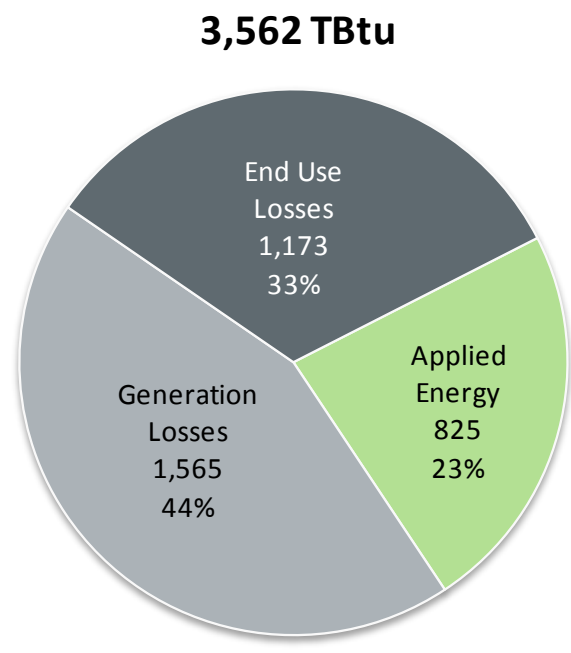

Fig. 2.3-13. Primary energy by loss and applied energy in the forest products sector

Applied energy can also be calculated for specific end uses, as shown in Fig. 2.3-14. This figure shows generation losses labeled as either steam or electricity losses. End use losses are labeled as process or nonprocess losses; in the case of machine drive end use, process losses are further defined as machine drive, or machine driven system losses. For process heating systems, only $21 \%$ of primary energy is applied to the process (detail of the methodology to estimate process heating losses are shown in Appendix F). In machine-driven systems, $18 \%$ of primary energy is applied to direct end uses, primarily due to the inefficiency in electricity generation.
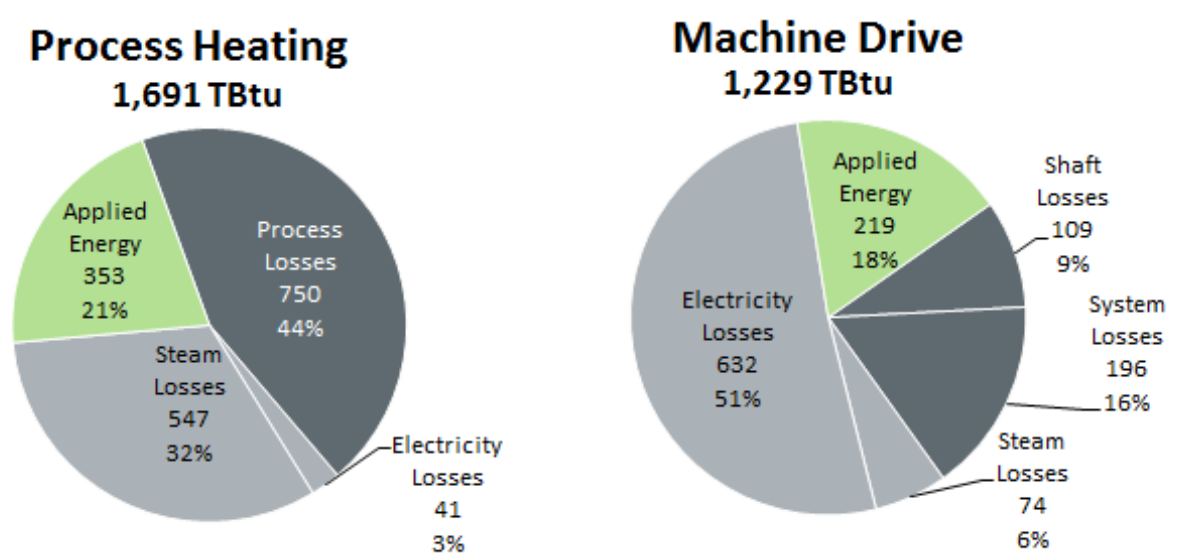

\section{Other Process End Uses 199 TBtu}
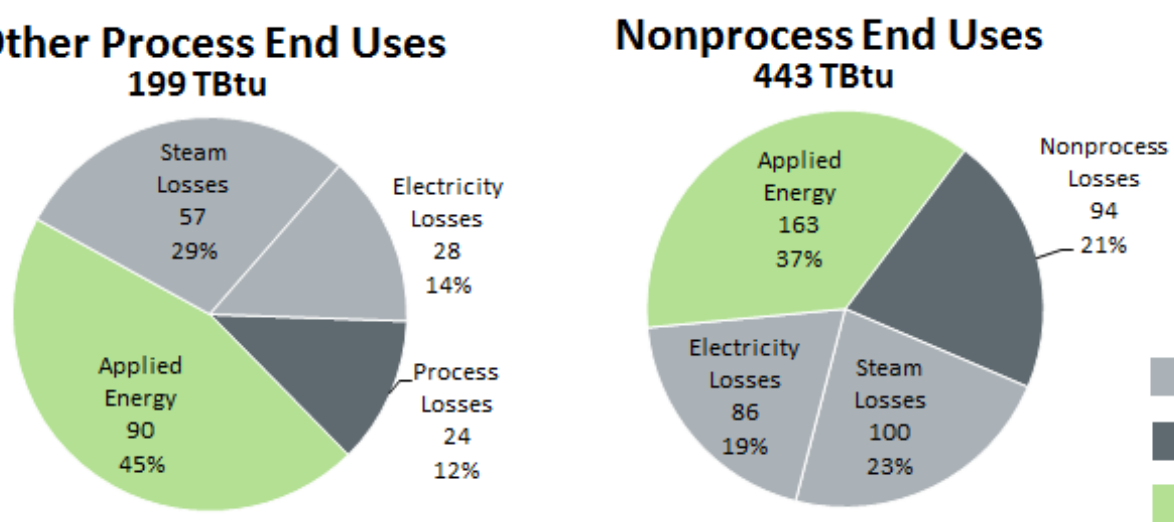

Generation Loss

End Use Loss

Applied Energy

Note: Pie chart areas are not proportional to magnitude of energy consumption

Fig. 2.3-14. Primary applied energy by direct end use in the forest products sector 


\subsubsection{Greenhouse Gas Combustion Emissions Profile for the Forest Products Sector}

The forest products sector released a total of $140 \mathrm{MMT} \mathrm{CO}_{2} \mathrm{e}$ in 2006, making it the third greatest emitter of GHG combustion emissions among U.S. manufacturing sectors. Emissions by offsite energy supply type are shown in Fig. 2.3-15. Emissions released during offsite production of electricity contribute $46 \%$ of sector emissions, while 5\% of emissions are attributed to the production of offsite steam. The onsite consumption of fuels (shown in yellow), including natural gas, byproduct fuels, coal, and other fuels accounts for $49 \%$ of total emissions. These fuels are used for both direct (e.g., process or nonprocess) and indirect (e.g., fuel for CHP units or boilers) end uses. Fuels such as natural gas and coal contributed about $49 \%$ of total emissions, while offsite electricity alone contributed nearly half (46\%) of emissions as well. Biomass and pulping/black liquor emissions reflect $\mathrm{CH}_{4}$ and $\mathrm{N}_{2} \mathrm{O}$ emissions from the combustion of these fuels, while $\mathrm{CO}_{2}$ emissions from these two fuels are excluded because the uptake of $\mathrm{CO}_{2}$ during biomass growth results in zero net emissions over time. Table D.5 shows fuel GHG combustion emission factors associated with fuel combustion, as well as electricity and steam generation.

\section{MMT CO2e}

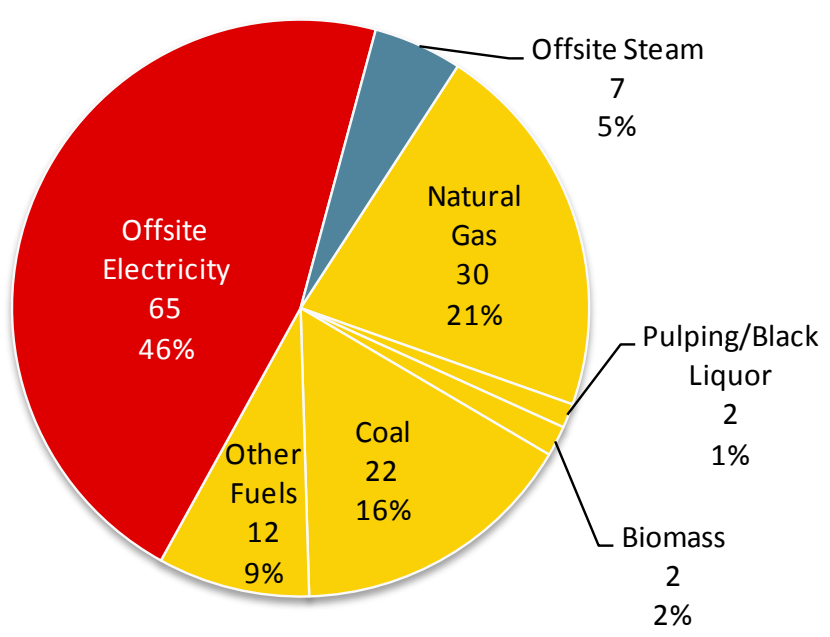

Fig. 2.3-15. Total GHG combustion emissions in the forest products sector (shown by energy supply type)

Figure 2.3-16 presents an alternate view, where total emissions are shown by energy type, but this figure assigns emissions to onsite electricity and steam production (as opposed to assigning emissions strictly to offsite supplied fuels). All emissions associated with electricity production are shown in red, including emissions released during offsite electricity generation and emissions released during onsite generation of electricity. All emissions associated with steam production are shown in blue, including emissions released during offsite steam generation and emissions released to generate steam onsite in boilers and CHP systems. The fuel emissions that are not associated with steam or electricity generation are assigned to either process or nonprocess emissions, shown in yellow. This figure shows that combined offsite and onsite electricity comprise approximately $50 \%$ of all emissions. Offsite and onsite steam make up about $37 \%$, and process and nonprocess fuel makes up the remaining $13 \%$ of emissions. 


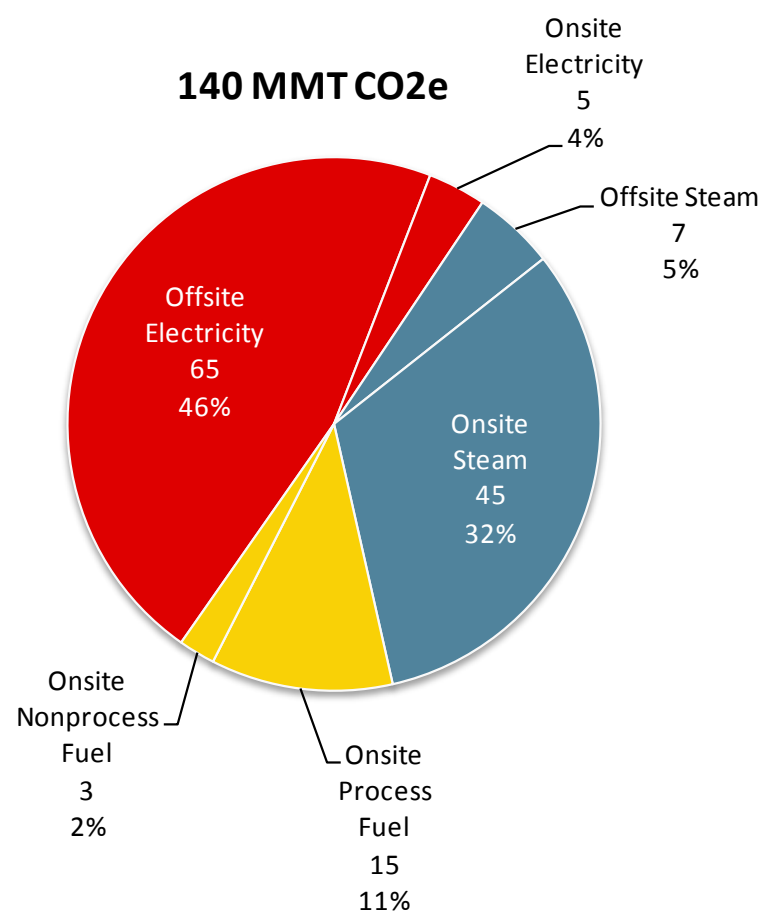

Fig. 2.3-16. Total GHG combustion emissions in the forest products sector (shown by energy end use type)

Emissions can also be associated with the direct end uses of energy, as is shown in Fig. 2.3-17. In this figure, the emissions released from offsite both offsite and onsite electricity and steam generation are distributed to direct end uses, along with emissions resulting from fuel consumed at the direct end uses. This pie chart allows for a direct comparison of the emissions resulting from individual direct process and nonprocess end uses. Process heating and cooling and machine-driven uses, both with their heavy steam system and electricity usage, contribute almost equally towards emissions at over $40 \%$ each. Facilities and HVAC nonprocess uses contribute nearly $10 \%$ of emissions, while all other process and nonprocess uses contribute just fewer than $10 \%$ of emissions.

\section{$140 \mathrm{MMTCO} 2 \mathrm{e}$}

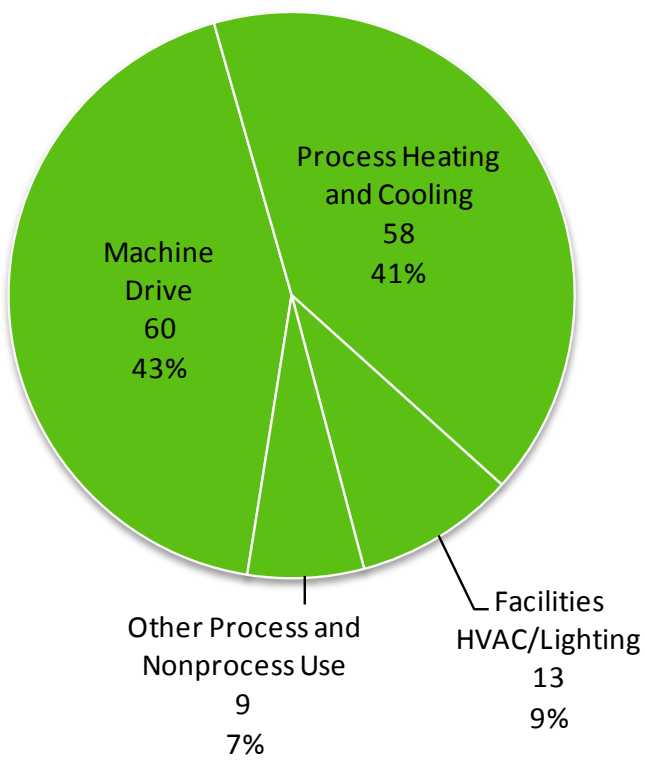

Fig. 2.3-17. Total GHG combustion emissions in the forest products sector (shown by direct energy end use) 


\subsubsection{Energy and Emissions Profile Summary Table}

The energy and emissions profiles for the forest products sector are summarized in Table 2.3-3 below. Offsite and onsite contributions to energy supply, use and loss are shown separately in this table, along with GHG combustion emissions. "Applied energy" is calculated for each direct energy use area by subtracting associated offsite and onsite energy losses. For GHG combustion emissions, emissions from the point of use, whether offsite or onsite, are depicted in the first emissions column; offsite emissions are combined with onsite emissions in the total emissions columns. The values in this table correspond to the energy and carbon footprints, which show two carbon values associated with each onsite end use: at point of use and the total based on onsite use.

Table 2.3-3. Energy use, loss, and GHG combustion emissions in the forest products sector

\begin{tabular}{|c|c|c|c|c|c|c|c|c|}
\hline & & \multirow[b]{2}{*}{ Forest products } & \multicolumn{3}{|c|}{$\begin{array}{l}\text { Energy } \\
\text { (TBtu) }\end{array}$} & \multicolumn{3}{|c|}{$\begin{array}{l}\text { GHG combustion emissions } \\
\left(\mathrm{MMT} \mathrm{CO}_{2} \mathrm{e}\right)\end{array}$} \\
\hline & & & $\begin{array}{l}\text { Energy } \\
\text { use }\end{array}$ & $\begin{array}{l}\text { Energy } \\
\text { loss }\end{array}$ & $\begin{array}{l}\text { Applied } \\
\text { energy }\end{array}$ & $\begin{array}{c}\text { At } \\
\text { point } \\
\text { of use }\end{array}$ & $\begin{array}{c}\text { Total } \\
\text { based on } \\
\text { onsite } \\
\text { use }^{*}\end{array}$ & $\begin{array}{c}\text { Total } \\
\text { based on } \\
\text { direct end } \\
\text { use** }\end{array}$ \\
\hline \multirow{4}{*}{\multicolumn{2}{|c|}{ : }} & Fuel supply (2,381 TBtu) & - & - & \multirow{4}{*}{ N/A } & - & \multirow{4}{*}{$\begin{array}{l}\text { Distributed } \\
\text { to onsite }\end{array}$} & \multirow{4}{*}{$\begin{array}{l}\text { Distributed } \\
\text { to onsite } \\
\text { direct }\end{array}$} \\
\hline & & Electricity generation/transmission & 1,069 & 731 & & 64.6 & & \\
\hline & & Steam generation/transmission & 110 & 30 & & 6.9 & & \\
\hline & & Total offsite (including fuel supply) & 3,559 & 760 & & 71.5 & & \\
\hline \multirow{12}{*}{ 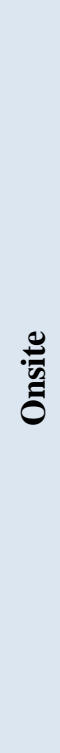 } & \multirow{5}{*}{ 范 } & Conventional boilers & 216 & 43 & \multirow{5}{*}{ N/A } & 10.7 & 13.0 & \multirow{5}{*}{$\begin{array}{c}\text { Distributed } \\
\text { to onsite } \\
\text { direct }\end{array}$} \\
\hline & & $\mathrm{CHP} /$ cogeneration & 1,884 & 461 & & 38.9 & 38.9 & \\
\hline & & Other electricity generation $^{\mathrm{a}}$ & 3 & 1 & & 0.2 & 0.2 & \\
\hline & & Steam distribution & - & 300 & & 0.0 & 0.0 & \\
\hline & & Total onsite generation & 2,103 & 805 & & 49.8 & 52.1 & \\
\hline & \multirow{7}{*}{ } & Process heating & 1,102 & 750 & 353 & 13.6 & 21.5 & 55.0 \\
\hline & & Process cooling and refrigeration & 40 & 14 & 26 & 0.1 & 1.2 & 2.5 \\
\hline & & Machine drive & 524 & 305 & 219 & 1.3 & 51.8 & 60.3 \\
\hline & & Electro-chemical & 5 & 3 & 2 & 0.0 & 0.6 & 0.6 \\
\hline & & Other process uses & 69 & 7 & 62 & 0.4 & 1.3 & 3.6 \\
\hline & & Nonprocess energy & 256 & 94 & 163 & 3.1 & 11.3 & 17.9 \\
\hline & & Total process and nonprocess & 1,997 & 1,173 & 825 & 18.5 & 87.8 & 139.9 \\
\hline
\end{tabular}

* These values are referenced as "Total" emissions in the footprints, Total emissions $=$ onsite emissions + offsite emissions (i.e., emissions associated with offsite generation are distributed to indirect and direct onsite end uses)

** These values represent direct end use carbon emissions only (i.e., emissions associated with offsite and onsite generation are distributed to direct (and final) end use)

${ }^{\text {a }}$ Onsite, renewable, non-combustion generation contributes 3 TBtu 


\subsubsection{Overview of the Petroleum Refining Manufacturing Sector}

Petroleum refining is a complex industry that generates a diverse slate of fuel products and petrochemicals, from gasoline to asphalt. Refining requires a range of processing steps, including distillation, cracking, reforming, and treating. Most of these processes are highly reliant on process heating and steam energy.

Petroleum refineries are an essential part of the U.S. economy. Crude oil and refined petroleum products have become some of the most highly scrutinized trading commodities in the world. The energy profile of this manufacturing sector is unique compared to other manufacturing sectors in that feedstock and many of the manufactured products are energy commodities that are often measured in terms of energy content, separate from the energy content of purchased fuels and electricity. Most other manufacturing sectors are highly dependent on refined petroleum products.

\subsubsection{Energy Use Profile for the Petroleum Refining Sector}

The petroleum refining sector is the largest consumer of fuel in U.S. manufacturing, when considering the inclusion of feedstocks or without feedstocks. Close to $90 \%$ of onsite fuel use in refining is applied toward process heating, $65 \%$ directly and an additional $23 \%$ for the generation of steam used in process heating. ${ }^{12}$ The petroleum refining sector has the largest process heating energy demand of all manufacturing sectors, and correspondingly is also the largest generator of onsite GHG combustion emissions.

A snapshot of how the petroleum refining sector ranks in terms of energy use and losses within manufacturing is shown in Table 2.4-1. Energy losses are shown in red font. All values are based on the most currently available complete set of manufacturing energy use statistics, representing annual energy use and loss values for calendar year 2006. The petroleum refining sector ranks first in onsite energy use. Since petroleum refineries use proportionally less electricity than fuel compared to other manufacturing sectors the sector falls to third in rank for total primary energy use (accounting for offsite electricity generation and transmission losses). In addition, a large portion of electricity is produced onsite (34\% of process and nonprocess electricity demand is produced onsite, compared to $15 \%$ for all of manufacturing). The sector ranks first in process applied energy due to the high process heating fuel demand.

Table 2.4-1. Snapshot of the petroleum refining sector: Energy use and rank within U.S. manufacturing

\begin{tabular}{|l|c|c|}
\hline \multicolumn{1}{|c|}{ Category } & Rank & Energy (TBtu) \\
\hline Total primary energy & 3 & 3,546 \\
Offsite losses & 8 & 315 \\
Onsite energy & 1 & 3,231 \\
Onsite losses & 3 & 1,052 \\
$\quad$ Steam generation and distribution & 3 & 350 \\
Electricity generation & 3 & 40 \\
Process energy & 3 & 641 \\
$\quad$ Nonprocess energy & 11 & 20 \\
Feedstock energy & 1 & 3,399 \\
Total primary and feedstock energy* & 2 & 6,944 \\
\hline GHG combustion emissions & 1 & MMT CO2e \\
Total & 244 \\
Onsite & 1 & 210 \\
\hline *When total primary energy and feedstock energy are summed, the energy value of byproduct fuels derived from \\
\hline
\end{tabular}

\footnotetext{
${ }^{12}$ The end use of steam is not provided in the EIA MECS source data. For the petroleum refining sector, it is assumed that $66 \%$ of steam production is used in for process heating, $16 \%$ for machine driven processes, $2 \%$ for process cooling and refrigeration, $10 \%$ for other process uses, $4 \%$ for facility HVAC, and $2 \%$ other nonprocess applications. More detail is available in Appendix D.
} 
Although it is outside the scope of the footprint analysis, it is worth noting that a significant amount of energy is consumed as non-fuel feedstock in the production of refined petroleum products. As reported in the MECS data, and shown in Fig. 2.4-1, the total feedstock energy consumed in this sector is 3,399 TBtu, which equates to about half of all reported feedstock energy consumed in all of U.S. manufacturing. When feedstock and fuel energy are combined, total primary fuel and feedstock energy used in petroleum refining is about 6.9 quads. This is more than any other manufacturing sector and approximately $25 \%$ of all fuel and feedstock energy use in manufacturing.

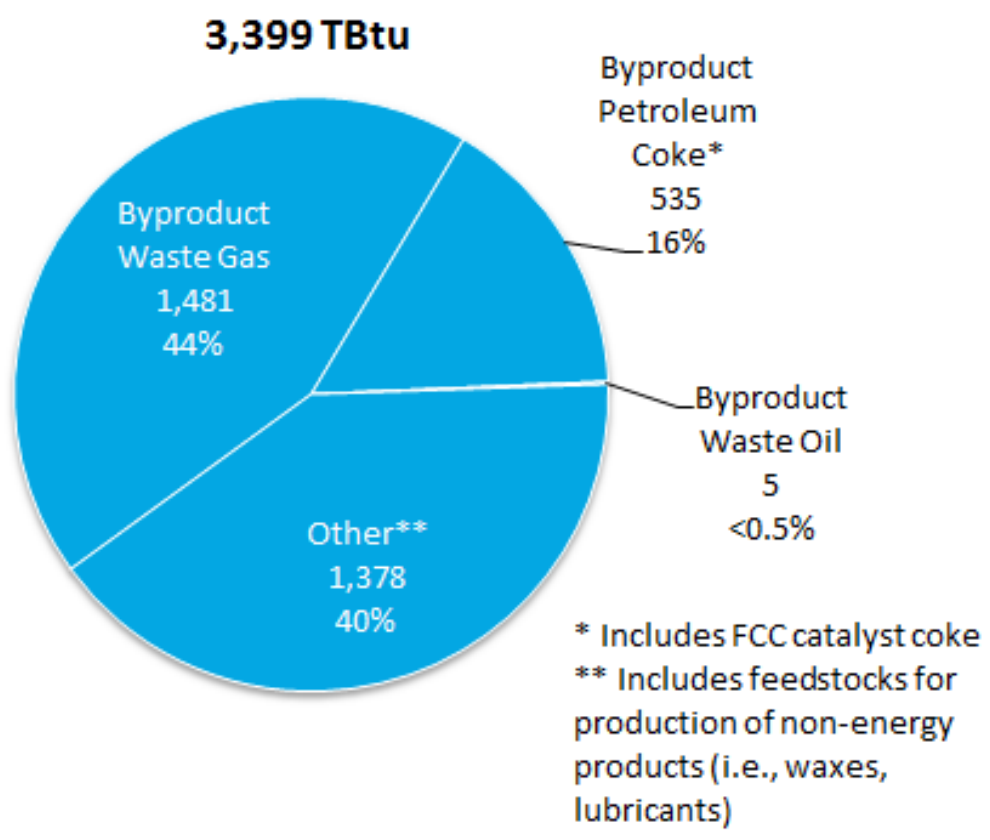

Fig. 2.4-1. Feedstock energy use in the petroleum refining sector

There is limited clarity regarding the composition of "other fuels" used as feedstock energy in this sector. In the MECS source data, feedstock energy for petroleum refining falls into the category of "Other Fuel" and is defined as follows: ${ }^{13}$

'Other' includes energy that respondents indicated was used as feedstock/raw material inputs.

For the petroleum refining sector only (NAICS 324110), the feedstocks and raw material inputs for the production of nonenergy products (i.e., asphalt, waxes, lubricants, and solvents) and feedstock consumption at adjoining petrochemical plants are included in the 'Other' column, regardless of type of energy. Those inputs and feedstocks that were converted to other energy products (e.g., crude oil converted to residual and distillate fuel oils) are excluded.

The total feedstock energy consumed in petroleum refining is significantly greater than 3.4 quads when accounting for feedstock energy that is converted to energy products, such as the conversion of crude oil into gasoline. Many of these energy products are subsequently used as purchased fuels.

The focus of the energy use and loss analysis that follows excludes all feedstock energy use.

${ }^{13}$ This definition can be found on the following website, http://www.eia.doe.gov/emeu/mecs/mecs2006/2006tables.html, in Table 2.2, under the definition of Other Fuel. 


\subsubsection{Energy and carbon footprint}

The Manufacturing Energy and Carbon Footprint for the petroleum refining sector is shown in Fig. 2.4-2 and Fig. 2.4-3. The footprints serve as the basis for characterizing the offsite and onsite flow of energy, as well as carbon emissions, from generation through end use in the sector.

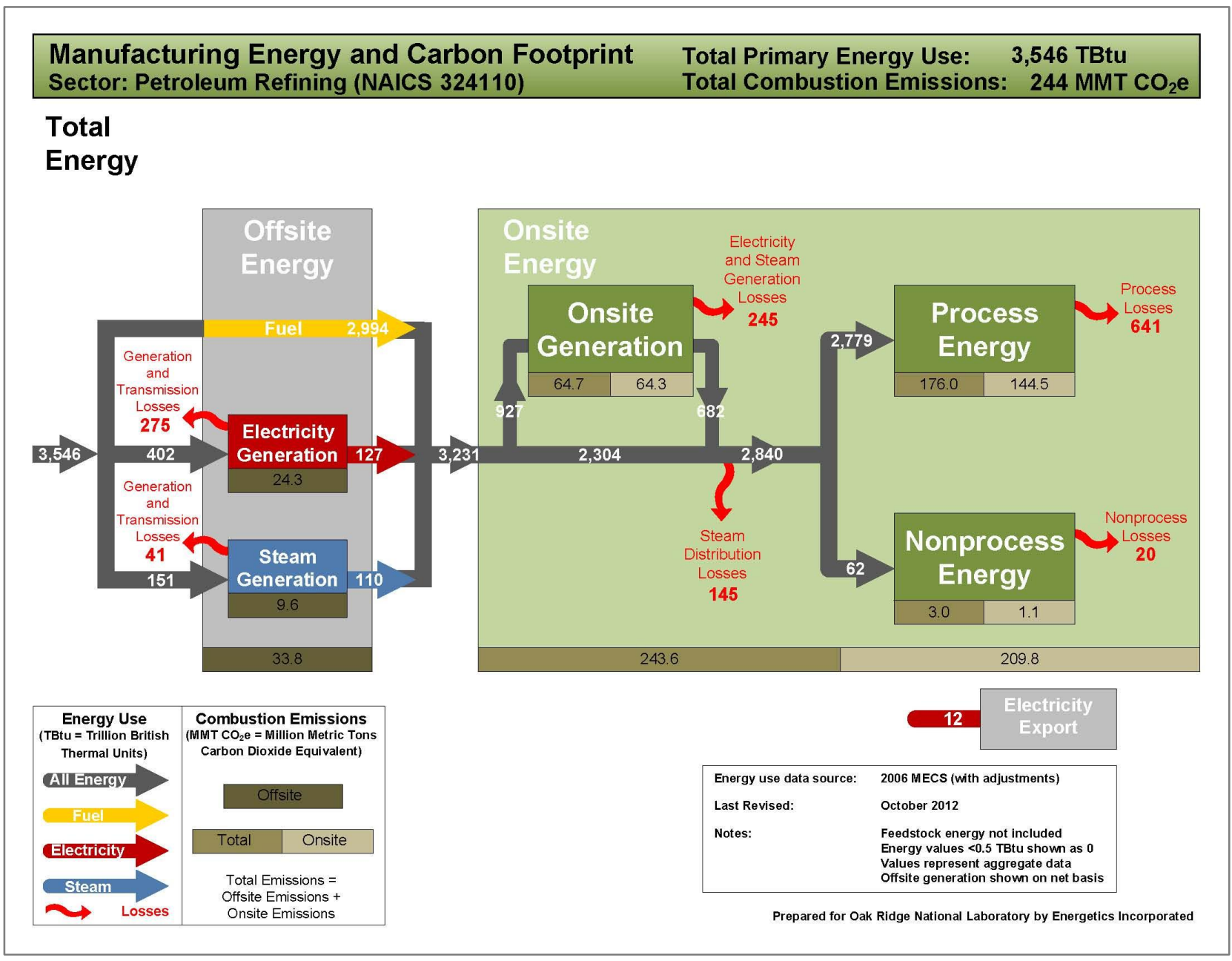

Fig. 2.4-2. Total energy and carbon footprint for the petroleum refining sector 


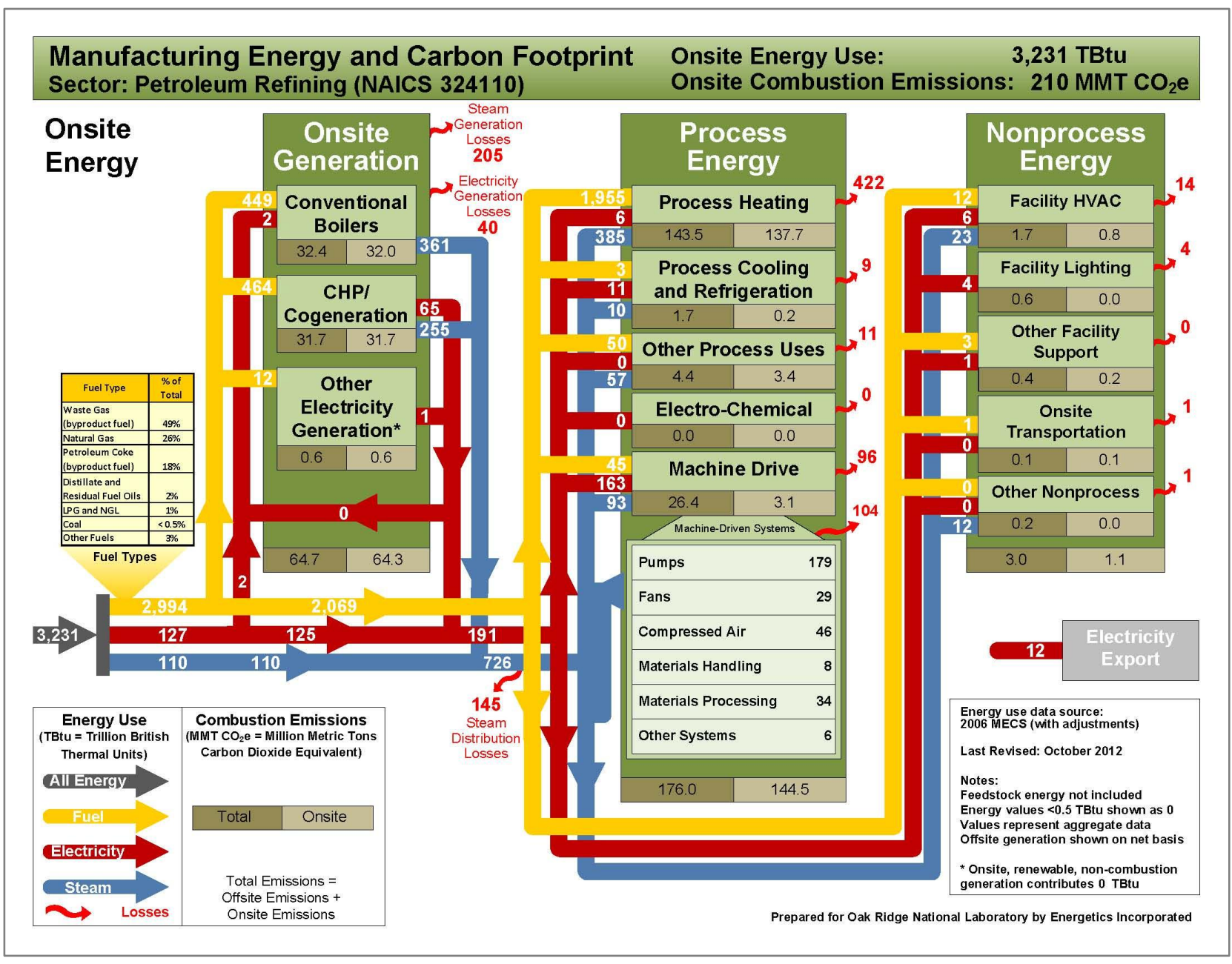

Fig. 2.4-3. Onsite energy and carbon footprint for the petroleum refining sector

\subsubsection{Primary energy}

Primary energy includes fuels, electricity, and steam from both onsite and offsite sources, including generation and distribution losses. In essence, primary energy provides the full picture of total fuel energy use from all sources from generation to end use. In 2006, the petroleum refining sector used 3,546 TBtu of primary energy.

There are three main primary offsite energy generation areas: steam generation, electricity generation, and direct fuel use. In Fig. 2.4-4, it can be seen that the majority of primary energy use, 58\%, is attributed to direct fuel use. Steam generation is the next largest contributor at $28 \%$, with the remaining $14 \%$ comprising electricity generation. Consistent with the footprints, blue represents steam energy, red represents electric energy, and yellow represents fuel energy. 


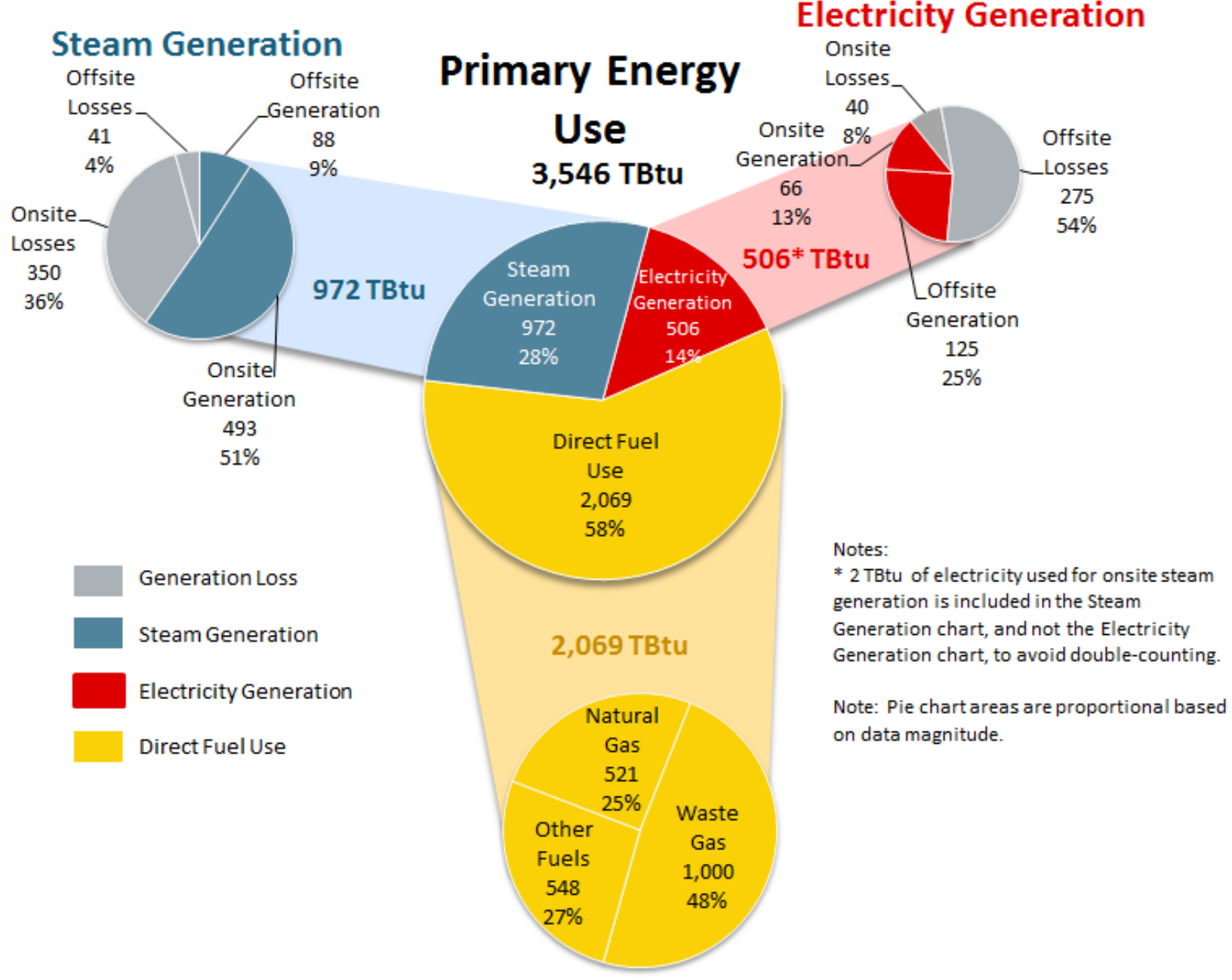

\section{Direct Fuel Use}

Fig. 2.4-4. Primary energy by energy type in the petroleum refining sector

Approximately $20 \%$ of the primary energy used in petroleum refining manufacturing is lost during utility production (encompassing generation, transmission, and distribution), with $9 \%$ associated with electricity production and the remaining $11 \%$ with steam production. The percentage of utility production loss is lower for petroleum refining than other sectors given that the majority of primary energy is direct fuel use where there is no significant generation losses accounted for. In contrast, over half of the primary energy for electricity generation is lost to generation and transmission losses; this is attributed mostly to offsite losses where the efficiency of electricity supplied from the grid is estimated to be only $31.6 \%$.

The primary energy use values in Fig. 2.4-4 are not directly apparent on the energy and carbon footprints as the footprint is presented in terms of offsite and onsite energy end use, not primary energy end use. The primary energy values in Fig. 2.4-4 are obtained from the footprint model and can be derived from the footprints by summing offsite and onsite generation and loss values. The primary direct fuel use, 2,069 TBtu, is the amount of fuel directed to process and nonprocess end uses after the subtraction of fuel for onsite generation. Almost half of this primary fuel use is waste gas, or what is referred to in refining as refinery fuel gas, consisting primarily of hydrogen, methane, and other light-end gases. 


\subsubsection{Onsite energy}

About 3.2 quads, or $91 \%$ of primary energy, were consumed onsite by the petroleum refining sector in 2006. This onsite energy enters the plant boundary in the form of three offsite energy types: fuel, steam, and electricity. As shown in Fig. 2.4-5 this energy is primarily fuel, with only a small amount of offsite energy supply in the form of steam and electricity (3\% and $4 \%$ respectively). Byproduct fuels such as refinery gas and petroleum coke are derived from feedstock in the production process. These byproduct fuels are relied upon heavily for fuel energy in this sector and contribute over $60 \%$ of the fuel energy supply. Natural gas makes up most of the remainder of offsite energy supply.

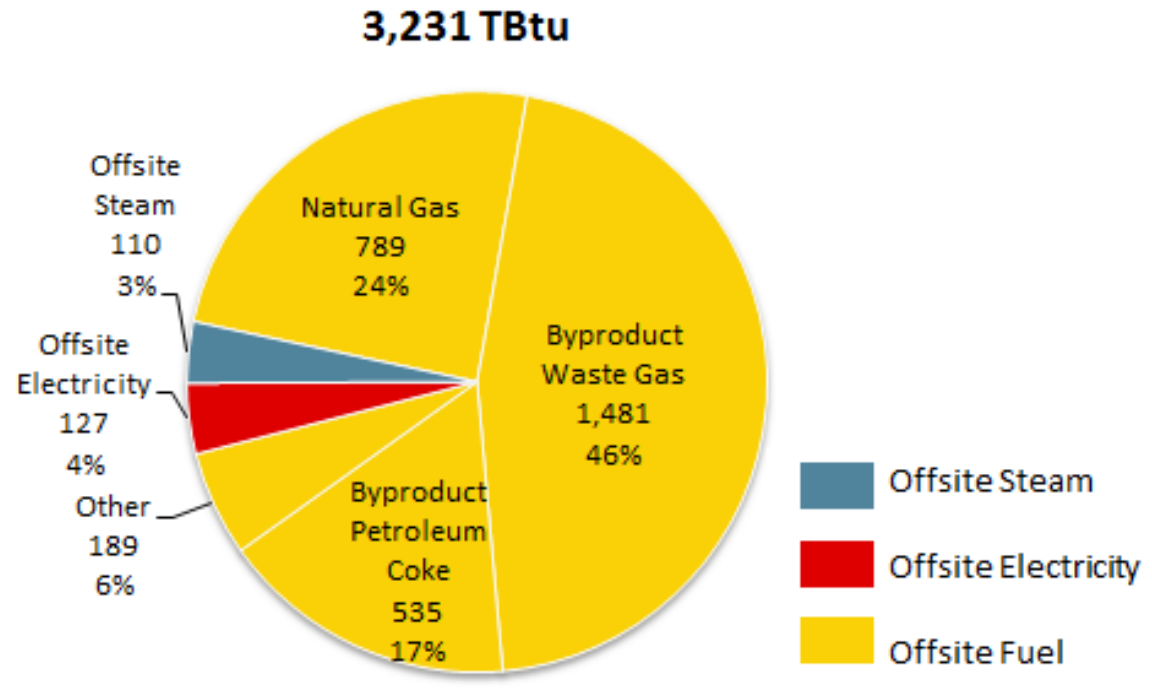

Fig. 2.4-5. Offsite energy supply in the petroleum refining sector

\subsubsection{Fuel energy}

The petroleum refining sector consumed 2,994 TBtu of fuel energy in 2006. Direct fuel use accounts for $58 \%$ of primary energy use, and indirect fuel use accounts for an additional $26 \%$ of primary energy use. Close to $93 \%$ of offsite energy supply in the petroleum refining sector is in the form of purchased or byproduct fuels, which does not include feedstock energy. Approximately $65 \%$ of petroleum refining fuel use (excluding feedstock energy) is consumed in process heating end uses, primarily for process unit feed preheaters and distillation reboilers. Furthermore, an additional $30 \%$ of fuel use is consumed by boilers and CHP units to generate steam that is used predominantly for process heating uses.

A large portion of the process heating fuel demand is supplied by byproduct fuels derived from feedstock in the production process. As shown in Fig. 2.4-5, 63\% of offsite energy supply to petroleum refineries is in the form of byproduct fuels. Waste gas, also called refinery fuel gas, is the most commonly used byproduct fuel and constitutes almost half (46\%) of offsite energy supply. Refinery fuel gas is an essential byproduct fuel in petroleum refineries; the hydrogen content in the fuel improves the enthalpy of combustion which allows for greater transfer of heat into the process, as compared to purchased natural gas. A second byproduct fuel category, petroleum coke, contributes $18 \%$ of onsite fuel use, or $17 \%$ of offsite energy supply. Review of the definition provided by EIA for "petroleum coke"14 confirms that the byproduct petroleum coke is primarily consumed in the fluid catalytic cracking (FCC) process unit, where coke deposited on the catalyst is combusted, or burned off, during catalyst regeneration. The combustion of this coke is internal to the process operation and provides the process heat energy necessary to raise the FCC

\footnotetext{
${ }^{14}$ EIA definition of "coke (petroleum)," http://www.eia.gov/glossary/index.cfm?id=C: A residue high in carbon content and low in hydrogen that is the final product of thermal decomposition in the condensation process in cracking. This product is reported as marketable coke or catalyst coke. The conversion is 5 barrels (of 42 U.S. gallons each) per short ton. Coke from petroleum has a heating value of 6.024 million Btu per barrel.
} 
reactor to reaction temperature. Likely there are other, less significant, forms of byproduct fuel used in petroleum refining that are not categorized in the MECS byproduct fuel data.

Natural gas is the second largest fuel type used in petroleum refining. Natural gas is purchased from outside suppliers to supplement the available refinery fuel gas supply. Natural gas contributes $26 \%$ of offsite energy supply, or $24 \%$ of all imported energy. Most process heaters, boilers, and turbines are fueled by a combination of fuel gas and natural gas, often times the two are blended and supplied from a central fuel gas drum. Other fuel sources not detailed in Fig. 2.4-5 include fuel oils, LPG, coal, and feedstocks for the production on nonenergy products (e.g., asphalt, wax) and petrochemical products.

\subsubsection{Electrical energy}

In 2006, the petroleum refining sector used 191 TBtu of electricity for direct ${ }^{15}$ process uses. By comparison, the chemicals sector used $676 \mathrm{TBtu}$ for direct process uses. Electricity accounts for $14 \%$ of primary energy use (see Fig. 2.4-4), but only $6 \%$ of direct end use energy (see Fig. 2.4-9). This difference can be explained by the relative inefficiency of offsite electricity generation, transmission, and distribution (T\&D) as compared to direct fuel use.

Figure 2.4-6 shows that $65 \%$ of sector electricity used for process and nonprocess end uses is produced offsite, while the remaining $34 \%$ of electricity is produced onsite. This proportion of onsite generation is higher than most other sectors; for example, in the iron and steel sector, only $7 \%$ of electricity is from onsite generation. Onsite electricity is primarily generated in CHP systems. In the petroleum refining sector, CHP units are $69 \%$ efficient, over twice as efficient as the efficiency of electricity supplied from the grid (31.6\%). The majority of electricity use (85\%) is to run machine-driven equipment. Process cooling and facility energy use (including HVAC and lighting) each consume 6\% of generated electricity.

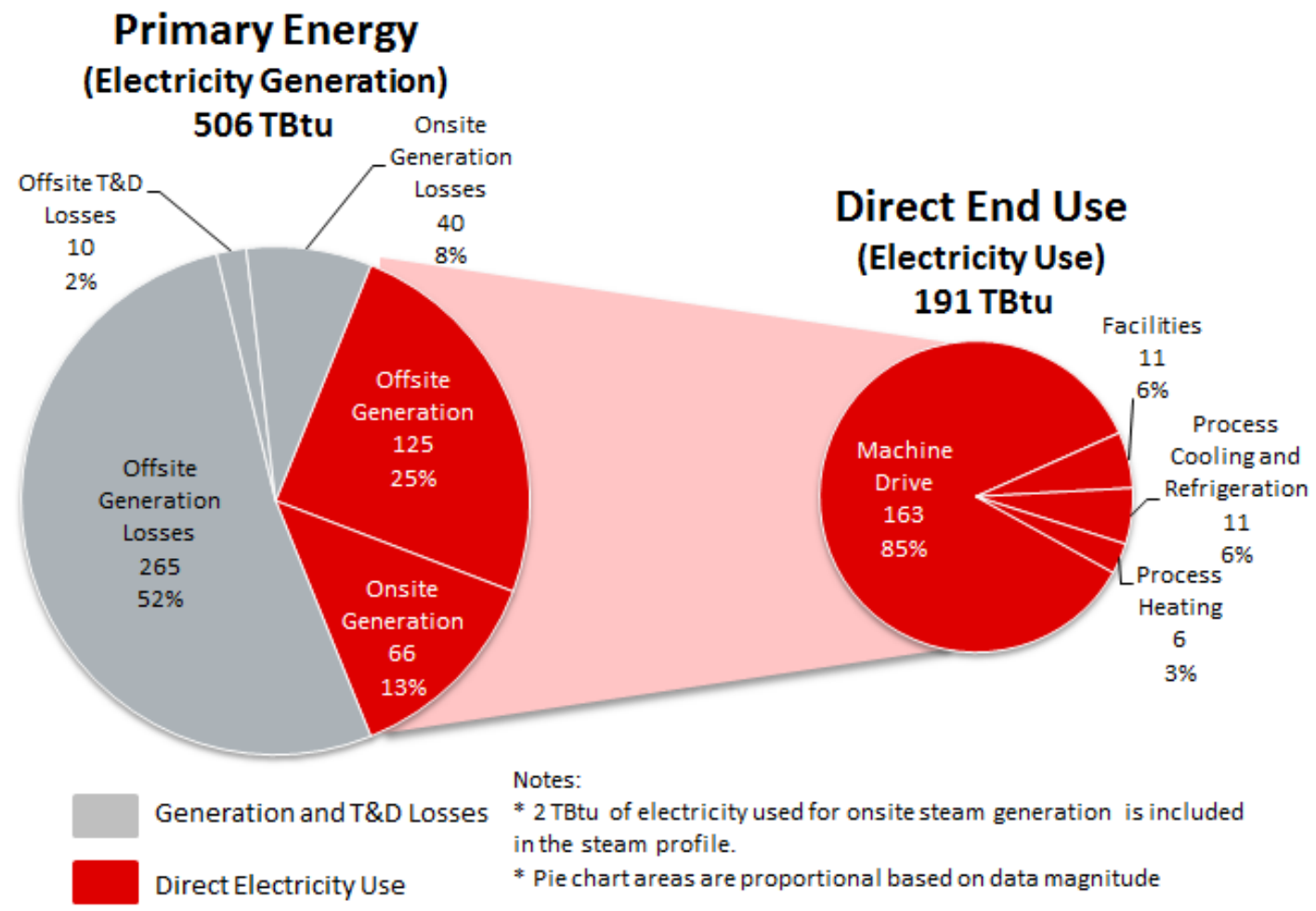

Fig. 2.4-6. Electricity generation and direct end use in the petroleum refining sector

\footnotetext{
${ }^{15}$ Offsite electricity generation (125 TBtu) shown in this chart is lower than the value of offsite energy entering the plant boundary shown in the energy and carbon footprint for this sector $(127 \mathrm{TBtu})$. This difference is due to the small portion of offsite electricity ( $2 \mathrm{TBtu})$ that is used by conventional boilers to generate steam.
} 


\subsubsection{Steam energy}

The petroleum refining sector uses 581 TBtu of steam energy, half as much as the forest products and chemicals manufacturing sectors and approximately five times as much as the iron and steel manufacturing sector. Fig. 2.4-7 shows the losses that occur in steam production (left pie chart) and the end uses of steam (right pie chart). Approximately $85 \%$ of steam is produced onsite in either CHP units or conventional steam boilers, while $15 \%$ of steam demand from offsite sources including transfers in from other facilities. Conventional boilers contribute a relatively large portion of onsite steam, nearly $60 \%$, as compared to steam from CHP generation.

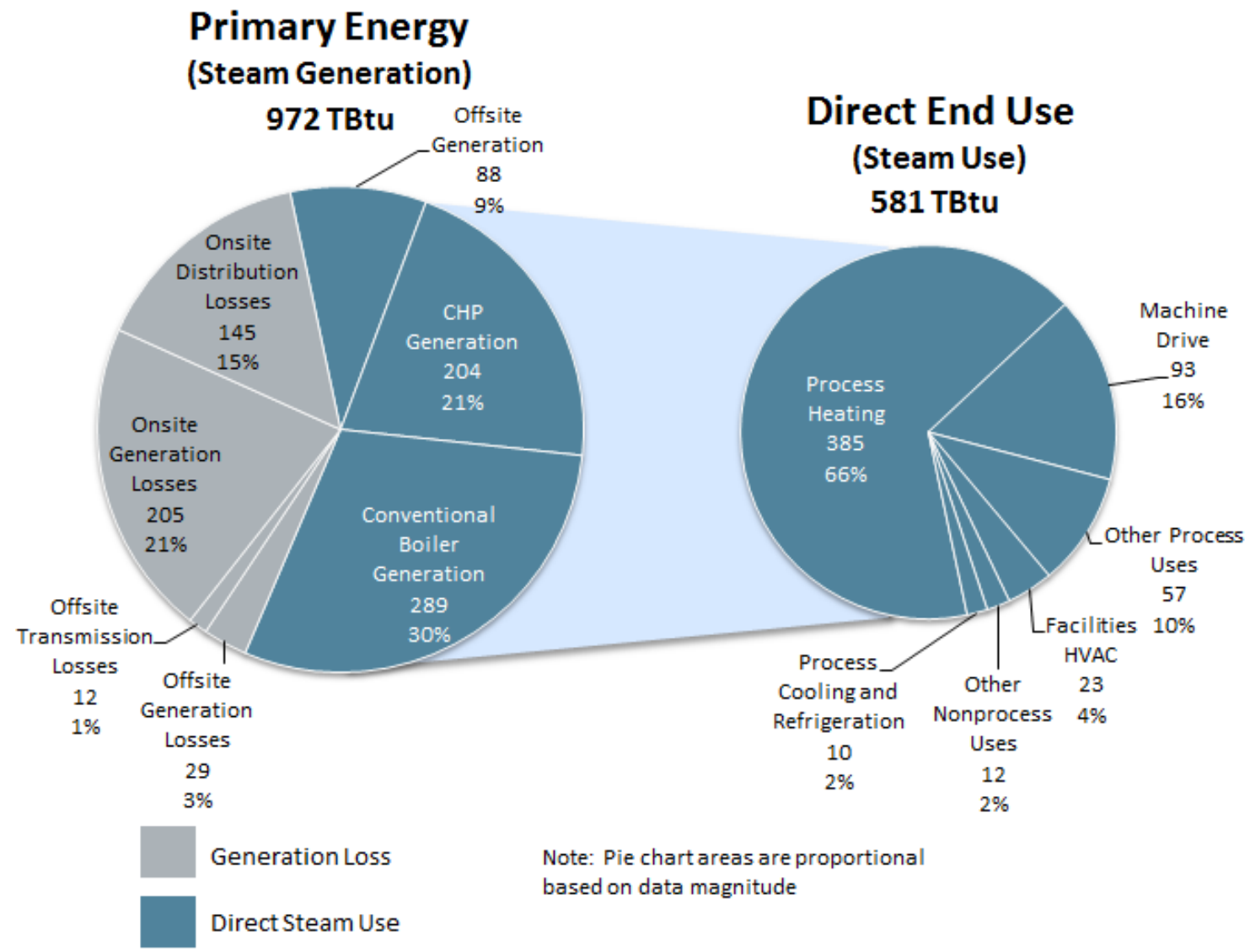

Fig. 2.4-7. Steam generation and direct end use in the petroleum refining sector

\subsubsection{Combined heat and power energy}

The petroleum refining sector meets a large amount of steam and electricity demand through onsite generation. CHP units contribute a large portion of this onsite generation, $41 \%$ of onsite steam and $98 \%$ of onsite electricity. One of the key reasons CHP generation is readily applied in petroleum refining is the availability of large quantities of byproduct waste gas. As with process heating and conventional boiler fuel use, the byproduct gas is blended with natural gas to fuel CHP systems. As shown in Fig. 2.4-8, 65\% of CHP fuel use is in the form of byproduct gas. 


\section{CHP Indirect Fuel Use}

\section{CHP Energy Output}

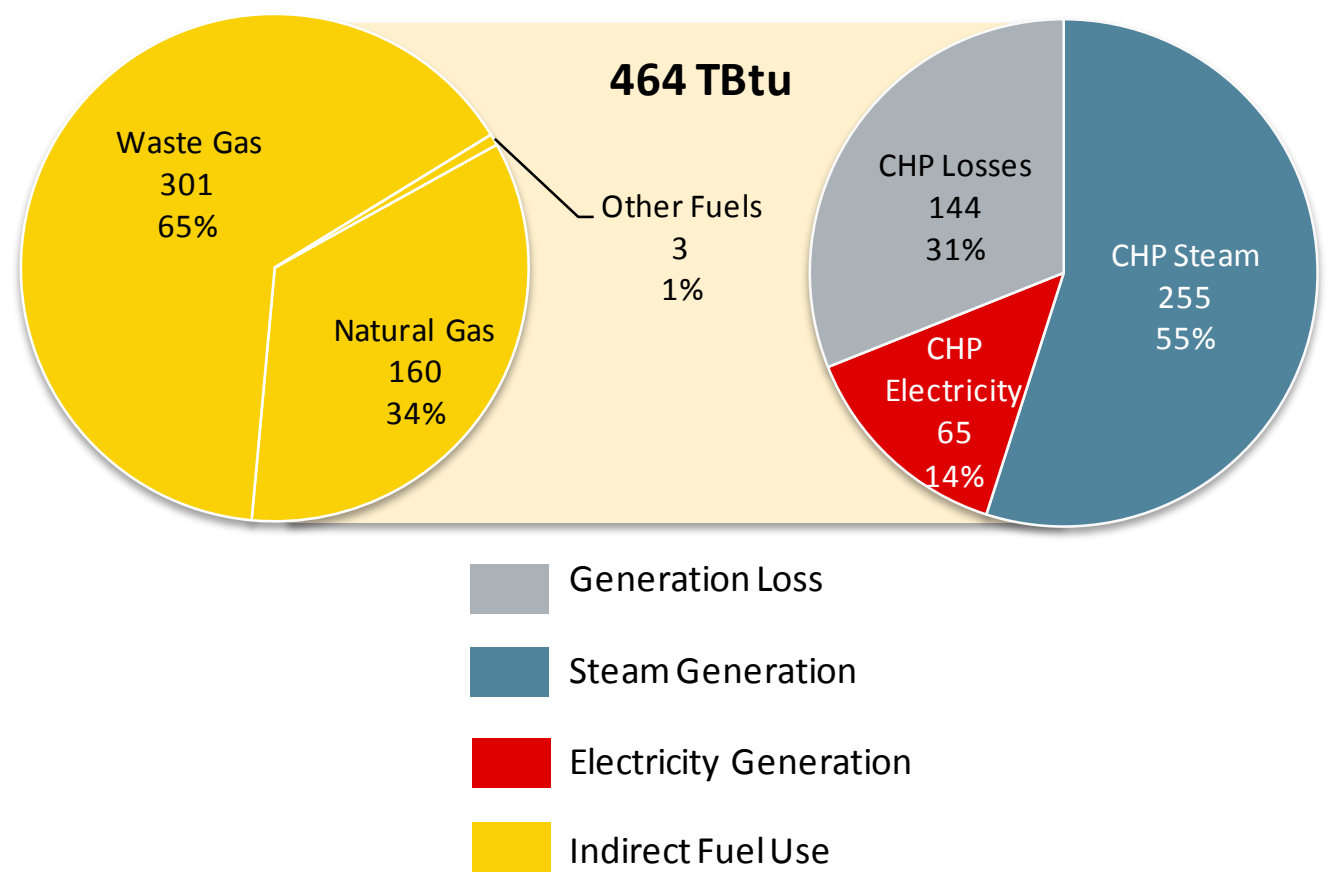

Fig. 2.4-8. CHP fuel consumption and energy output in the petroleum refining sector

\subsubsection{Direct end use energy}

Fig. 2.4-9 shows the breakdown of primary energy by type at its direct end use. Direct fuel use is the most significant share of primary energy, at $58 \%$, followed by steam at $16 \%$ and electricity at $6 \%$. Generation losses account for the remaining $20 \%$ of primary energy use.

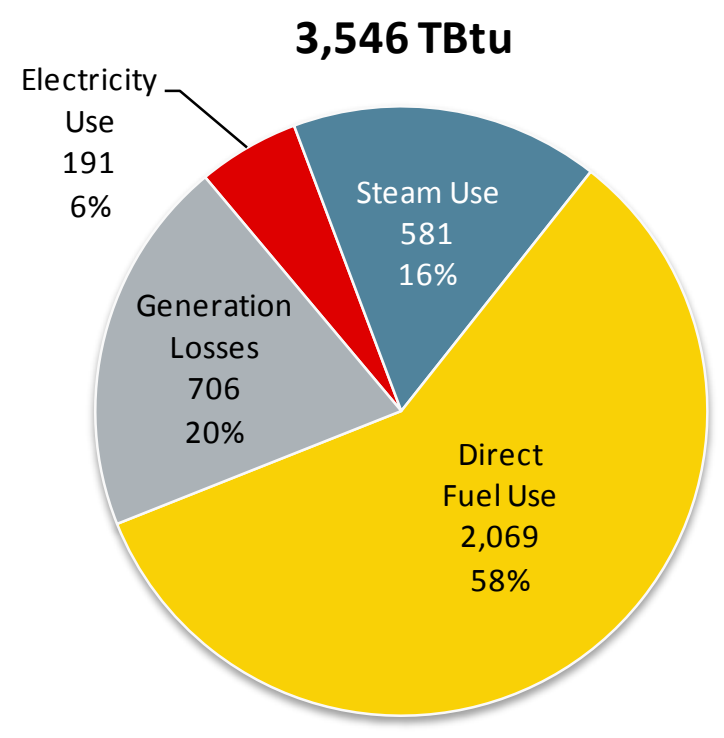

Fig. 2.4-9. Primary energy by type at direct end use in the petroleum refining sector 
A more detailed view of primary energy use is detailed in Fig. 2.4-10, where it can be seen that the great majority of primary energy is used for process end uses (78\%, 2,779 TBtu), largely process heating. Energy lost during the generation of electricity and steam is also significant $(20 \%, 706 \mathrm{TBtu})$.Nonprocess end uses account for only $2 \%$ of primary direct end use energy.

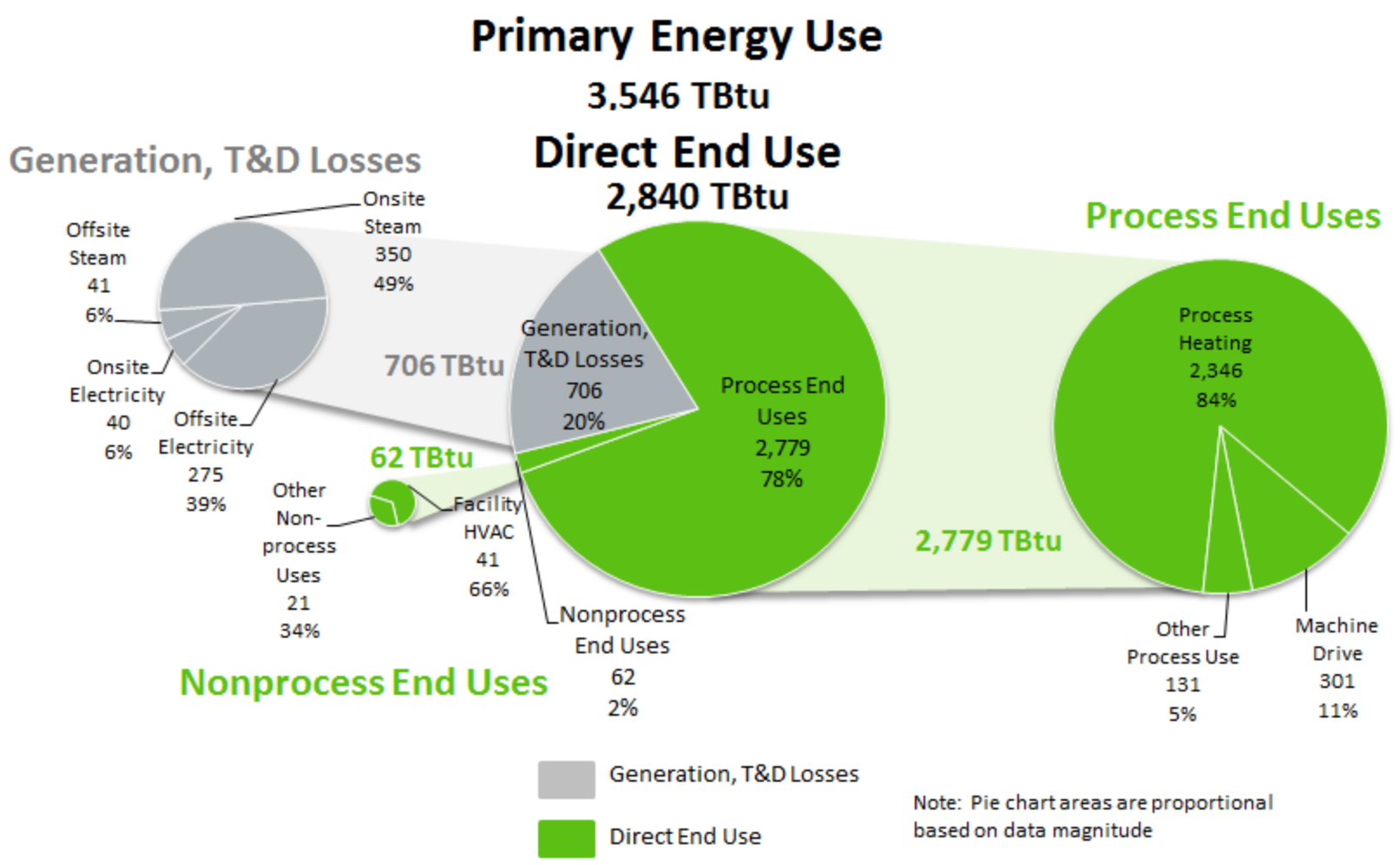

Fig. 2.4-10. Primary energy by direct end use in the petroleum refining sector

Compared to other U.S. manufacturing sectors, petroleum refining sector consumes the most energy for process heating systems, and is the third-greatest consumer of energy for machine-driven systems. Process heating systems consume 2,346 TBtu out of the 2,779 TBtu total (84\%) delivered to process end uses. These process heating systems include steam and fired systems such as furnaces and reboilers. Machinedriven systems are the next largest use of process energy in the sector at 301 TBtu (11\%). As shown in Fig. 2.4-7, the majority of steam is used for process heating systems, while electricity is the main source of energy for machine-driven systems.

Onsite steam losses are $350 \mathrm{TBtu}$, which equals nearly $50 \%$ of sector generation losses. Offsite electricity losses are the next-largest category of generation losses, equal to $275 \mathrm{TBtu}$ (39\%). Facility HVAC is the largest user of nonprocess energy. Other nonprocess energy uses include facility lighting, onsite transportation, and other facility support. 


\subsubsection{Applied end use energy}

In addition to the energy generation losses identified above, direct end use losses have also been calculated in the energy footprint model. When both generation and end use losses are accounted for, the energy that remains is the applied energy. Applied energy can be illustrated by re-examining Fig. 2.4-4, which shows primary energy by energy type for the petroleum refining sector. Each of the energy types (i.e., fuel, electricity, or steam) shown in this figure have associated onsite and offsite generation losses (shown with onsite and offsite losses combined in light gray) that are incurred during energy generation and transmission and distribution). While the majority of electricity generation losses take place offsite (as shown in Fig. 2.4-6), the majority of steam generation losses are onsite (as shown in Fig. 2.4-7), and direct fuel use is assumed to have no associated generation losses. After taking into account these generation losses, a further portion of the remaining energy is lost at direct end uses, due to process and nonprocess system and equipment inefficiencies, shown in dark gray. The remaining energy is applied to end uses, shown in light green as "Applied Energy" in Fig. 2.4-11.

\section{Primary Energy Use}

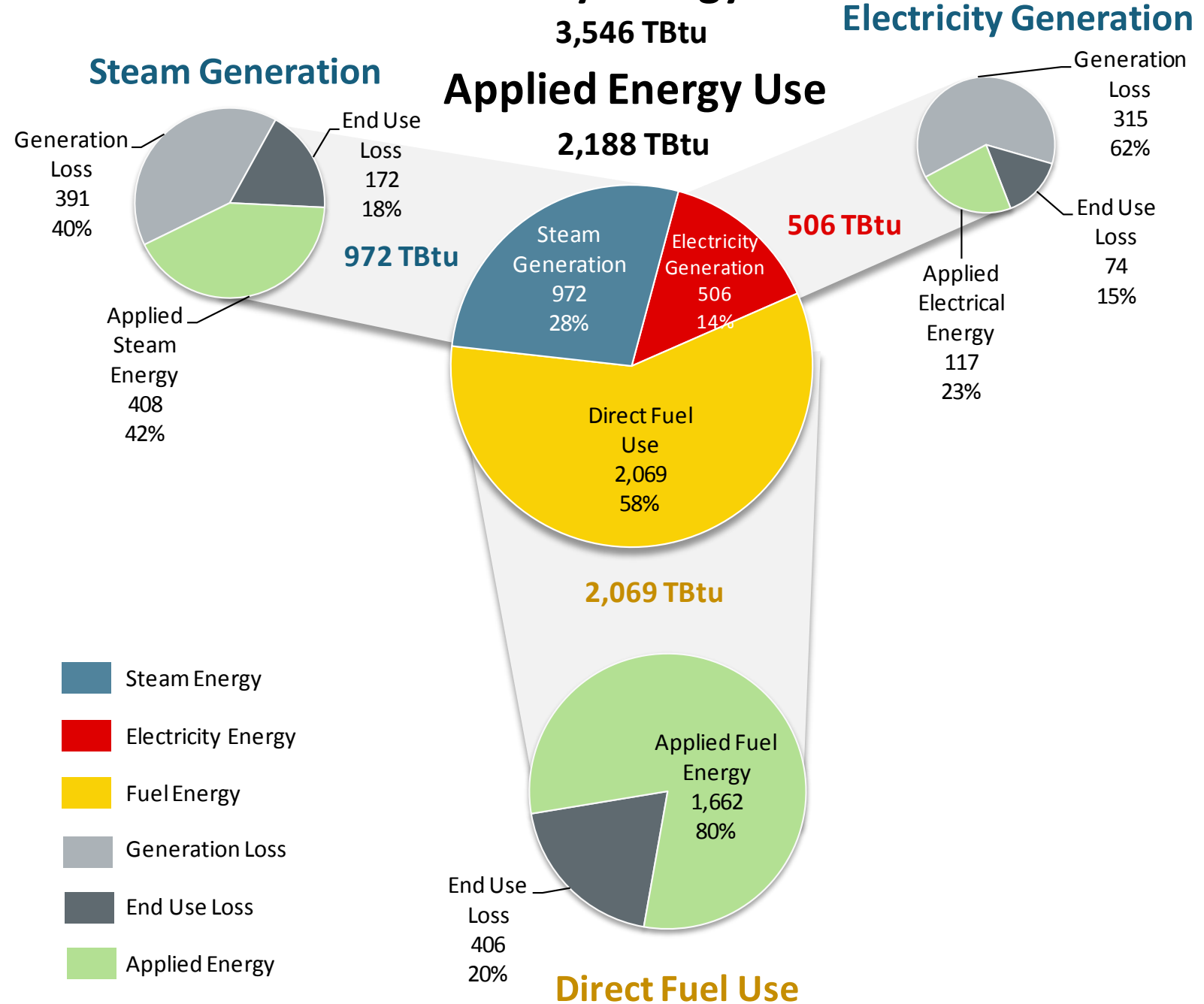

Fig. 2.4-11. Primary energy and applied energy by energy type in the petroleum refining sector

Fig. 2.4-12 shows the breakdown of primary energy by energy loss and applied energy. In this sector, 61\% of primary energy input is applied to process and nonprocess end uses, significantly higher than the manufacturing average of $34 \%$ and more than any other individual sector. Applied end use energy is larger in this sector than other manufacturing sectors due to the high demand for fuel use and lower associated electricity generation losses. 


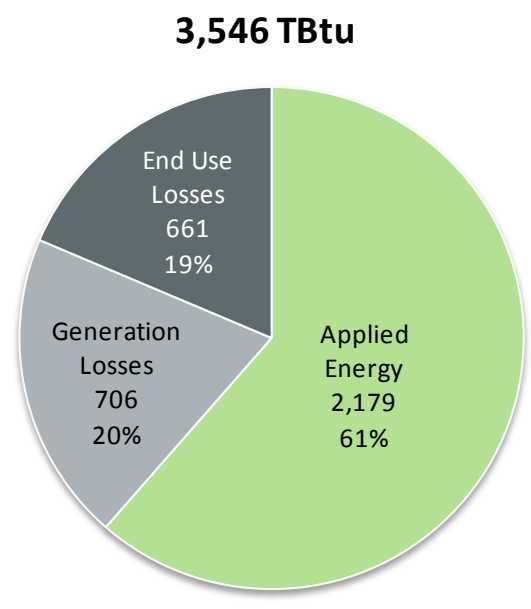

Fig. 2.4-12. Primary energy by loss and applied energy in the petroleum refining sector

Applied energy can also be calculated for specific end uses, as shown in Fig. 2.4-13. End use losses are labeled as process or nonprocess losses; in the case of machine drive end use, process losses are further defined as machine drive, or machine driven system losses. For process heating, $74 \%$ of primary energy is applied to the process (detail of the methodology to estimate process heating losses are shown in Appendix F). Process heating applied energy is relatively high compared to other end uses, because the majority of process heating energy is consumed in the form of steam and fuel. In machine-driven systems, only $16 \%$ of primary energy is applied to direct end uses, primarily because of the inefficiency in electricity generation.
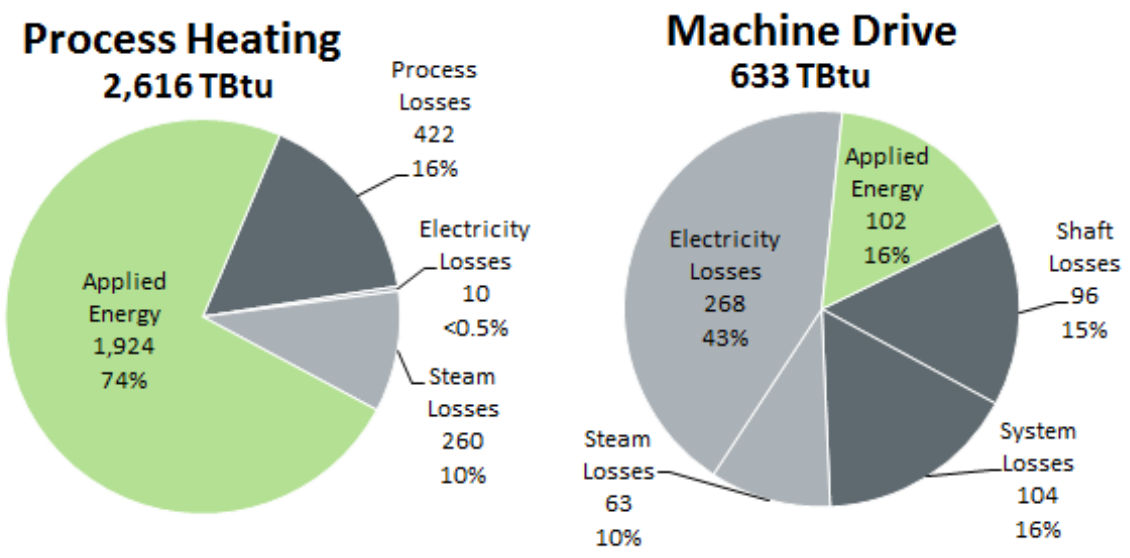

\section{Other Process End Uses 195 TBtu}

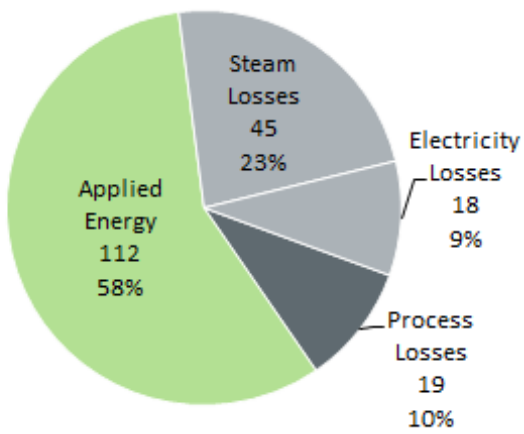

Nonprocess End Uses 104 TBtu

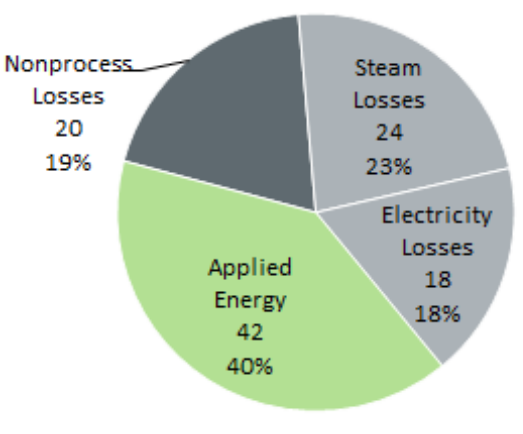

Generation Loss

End Use Loss

Applied Energy

Note: Pie chart areas are not proportional to magnitude of energy consumption

Fig. 2.4-13. Primary applied energy by direct end use in the petroleum refining sector 


\subsubsection{Greenhouse Gas Combustion Emissions Profile for the Petroleum Refining Sector}

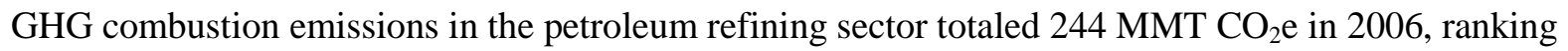
second among manufacturing sectors (fewer emissions than only the chemicals sector). Greenhouse gas emissions by offsite energy supply type are shown in Fig. 2.4-14. This sector releases more onsite emissions than any other manufacturing sector $\left(210 \mathrm{MMT} \mathrm{CO}_{2} \mathrm{e}\right)$, which is reflected in the abundance of yellow colored fuel use in Fig. 2.4-14. Emissions released during offsite electricity and steam generation contribute a relatively small portion of overall sector emissions, with offsite electricity contributing $10 \%$ of emissions and offsite steam generation contributing $4 \%$ of emissions. The onsite consumption of fuels, including natural gas, byproduct waste gases, byproduct petroleum coke, coal, and other fuels accounts for $86 \%$ of total emissions. These fuels are used for both direct (e.g., process or nonprocess) and indirect (e.g., fuel for CHP units or boilers) end uses. Table D.5 shows fuel GHG combustion emission factors associated with fuel combustion, as well as electricity and steam generation

\section{MMT CO2e}

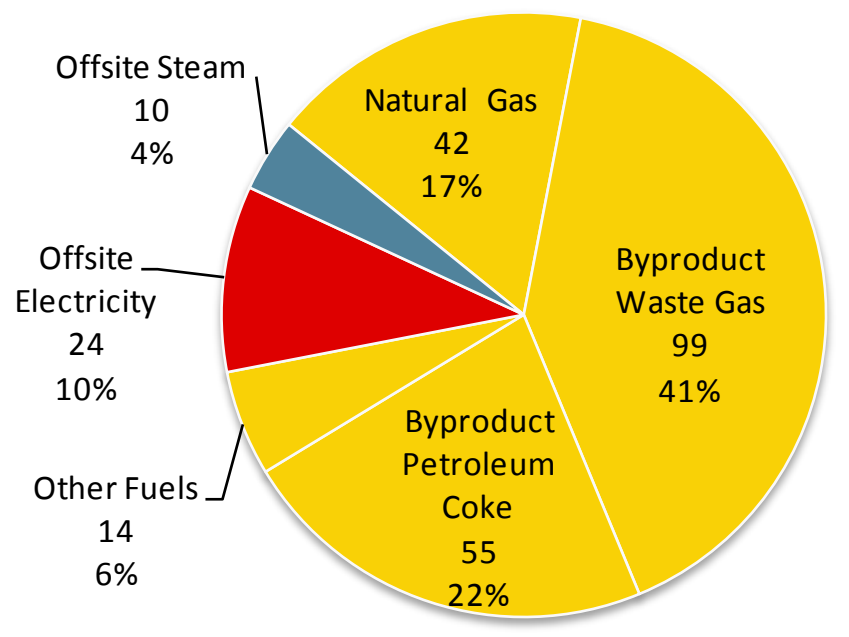

Fig. 2.4-14. Total GHG combustion emissions in the petroleum refining sector (shown by energy supply type)

An alternative view of emissions is shown in Fig. 2.4-15, which also shows total emissions by energy type, but this figure assigns emissions to onsite electricity and steam production (as opposed to assigning emissions strictly to offsite supplied fuels). All emissions associated with electricity production are shown in red, including emissions released during offsite electricity generation and emissions released during onsite generation of electricity. All emissions associated with steam production are shown in blue, including emissions released during offsite steam generation and emissions released to generate steam onsite in boilers and CHP systems. Lastly, all emissions associated with fuel combustion at process and nonprocess end uses are shown in yellow. Electricity generation (offsite and onsite) contributes only $13 \%$ of all emissions. Steam generation (offsite or onsite) contributes a further $28 \%$ of emissions, while the majority of emissions, 59\% (145 MMT), are released during the combustion of fuel for process or nonprocess end uses. 


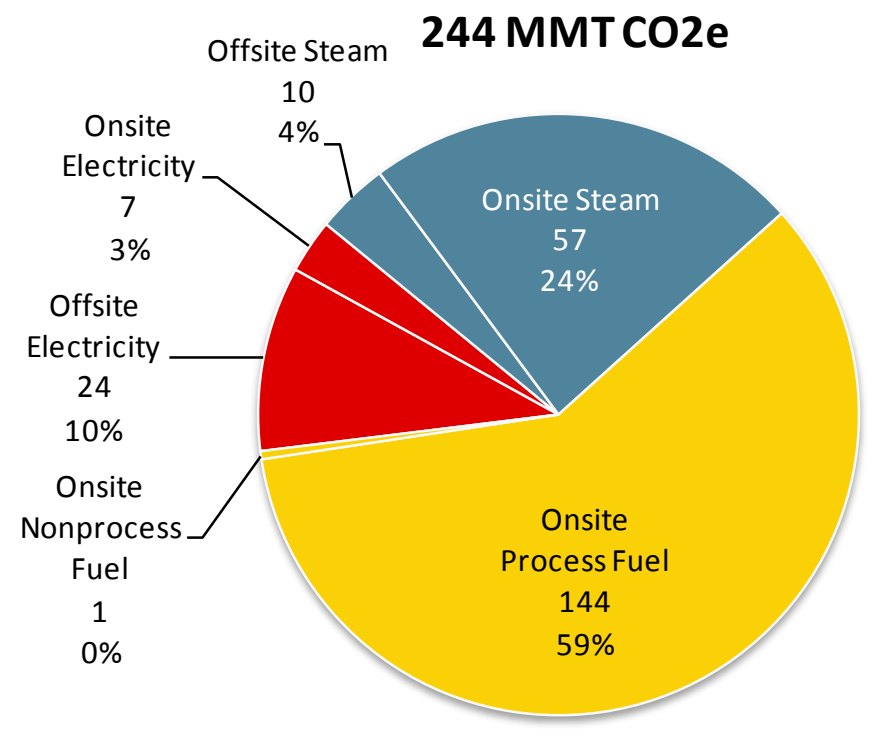

Fig. 2.4-15. Total GHG combustion emissions in the petroleum refining sector (shown by energy end use type)

Emissions can also be associated by the direct end uses of energy, as is shown in Fig. 2.4-16. In this figure, the emissions released from offsite both offsite and onsite electricity and steam generation are distributed to direct end uses, along with emissions resulting from fuel consumed at the direct end uses. This pie chart allows for a direct comparison of the emissions resulting from individual direct process and nonprocess end uses. Process heating accounts for $75 \%$ of emissions, while machine driven end uses account for $17 \%$ of total emissions.

\section{MMT CO2e}

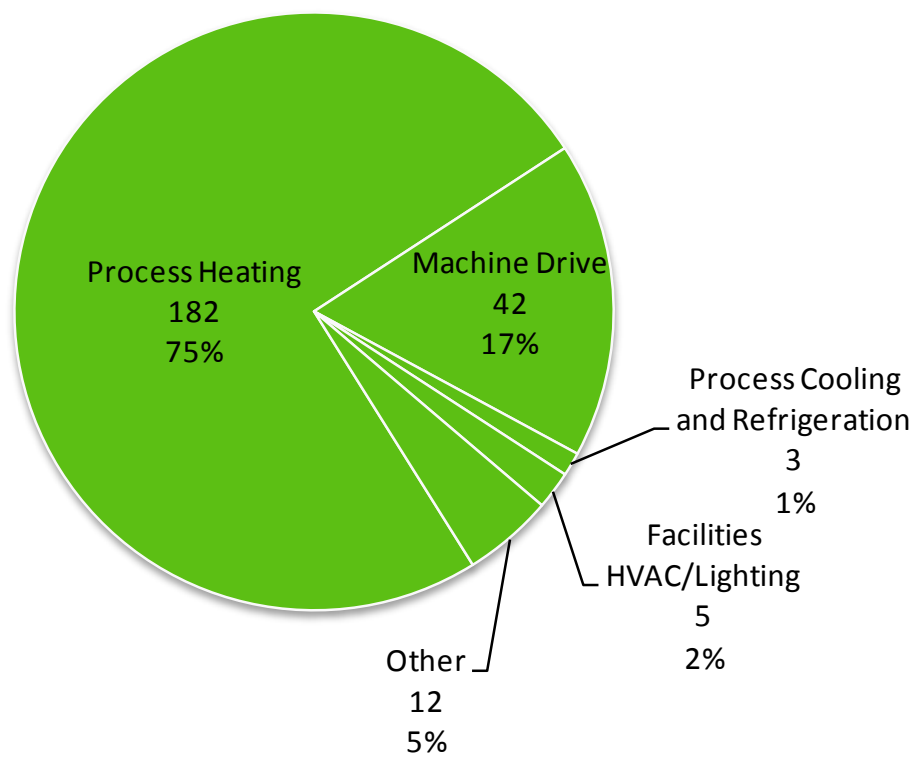

Fig. 2.4-16. Total GHG combustion emissions in the petroleum refining sector (shown by direct energy end use) 


\subsubsection{Energy and Emissions Profile Summary Table}

The energy and emissions profiles for the petroleum refining sector are summarized in Table 2.4-2 below. Offsite and onsite contributions to energy supply, use and loss are shown separately in this table, along with GHG combustion emissions. "Applied energy" is calculated for each direct energy use area by subtracting associated offsite and onsite energy losses. For GHG combustion emissions, emissions from the point of use, whether offsite or onsite, are depicted in the first emissions column; offsite emissions are combined with onsite emissions in the total emissions columns. The values in this table correspond to the energy and carbon footprints, which show two carbon values associated with each onsite end use: at point of use and the total based on onsite use.

Table 2.4-2. Energy use, loss, and GHG combustion emissions in the petroleum refining sector

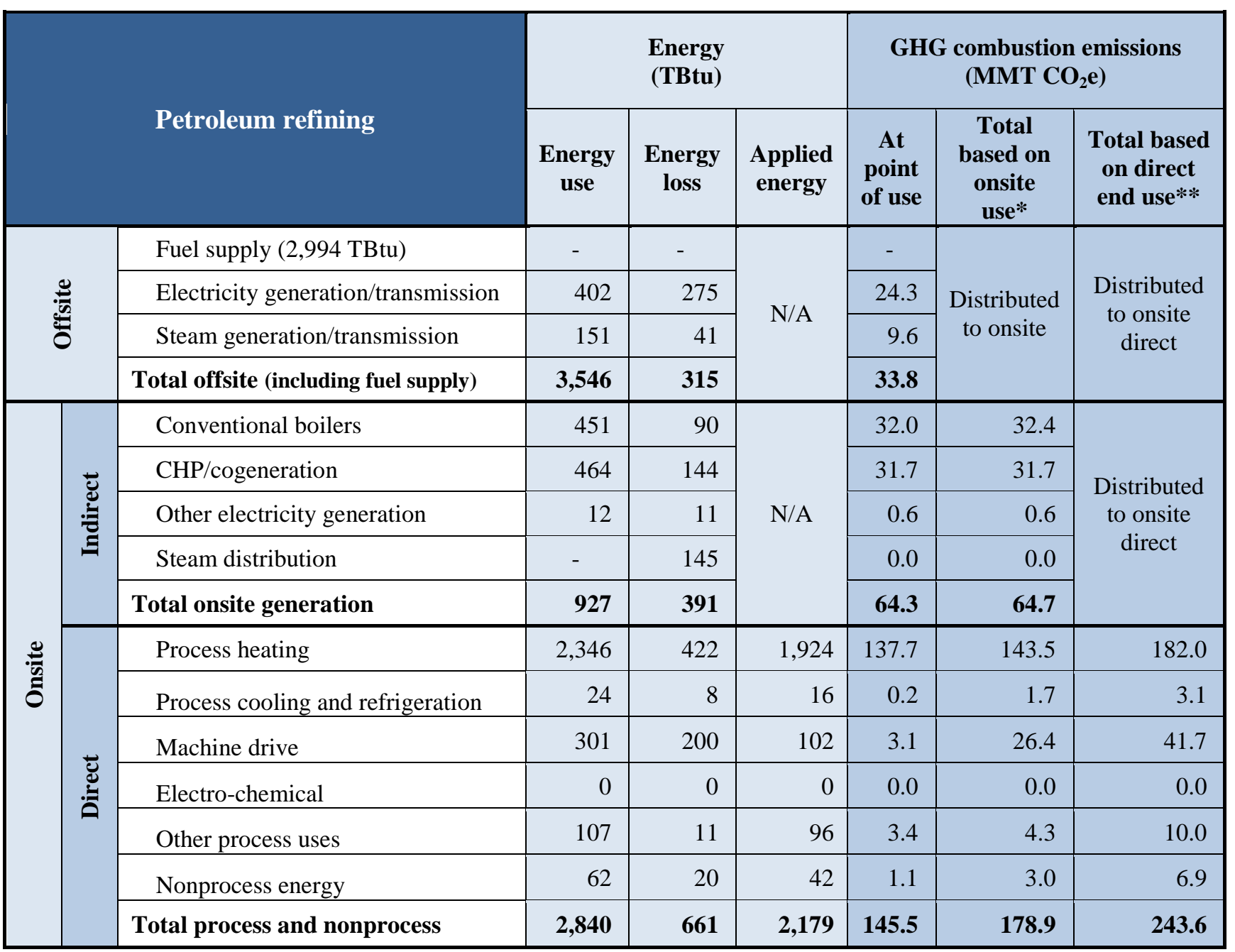

* These values are referenced as "Total" emissions in the footprints, Total emissions = onsite emissions + offsite emissions (i.e., emissions associated with offsite generation are distributed to indirect and direct onsite end uses)

** These values represent direct end use carbon emissions only (i.e., emissions associated with offsite and onsite generation are distributed to direct (and final) end use) 


\subsection{FOOD AND BEVERAGE SECTOR (NAICS 311 AND 312)}

\subsubsection{Overview of the Food and Beverage Manufacturing Sector}

The food and beverage sector is an integral component of the U.S. economy, transforming livestock and agricultural products into intermediate and final food and beverage products. Food and beverage is one of the largest manufacturing sectors, resulting in considerable consumer expenditures for food and beverage products. In addition, increasing globalization of agriculture markets and companies has led to increased trade for food and beverage products.

The food and beverage sector is highly diversified and produces thousands of different products. Processing facilities range from small plants to large industrial units, and most plants produce more than one product. Major NAICS code subsectors for the food and beverage sector are shown in Table 2.5-1.

Table 2.5-1. Food and beverage subsectors with data reported in MECS

\begin{tabular}{|l|l|}
\hline NAICS code & \multicolumn{1}{c|}{ Food and beverage subsector } \\
\hline 311 & Food manufacturing \\
\hline 3112 & Grain and oilseed milling \\
\hline 311221 & Wet corn milling \\
\hline 31131 & Sugar manufacturing \\
\hline 3114 & Fruit and vegetable preserving and specialty foods \\
\hline 3115 & Dairy products \\
\hline 3116 & Animal slaughtering and processing \\
\hline 312 & Beverage and tobacco products \\
\hline 3121 & Beverages \\
\hline 3122 & Tobacco \\
\hline
\end{tabular}

The food and beverage sector is one of the top five consumers of fuels and power in U.S. manufacturing. The manufacture of foods and beverages often requires significant quantities of thermal energy to convert raw materials to useful products. The efficiency of the processes and equipment used to produce foods and beverages is often constrained by thermodynamic, kinetic, or transport limitations, and high temperature or pressure operating conditions.

\subsubsection{Energy Use Profile for the Food and Beverage Sector}

Differentiating between inside or outside the plant boundary is important when evaluating technology options for improving energy efficiency. Within the plant boundary, food and beverage companies have control over facility energy consumption. Outside the plant boundary, where energy is generated by or provided by utilities, companies have little or no control over technology efficiency. However, a company can reduce energy losses associated with external energy supply by adopting technologies that allow its facilities to generate more energy onsite, more efficiently than the utility (e.g., cogeneration).

A snapshot of where the food and beverage sector ranks in terms of energy use, losses, and emissions within U.S. manufacturing is shown in Table 2.5-2. Energy losses are shown in red font. All values are based on the most currently available complete set of manufacturing energy use statistics, representing annual energy use and loss values for calendar year 2006. The food and beverage sector ranks among the top five in nearly every energy and loss category. 
Table 2.5-2. Snapshot of the food and beverage sector: Energy use and rank within U.S. manufacturing

\begin{tabular}{|l|c|c|}
\hline \multicolumn{1}{|c|}{ Category } & Rank & $\begin{array}{c}\text { Energy } \\
\text { (TBtu) }\end{array}$ \\
\hline Total primary energy & 4 & 1,934 \\
Offsite losses & 3 & 639 \\
Onsite energy & 4 & 1,295 \\
Onsite losses & 4 & 831 \\
Steam generation and distribution & 4 & 238 \\
Electricity generation & 5 & 7 \\
Process energy & 4 & 524 \\
Nonprocess energy & 4 & 63 \\
Feedstock energy & 9 & 3 \\
Total primary and feedstock energy* & 4 & 1,932 \\
\hline GHG combustion emissions & 4 & MMT CO \\
Total & 4 & 117 \\
Onsite & 4 & 56 \\
\hline *When total primary energy and feedstock energy are summed, the energy value of byproduct fuels derived from \\
feedstock energy sources is excluded to avoid double counting of feedstock energy \\
\hline
\end{tabular}

Although it is outside the scope of the footprint analysis, a small amount of energy in the food and beverage sector is consumed as non-fuel feedstock. Of the 3 TBtu of feedstock energy use shown in Fig. 2.5-1, 2 TBtu is natural gas used for non-fuel purposes in grain and oilseed milling.

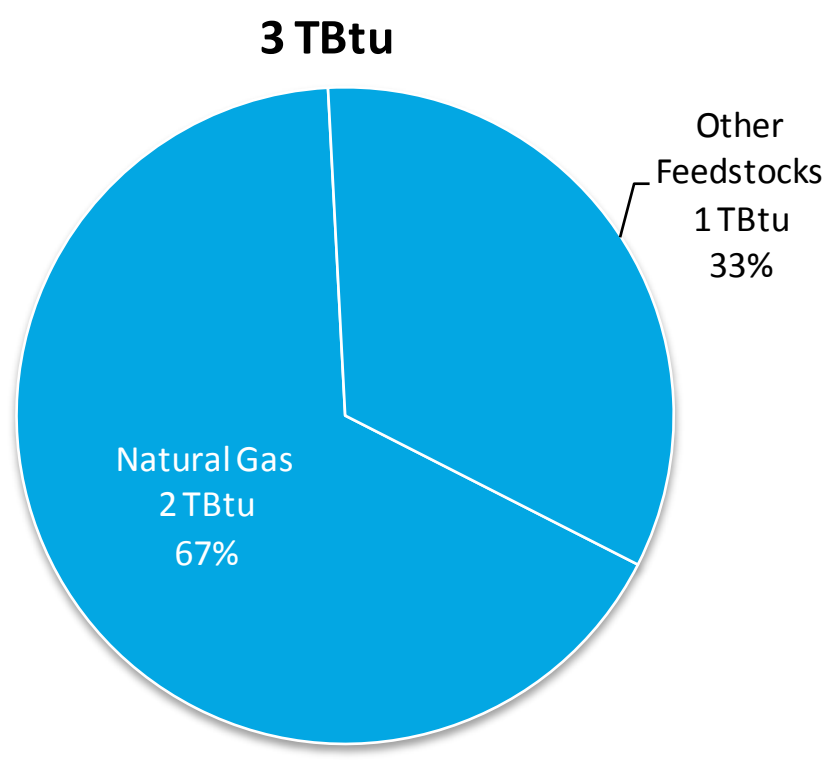

Fig. 2.5-1. Feedstock energy use in the food and beverage sector 


\subsubsection{Energy and carbon footprint}

The Manufacturing Energy and Carbon Footprint for the food and beverage sector is shown in Fig. 2.5-2 and Fig. 2.5-3. The footprint serves as the basis for characterizing the offsite and onsite flow of energy, as well as carbon emissions, from generation through end use in the sector.

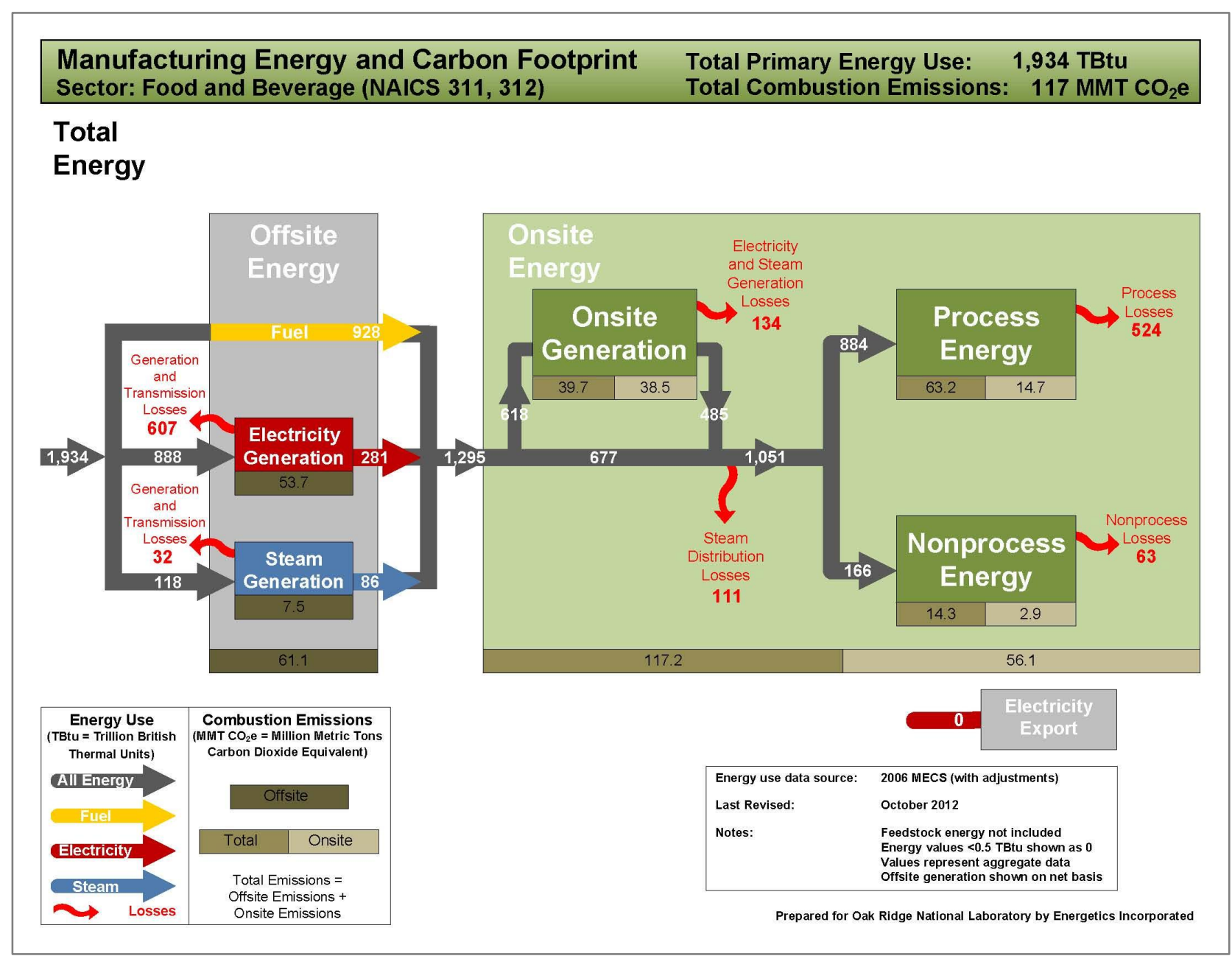

Fig. 2.5-2. Total energy and carbon footprint for the food and beverage sector 


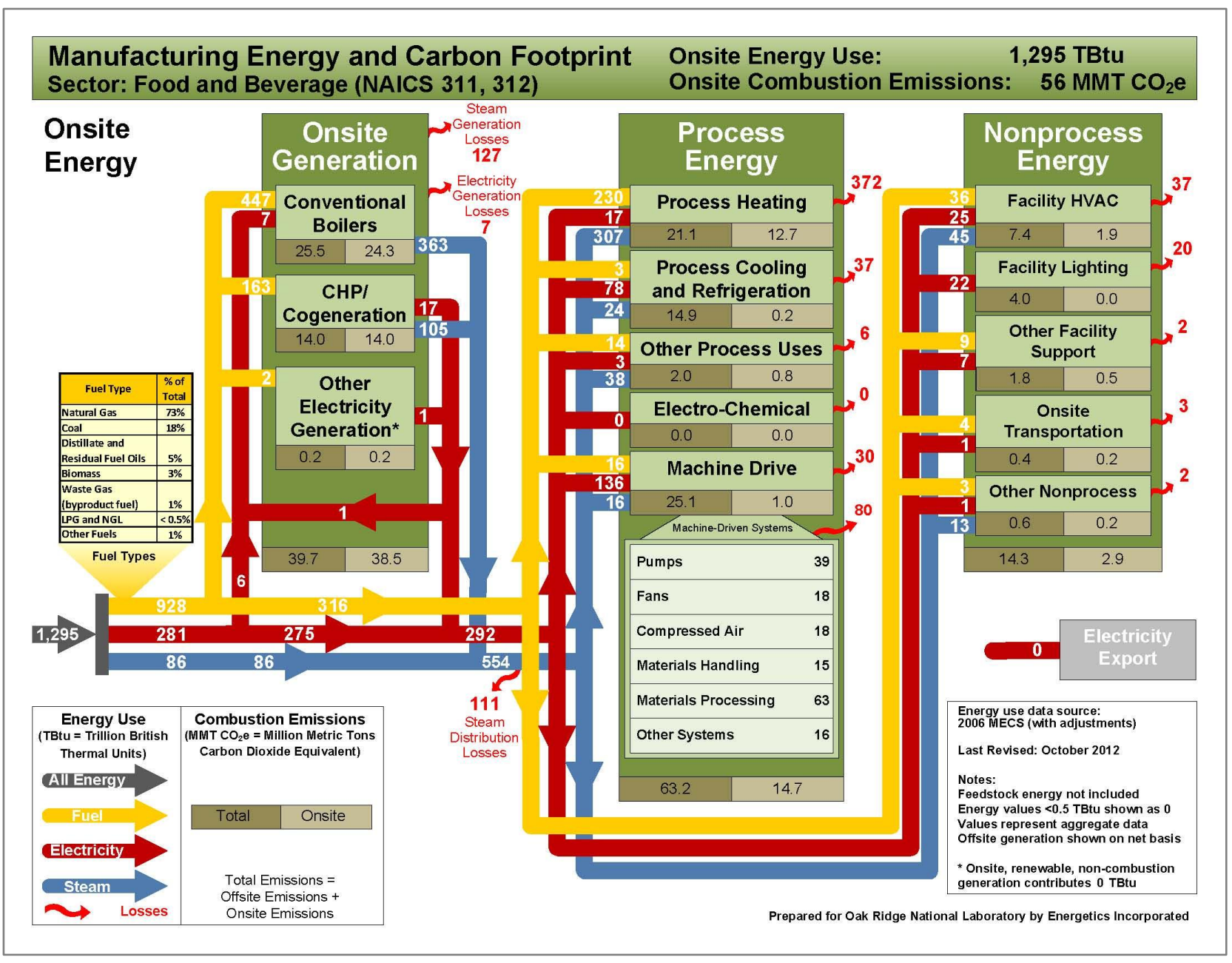

Fig. 2.5-3. Onsite energy and carbon footprint for the food and beverage sector

\subsubsection{Primary energy}

Primary energy use includes fuels, electricity, and steam consumed in manufacturing, including the generation and distribution/transmission losses associated with offsite and onsite electricity and steam generation. The primary energy use by energy type for the food and beverage sector is depicted in Fig. 2.5-4. Consistent with the footprints, blue represents steam energy, red represents electric energy, and yellow represents fuel energy.

The food and beverage sector utilizes 1,934 TBtu of primary energy, ranking fourth across U.S. manufacturing. Electricity generation accounts for $906 \mathrm{TBtu}(47 \%)$ of this total primary energy consumption, accounting for the largest piece of this total. Offsite electricity losses, which consume 607 TBtu, are the single greatest portion of electricity consumption. Offsite generated electricity provides 275 TBtu to direct end uses (excludes electricity used to generate steam onsite), while onsite electricity generation provides an additional 17 TBtu to direct end uses. Onsite electricity losses account for 7 TBtu of energy.

Steam generation is the next largest use of primary energy, consuming 713 TBtu (37\%) of total primary energy. Onsite generation of steam accounts for 375 TBtu of this total, while associated onsite generation and distribution losses accounts for a further $238 \mathrm{TBtu}$. The remaining steam is due to offsite steam and associated generation and distribution losses, accounting for $69 \mathrm{TBtu}$ and $32 \mathrm{TBtu}$, respectively. 
Direct fuel uses comprise the smallest application of primary energy at $316 \mathrm{TBtu}(16 \%)$. Natural gas accounts for $287 \mathrm{TBtu}$ - about $91 \%$ of direct fuel consumption. Other fuels including coal, distillate fuel oil, residual fuel oil, LPG and NGL, and coke and breeze consume the remaining 29 TBtu of energy.

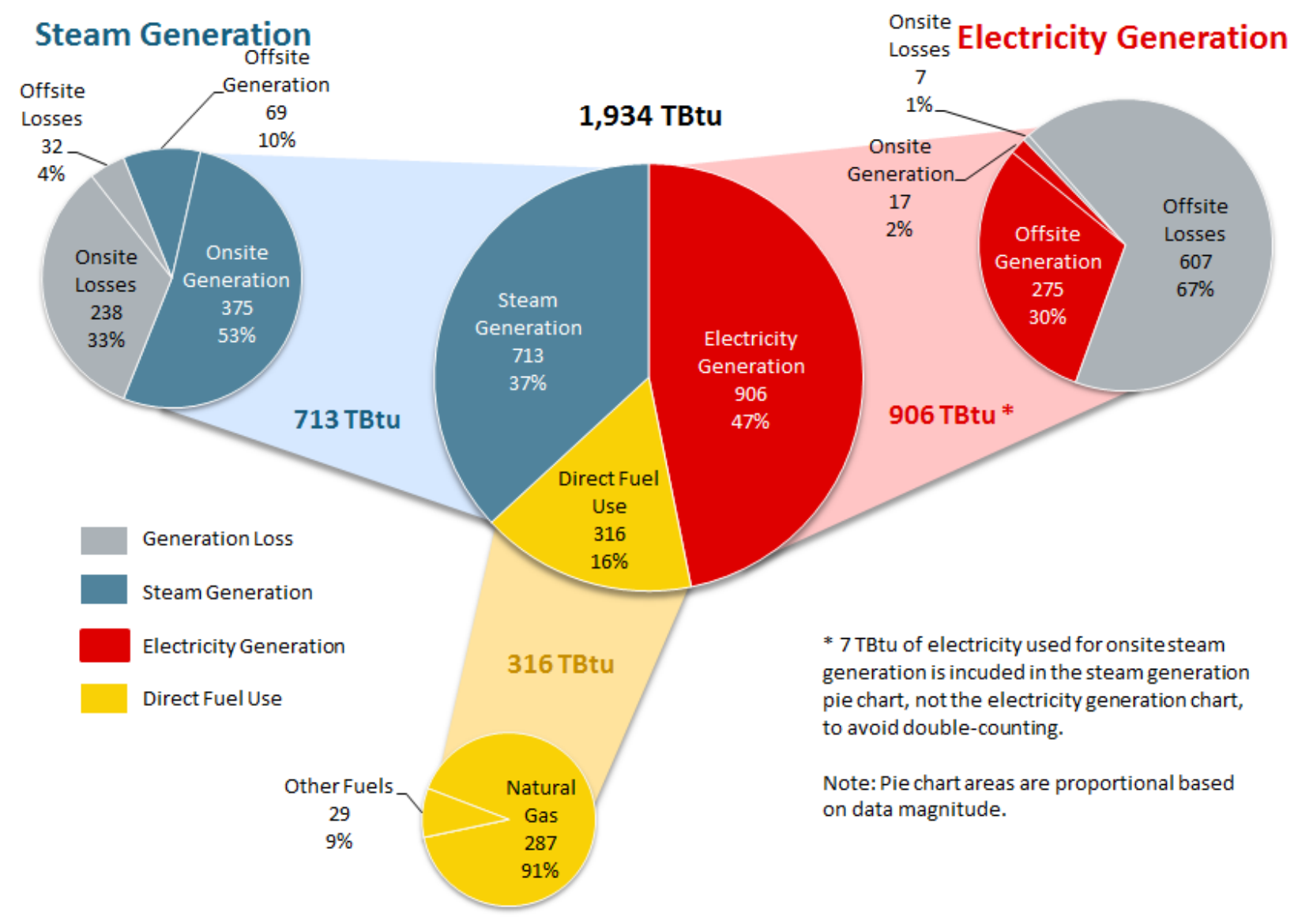

Direct Fuel Use

Fig. 2.5-4. Primary energy by energy type in the food and beverage sector

\subsubsection{Onsite energy}

Onsite energy is a measure of the energy entering the plant boundary in the form of three offsite energy types: fuel, steam, and electricity. Sector energy consumption from offsite energy supply totaled 1,295 TBtu in 2006. The sector makes an array of different products and uses many different processes in their manufacture. As a result, energy use patterns can vary significantly across subsectors.

Overall, as shown in Fig. 2.5-5, natural gas provides for over half (52\%) of the onsite energy in the sector at $676 \mathrm{TBtu}$. Offsite electricity is the next largest with $22 \%$ of the total $(281 \mathrm{TBtu})$, followed by coal at $13 \%$ (167 TBtu). Offsite steam comprises $86 \mathrm{TBtu}$, or $7 \%$ of total offsite energy supply. Lesser amounts of biomass and other fuels serve as sources energy for use in the sector. 


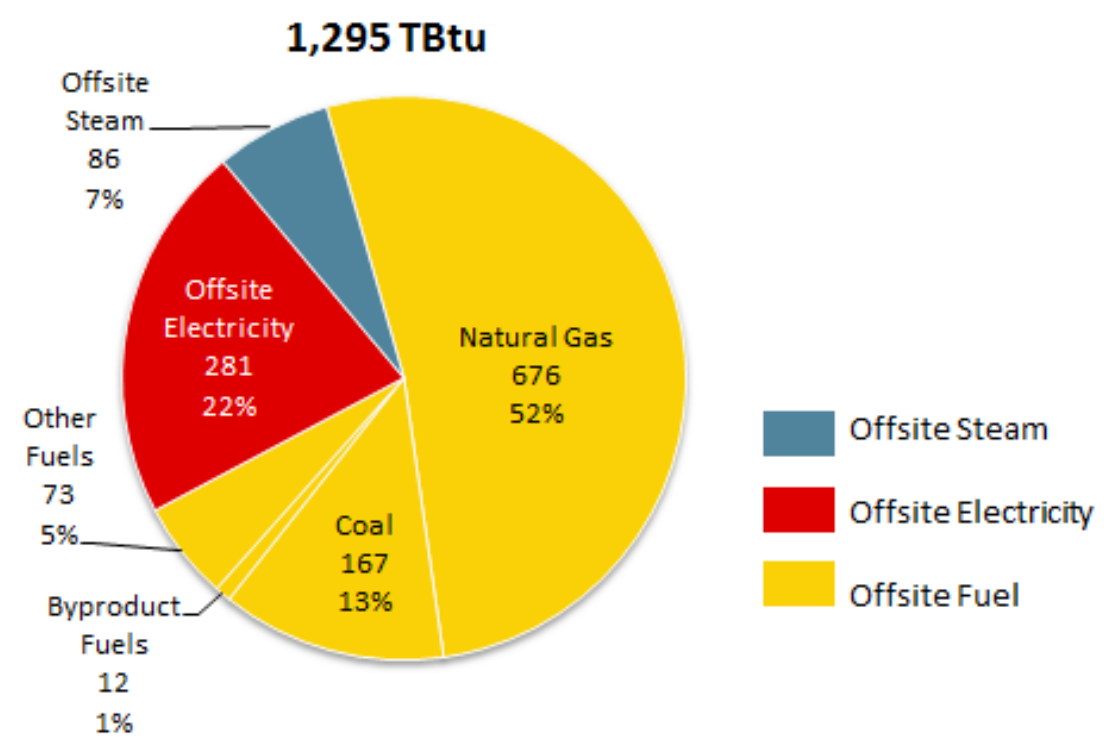

Fig. 2.5-5. Offsite energy supply in the food and beverage sector

Fig. 2.5-6 illustrates the energy consumption patterns across major subsectors in the food and beverage sector (the sum of onsite energy use across these subsectors is equal to 93\% of sector-wide onsite energy use). The largest onsite energy using subsector is grain and oilseed milling (NAICS 3112), which consumes over 300 TBtu. The remaining other subsectors such as animal slaughter and processing (NAICS 3116), dairy products (NAICS 3115), and beverages (NAICS 3121) each use less than 250 TBtu of onsite energy.
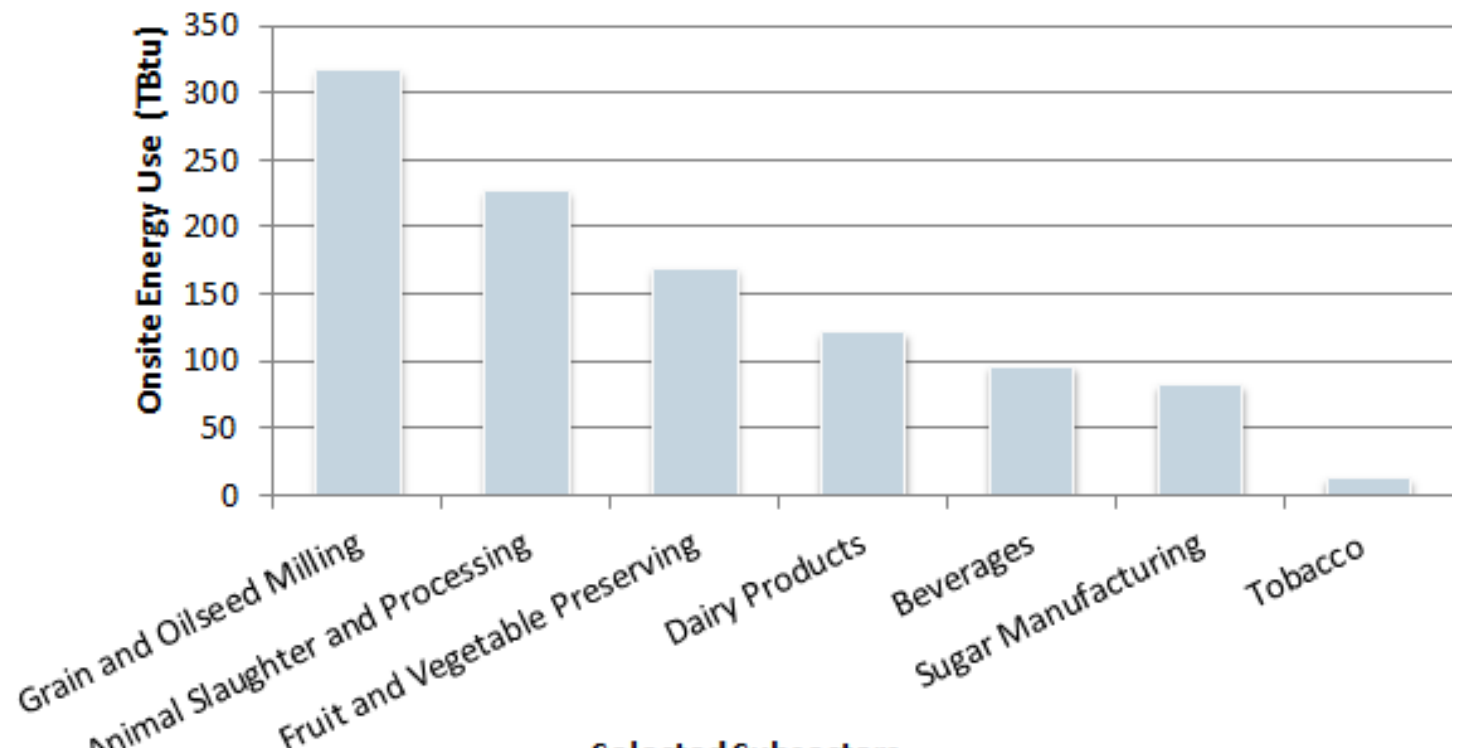

Selected Subsectors

Fig. 2.5-6. Onsite energy use in selected food and beverage subsectors

\subsubsection{Fuel energy}

Onsite fuel use in the food and beverage sector is $928 \mathrm{TBtu}$. Natural gas makes up over half of onsite fuel use, with coal providing the next largest contribution at $13 \%$. Natural gas is used primarily in process heating applications such as food dehydration. Coal is the most commonly used fuel for CHP and/or cogeneration processes, which is a unique characteristic of CHP operations for this sector. 


\subsubsection{Electrical energy}

The food and beverage sector is ranked third among U.S. manufacturing sectors in onsite direct demand for electricity at 292 TBtu per year. Onsite direct electricity demand is equal to purchases of electricity summed with electricity generated onsite, and provides the most complete picture of actual electricity use. On average, electricity use only accounts for a little more than $20 \%$ of onsite and $15 \%$ of primary energy consumption. However, some subsectors may be more electricity intensive than others.

As shown in Fig. 2.5-7, a large portion of the primary energy consumed for electricity use is associated with generation, transmission and distribution (T\&D) losses, taking place mostly offsite. On average, the efficiency of utility power generation and transmission is assumed to be $31.6 \%$, generating over $614 \mathrm{TBtu}$ of energy losses in order to produce $292 \mathrm{TBtu}$ of electricity that is used for direct ${ }^{16}$ end uses in the sector.

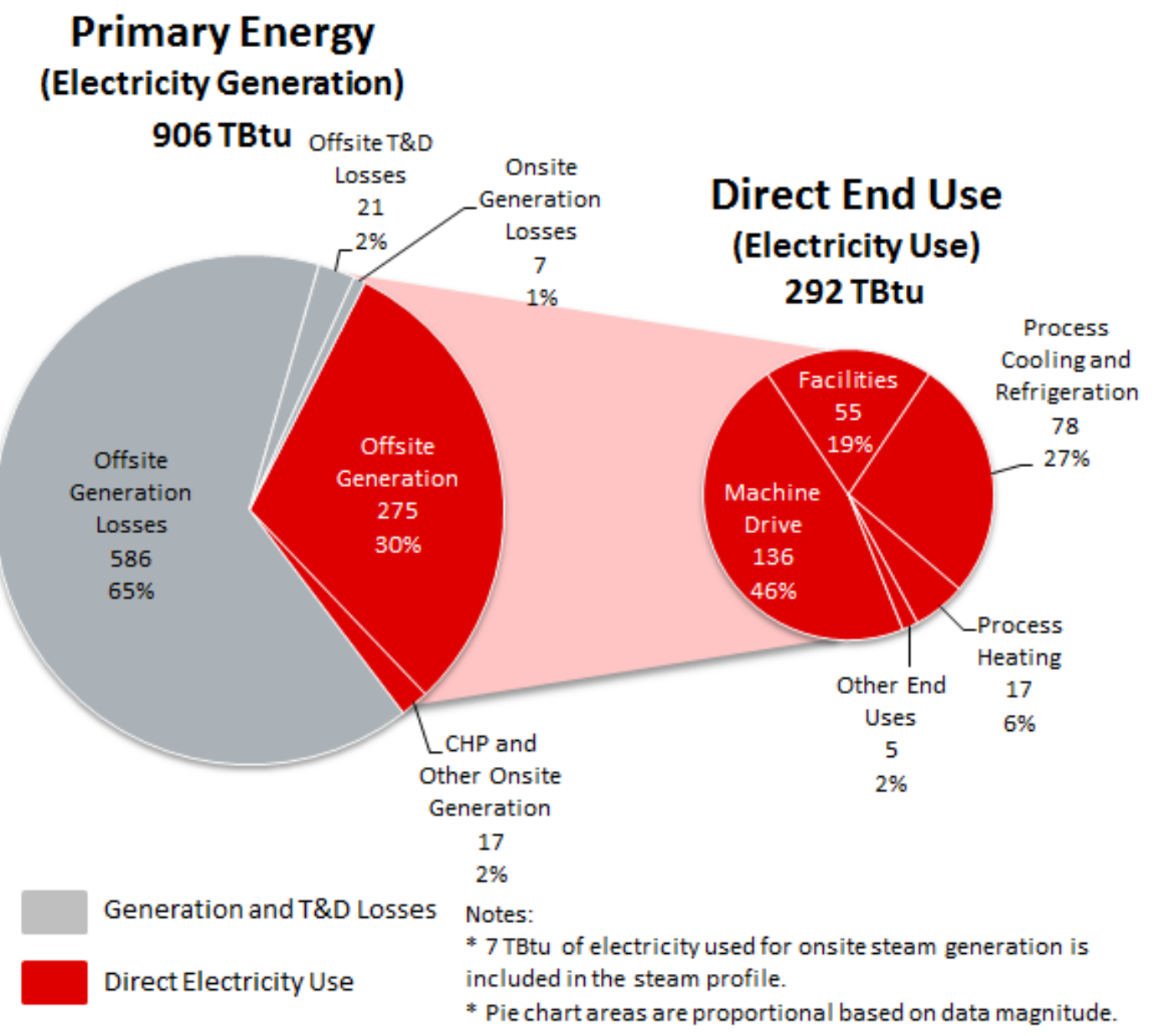

Fig. 2.5-7. Electricity generation and direct end use in the food and beverage sector

The food and beverage sector does meet a small portion (6\%) of direct end use energy through onsite generation. About 17 TBtu of energy use is associated with the generation of onsite electricity. Most of the electricity produced onsite in the sector comes from CHP units, with only a small percentage of onsite generation originating from other generation methods such as the use of generators running on combustible energy sources or renewable energy such as wind or solar.

\footnotetext{
${ }^{16}$ Offsite electricity generation (275 TBtu) shown in this chart is lower than the value of offsite energy entering the plant boundary shown in the energy and carbon footprint for this sector $(281 \mathrm{TBtu})$. This difference is due to the small portion of offsite electricity (7 TBtu) that is used by conventional boilers to generate steam.
} 
About $46 \%$ of the electricity use in the food and beverage sector is consumed by machine-driven systems such as pumps, conveyors, compressors, fans, mixers, grinders, and other materials handling or processing equipment. Process cooling and refrigeration is the next largest category of electricity consumption within the sector, comprising $27 \%$ of electricity usage. Facilities use, such as HVAC and lighting, follows at $19 \%$. The remaining $8 \%$ of sector electricity use is consumed by other process uses such as process heating, boilers, and other end uses.

\subsubsection{Steam energy}

The food and beverage sector ranks fourth across U.S. manufacturing in steam usage. A profile of food and beverage sector steam use from primary energy and associated losses is shown in Fig. 2.5-8. About 38\% of primary energy inputs are lost due to system inefficiencies in steam generation and transmission, both offsite and onsite. The bulk of these occur in the boiler, where thermal efficiencies range between 55\%$85 \%$, depending upon the age of the boiler and type of fuel burned. Conventional boiler steam comprises $41 \%$ (291 TBtu) of primary energy, serving as the principal source of energy to be applied towards end use. CHP steam generation provides for about $12 \%$ (84 TBtu) of the energy for end use, followed by steam generated offsite at $10 \%$ (69 TBtu).

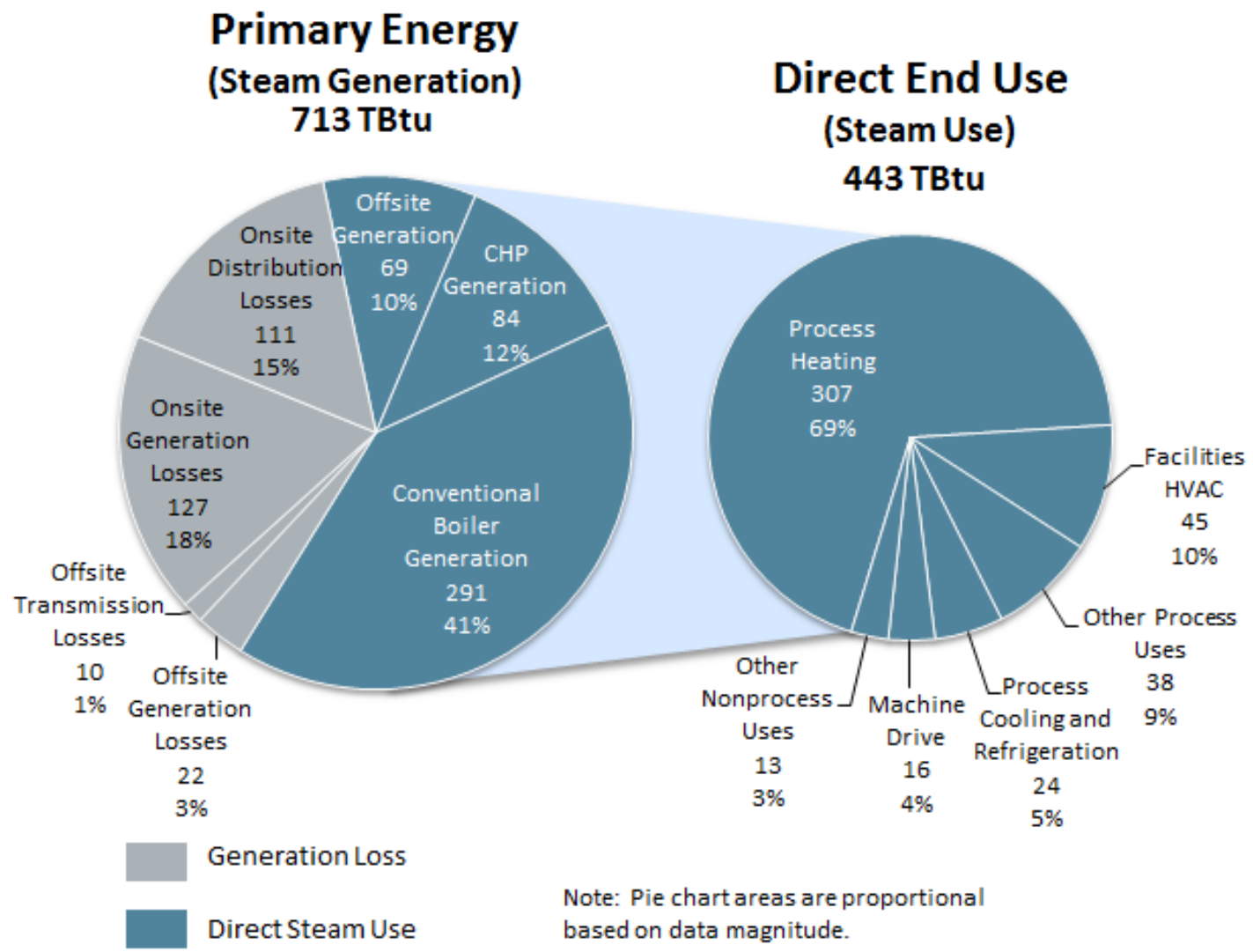

Fig. 2.5-8. Steam generation and direct end use in the food and beverage sector

Of the 713 TBtu of primary energy made available for steam, 443 TBtu of energy is used onsite. Process heating receives the bulk of the energy at 69\% (307 TBtu), followed by facility HVAC uses at 10\% (45 TBtu), other process uses at 9\% (38 TBtu), process cooling and refrigeration at 5\% (24 TBtu), machine drive uses at 4\% (16 TBtu), and the remaining 3\% going to other nonprocess uses (13 TBtu). 


\subsubsection{Combined heat and power energy}

The food and beverage sector meets a moderate amount of energy demand through onsite generation, ranking fourth in CHP output across sectors. As shown in Fig. 2.5-9, CHP units produce 163 TBtu of energy output, with $64 \%$ of this output in the form of steam. Electricity encompasses about $10 \%$ of CHP output, with the remaining $26 \%$ of energy composed of losses. More than three-fourths $(76 \%)$ of fuel energy to CHP units is in the form of coal, which is significantly higher than other energy-intensive sectors where waste fuels, waste gas, and natural gas are more typical CHP fuels. Natural gas supplied $18 \%$ of fuel used for CHP with the remaining 6\% consisting of other fuels such as distillate and residual fuel oils.

\section{CHP Indirect Fuel Use CHP Energy Output}

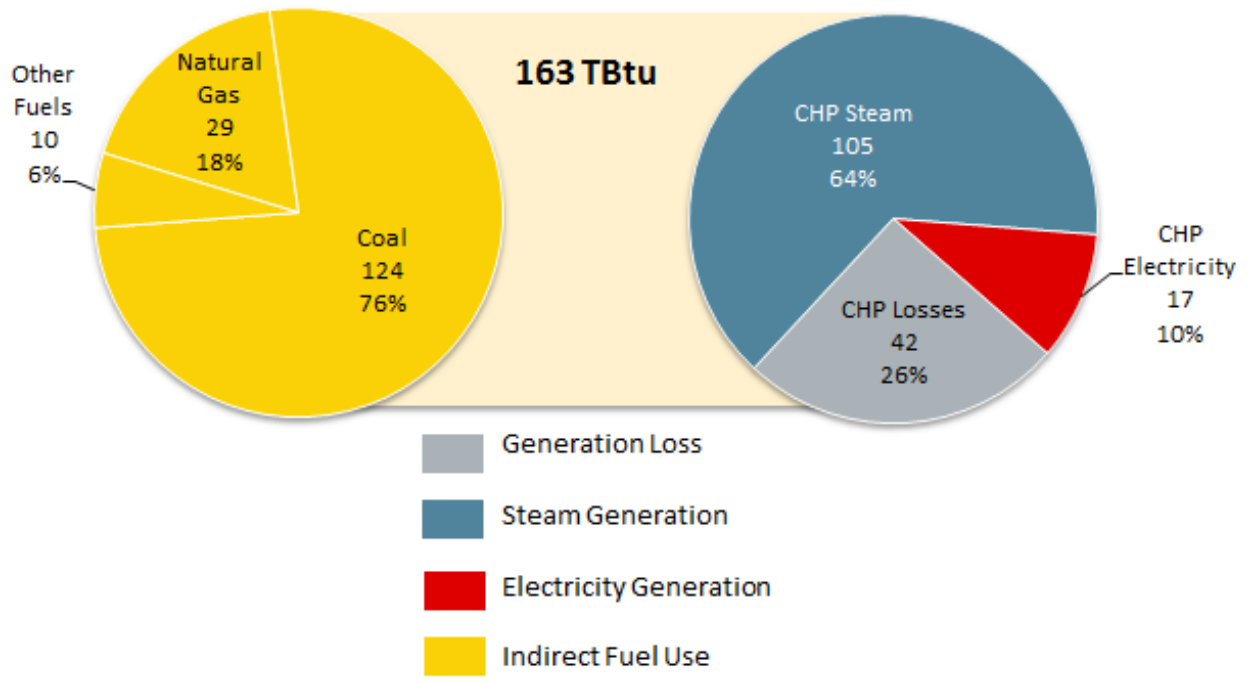

Fig. 2.5-9. CHP fuel consumption and energy output in the food and beverage sector

\subsubsection{Direct end use energy}

Energy is consumed in food and beverage manufacturing to provide process heating and cooling, to power motor-driven systems, and for various other purposes. A simple breakdown of primary energy by type at direct end use is shown in Fig. 2.5-10. It should be noted that the energy trends shown here are an average for the sector and may not reflect subsector differences. Steam comprises over half the energy used in process heating, followed by natural gas, while electricity serves as the major input for machine-driven systems. As mentioned in the CHP section above, coal serves as the primary fuel in cogeneration.

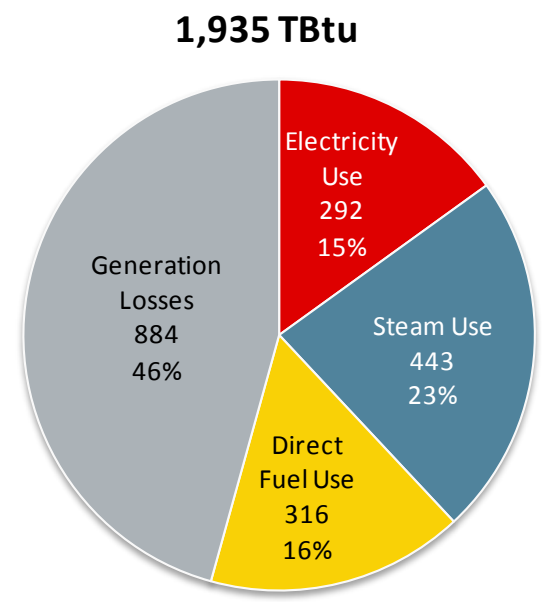

Fig. 2.5-10. Primary energy by type at direct end use in the food and beverage sector 
A breakdown of primary energy by all direct end uses is shown in Fig. 2.5-11. Process uses and losses incurred during the generation of electricity and steam both consume $884 \mathrm{TBtu}(46 \%)$. Nonprocess uses account for only $8 \%$ (166 TBtu) of energy use in the sector.

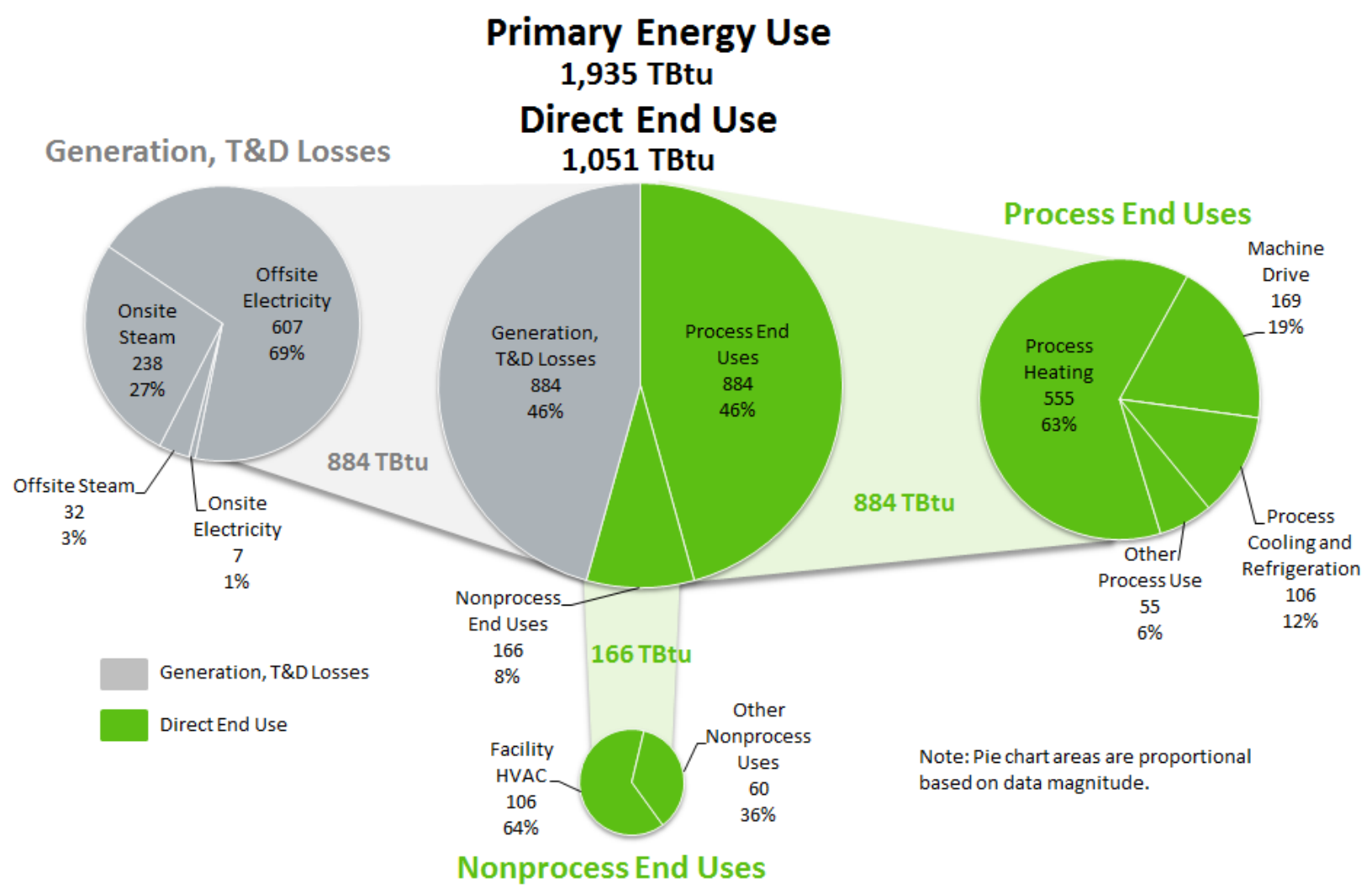

Fig. 2.5-11. Primary energy by direct end use in the food and beverage sector

The food and beverage sector ranks fifth across U.S. manufacturing in the use of process heating and cooling systems, and fourth in the use of machine driven systems. Process heating systems consume $63 \%$ (555 TBtu) of the $884 \mathrm{TBtu}$ consumed by process end uses. These systems include steam systems and fired systems such as ovens and furnaces. Machine-driven systems are the next largest use of process energy in the sector at $169 \mathrm{TBtu}(19 \%)$, followed by process cooling and refrigeration systems at $106 \mathrm{TBtu}(12 \%)$. As shown in Fig. 2.5-8, steam serves as the primary energy source for process heating systems, while electricity is the main source of energy for the largely electric-based, machine-driven systems. The food and beverage sector also ranks fourth across U.S. manufacturing in nonprocess energy end uses, with facility HVAC the largest user of nonprocess energy. 


\subsubsection{Applied end use energy}

In addition to the energy generation losses identified above, direct end use losses have also been calculated in the energy footprint model. When both generation and end use losses are accounted for, the energy that remains is the applied energy. Applied energy can be illustrated by re-examining Fig. 2.5-4, which shows primary energy by energy type for the food and beverage sector. Each of the energy types (i.e., fuel, electricity, or steam) shown in this figure have associated onsite and offsite generation losses (shown with onsite and offsite losses combined in light gray) that are incurred during energy generation (and transmission and distribution). While the majority of electricity generation losses take place offsite (as shown in Fig. 2.5-7), the majority of steam generation losses are onsite (as shown in Fig. 2.5-8), and direct fuel use is assumed to have no associated generation losses. After taking into account these generation losses, a further portion of the remaining energy is lost at direct end uses, due to process and nonprocess system and equipment inefficiencies, shown in dark gray. The remaining energy is applied to end uses, shown in light green as "Applied Energy" in Fig. 2.5-12.

\section{Primary Energy Use}

1,934 TBtu

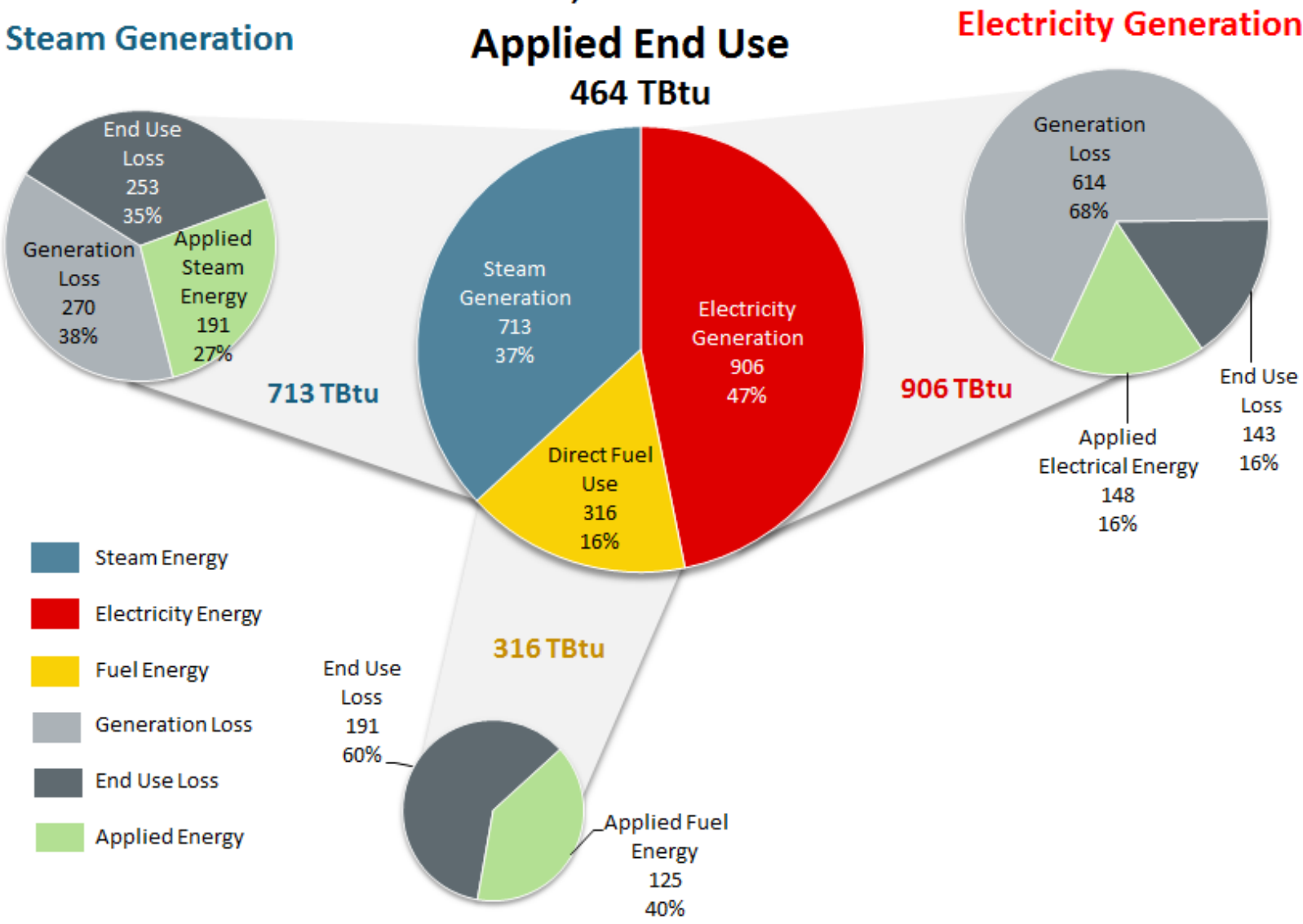

Direct Fuel Use

Fig. 2.5-12. Primary energy and applied energy by energy type in the food and beverage sector

Figure 2.5-13 shows the breakdown of primary energy by energy loss and applied energy. In this sector, only $24 \%$ of primary energy input is applied to process and nonprocess end uses, significantly less than the manufacturing average of $34 \%$. Generation losses account for $46 \%$ of primary energy input and end use losses account for the remaining $30 \%$ of primary energy input. 


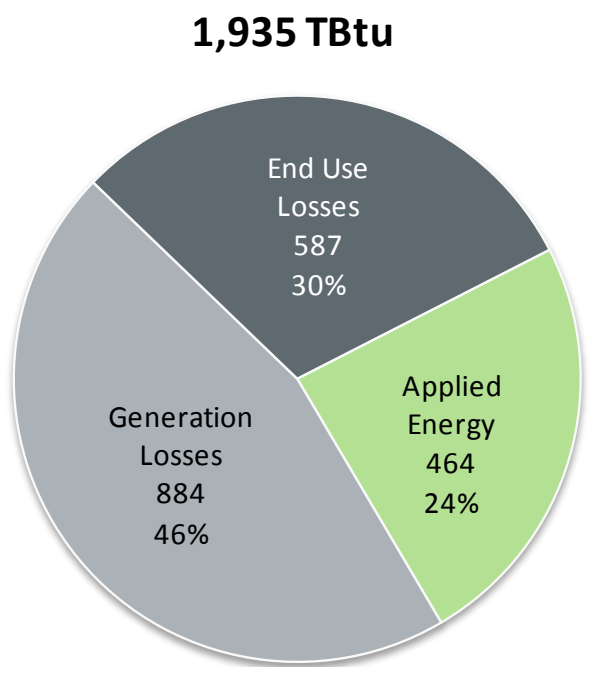

Fig. 2.5-13. Primary energy by loss and applied energy in the food and beverage sector

Applied energy can also be calculated for specific end uses, as shown in Fig. 2.5-14. End use losses are labeled as process or nonprocess losses; in the case of machine drive end use, process losses are further defined as machine drive, or machine driven system losses. For process heating, 23\% of primary energy is applied to the process (detail of the methodology to estimate process heating losses are shown in Appendix F). In machine-driven systems, only $13 \%$ of primary energy is applied, primarily because of the inefficiency in electricity generation.

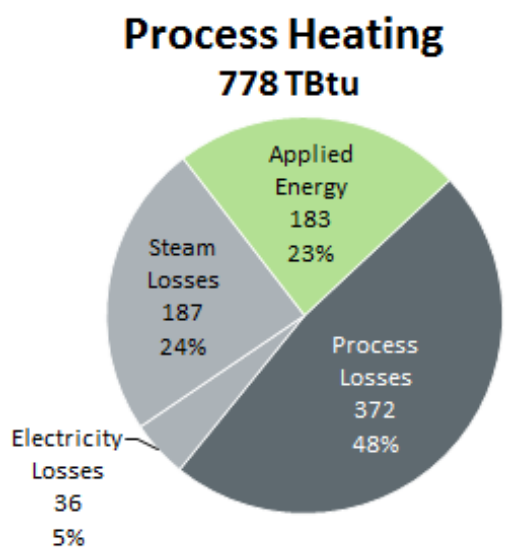

\section{Other Process End Uses 369 TBtu}

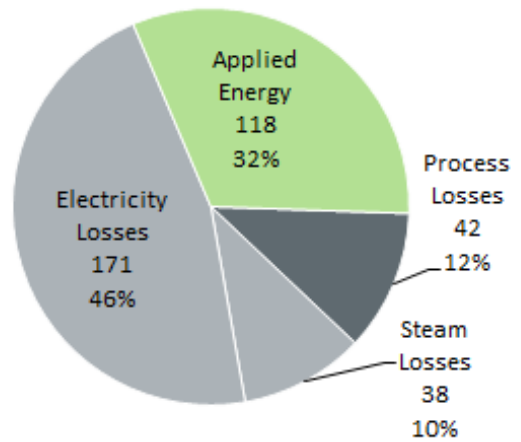

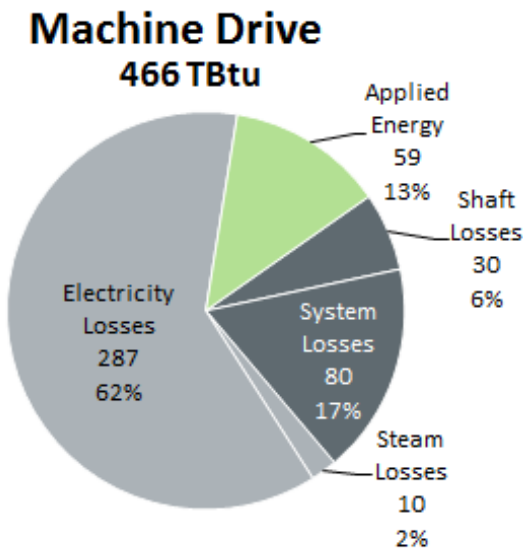

Nonprocess End Uses 322 TBtu

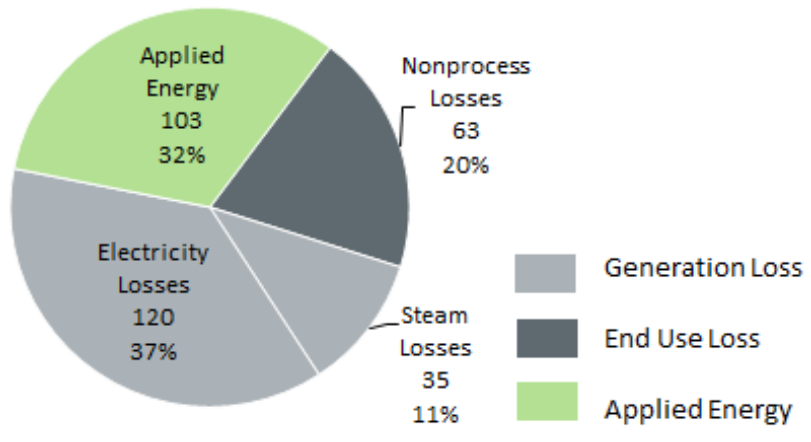

Note: Pie chart areas are not proportional to magnitude of energy consumption

Fig. 2.5-14. Primary applied energy by direct end use in the food and beverage sector 


\subsubsection{Greenhouse Gas Combustion Emissions Profile for the Food and Beverage Sector}

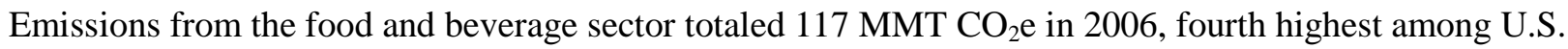
manufacturing sectors. Greenhouse gas emissions by offsite energy supply type are shown in Fig. 2.5-15. Emissions released during offsite production of electricity contribute $46 \%$ of sector emissions, while $6 \%$ of emissions are attributed to the production of offsite steam. The onsite consumption of fuels (shown in yellow), including natural gas, coal, and other fuels, accounts for nearly half of total emissions. These fuels are used for both direct (e.g., process or nonprocess) and indirect (e.g., fuel for CHP units or boilers) end uses. Table D.5 shows fuel GHG combustion emission factors associated with fuel combustion, as well as electricity and steam generation.

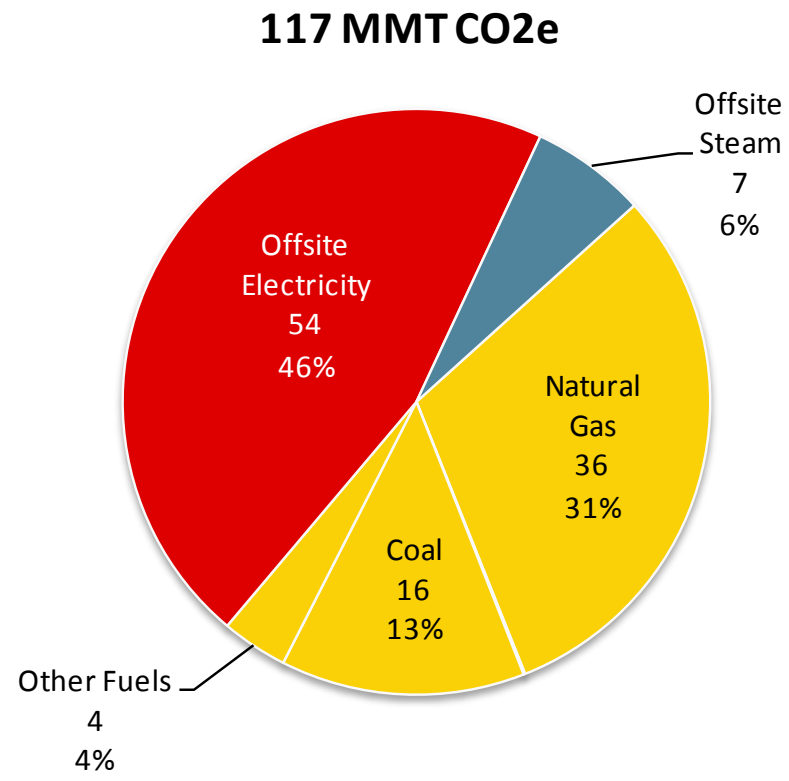

Fig. 2.5-15. Total GHG combustion emissions in the food and beverage sector (shown by energy supply type)

An alternative view of emissions is shown in Fig. 2.5-16, which also shows total emissions by energy type, but this figure assigns emissions to onsite electricity and steam production (as opposed to assigning emissions strictly to offsite supplied fuels). All emissions associated with electricity production are shown in red, including emissions released during offsite electricity generation and emissions released during onsite generation of electricity. All emissions associated with steam production are shown in blue, including emissions released during offsite steam generation and emissions released to generate steam onsite in boilers and CHP systems. Lastly, all emissions associated with fuel combustion at process and nonprocess end uses are shown in yellow. Electricity generation (offsite and onsite) contributes about $48 \%$ of all emissions. Steam generation (offsite or onsite) contributes a further $37 \%$ of emissions, while the remaining $15 \%$ of emissions are released during fuel combustion for process and nonprocess end uses. 


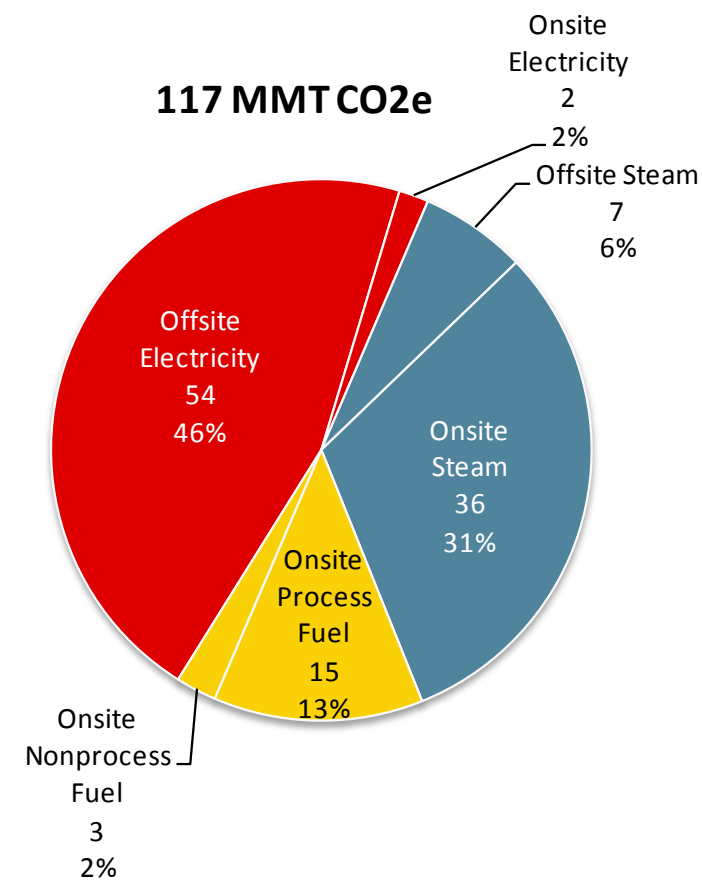

Fig. 2.5-16. Total GHG combustion emissions in the food and beverage sector (shown by energy end use type)

Emissions can also be associated with the direct end uses of energy, as is shown in Fig. 2.5-17. In this figure, the emissions released from offsite both offsite and onsite electricity and steam generation are distributed to direct end uses, along with emissions resulting from fuel consumed at the direct end uses. This pie chart allows for a direct comparison of the emissions resulting from individual direct process and nonprocess end uses. Similar to the forest products sector, $\mathrm{CO}_{2}$ emissions from biomass use (within the other fuels category) are excluded. Process heating accounts for $40 \%$ of emissions, while machine driven end uses account for $24 \%$ of emissions. Process cooling and refrigeration end uses account for $15 \%$ of sector emissions, equal to one-third of all manufacturing process cooling and refrigeration emissions. Emissions resulting from facilities, HVAC and lighting nonprocess end uses account for an additional 13\% of emissions, while other process and nonprocess end uses account for just $8 \%$ of emissions.

\section{MMT CO2e}

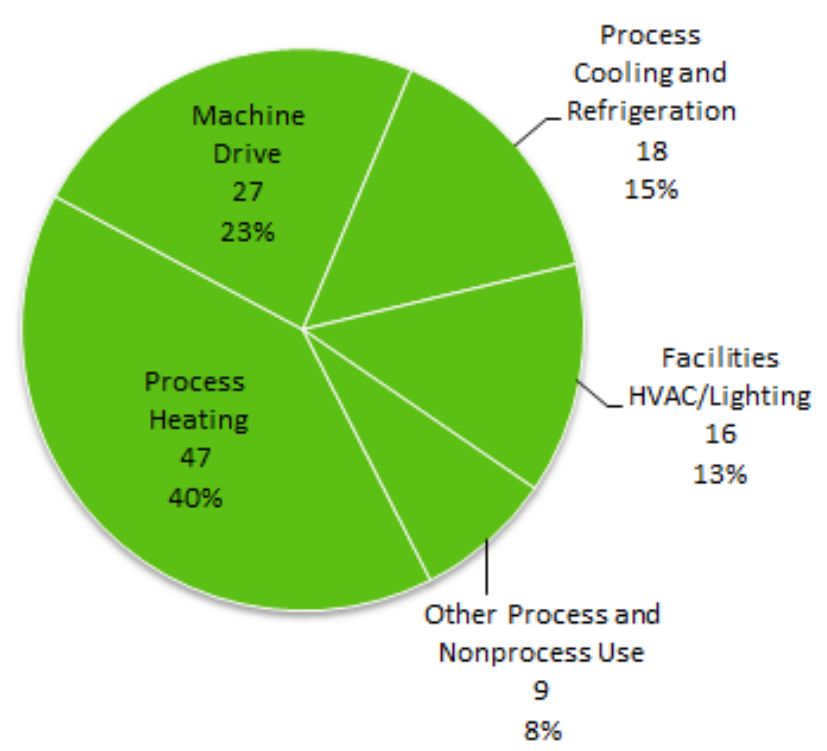

Fig. 2.5-17. Total GHG combustion emissions in the food and beverage sector (shown by direct energy end use) 


\subsubsection{Energy and Emissions Profile Summary Table}

The energy and emissions profiles for the food and beverage sector are summarized in Table 2.5-3 below. Offsite and onsite contributions to energy supply, use and loss are shown separately in this table, along with GHG combustion emissions. "Applied energy" is calculated for each direct energy use area by subtracting associated offsite and onsite energy losses. For GHG combustion emissions, emissions from the point of use, whether offsite or onsite, are depicted in the first emissions column; offsite emissions are combined with onsite emissions in the total emissions columns. The values in this table correspond to the energy and carbon footprints, which show two carbon values associated with each onsite end use: at point of use and the total based on onsite use.

Table 2.5-3. Energy use, loss, and GHG combustion emissions in the food and beverage sector

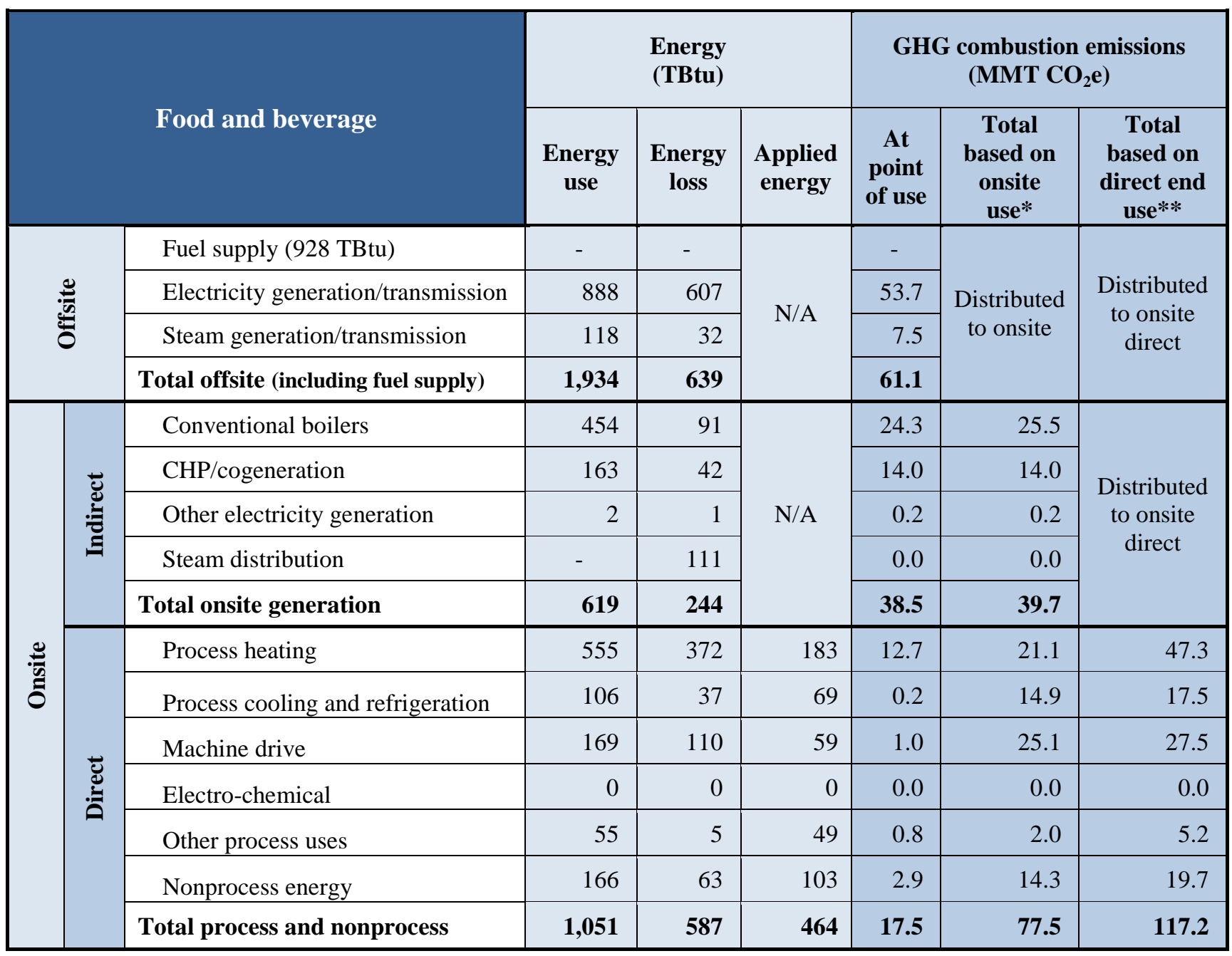

* These values are referenced as "Total" emissions in the footprints, Total emissions = onsite emissions + offsite emissions (i.e., emissions associated with offsite generation are distributed to indirect and direct onsite end uses)

** These values represent direct end use carbon emissions only (i.e., emissions associated with offsite and onsite generation are distributed to direct (and final) end use) 


\subsection{IRON AND STEEL SECTOR (NAICS 3311, 3312)}

\subsubsection{Overview of the Iron and Steel Manufacturing Sector}

The iron and steel sector is an essential part of the U.S. manufacturing sector, providing the necessary raw material for the extensive industrial supply chain. U.S. infrastructure is heavily reliant on the U.S. iron and steel sector, as it provides the foundation for construction (bridges, buildings), transportation systems (railroads, cars, trucks), utility systems (municipal water systems, power systems), as well as other diverse applications including military equipment, food storage, appliances, and tools.

Steel is typically produced through one of two manufacturing methods, each of which is relatively energyintensive. An integrated steel mill produces molten iron in blast furnaces using a form of coal known as coke, which is either produced onsite or purchased. This iron is used as a charge to produce steel in a basic oxygen furnace (BOF). Alternatively, an electric arc furnace (EAF) steel producer, also known as a minimill, uses EAFs to produce steel from steel scrap and other iron-bearing materials. Table 2.6-1 shows the NAICS code subsectors in iron and steel manufacturing with data reported in MECS.

Table 2.6-1. Iron and steel subsectors with data reported in MECS

\begin{tabular}{|l|l|}
\hline \multicolumn{1}{|c|}{ NAICS code } & \multicolumn{1}{c|}{ Iron and steel subsector } \\
\hline 3311 & Iron and steel mills and ferroalloy manufacturing \\
\hline 331111 & Iron and steel mills \\
\hline 331112 & Electrometallurgical ferroalloy product manufacturing \\
\hline 3312 & Steel product manufacturing from purchased steel \\
\hline
\end{tabular}

\subsubsection{Energy Use Profile for the Iron and Steel Sector}

Steel is the fifth largest consumer of fuels among U.S. manufacturing sectors. The efficiency of the processes and equipment used to produce iron and steel is constrained by severe operating conditions (high temperatures, corrosive environments) and thermodynamic, kinetic, or transport limitations. These factors collectively contribute to proportionally high energy use per ton of product produced.

A snapshot of where the iron and steel sector ranks in terms of energy use and losses within manufacturing is shown in Table 2.6-2. Energy losses are shown in red font. All values are based on the most currently available complete set of manufacturing energy use statistics, representing annual energy use and loss values for calendar year 2006. The sector ranks among the top five in U.S. manufacturing in most energy end use categories. 
Table 2.6-2. Snapshot of the iron and steel sector: Energy use and rank within U.S. manufacturing

\begin{tabular}{|l|c|c|}
\hline \multicolumn{1}{|c|}{ Category } & Rank & $\begin{array}{c}\text { Energy } \\
\text { (TBtu) }\end{array}$ \\
\hline Total primary energy & 5 & 1,481 \\
Offsite losses & 4 & 439 \\
Onsite energy & 5 & 1,043 \\
Onsite losses & 5 & 550 \\
$\quad$ Steam generation and distribution & 5 & 78 \\
$\quad$ Electricity generation & 4 & 8 \\
$\quad$ Process energy & 5 & 431 \\
$\quad$ Nonprocess energy & 9 & 33 \\
Feedstock energy & 3 & 448 \\
Total primary and feedstock energy* & 5 & 1,557 \\
\hline GHG combustion emissions & 5 & MMT CO$_{\mathbf{2}} \mathbf{e}$ \\
Total & 6 & 62 \\
Onsite & \multicolumn{2}{|c|}{} \\
\hline *When total primary energy and feedstock energy are summed, the energy value of byproduct fuels derived from \\
feedstock energy sources is excluded to avoid double counting of feedstock energy \\
\hline
\end{tabular}

Although outside the scope of the footprint analysis, a substantial amount of energy in the iron and steel sector is consumed as non-fuel feedstocks in this sector. As shown in Fig. 2.6-1, the total feedstock energy consumed by the sector is $448 \mathrm{TBtu}$. The only two manufacturing sectors with greater feedstock energy use are the petroleum refining sector (NAICS 324110, feedstock energy consumption equal to 3.4 quads) and the chemicals sector (NAICS 325, feedstock energy consumption equal to 2.8 quads).

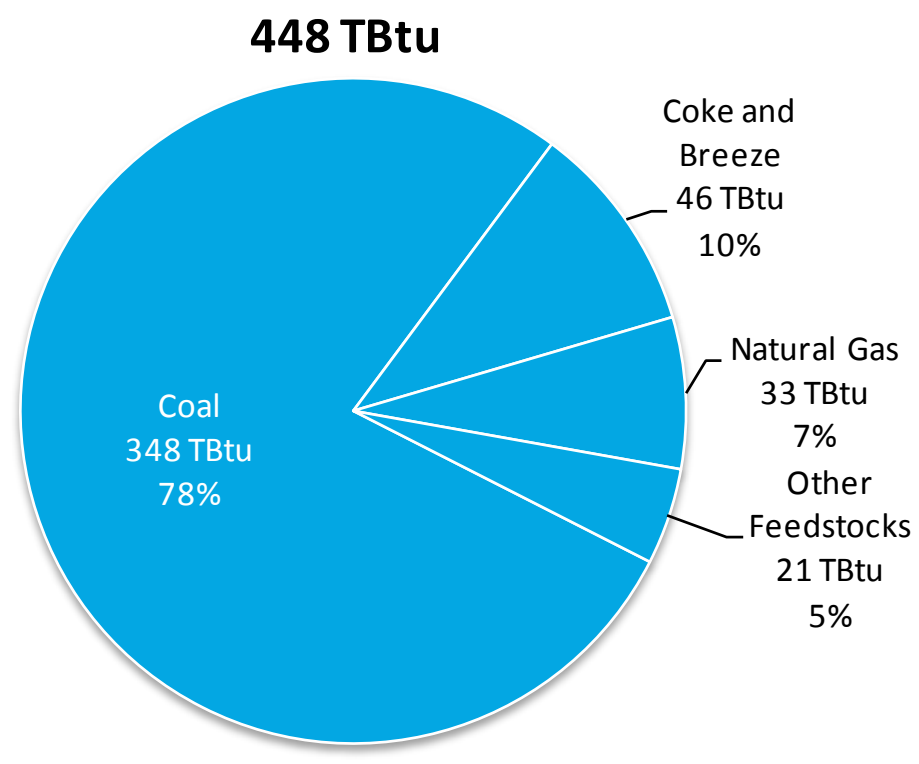

Fig. 2.6-1. Feedstock energy use in the iron and steel sector 


\subsubsection{Energy and carbon footprint}

The Manufacturing Energy and Carbon Footprint for the iron and steel sector is shown in Fig. 2.6-2 and Fig. 2.6-3. The footprint serves as the basis for characterizing the offsite and onsite flow of energy, as well as carbon emissions from generation through end use in this sector.

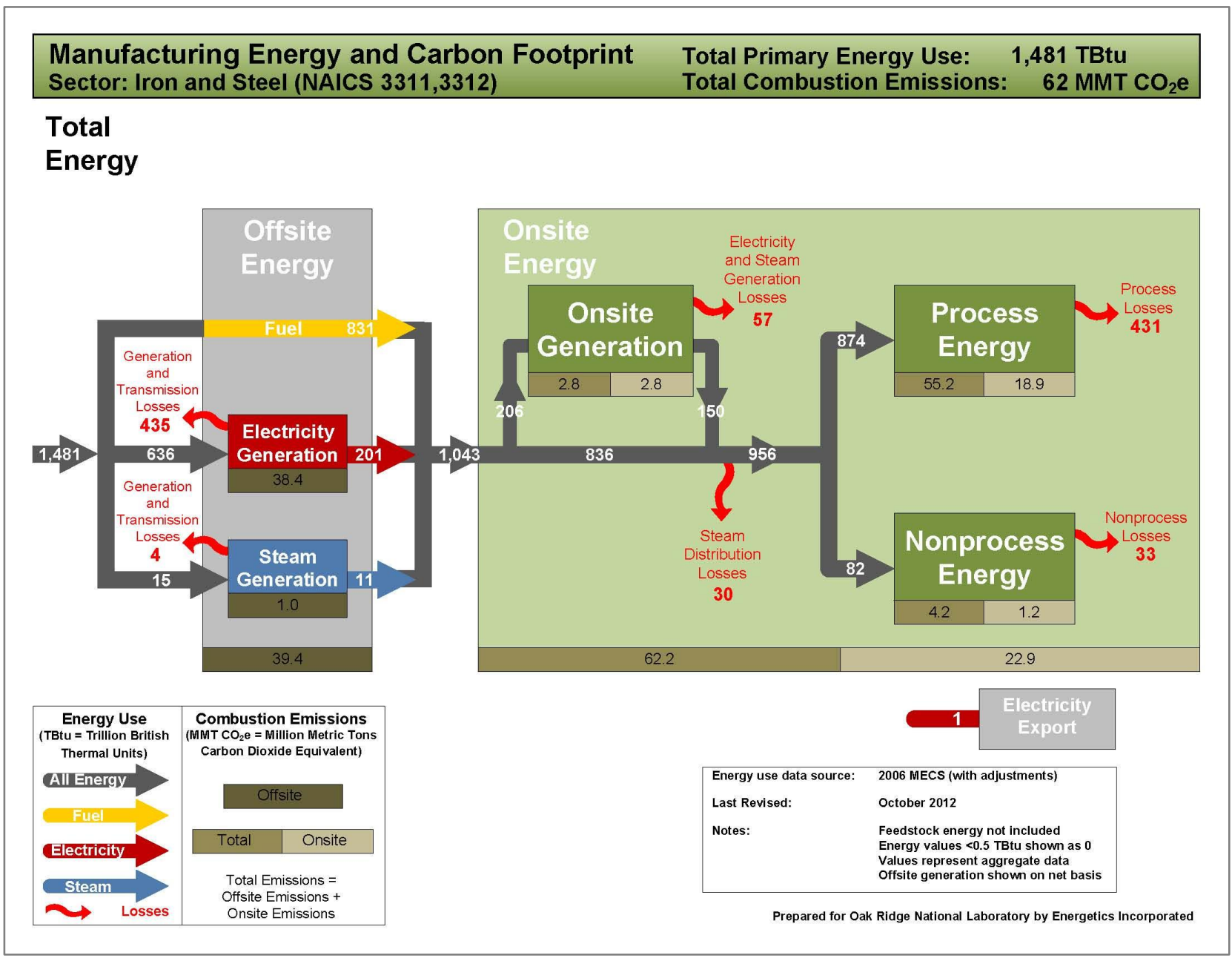

Fig. 2.6-2. Total energy and carbon footprint for the iron and steel sector 


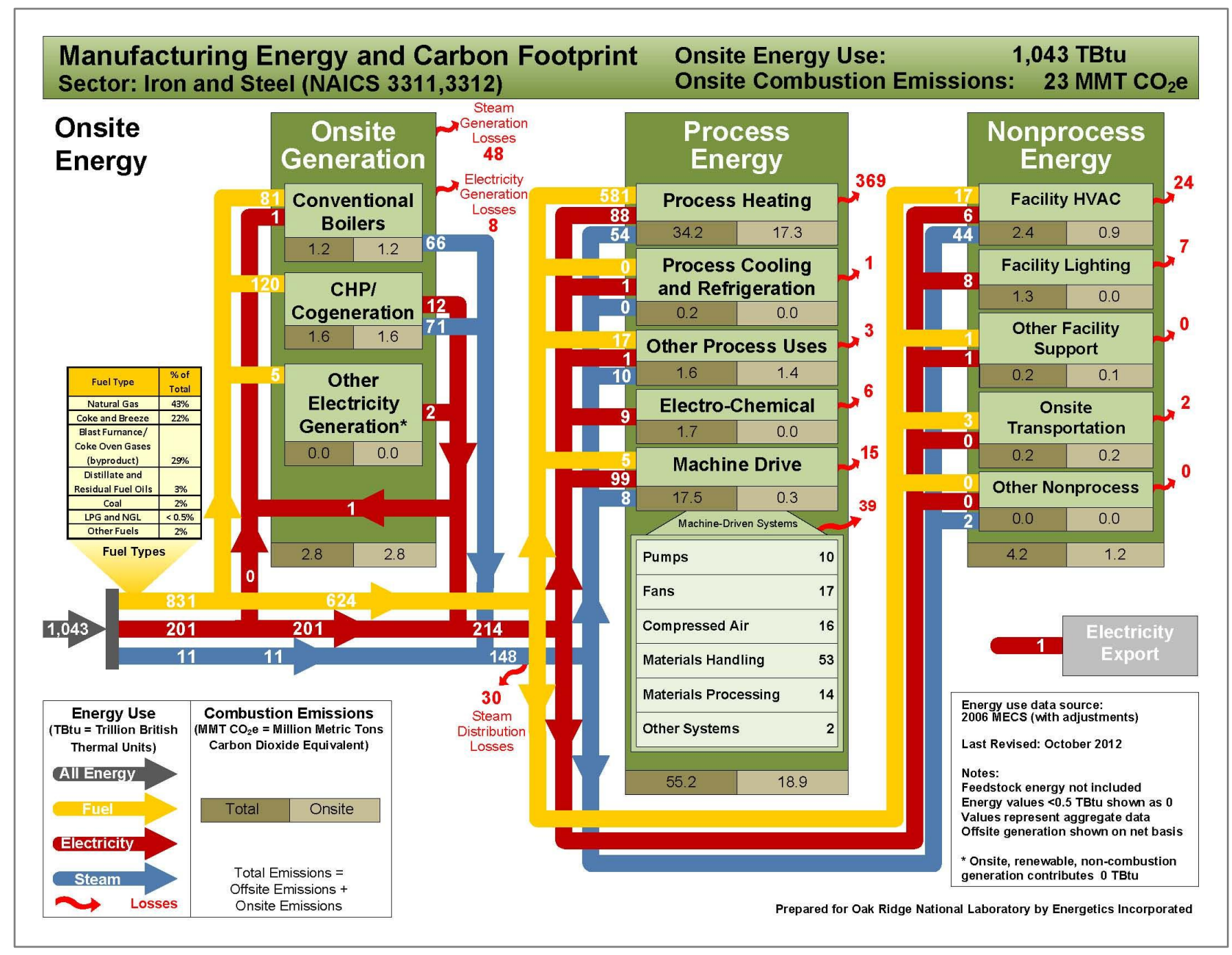

Fig. 2.6-3. Onsite energy and carbon footprint for the iron and steel sector

\subsubsection{Primary energy}

Primary energy use includes fuels, electricity, and steam consumed in manufacturing, including the generation and distribution/transmission losses associated with offsite and onsite electricity and steam generation. The primary energy use by energy type for the iron and steel sector is depicted in Fig. 2.6-4. Consistent with the footprints, blue represents steam energy, red represents electric energy, and yellow represents fuel energy.

The iron and steel sector consumes 1,481 TBtu of primary energy. Electricity generation accounts for the largest portion of this total $-657 \mathrm{TBtu}(44 \%)$. Offsite electricity generation and transmission losses account for two-thirds of electricity generation energy consumption (435 TBtu) while $201 \mathrm{TBtu}$ of offsite electricity enters the plant boundary. Onsite electricity generation accounts for only 13 TBtu and onsite electricity losses account for a further 8 TBtu of energy.

Direct fuel use is the next largest category of primary energy, consuming 624 TBtu (42\%) of total primary energy consumption. Natural gas is the most used fuel, accounting for nearly half of direct fuel consumption at $322 \mathrm{TBtu}$, while coke and breeze is the next largest fraction of direct fuel at $181 \mathrm{TBtu}$. Blast furnace gas (a byproduct fuel of coke and breeze) and coke oven gas (also a byproduct fuel) together consume 90 TBtu for direct fuel uses. Other fuels including coal, residual fuel oil, and distillate fuel oil consume the remaining 32 TBtu of direct fuel energy. 
Steam is the smallest category of primary energy — consuming $200 \mathrm{TBtu}(14 \%)$ of total primary energy. Onsite generation of steam accounts for $109 \mathrm{TBtu}$ of this total, while losses from onsite steam generation and distribution account for an additional $78 \mathrm{TBtu}$. In contrast with electricity generation, only $6 \%$ of steam generation energy is offsite.

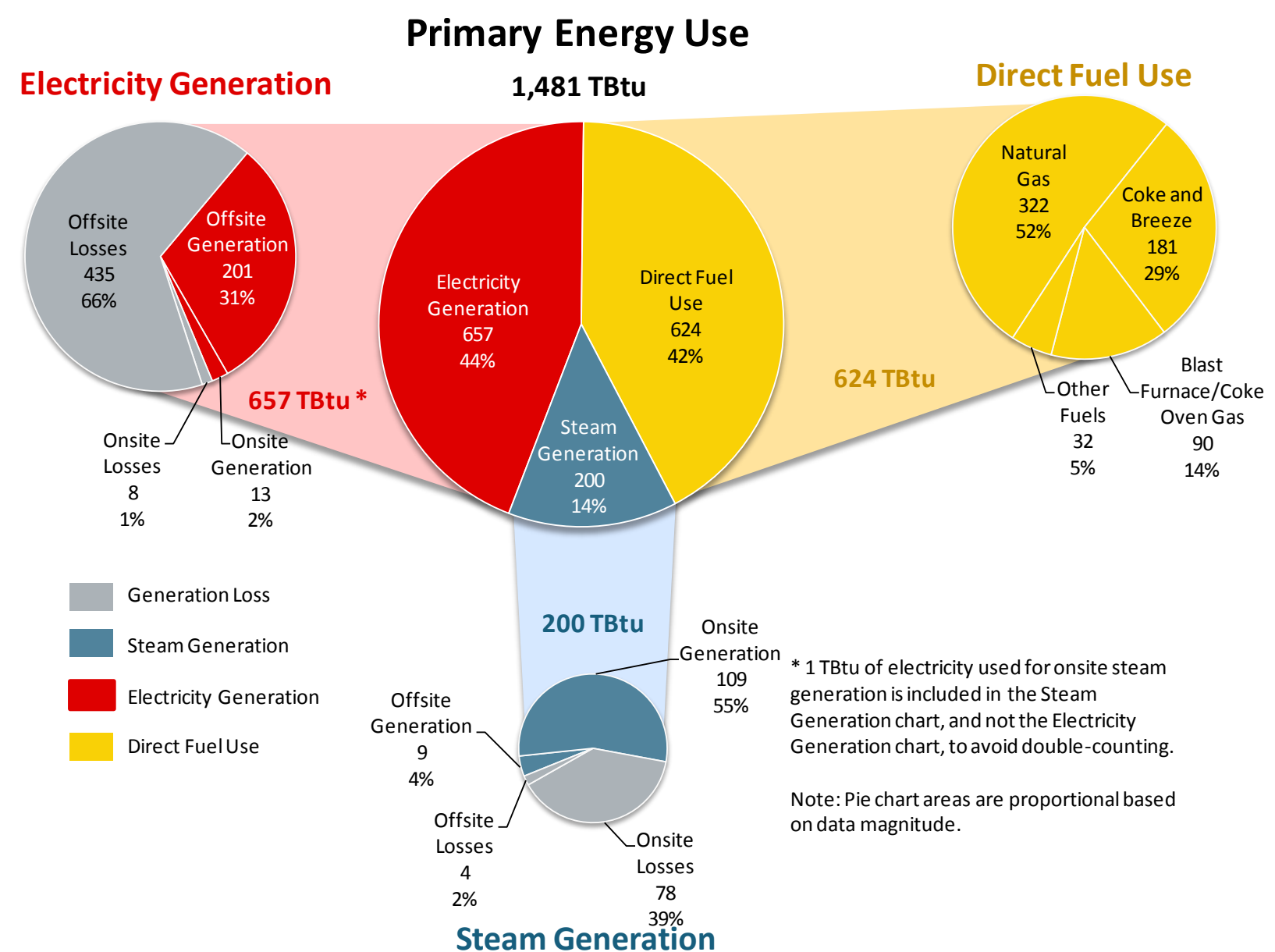

Fig. 2.6-4. Primary energy by energy type in the iron and steel sector

\subsubsection{Onsite energy}

Onsite energy enters the plant boundary in the form of three offsite energy types: fuel, steam, and electricity. The onsite energy consumed in iron and steel manufacturing in 2006 was 1,043 TBtu, or 70\% of primary energy. As shown in Fig. 2.6-5, the onsite energy supply consists mainly of fuel. Offsite electricity accounts for $19 \%$, and offsite steam only $1 \%$, of the offsite energy supply. The largest fuel type supplied to the iron and steel sector is natural gas, at $34 \%$, followed by byproduct waste gases including blast furnace and coke oven gases which account for a further $23 \%$ of the total. Compared to other sectors, the iron and steel sector is unique for its heavy reliance on coke and breeze purchased from offsite sources, which contributes $181 \mathrm{TBtu}$ or 17\% of onsite energy use. It should be noted that this value of coke and breeze fuel use has been adjusted downward to avoid the double counting of fuel use with blast furnace gas. 


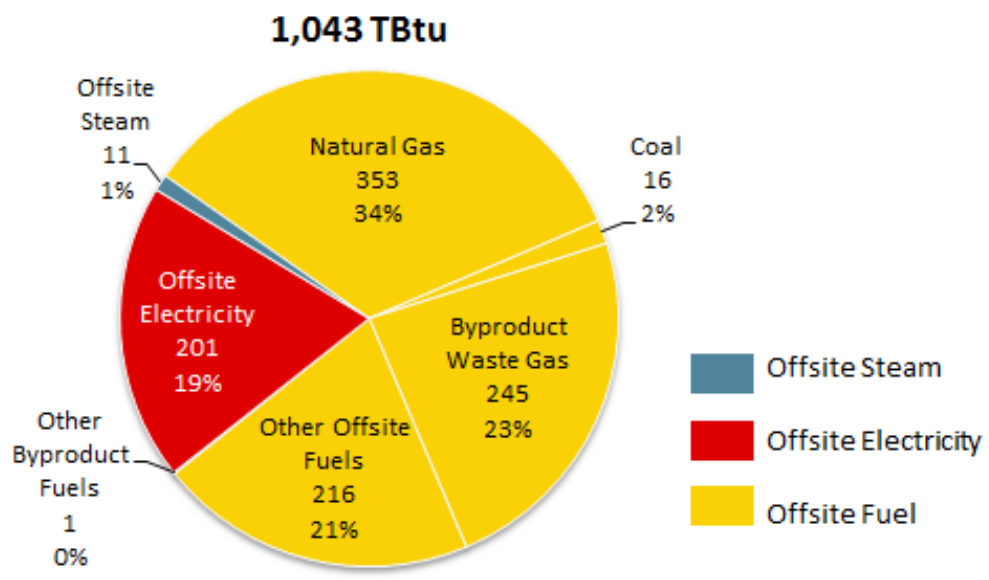

Fig. 2.6-5. Offsite energy supply in the iron and steel sector

Figure 2.6-6 illustrates the energy use patterns across major iron and steel subsectors. The vast majority (94\%) of energy use within the sector occurs in iron and steel mills (NAICS 331111) subsector. The other two NAICS-based subsectors with data shown in MECS, electrometallurgical ferroalloy products and steel products from purchased steel, consume less than $5 \%$ of sector fuel and electricity use.

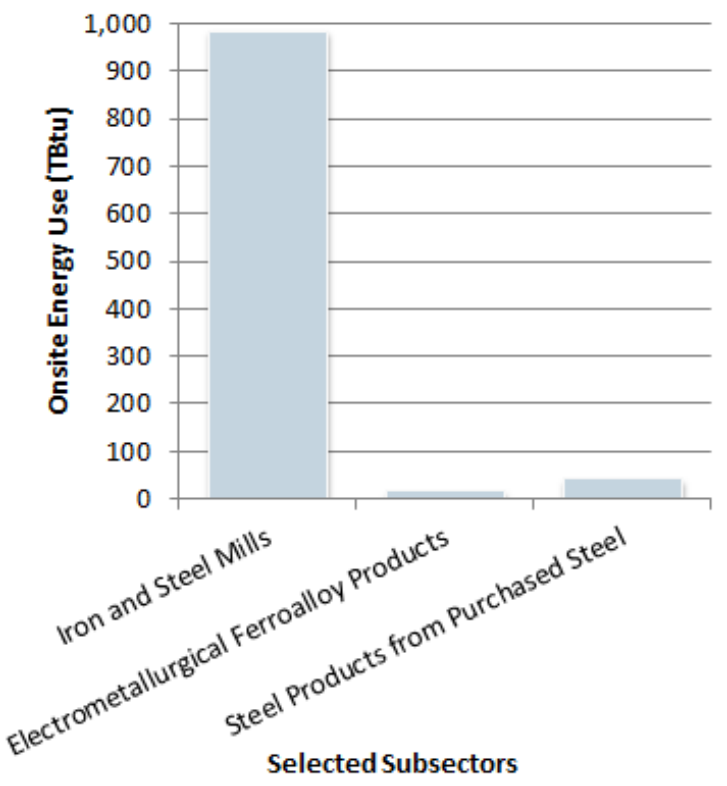

Fig. 2.6-6. Onsite energy use in selected iron and steel subsectors

\subsubsection{Fuel energy}

Onsite fuel use in the iron and steel sector was 831 TBtu in 2006. Natural gas is the largest source of fuel in the sector, supplying $43 \%$ of onsite fuel. The iron and steel sector is also reliant on coke and breeze and utilizes byproduct fuels including coke oven gases and blast furnace gases.

EIA MECS data assumes for purposes of estimation that all energy sources used for fuel are completely consumed in the process. However, in the case of iron making processes using blast furnaces, incomplete consumption of blast furnace fuel inputs may be a significant cause of duplication. Following a literature reviews and consultation with iron and steel industry experts, it was determined that the majority of blast furnace gas formation results from the input fuel use of coke. To address this issue, MECS suggests adjusting the fuel use of coal coke downward by the heat content of the blast furnace gas consumed in the 
sector, which is approximately two-thirds. ${ }^{17}$ As a result, this analysis has adjusted the reported MECS coke and breeze value downward to avoid double-counting between coke consumed in a blast furnace and blast furnace gases. About two-thirds of byproduct waste gases are assumed to be blast furnace gases; thus, coke and breeze energy consumption was adjusted down by two-thirds of $245 \mathrm{TBtu}$ (163 TBtu).

\subsubsection{Electrical energy}

The iron and steel sector is ranked fourth in the use of onsite direct electricity. A large portion of primary use is associated with generation, transmission and distribution (T\&D) losses, taking place mostly offsite. On average, the efficiency of utility electricity generation and transmission is assumed to be $31.6 \%$, resulting in over 419 TBtu of energy losses in order to produce $201 \mathrm{TBtu}$ of electricity that is used in the sector. A profile of electricity generation, use, and loss is shown in Fig. 2.6-7.

The sector does meet a small portion of its electricity demand through onsite generation. About 13 TBtu of energy use is associated with onsite electricity generation. Most of the electricity produced onsite in the steel sector comes from CHP units; less than $20 \%$ of onsite generation is produced using other generation methods, such as the generators running on combustible energy sources or renewable resources.

Nearly half $(46 \%)$ of electricity use in the iron and steel sector is consumed by machine-driven systems such as compressors, fans, motors, and pumps. Process heating end uses is the next largest category of electricity consumption within the sector, consuming $41 \%$ of electricity use. Electric arc furnaces, which use electric power to melt scrap steel and produce new steel, is the major process heating user of electricity. Other heating methods such as induction heaters also consume large amounts of electricity. Less than 15\% of sector electricity use is consumed by other process uses such as process cooling and refrigeration, electrochemical processes, and nonprocess uses such as facility HVAC and lighting.

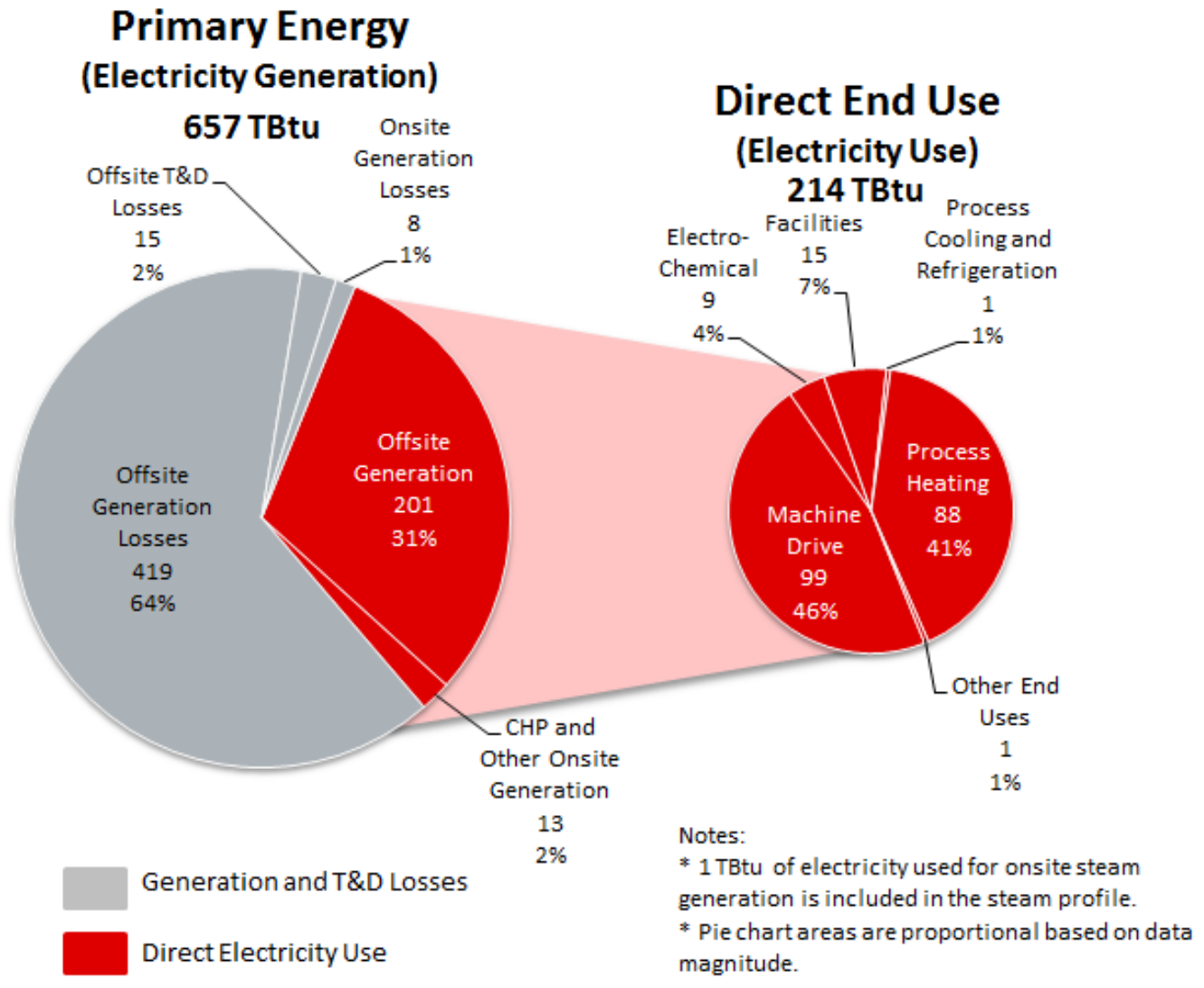

Fig. 2.6-7. Electricity generation and direct end use in the iron and steel sector

${ }^{17}$ [2002 Manufacturing Energy Consumption Survey (MECS) Methodology, http://www.eia.doe.gov/emeu/mecs/mecs2002/methodology_02/meth_02.html] 


\subsubsection{Steam energy}

A profile of iron and steel sector steam generation, use, and associated losses is shown in Fig. 2.6-8. Steam is produced through one of three methods: offsite steam that is transferred into plants or purchased through the local utility or other sources (9 TBtu), steam generated using CHP units (57 TBtu), and steam generated using conventional boilers (52 TBtu). Less than half of produced steam is lost through offsite generation and transmission losses (1 TBtu), onsite generation losses (48 TBtu), or onsite steam distribution losses (30 TBtu). Process heating applications use $46 \%$ of steam, with $38 \%$ used in facility HVAC, $8 \%$ used in other process uses, $7 \%$ used in machine-driven applications, and 1\% used in other nonprocess uses.

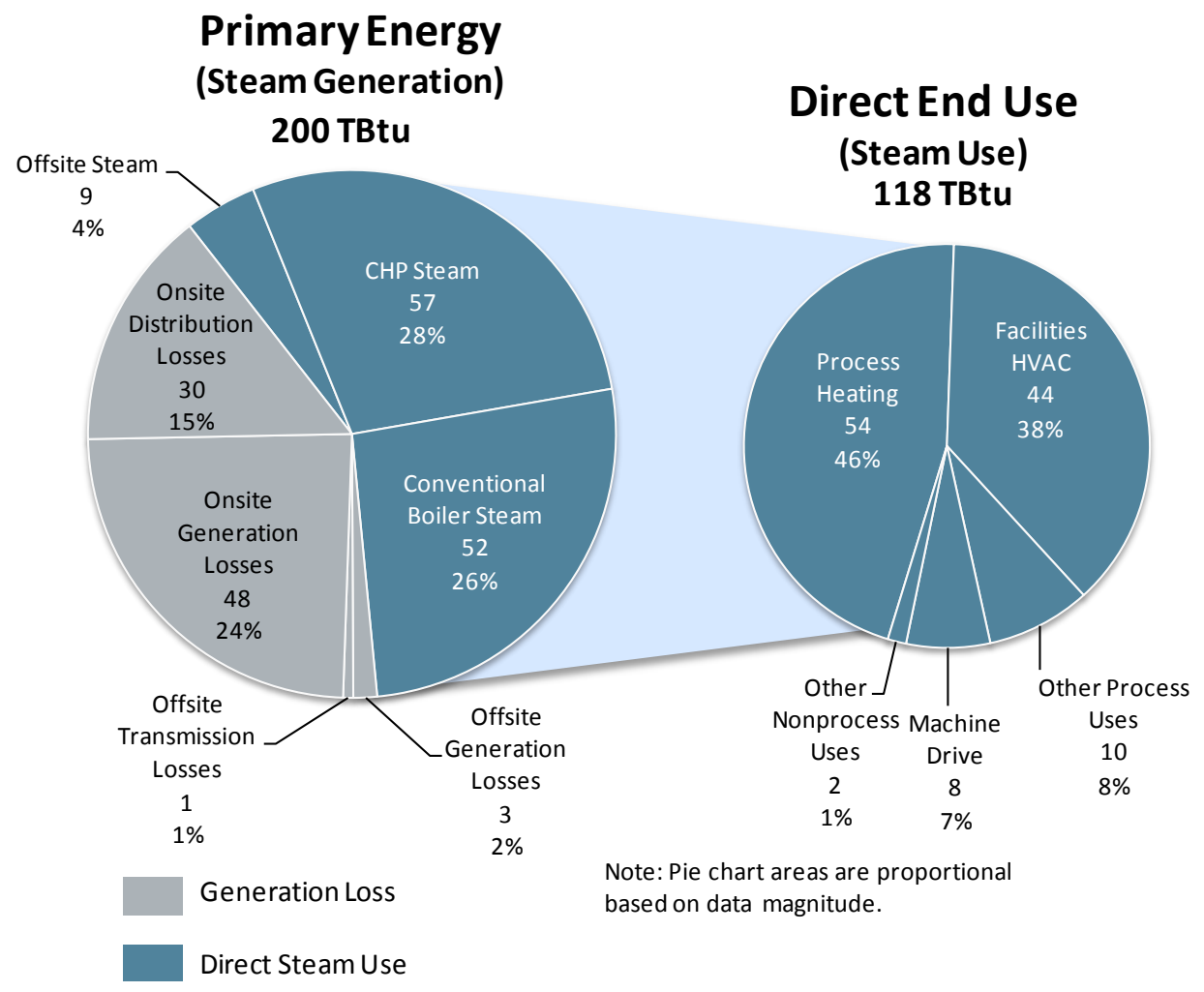

Fig. 2.6-8. Steam generation and direct end use in the iron and steel sector

\subsubsection{Combined heat and power energy}

Combined heat and power systems produce the majority of steam for iron and steel plants and also generate the majority of onsite electricity production. Blast furnace or coke oven gas is the main fuel used for CHP applications, followed by natural gas and other fuels including residual fuel oil and coal. CHP systems produce more steam than electricity, with CHP-generated steam production nearly six times greater than CHP-generated electricity. Nearly one-third of CHP fuel input results in losses. CHP fuel use and output is shown in Fig. 2.6-9. 


\section{CHP Indirect Fuel Use $\quad$ CHP Energy Output}

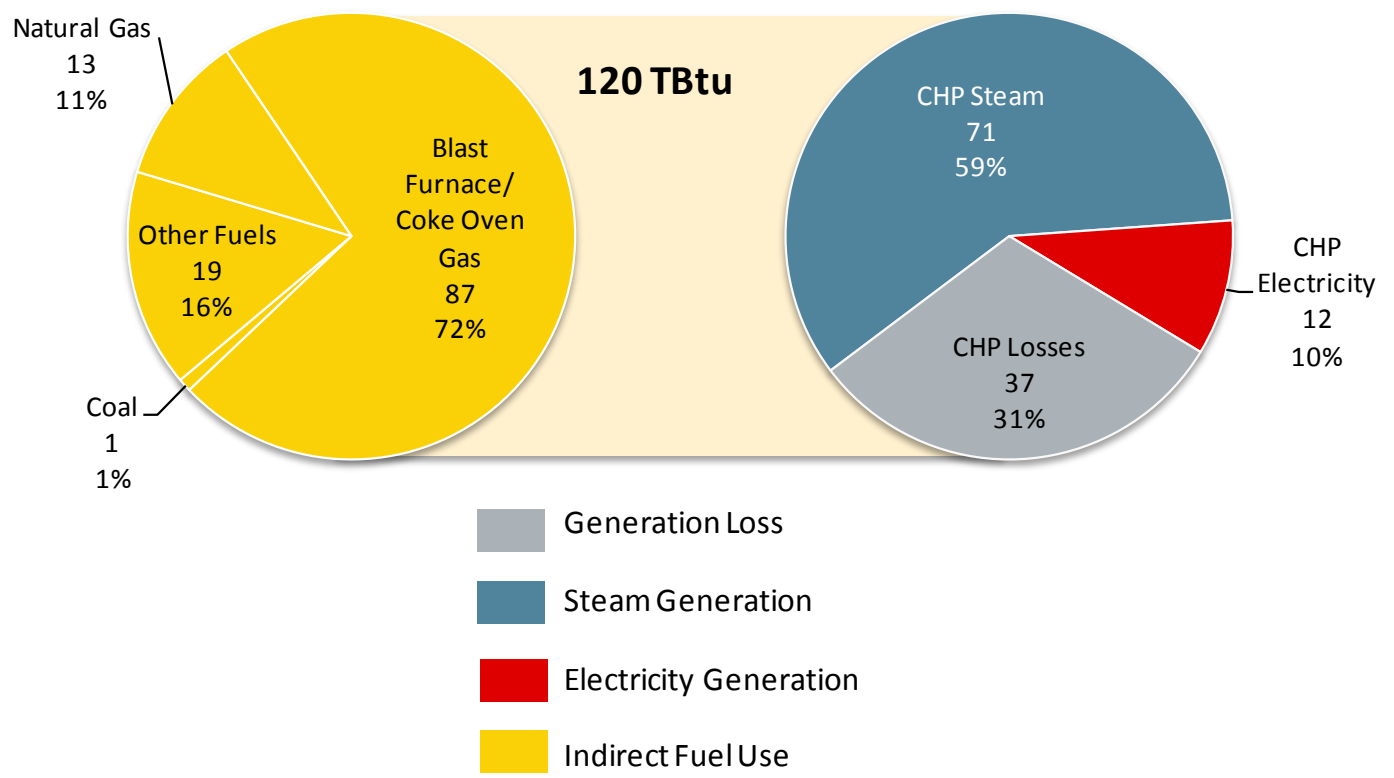

Fig. 2.6-9. CHP fuel consumption and energy output in the iron and steel sector

\subsubsection{Direct end use energy}

Figure 2.6-10 shows a simple breakdown of primary energy by type at direct end use. Direct fuel use is the largest share of direct energy use, while generation and distribution losses (including both electricity and steam generation losses) account for $36 \%$ of primary energy.

\section{$1,480 \mathrm{TBtu}$}

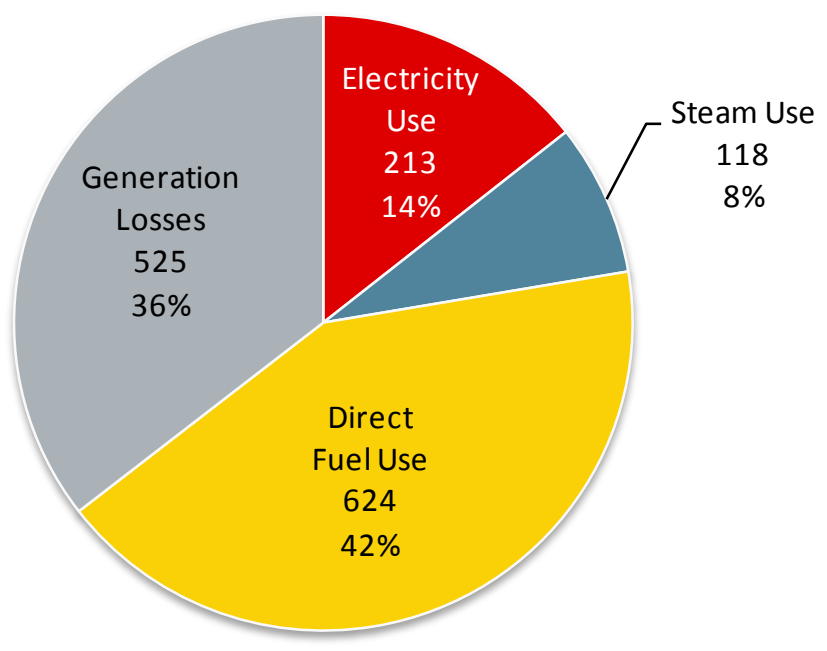

Fig. 2.6-10. Primary energy by type at direct end use in the iron and steel sector

The direct end uses of energy are shown in Fig. 2.6-11. The majority of energy is used directly for process use. Nonprocess uses account for only $6 \%$ of energy use in the sector. 


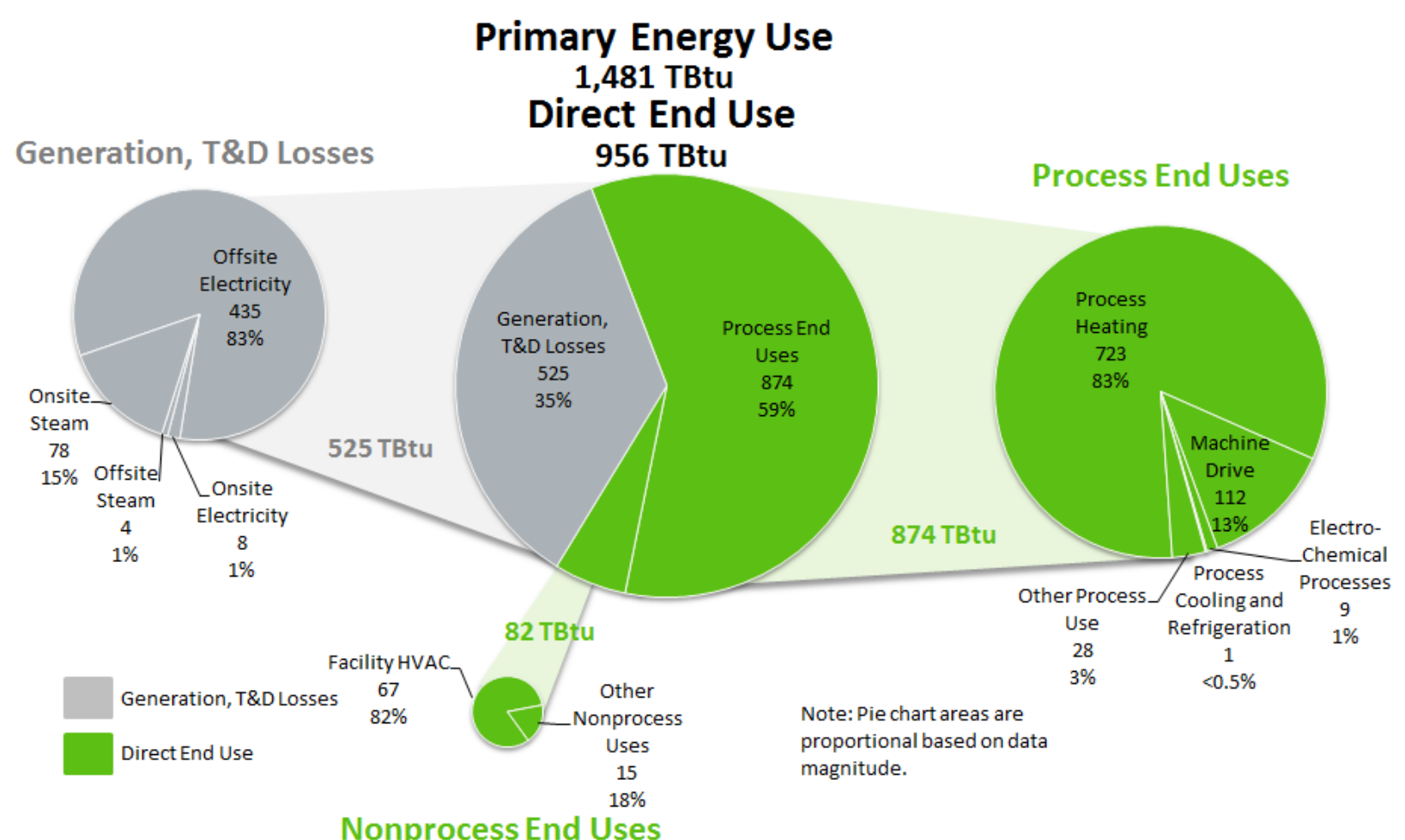

Fig. 2.6-11. Primary energy by direct end use in the iron and steel sector

Process heating is the single largest end use of energy, consuming 723 TBtu out of 874 TBtu (83\%) total delivered to process end uses. Natural gas, waste gas, and coke and breeze are the three major fuels for process heating, used largely for combustion-based furnaces in the iron and steel sector. Electricity is also a large source of energy for process heating, largely utilized by electric arc furnaces and induction heaters. Machine-driven systems are the next largest users of process energy, followed by electrochemical processes. Electricity is the principal source of energy for these processes, which are predominantly electric-based. Facility HVAC is the largest user of nonprocess energy, followed by facility lighting, and other nonprocess energy uses such as onsite transportation and other facility support.

\subsubsection{Applied end use energy}

In addition to the energy generation losses identified above, the direct end use losses have also been calculated in the energy footprint model. When both generation and end use losses are accounted for, the energy that remains is the applied energy. Applied energy can be illustrated by re-examining Fig. 2.6-4, which shows primary energy by energy type for U.S. manufacturing. Each of the energy types (i.e., fuel, electricity, or steam) shown in this figure have associated onsite and offsite generation losses (shown with onsite and offsite losses combined in light gray) that are incurred during energy generation (and transmission and distribution). While the majority of electricity generation losses take place offsite (as shown in Fig. 2.6-7), the majority of steam generation losses are onsite (as shown in Fig. 2.6-8), and direct fuel use is assumed to have no associated generation losses. The non-gray areas of each of the satellite pie charts show the energy that remains after generation losses. After taking into account these generation losses, a further portion of the remaining energy is lost at direct end uses, due to process and nonprocess system and equipment inefficiencies, shown in dark gray. The remaining energy is applied to end uses, shown in light green as "Applied Energy" in Fig. 2.6-12. 


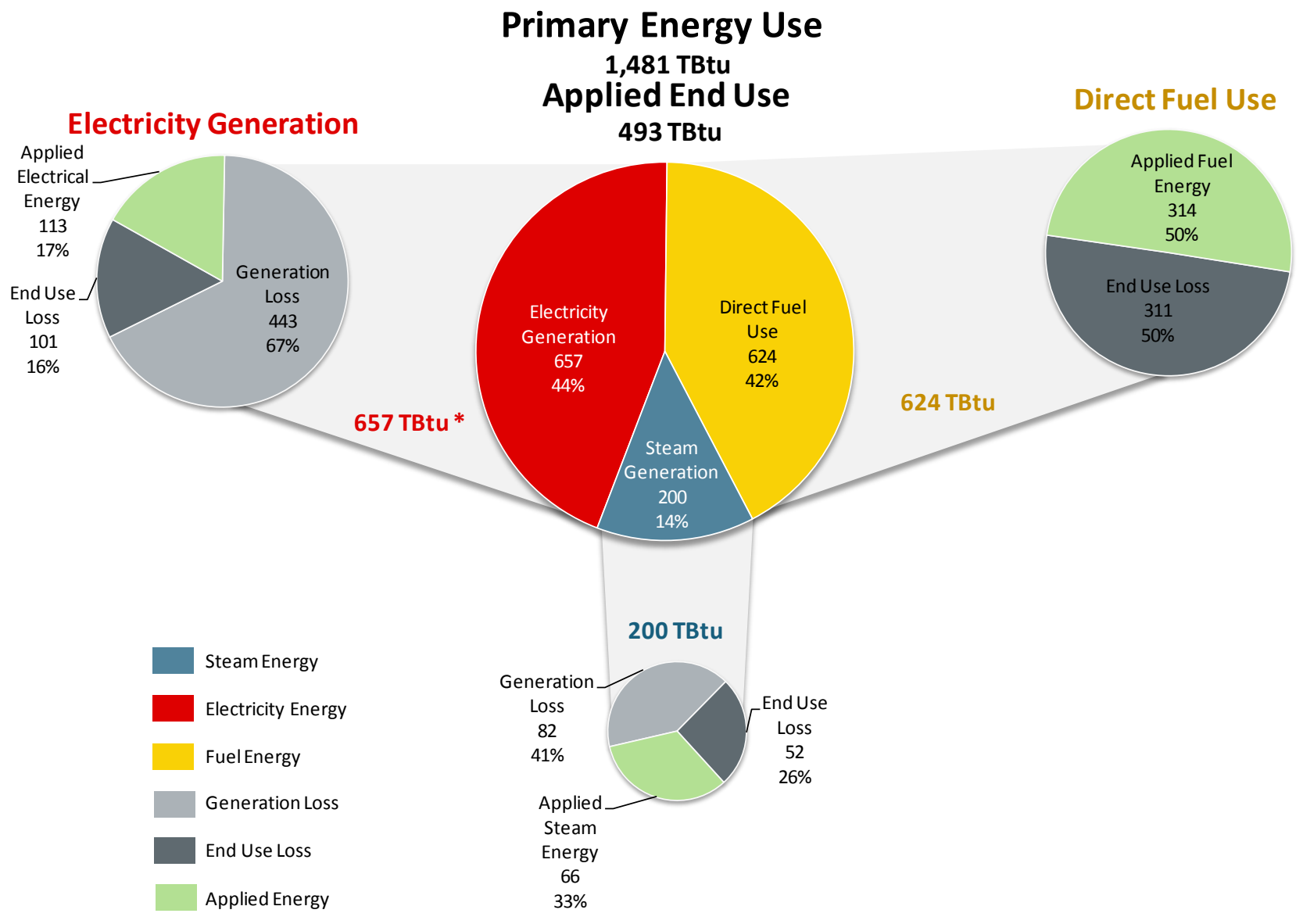

Steam Generation

Fig. 2.6-12. Primary energy and applied energy by energy type in the iron and steel sector

Figure 2.6-13 shows the breakdown of primary energy by energy loss and applied energy. In this sector, $33 \%$ of primary energy input is applied to process and nonprocess end uses. Generation losses account for $36 \%$ of primary energy input and end use losses account for the remaining $31 \%$ of primary energy input

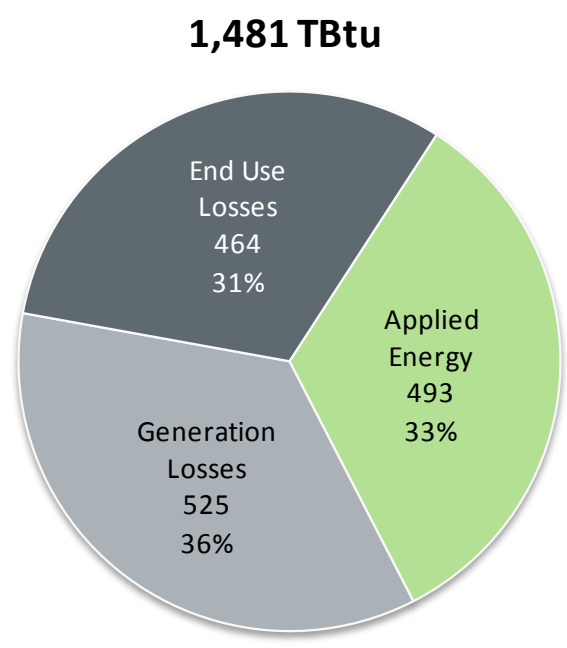

Fig. 2.6-13. Primary energy by loss and applied energy in the iron and steel sector 
Applied energy can also be calculated for specific end uses, as shown in Fig. 2.6-14. This figure shows generation losses labeled as either steam or electricity losses. End use losses are labeled as process or nonprocess losses; in the case of machine drive end use, process losses are further defined as machine drive, or machine driven system losses. For process heating, 38\% of primary energy is applied to the process (detail of the methodology to estimate process heating losses are shown in Appendix F). In machine-driven systems, only $18 \%$ of primary energy is applied, primarily because of the inefficiency in electricity generation.

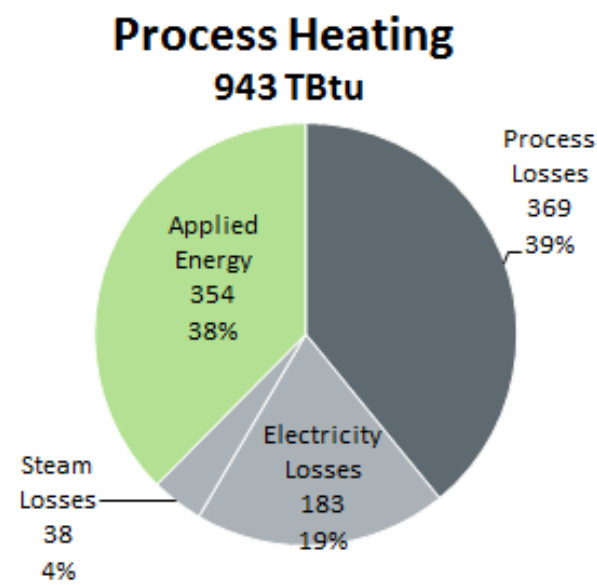

\section{Machine Drive 324 TBtu}

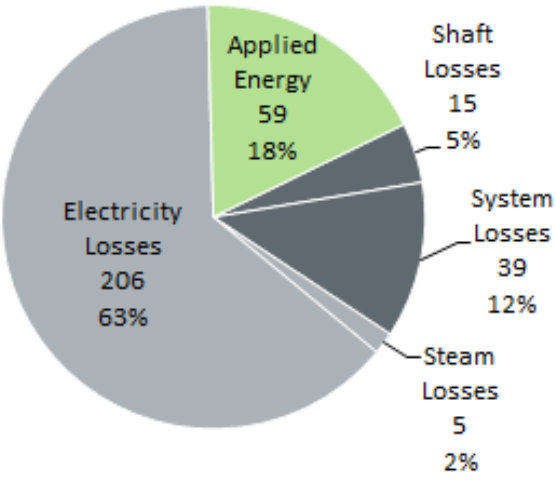

\section{Other Process End Uses} 69 TBtu

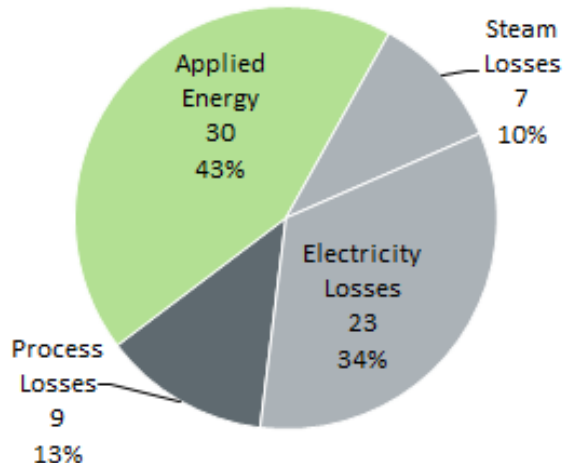

Nonprocess End Uses

146 TBtu

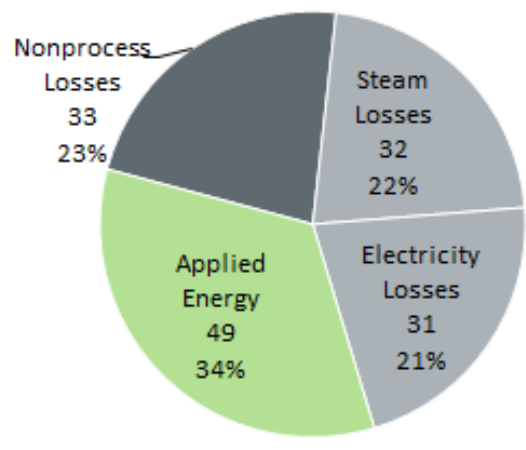

Generation Loss

End Use Loss

Applied Energy

Note: Pie chart areas are not proportional to magnitude of energy consumption

Fig. 2.6-14. Primary applied energy by direct end use in the iron and steel sector 


\subsubsection{Greenhouse Gas Combustion Emissions Profile for the Iron and Steel Sector}

Emissions from the iron and steel sector totaled $62 \mathrm{MMT} \mathrm{CO}_{2} \mathrm{e}$ in 2006, emitting the fifth-highest amount compared to other manufacturing sectors. Greenhouse gas emissions ${ }^{18}$ by offsite energy supply type are shown in Fig. 2.6-15. Emissions released during offsite production of electricity contribute $60 \%$ of sector emissions, while only $2 \%$ of emissions are attributed to the production of offsite steam. There is a comparatively small amount of offsite and onsite steam generation emissions in the iron and steel sector compared to other energy-intensive sectors. The onsite consumption of fuels (shown in yellow), including natural gas, byproduct fuels, coal, and other fuels accounts for $36 \%$ of total emissions. These fuels are used for both direct (e.g., process or nonprocess) and indirect (e.g., fuel for CHP units or boilers) end uses. Table D.5 shows fuel GHG combustion emission factors associated with fuel combustion, as well as electricity and steam generation.

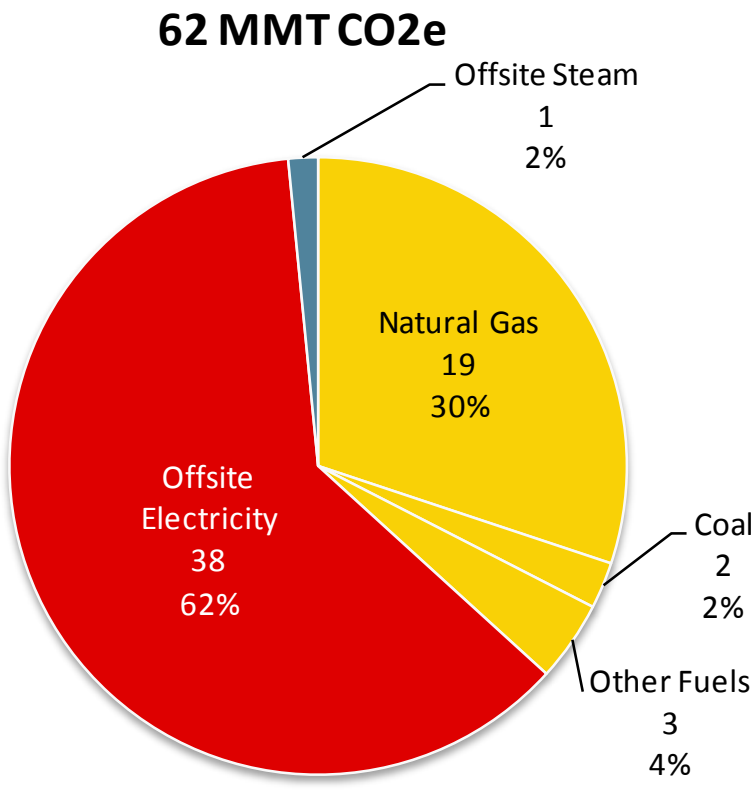

Fig. 2.6-15. Total GHG combustion emissions in the iron and steel sector (shown by energy supply type)

An alternative view of emissions is shown in Fig. 2.6-16, which also shows total emissions by energy type, but this figure assigns emissions to onsite electricity and steam production (as opposed to assigning emissions strictly to offsite supplied fuels). All emissions associated with electricity production are shown in red, including emissions released during offsite electricity generation and emissions released during onsite generation of electricity. All emissions associated with steam production are shown in blue, including emissions released during offsite steam generation and emissions released to generate steam onsite in boilers and CHP systems. Lastly, all emissions associated with fuel combustion at process and nonprocess end uses are shown in yellow. Electricity generation is the largest source of emissions; onsite electricity generation emissions are negligible, however offsite electricity contributes $62 \%$ of total emissions. Combined offsite and onsite steam emissions contribute an additional $6 \%$ of emissions, while the remaining $32 \%$ of emissions are released during fuel combustion for process and nonprocess end uses.

\footnotetext{
${ }^{18}$ Iron and steel production is an energy-intensive activity that also generates significant process-related emissions. In the iron and steel sector, carbon serves a dual purpose - as a reducing agent to convert iron oxides to iron, and also as an energy source. Methodologies for accounting between energy and process carbon emissions can vary in this sector, and are dependent on processes employed at individual facilities. For example, the IPCC indicates that all carbon used in blast and EAF furnaces should be considered as process emissions. As a detailed analysis of carbon emissions for this sector was beyond the scope of this report, it is assumed that all carbon emissions for blast furnace gas, coke oven gas, and coke and breeze in this sector are process emissions. Other reports such as the EPA Inventory of U.S. Greenhouse Gas Emissions and Sinks: 1990-2010 provide a more thorough analysis of the uncertainties and nuances involved in measuring and reporting GHG emissions for this sector.
} 


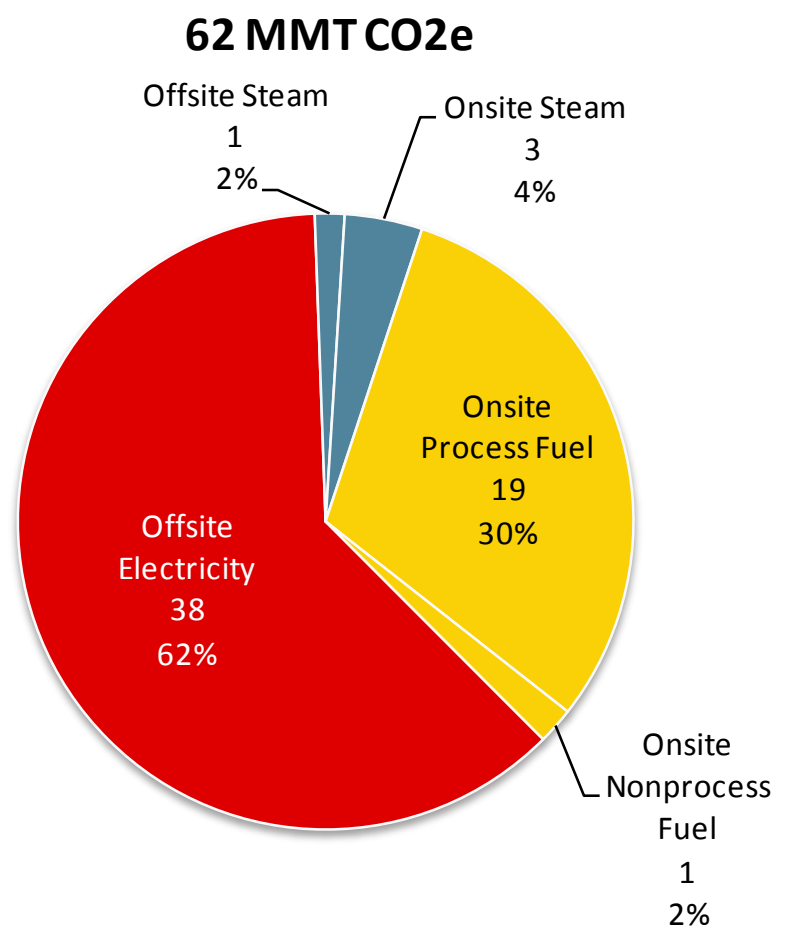

Fig. 2.6-16. Total GHG combustion emissions in the iron and steel sector (shown by energy end use type)

Emissions can also be associated with the direct end uses of energy, as is shown in Fig. 2.6-17. In this figure, the emissions released from offsite both offsite and onsite electricity and steam generation are distributed to direct end uses, along with emissions resulting from fuel consumed at the direct end uses. This pie chart allows for a direct comparison of the emissions resulting from individual direct process and nonprocess end uses. Process heating accounts for 57\% of emissions, while machine driven end uses account for $29 \%$ of emissions. The emissions associated other process and nonprocess uses are also shown in the figure.

\section{MMT CO2e}

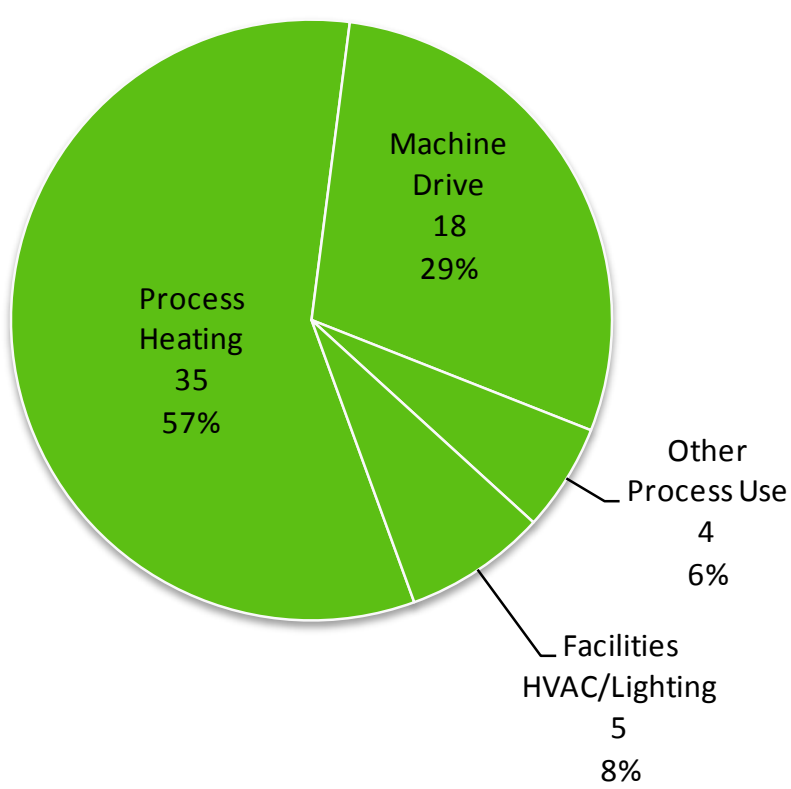

Fig. 2.6-17. Total GHG combustion emissions in the iron and steel sector (shown by direct energy end use) 


\subsubsection{Energy and Emissions Profile Summary Table}

The energy and emissions profiles for the iron and steel sector discussed above are summarized in Table 2.6-3 below. Offsite and onsite contributions to energy supply, use and loss are shown separately in this table, along with GHG combustion emissions. "Applied energy" is calculated for each direct energy use area by subtracting associated offsite and onsite energy losses. For GHG combustion emissions, emissions from the point of use, whether offsite or onsite, are depicted in the first emissions column; offsite emissions are combined with onsite emissions in the total emissions columns. The values in this table correspond to the energy and carbon footprints, which show two carbon values associated with each onsite end use: at point of use and the total based on onsite use.

Table 2.6-3. Energy use, loss, and GHG combustion emissions in the iron and steel sector

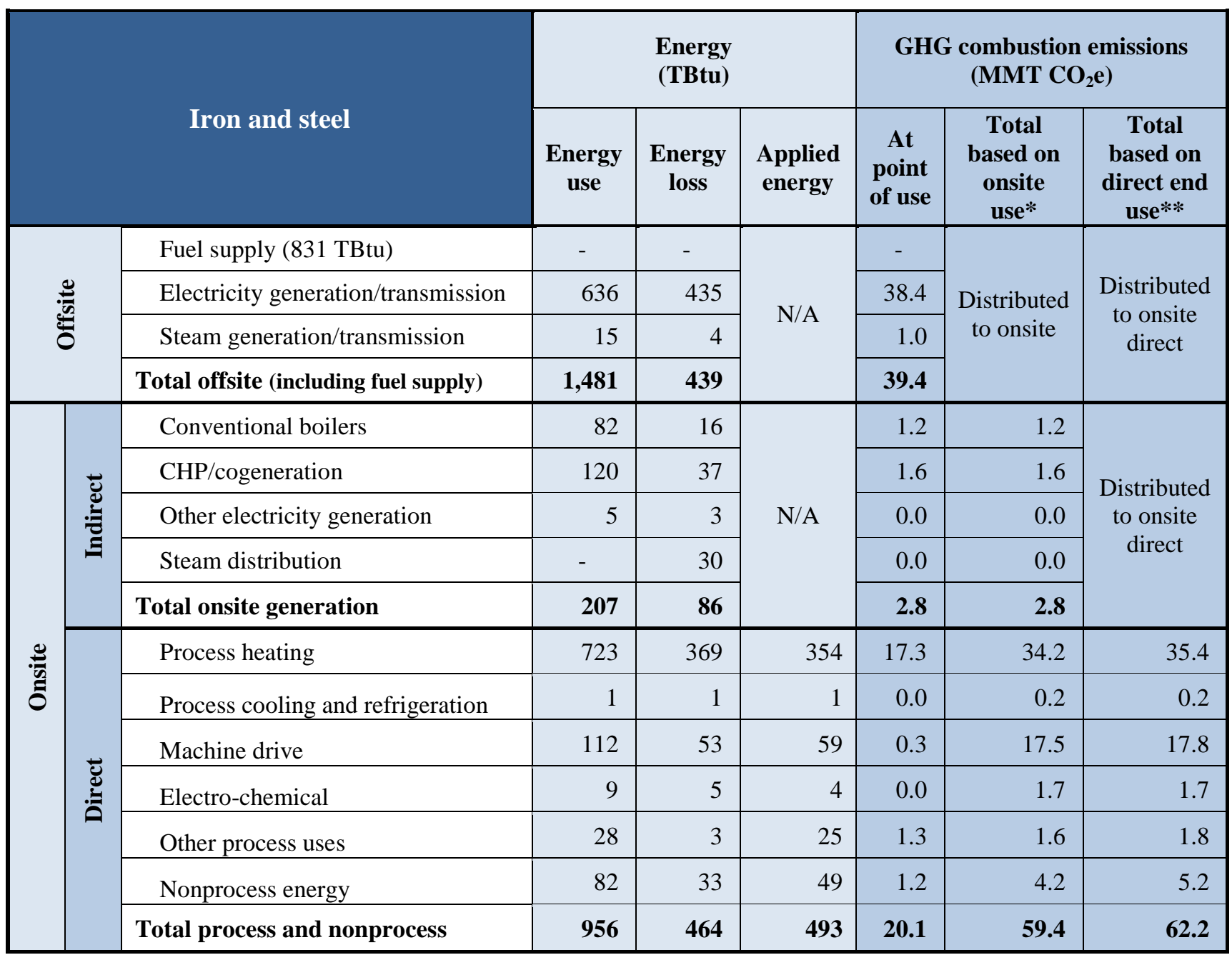

* These values are referenced as "Total" emissions in the footprints, Total emissions = onsite emissions + offsite emissions (i.e., emissions associated with offsite generation are distributed to indirect and direct onsite end uses)

** These values represent direct end use carbon emissions only (i.e., emissions associated with offsite and onsite generation are distributed to direct (and final) end use) 


\section{REFERENCES}

AMO (Advanced Manufacturing Office), EERE (Energy Efficiency and Renewable Energy). 2012a. Consider Installing High-Pressure Boilers with Backpressure Turbine-Generators. U.S. Department of Energy. http://www1.eere.energy.gov/manufacturing/tech deployment/pdfs/steam22 backpressure.pdf

AMO (Advanced Manufacturing Office), EERE (Energy Efficiency and Renewable Energy). 2012b. Improving Steam System Performance: A Sourcebook for Industry, Second Edition. DOE-GO $102012-$ 3423. Prepared by National Renewable Energy Laboratory, Golden, CO, Lawrence Berkeley National Laboratory, Washington, DC, and Resource Dynamics Corporation, Vienna, VA. U.S. Department of Energy. http://www1.eere.energy.gov/manufacturing/tech deployment/pdfs/steamsourcebook.pdf

AMO (Advanced Manufacturing Office), EERE (Energy Efficiency and Renewable Energy). 2012c. "Manufacturing Energy and Carbon Footprints." U.S. Department of Energy. http://www1.eere.energy.gov/manufacturing/resources/footprints.html

Beck, Theodore R. 2001. "Electrolytic Production of Aluminum." Case Western Reserve University. Last modified May 2008. http://electrochem.cwru.edu/encycl/art-a01-al-prod.htm

Bell, Arthur. HVAC Equations, Data, and Rules of Thumb. 2nd ed. United States: McGraw Hill, 2007.

Bennett, Bonnie, Mark Boddy, Frank Doyle, Mo Jamshidi, and Tunde Ogunnaike. 2004. Assessment Study on Sensors and Automation in the Industries of the Future: Reports on Industrial Controls, Information Processing, Automation, and Robotics. U.S. Department of Energy, Office of Energy Efficiency and Renewable Energy, Industrial Technologies Program.

http://www1.eere.energy.gov/manufacturing/industries_technologies/sensors_automation/pdfs/doe_report.pdf

BTP (Buildings Technology Program), EERE (Energy Efficiency and Renewable Energy. 2009. 2009 Buildings Energy Data Book. Prepared by D\&R International, Inc., Silver Spring, MD. U.S. Department of Energy. http://buildingsdatabook.eren.doe.gov/docs/DataBooks/2009_BEDB_Updated.pdf

EERE (Energy Efficiency and Renewable Energy). 2003. Improving Compressed Air System Performance: A Sourcebook for Industry. DOE-GO-102003-1822. Prepared by Lawrence Berkeley National Laboratory, Washington, DC, and Resource Dynamics Corporation, Vienna, VA. U.S. Department of Energy. http://www1.eere.energy.gov/manufacturing/tech_deployment/pdfs/compressed_air_sourcebook.pdf

EIA (U.S. Energy Information Administration). 1999. "Glossary for the Manufacturing Sector." U.S. Department of Energy. http://www.eia.doe.gov/emeu/efficiency/mecs_glossary.htm

EIA (U.S. Energy Information Administration). 2005. "2002 Manufacturing Energy Consumption Survey Methodology and Data Quality: Survey Design, Implementation, and Estimates." U.S. Department of Energy. http://www.eia.doe.gov/emeu/mecs/mecs2002/methodology_02/meth_02.html

EIA (U.S. Energy Information Administration). 2006. "Form EIA-906, EIA-920, and EIA-923

Databases." U.S. Department of Energy. http://www.eia.doe.gov/cneaf/electricity/page/eia906_920.html

EIA (U.S. Energy Information Administration). 2007. "2006 Manufacturing Energy Consumption Survey Form EIA-846.” U.S. Department of Energy.

http://www.eia.doe.gov/emeu/mecs/mecs2006/EIA-846A_2006.pdf

EIA (U.S. Energy Information Administration). 2008. "Voluntary Reporting of Greenhouse Gases." U.S. Department of Energy. http://www.eia.doe.gov/oiaf/1605/

EIA (U.S. Energy Information Administration). 2009. "Manufacturing Energy Consumption Survey (MECS): 2006 Energy Consumption by Manufacturers -- Data Tables.” U.S. Department of Energy. http://www.eia.doe.gov/emeu/mecs/mecs2006/2006tables.html

EIA (U.S. Energy Information Administration). 2010a. Annual Energy Review 2009. DOE/EIA-0384 (2009), U.S. Department of Energy. http://www.eia.gov/totalenergy/data/annual/archive/038409.pdf

EIA (U.S. Energy Information Administration). 2010b. Monthly Energy Review November 2010. DOE/EIA-0035 (2010/11), U.S. Department of Energy. http://www.eia.gov/totalenergy/data/monthly/archive/00351011.pdf 
Elliott, R. N., and S. Nadal. 2003. Realizing Energy Efficiency Opportunities in Industrial Fan and Pump Systems. A034, American Council for an Energy-Efficient Economy. http://aceee.org/research$\underline{\text { report } / \mathrm{a} 034}$

EPA (U.S. Environmental Protection Agency). 2002. Technology Characterization: Gas Turbines. Prepared by Energy Nexus Group, Arlington, VA. U.S. Environmental Protection Agency. http://www.stsm.ir/resources/10301-09101387135242Technology\%20Characterization\%20Gas\%20Turbines.pdf

EPA (U.S. Environmental Protection Agency). 2007. "Emissions and Generation Resource Integrated Database (eGRID), eGRID2007 Version 1.1." U.S. Environmental Protection Agency. Last modified May 10. http://www.epa.gov/cleanenergy/egrid

EPA (U.S. Environmental Protection Agency). 2009a. "Glossary of Climate Change Terms." U.S. Environmental Protection Agency. Last modified June 14. http://www.epa.gov/climatechange/glossary.html

EPA (U.S. Environmental Protection Agency). 2009b. "Mandatory Greenhouse Gas Reporting Rule." U.S. Environmental Protection Agency, 40 CFR Part 98. Last modified August 30. http://www.epa.gov/ghgreporting/basic-info/index.html

EPA (U.S. Environmental Protection Agency). 2010. Inventory of U.S. Greenhouse Gas Emissions and Sinks: 1990-2008. U.S. Environmental Protection Agency. http://www.epa.gov/climatechange/Downloads/ghgemissions/508_Complete_GHG_1990_2008.pdf

Gates Corporation. 2009. Improving Motor System Efficiency with High Efficiency Belt Drive Systems. Gates Corporation.

http://www.gates.com/ptPartners/file_display_common.cfm?thispath=Gates\%2Fdocuments module\&file=motorswp final.pdf

Giraldo, Luis, and Barry Hyman. "Energy End-Use Models for Pulp, Paper, and Paperboard Mills." Energy 20(10): 1005-19.

Granade, Hannah Choi, Jon Creyts, Anton Derkach, Philip Farese, Scott Nyquist, and Ken Ostrowski. 2009. Unlocking Energy Efficiency in the U.S. Economy. McKinsey \& Company. http://www.mckinsey.com/client_service/electric_power_and_natural_gas/latest_thinking/unlocking_energy_efficienc y_in the us_economy

Hooper, Frederic A., and Ronald D. Gillette. 1999. "How Efficient is Your Steam Distribution System?” Steam Conservation Systems. www.swopnet.com/engr/stm/steam_dist_eff.html

IEA (International Energy Agency). 2006. Light's Labour's Lost: Policies for Energy Efficient Lighting. Paris: International Energy Agency.

http://www.iea.org/publications/freepublications/publication/light2006.pdf

IEA (International Energy Agency). 2007. Tracking Industrial Energy Efficiency and $\mathrm{CO}_{2}$ Emissions. Paris: International Energy Agency. http://www.iea.org/textbase/nppdf/free/2007/tracking_emissions.pdf

IPCC (Intergovernmental Panel on Climate Change). 2007. Climate Change 2007. Intergovernmental Panel on Climate Change, Fourth Assessment Report. http://www.ipcc.ch/publications_and_data/publications_and_data_reports.htm\#1

ITP (Industrial Technologies Program), EERE (Energy Efficiency and Renewable Energy). 2004a. Energy Loss Reduction and Recovery in Industrial Energy Systems. Prepared by Energetics, Incorporated, Columbia, MD. U.S. Department of Energy. http://www1.eere.energy.gov/manufacturing/intensiveprocesses/pdfs/reduction_roadmap.pdf

ITP (Industrial Technologies Program), EERE (Energy Efficiency and Renewable Energy). 2004b. Energy Use, Loss and Opportunities Analysis: U.S. Manufacturing \& Mining. Prepared by Energetics, Incorporated, Columbia, MD, and E3M, Incorporated, North Potomac, MD. U.S. Department of Energy. http://www1.eere.energy.gov/manufacturing/intensiveprocesses/pdfs/energy_use_loss_opportunities_analysis.pdf

ITP (Industrial Technologies Program), EERE (Energy Efficiency and Renewable Energy). 2005a. Estimating Motor Efficiency in the Field. DOE/GO-102005-2021. U.S. Department of Energy. http://www1.eere.energy.gov/manufacturing/tech_deployment/pdfs/estimate_motor_efficiency_motor_systemts2.pdf 
ITP (Industrial Technologies Program), EERE (Energy Efficiency and Renewable Energy). 2005b. Replace V-Belts with Cogged or Synchronous Belt Drives. DOE/GO-102005-2060. U.S. Department of Energy. http://www1.eere.energy.gov/manufacturing/tech deployment/pdfs/replace vbelts motor_systemts5.pdf

ITP (Industrial Technologies Program), EERE (Energy Efficiency and Renewable Energy). 2005c. Test for Pumping System Efficiency. DOE/GO-102005-2158. U.S. Department of Energy.

http://www1.eere.energy.gov/manufacturing/tech_deployment/pdfs/test_pumping_system_pumping_systemts4.pdf

ITP (Industrial Technologies Program), EERE (Energy Efficiency and Renewable Energy). 2006a. Improving Pump System Performance: A Sourcebook for Industry, Second Edition. DOE-GO 102006-2079. Prepared by Lawrence Berkeley National Laboratory, Berkeley, CA, Resource Dynamics Corporation, Vienna, VA, and the Alliance to Save Energy, Washington, DC. U.S. Department of Energy. http://www1.eere.energy.gov/manufacturing/tech_deployment/pdfs/pump.pdf

ITP (Industrial Technologies Program), EERE (Energy Efficiency and Renewable Energy). 2006b. Low-Temperature Reduction of Alumina Using Fluorine-Containing Ionic Liquids. U.S. Department of Energy. http://www1.eere.energy.gov/manufacturing/industries technologies/aluminum/pdfs/ionicliquids.pdf

ITP (Industrial Technologies Program), EERE (Energy Efficiency and Renewable Energy). 2008a. Improving Process Heating System Performance: A Sourcebook for Industry, Second Edition. DOE-GO 102008-2429. Prepared by Lawrence Berkeley National Laboratory, Berkeley, CA, and Resource Dynamics Corporation, Vienna, VA. U.S. Department of Energy and Industrial Heating Equipment Association. http://www1.eere.energy.gov/manufacturing/tech_deployment/pdfs/process_heating_sourcebook2.pdf

ITP (Industrial Technologies Program), EERE (Energy Efficiency and Renewable Energy). 2008b. Waste Heat Recovery: Technology and Opportunities in U.S. Industry. Prepared by BCS, Incorporated, Laurel, MD. U.S. Department of Energy.

http://www1.eere.energy.gov/manufacturing/intensiveprocesses/pdfs/waste_heat_recovery.pdf

ITP (Industrial Technologies Program), EERE (Energy Efficiency and Renewable Energy). 2009. Combined Heat and Power: A Decade of Progress, A Vision for the Future. U.S. Department of Energy. http://www1.eere.energy.gov/manufacturing/distributedenergy/pdfs/chp_accomplishments_booklet.pdf

ITP (Industrial Technologies Program), EERE (Energy Efficiency and Renewable Energy). 2010a. BestPractices Steam Specialist Qualification Training. U.S. Department of Energy.

ITP (Industrial Technologies Program), EERE (Energy Efficiency and Renewable Energy). 2010b. Linking Transformational Materials and Processing for an Energy Efficient and Low-Carbon Economy: Creating the Vision and Accelerating Realization. Prepared by The Minerals, Metals, and Mining Society. U.S. Department of Energy. http://energy.tms.org/docs/pdfs/VisionReport2010.pdf

ITP (Industrial Technologies Program), EERE (Energy Efficiency and Renewable Energy). 2010c. Wireless Sensor Technology. U.S. Department of Energy. http://www1.eere.energy.gov/manufacturing/industries_technologies/sensors_automation/pdfs/transformational_wirel ess.pdf

Motor Challenge. 1996. Buying an Energy-Efficient Electric Motor. DOE/GO-10096-314. U.S. Department of Energy. http://www1.eere.energy.gov/manufacturing/tech_deployment/pdfs/mc-0382.pdf

Motor Challenge. 1997. Determining Electric Motor Load and Efficiency. DOE/GO-10097-517. U.S. Department of Energy. http://www1.eere.energy.gov/manufacturing/tech_deployment/pdfs/10097517.pdf

OIT (Office of Industrial Technologies), EERE (Energy Efficiency and Renewable Energy). 2000. Overview of Energy Flow for Industries in Standard Industrial Classifications 20-39. 71563-00. Prepared by Arthur D. Little, Inc., Cambridge, MA. U.S. Department of Energy.

http://steamingahead.org/library/adlittle.pdf

OIT (Office of Industrial Technologies), EERE (Energy Efficiency and Renewable Energy). 2001. Assessment of the Market for Compressed Air Efficiency Services. DOE/GO-102001-1197. Prepared by XENERGY, Inc., Burlington, MA. U.S. Department of Energy. http://www1.eere.energy.gov/manufacturing/tech_deployment/pdfs/newmarket5.pdf

OIT (Office of Industrial Technologies), EERE (Energy Efficiency and Renewable Energy). 2002a. Steam System Opportunity Assessment for the Pulp and Paper, Chemical Manufacturing, and Petroleum 
Refining Industries. Prepared by Resource Dynamics Corporation, Vienna, VA. U.S. Department of Energy. http://www1.eere.energy.gov/manufacturing/tech deployment/pdfs/steam assess mainreport.pdf

OIT (Office of Industrial Technologies), EERE (Energy Efficiency and Renewable Energy). 2002b. United States Industrial Electric Motor Systems Market Opportunities Assessment, Prepared by Xenergy, Inc., Burlington, MA. U.S. Department of Energy and Oak Ridge National Laboratory.

http://www1.eere.energy.gov/manufacturing/tech_deployment/pdfs/mtrmkt.pdf

Ozalp, Nesrin, and Barry Hyman. 2007. "Allocation of Energy Inputs Among the End-Uses in the US Petroleum and Coal Products Industry.” Energy 32(8): 1460-70.

Ozalp, Nesrin, and Barry Hyman. 2006. "Energy End-Use Model of Paper Manufacturing in the US." Applied Thermal Engineering 26(5-6): 540-8.

Ozalp, Nesrin. 2008. "Energy and Material Flow Models of Hydrogen Production in the U.S. Chemical Industry.” International Journal of Hydrogen Energy 33(19): 5020-34.

Platts. 2004. "HVAC: Fans." Platts. http://www.reliant.com/en_US/Platts/PDF/P_PA_32.pdf

Roth, Kurt W., Detlef Westphalen, John Dieckmann, Sephir D. Hamilton, and William Goetzler. 2002. Energy Consumption Characteristics of Commercial Building HVAC Systems, Volume III: Energy Savings Potential. Prepared by TIAX LLC, Cambridge, MA. U.S. Department of Energy, Building Technologies Program. http://apps1.eere.energy.gov/buildings/publications/pdfs/commercial_initiative/hvac_volume3_final_report.pdf

Shipley, Anna, Anne Hampson, Bruce Hedman, Patti Garland, and Paul Bautistia. 2008. Combined Heat and Power: Effective Energy Solutions for a Sustainable Future. ORNL/TM-2008/224. Prepared by Oak Ridge National Laboratory, Oak Ridge, TN, SENTECH, Inc., Bethesda, MD, and Energy and Environmental Analysis, and ICF, International Company, Arlington, VA. U.S. Department of Energy, Office of Energy Efficiency and Renewable Energy, Industrial Technologies Program. http://www1.eere.energy.gov/manufacturing/distributedenergy/pdfs/chp_report_12-08.pdf

Sustainability Victoria. 2009. Energy Efficiency Best Practice Guide Industrial Refrigeration. Prepared by Climate Managers. Sustainability Victoria. http://www.resourcesmart.vic.gov.au/documents/BP_Refrigeration_Manual.pdf

U.S. Census Bureau. 2007. "North American Industry Classification System (NAICS).” U.S. Census Bureau. http://www.census.gov/eos/www/naics/ 

Appendix A GLOSSARY 



\section{Appendix A. GLOSSARY}

Applied energy - the amount of energy actually employed in a manufacturing direct end use, with consideration of all energy losses incurred by or associated with that end use, including: (1) onsite process/nonprocess losses (system and equipment losses), (2) onsite generation losses (generation and distribution losses associated with producing and transporting steam and electricity onsite), and (3) offsite generation losses (generation and transmission losses associated with bringing steam and electricity to the plant boundary).

Byproduct fuel $^{19}$ - a secondary or additional product derived from feedstock in the production process that is subsequently used for fuel purposes, such as coal gas (byproduct of coke ovens) or black liquor (byproduct fuel used in the forest products industry). Byproduct fuels are quantified in the footprints and shown as a contributing portion of the onsite fuel use.

Carbon dioxide equivalent $\left(\mathrm{CO}_{2} \mathrm{e}\right)$ - a measure used to compare the emissions of various greenhouse gases, such as $\mathrm{CH}_{4}$ and $\mathrm{N}_{2} \mathrm{O}$, based upon their global warming potential (GWP). ${ }^{20}$ The functionally equivalent amount or concentration of $\mathrm{CO}_{2}$ serves as the reference. $\mathrm{CO}_{2} \mathrm{e}$ is derived by multiplying the mass of the gas by its associated GWP, with units commonly expressed as million metric tons of

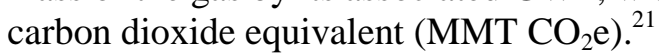

CHP/cogeneration - the production of electrical energy and another form of useful energy (such as heat or steam) through the sequential use of energy.

Conventional boiler - a boiler vessel that consumes fossil fuels as the primary energy source to produce heat and generate steam or hot water. Boiler losses represent energy lost due to boiler inefficiency. In practice, boiler efficiency can be as low as $55 \%-60 \%$, or as high as $90 \%$. The age of the boiler, boiler size, maintenance practices, and fuel type are important factors. Power generation losses vary depending on whether cogeneration is employed (systems producing both steam and electricity). An average boiler efficiency of $80 \%$ was used for all sectors, boiler types, and fuels [OIT EERE 2000]. ${ }^{22}$

Electricity export - sales and transfers offsite of electricity to utilities and to other entities. The footprint analysis considers only the net electricity consumed onsite, so electricity export is not included in the total primary and onsite energy use value; hence, it is not directly connected to the energy flow diagram. This figure is included for informative purposes.

\footnotetext{
${ }^{19}$ In this analysis, the value of coke and breeze fuel use has been adjusted to avoid the duplication of fuel use with blast furnace gas. The Manufacturing Energy Consumption Survey (MECS) assumes for purposes of estimation that all energy sources used for fuel are completely consumed in the process. However, in the case of a blast furnace used in the iron making process, incomplete consumption of blast furnace fuel inputs may be a significant cause of duplication. Literature reviews and consultation have revealed that the majority of blast furnace gas formation would arise from the input fuel use of coke. To address this issue, MECS suggests adjusting the fuel use of coal coke downward by the heat content of the blast furnace gas consumed in the industry, which is approximately two-thirds [2002 Manufacturing Energy Consumption Survey (MECS) Methodology,

http://www.eia.doe.gov/emeu/mecs/mecs2002/methodology_02/meth_02.html]. This adjustment is reflected in the Iron and Steel industry footprint "Fuel Type Detail" table, with blast furnace gas indicated as being a byproduct of coke and breeze.

${ }^{20} \mathrm{GWP}$ is a measure of how much a given mass of greenhouse gas is estimated to contribute to global warming. For this analysis, a 100-year time interval is used, with GWPs sourced from the Fourth Assessment Report from the Intergovernmental Panel on Climate Change (IPCC) [IPCC 2007]. The GWP-weighted emissions in the U.S. Inventory are presented in terms of $\mathrm{CO}_{2} \mathrm{e}$ emissions with units of teragrams ( $\mathrm{Tg}$ ) of carbon dioxide equivalent $\left(\mathrm{Tg} \mathrm{CO}_{2} \mathrm{e}\right)$ [EPA 2009a]. Specifically the GWPs used for $\mathrm{CO}_{2}$, $\mathrm{CH}_{4}$, and $\mathrm{N}_{2} \mathrm{O}$ are 1,25 , and $298 \mathrm{Tg} \mathrm{CO}_{2} \mathrm{e}$ [IPCC 2007] respectively.

${ }^{21}$ EPA (U.S. Environmental Protection Agency). 2009. "Glossary of Climate Change Terms." U.S. Environmental Protection Agency. Last modified June 14. http://www.epa.gov/climatechange/glossary.html

${ }^{22}$ OIT (Office of Industrial Technologies), EERE (Energy Efficiency and Renewable Energy). 2000. Overview of Energy Flow for Industries in Standard Industrial Classifications 20-39. 71563-00. Prepared by Arthur D. Little, Inc., Cambridge, MA. U.S. Department of Energy. http://steamingahead.org/library/adlittle.pdf
} 
Electricity generation losses - the energy losses incurred during the onsite or offsite generation of electricity. This term includes losses from offsite generated electricity, electricity cogeneration, and other onsite electricity generation.

Electro-chemical - the direct process end use in which electricity is used to cause a chemical transformation (e.g., reduction of alumina to aluminum and oxygen).

Facility HVAC - the direct nonprocess end use that includes energy used to provide heating, ventilation, and air conditioning for building envelopes within the manufacturing plant boundary.

Facility lighting - the direct nonprocess end use that includes energy used in equipment that illuminates buildings and other areas within the manufacturing plant boundary.

Greenhouse gas (GHG) combustion emissions - for this analysis, the emissions considered from the fuel use of energy include carbon dioxide $\left(\mathrm{CO}_{2}\right)$, methane $\left(\mathrm{CH}_{4}\right)$, and nitrous oxide $\left(\mathrm{N}_{2} \mathrm{O}\right)$, as these are the greenhouse gases released during the combustion of fuel. As shown in Table D.5, the emission factors used were sourced primarily from the Environmental Protection Agency's (EPA) Mandatory Greenhouse Gas Reporting Rule ${ }^{23}$ and the EPA's Inventory of U.S. Greenhouse Gas Emissions and Sinks. ${ }^{24}$ Over $99 \%$ of the emissions from combustion are $\mathrm{CO}_{2}$. While $\mathrm{CH}_{4}$ and $\mathrm{N}_{2} \mathrm{O}$ contribute a small portion of total emissions, they are included in this analysis to best adhere to the EPA reporting rule.

Machine drive - the direct process end use in which thermal or electric energy is converted into mechanical energy and is used to power motor-driven systems, such as compressors, fans, pumps, and materials handling and processing equipment. Motors are found in almost every process in manufacturing. Therefore, when motors are found in equipment that is wholly contained in another end use (such as a compressor in process cooling and refrigeration), the energy is classified there rather than in machine drive.

Machine drive losses (shaft losses) - the energy lost in the conversion of thermal or electric energy into kinetic or mechanical energy. Machine drive losses are estimated from electric motor, turbine, and engine efficiencies.

Machine-driven systems losses - the sum of machine-driven systems losses: specifically losses in pumps, fans, compressed air systems, materials-handling systems, materials processing systems, and other systems. Machine drive (motor) losses are considered separately from these system losses. The distribution of these six categories of losses is unique within each industry sector [OIT EERE 2002b]. ${ }^{25}$

Net electricity - the sum of electricity purchases, transfers in, and generation from noncombustible renewable resources, minus quantities sold and transferred out. Net electricity does not include electricity inputs from onsite cogeneration or generation from combustible fuels because that energy has already been included as generating fuel (for example, coal).

Nonprocess energy - energy used for purposes other than industry-specific processes, defined in MECS Table 5.2 to include facility HVAC, facility lighting, other facility support (e.g., cooking, water heating, office equipment), onsite transportation, and other nonprocess use.

\footnotetext{
${ }^{23}$ EPA (U.S. Environmental Protection Agency). 2009. "Mandatory Greenhouse Gas Reporting Rule.” U.S. Environmental Protection Agency, 40 CFR Part 98. Last modified August 30. http://www.epa.gov/ghgreporting/basic-info/index.html

${ }^{24}$ EPA (U.S. Environmental Protection Agency). 2010. Inventory of U.S. Greenhouse Gas Emissions and Sinks: 1990-2008. U.S. Environmental Protection Agency. http://www.epa.gov/climatechange/emissions/usinventoryreport.html

${ }^{25}$ OIT (Office of Industrial Technologies), EERE (Energy Efficiency and Renewable Energy). 2002.United States Industrial Electric Motor Systems Market Opportunities Assessment, Prepared by Xenergy, Inc., Burlington, MA. U.S. Department of Energy and Oak Ridge National Laboratory. http://www1.eere.energy.gov/manufacturing/tech_deployment/pdfs/mtrmkt.pdf 
Offsite GHG combustion emissions - the emissions released by the combustion of fuels outside a manufacturing facility, but associated with energy later consumed by the facility. For example, a power plant generates electricity by burning coal as fuel. A manufacturing facility then purchases this electricity and consumes it at its facility. The offsite emissions associated with this electricity use are those that were released during the combustion of coal at the power plant while generating that electricity. Similarly, emissions are released during the generation of offsite steam.

Offsite electricity generation - the sum of purchased electricity and electricity transfers into the plant boundary.

Offsite electricity generation and transmission losses - the energy losses incurred during the generation and transmission of electricity to the plant boundary. The efficiency of utility power generation and transmission is assumed to be $31.6 \%$. This does not represent the state-of-the-art, but an average value for the national grid.

Offsite energy - energy that is generated outside the plant boundary (offsite) or otherwise originally externally-sourced. Includes offsite electricity, offsite steam, and offsite fuel (including byproduct fuel derived from feedstock).

Offsite fuel - the sum of purchased fuel, fuel transferred into the plant boundary, and byproduct fuel from externally-sourced feedstocks.

Offsite steam generation - the sum of net steam transfers, generation from renewables, and purchased steam from the local utility or other sources.

Offsite steam generation and transmission losses - the energy losses incurred during the generation and transport of steam to the plant boundary. Energy losses are assumed to be $19 \%$ during the generation of steam and 10\% during the transmission of steam to the plant boundary. See Table D.1 for a listing of energy loss assumptions.

Onsite energy use - includes both direct (process and nonprocess end uses) and indirect (steam and electricity generation) uses of fuels, steam, and electricity within the industrial plant boundary. Electricity includes purchased electricity and any electricity produced onsite that is later sold or transferred offsite. Losses from offsite steam and electricity are not included.

Onsite GHG combustion emissions - the emissions released by the fuel use of energy (i.e., combustion) within the industrial plant boundary. This fuel is used "indirectly," to generate steam and electricity for later use, and "directly," to power processes and supporting equipment. In the footprint diagram, the emissions from indirect end uses, namely onsite steam and power generation, are not distributed to the direct end uses of that energy. For example, process heating onsite emissions do not include the emissions released during onsite generation of steam used for process heating. Indirect emissions are distributed to direct end uses in the accompanying report. Excluded are $\mathrm{CO}_{2}$ from biomass use and some carbon emissions from steel production, which are detailed in the emissions profile sections for the forest products, food and beverage, and iron and steel sectors

Onsite generation - the generation of steam or electricity within the plant boundaries using purchased fuel or electricity. Onsite generation includes three categories: conventional boilers (to produce steam), $\mathrm{CHP} /$ cogeneration (to produce steam and/or electricity), and other (onsite) electricity generation (defined below).

Other electricity generation (onsite) - consists of (1) electricity obtained from generators running on combustible energy sources including natural gas, fuel oils, and coal and (2) electricity generated onsite from renewables including solar, wind, hydropower, and geothermal; does not include wood/biomass. 
Other facility support - the direct nonprocess end use that includes energy used in diverse applications that are normally associated with office or building operations such as cooking, operation of office equipment, and the operation of elevators.

Other nonprocess - the direct nonprocess end use that includes energy used for nonprocess uses other than the defined nonprocess energy categories.

Other process uses - the direct process end use that includes energy used for other direct process uses not falling under a specified process end use category.

Onsite transportation - the direct nonprocess end use that includes energy used in vehicles and transportation equipment that primarily consume energy within the boundaries of the plant.

Plant boundary - includes all plant facilities and processes (manufacturing processes, support facilities, and generation facilities) controlled by a manufacturing establishment at a single location where mechanical or chemical transformations of materials or substances into new products are performed. This boundary is also termed onsite.

Primary energy use - the sum of energy purchases (fuel, steam, and electricity), the offsite losses associated with these energy purchases (see above offsite steam generation and transmission losses and offsite electricity generation and transmission losses), byproduct energy produced and used onsite, and energy from renewables and biomass. Primary energy use does not include energy consumed as a feedstock, that is, energy used for purposes other than for heat, power, and electricity generation.

Process cooling and refrigeration - the direct process end use in which energy is used to lower the temperature of substances involved in the manufacturing process. Examples include freezing processed meats for later sale in the food industry and lowering the temperature of chemical feedstocks below ambient temperature for use in reactions in the chemicals industry.

Process energy - energy used in industry-specific processes, such as chemical reactors, steel furnaces, glass melters, casting, concentrators, distillation columns, etc. Categories of process energy (defined in MECS Table 5.2) include process heating (e.g., kilns, ovens, furnaces, strip heaters), process cooling and refrigeration, machine drive (e.g., motors, pumps associated with process equipment), electrochemical processes (e.g., reduction process), and other direct process uses.

Process heating - the direct process end use in which energy is used to raise the temperature of substances involved in the manufacturing process. Examples include the use of heat to melt scrap for electric-arc furnaces in steel-making, to separate components of crude oil in petroleum refining, to dry paint in automobile manufacturing, and to cook packaged foods.

Process heating losses - process heating losses include both system losses (radiation, convection, cooling losses etc.) and exhaust losses (stack, vent losses etc.). Process heating energy losses are estimated by sector; an industry peer review group was formed to guide this estimation approach (see Appendix F).

Steam distribution losses - the energy losses incurred during the distribution of steam within the plant boundaries. Losses in steam pipes and traps have been reported to be as high as $20 \%-40 \%$ [Hooper and Gillette 1999]. ${ }^{26}$ For this analysis, a value of $20 \%$ was used for onsite steam distribution losses.

Steam generation losses - the energy losses incurred during the generation of steam within plant boundaries. This term includes steam cogeneration and conventional boiler steam generation losses.

Total GHG combustion emissions - the sum of offsite and onsite GHG combustion emissions.

\footnotetext{
${ }^{26}$ Hooper, Frederic A., and Ronald D. Gillette. 1999. "How Efficient is Your Steam Distribution System?” Steam Conservation Systems. www.swopnet.com/engr/stm/steam dist eff.html
} 
Appendix B

FOOTPRINTS SCOPE AND SECTOR DESCRIPTIONS 



\section{Appendix B. FOOTPRINTS SCOPE AND SECTOR DESCRIPTIONS}

\section{Scope}

The footprint analysis looks at a large subset of U.S. manufacturing, with the objective of capturing the bulk share of energy consumption and carbon emissions. Table B.1 lists the 15 manufacturing sectors selected for analysis; a sixteenth footprint has also been prepared for the entire manufacturing sector. Manufacturing sectors are listed by their respective NAICS (North American Industry Classification System) codes. NAICS descriptions of the specific products manufactured in each sector are provided below.

Manufacturing sectors were selected based on their relative energy intensities, contribution to the economy, and relative importance to energy efficiency programs. Energy consumption and emissions for all manufacturing sectors within NAICS 31-33 are included in the overall manufacturing energy and carbon footprint.

Table B.1. Manufacturing sectors selected for analysis

\begin{tabular}{|c|c|}
\hline $\begin{array}{l}\text { Food and beverage } \\
\text { NAICS } 311 \text { Food } \\
\text { NAICS } 312 \text { Beverage and tobacco products }\end{array}$ & $\begin{array}{l}\text { Iron and steel } \\
\text { NAICS } 3311 \text { Iron and steel mills and ferroalloys } \\
\text { NAICS } 3312 \text { Steel products }\end{array}$ \\
\hline $\begin{array}{l}\text { Textiles } \\
\text { NAICS } 313 \text { Textile mills } \\
\text { NAICS } 314 \text { Textile product mills } \\
\text { NAICS } 315 \text { Apparel } \\
\text { NAICS } 316 \text { Leather and allied products }\end{array}$ & $\begin{array}{l}\text { Alumina and aluminum } \\
\text { NAICS } 3313\end{array}$ \\
\hline $\begin{array}{l}\text { Forest products } \\
\text { NAICS } 321 \text { Wood products } \\
\text { NAICS } 322 \text { Paper }\end{array}$ & $\begin{array}{l}\text { Foundries } \\
\text { NAICS } 3315\end{array}$ \\
\hline $\begin{array}{l}\text { Petroleum refining } \\
\text { NAICS } 324110\end{array}$ & $\begin{array}{l}\text { Fabricated metals } \\
\text { NAICS } 332\end{array}$ \\
\hline $\begin{array}{l}\text { Chemicals } \\
\text { NAICS } 325\end{array}$ & $\begin{array}{l}\text { Machinery } \\
\text { NAICS } 333\end{array}$ \\
\hline $\begin{array}{l}\text { Plastics and rubber products } \\
\text { NAICS } 326\end{array}$ & $\begin{array}{l}\text { Computers, electronics, electrical equipment, and electrical } \\
\text { equipment } \\
\text { NAICS } 334 \text { Computer and electronic products } \\
\text { NAICS } 335 \text { Electrical equipment, appliances, and components }\end{array}$ \\
\hline $\begin{array}{l}\text { Glass and glass products } \\
\text { NAICS } 3272 \text { Glass and glass products } \\
\text { NAICS } 327993 \text { Mineral wool }\end{array}$ & $\begin{array}{l}\text { Transportation equipment } \\
\text { NAICS } 336\end{array}$ \\
\hline $\begin{array}{l}\text { Cement } \\
\text { NAICS } 327310\end{array}$ & \\
\hline
\end{tabular}

Source: U.S. Census Bureau. 2007. "North American Industry Classification System (NAICS).” U.S. Census Bureau. http://www.census.gov/eos/www/naics/ 


\section{NAICS Descriptions}

\section{1 - Food Manufacturing}

Industries in the food manufacturing subsector transform livestock and agricultural products into products for intermediate or final consumption. The food products manufactured in these establishments are typically sold to wholesalers or retailers for distribution to consumers, but establishments primarily engaged in retailing bakery and candy products made on the premises not for immediate consumption are included.

\section{2 - Beverage and Tobacco Product Manufacturing}

Industries in the beverage and tobacco product manufacturing subsector manufacture beverages and tobacco products. Beverage manufacturing includes three types of establishments: (1) those that manufacture nonalcoholic beverages, (2) those that manufacture alcoholic beverages through the fermentation process, and (3) those that produce distilled alcoholic beverages. Ice manufacturing is included with nonalcoholic beverage manufacturing because it uses the same production process as water purification. Tobacco manufacturing includes two types of establishments: (1) those engaged in re-drying and stemming tobacco and (2) those that manufacture tobacco products, such as cigarettes and cigars.

\section{3 - Textile Mills}

Industries in the textile mills subsector group transform a basic fiber (natural or synthetic) into a product, such as yarn or fabric that is further manufactured into usable items, such as apparel, sheets, towels, and textile bags for individual or industrial consumption. Further manufacturing may be performed in the same establishment and classified in this subsector, or it may be performed at a separate establishment and be classified elsewhere in manufacturing.

\section{4 - Textile Product Mills}

Industries in the textile product mills subsector group make textile products (except apparel). With a few exceptions, processes used in these industries are generally cut and sew (i.e., purchasing fabric and cutting and sewing to make non-apparel textile products, such as sheets and towels).

\section{5 - Apparel Manufacturing}

Industries in the apparel manufacturing subsector group have two distinct manufacturing processes: (1) cut and sew (i.e., purchasing fabric and cutting and sewing to make a garment) and (2) the manufacture of garments in establishments that first knit fabric and then cut and sew the fabric into a garment. The apparel manufacturing subsector includes a diverse range of establishments manufacturing full lines of ready-towear apparel and custom apparel. Knitting, when done alone, is classified in the Textile Mills subsector, but when knitting is combined with the production of complete garments, the activity is classified in apparel manufacturing.

\section{6 - Leather and Allied Product Manufacturing}

Establishments in the leather and allied product manufacturing subsector transform hides into leather by tanning or curing and fabricating the leather into products for final consumption. It also includes the manufacture of similar products from other materials, including products (except apparel) made from "leather substitutes," such as rubber, plastics, or textiles. Rubber footwear, textile luggage, and plastic purses or wallets are examples of "leather substitute" products included in this group. The products made from leather substitutes are included in this subsector because they are made in similar ways leather products are made (e.g., luggage). They are made in the same establishments, so it is not practical to separate them.

\section{1 - Wood Product Manufacturing}

Industries in the wood product manufacturing subsector manufacture wood products, such as lumber, plywood, veneers, wood containers, wood flooring, wood trusses, manufactured homes (i.e., mobile homes), and prefabricated wood buildings. 


\section{2 - Paper Manufacturing}

Industries in the paper manufacturing subsector make pulp, paper, or converted paper products. The manufacturing of these products is grouped together because they constitute a series of vertically connected processes. More than one is often carried out in a single establishment.

\section{0 - Petroleum Refineries}

This industry comprises establishments primarily engaged in refining crude petroleum into refined petroleum. Petroleum refining involves one or more of the following activities: (1) fractionation, (2) straight distillation of crude oil, and (3) cracking.

\section{5 - Chemicals Manufacturing}

The chemicals manufacturing subsector is based on the transformation of organic and inorganic raw materials by a chemical process and the formulation of products. This subsector distinguishes the production of basic chemicals that comprise the first industry group from the production of intermediate and end products produced by further processing of basic chemicals that make up the remaining industry groups.

\section{6 - Plastics and Rubber Products Manufacturing}

Industries in the plastics and rubber products manufacturing subsector make goods by processing plastics materials and raw rubber. Plastics and rubber are combined in the same subsector because plastics are increasingly being used as a substitute for rubber; however, the subsector is generally restricted to the production of products made of just one material, either solely plastics or rubber.

\section{2 - Glass and Glass Product Manufacturing}

This industry comprises establishments primarily engaged in manufacturing glass and/or glass products. Establishments in this industry may manufacture glass and/or glass products by melting silica sand or cullet, or purchasing glass.

\section{3 - Mineral Wool Manufacturing}

This industry comprises establishments primarily engaged in manufacturing mineral wool and mineral wool (i.e., fiberglass) insulation products made of such siliceous materials as rock, slag, and glass, or combinations thereof.

\section{0 - Cement Manufacturing}

This industry comprises establishments primarily engaged in manufacturing portland, natural, masonry, pozzolanic, and other hydraulic cements. Cement manufacturing establishments may calcine earths or mine, quarry, manufacture, or purchase lime.

\section{1 - Iron and Steel Mills and Ferroalloy Manufacturing}

This industry comprises establishments primarily engaged in one or more of the following: (1) direct reduction of iron ore, (2) manufacturing pig iron in molten or solid form, (3) converting pig iron into steel, (4) manufacturing ferroalloys,; (5) making steel, (6) making steel and manufacturing shapes (e.g., bar, plate, rod, sheet, strip, wire),; and (7) making steel and forming pipe and tube.

\section{2 - Steel Product Manufacturing from Purchased Steel}

This industry group comprises establishments primarily engaged in manufacturing iron and steel tube and pipe, drawing steel wire, and rolling or drawing shapes from purchased iron or steel.

\section{3 - Alumina and Aluminum Production and Processing}

This industry comprises establishments primarily engaged in one or more of the following: (1) refining alumina, (2) making (i.e., the primary production) aluminum from alumina,; (3) recovering aluminum from scrap or dross, (4) alloying purchased aluminum, and (5) manufacturing aluminum primary forms (e.g., bar, foil, pipe, plate, rod, sheet, tube, wire).

\section{5 - Foundries}

This industry group comprises establishments primarily engaged in pouring molten metal into molds or dies to form castings. Foundries may perform operations, such as cleaning and deburring, on the castings they manufacture. 


\section{2 - Fabricated Metal Product Manufacturing}

Industries in the fabricated metal product manufacturing subsector transform metal into intermediate or end products. Important fabricated metal processes are forging, stamping, bending, forming, and machining, used to shape individual pieces of metal; and other processes, such as welding and assembling, used to join separate parts together. Establishments in this subsector may use one of these processes or a combination of these processes.

\section{3 - Machinery Manufacturing}

Industries in the machinery manufacturing subsector create end products that apply mechanical force to perform work. Some important processes for the manufacture of machinery are forging, stamping, bending, forming, and machining that are used to shape individual pieces of metal. Processes such as welding and assembling are used to join separate parts together. Although these processes are similar to those used in metal fabricating establishments, machinery manufacturing is different because it typically employs multiple metal forming processes in manufacturing the various parts of the machine. Moreover, complex assembly operations are an inherent part of the production process.

\section{4 - Computer and Electronic Product Manufacturing}

Industries in the computer and electronic product manufacturing subsector group manufacture computers, computer peripherals, communications equipment, and similar electronic products, as well as the components for such products.

\section{5 - Electrical Equipment, Appliance, and Component Manufacturing}

Industries in the electrical equipment, appliance, and component Manufacturing subsector manufacture products that generate, distribute, and use electrical power. Electric lighting equipment manufacturing establishments produce electric lamp bulbs, lighting fixtures, and parts. Household appliance manufacturing establishments make both small and major electrical appliances and parts. Electrical equipment manufacturing establishments make goods, such as electric motors, generators, transformers, and switchgear apparatus. Other component manufacturing establishments make devices for storing electrical power (e.g., batteries) and for transmitting electricity (e.g., insulated wire), as well as wiring devices (e.g., electrical outlets, fuse boxes, and light switches).

\section{6 - Transportation Equipment Manufacturing}

Industries in the transportation equipment manufacturing subsector produce equipment for transporting people and goods. Transportation equipment is a type of machinery. An entire subsector is devoted to this activity because of the significance of its economic size in all three North American countries. 
Appendix C

FOOTPRINTS BY SECTOR 



\section{Appendix C. FOOTPRINTS BY SECTOR}

Listed in this appendix are the manufacturing energy and carbon footprints by sector. Data is presented in two levels of detail for each sector. The first page provides a high level snapshot of the offsite and onsite energy flow; the second page shows the detail for onsite generation and end use of energy.

Sector

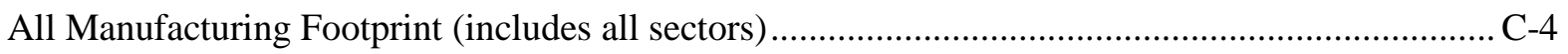

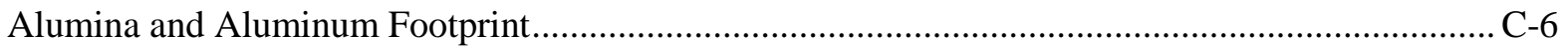

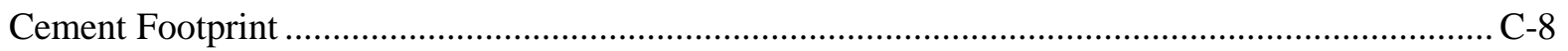

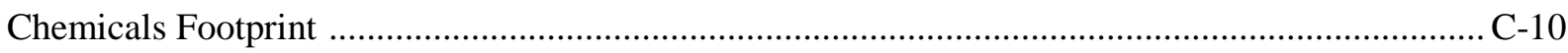

Computers, Electronics, and Electrical Equipment Footprint........................................................ C-12

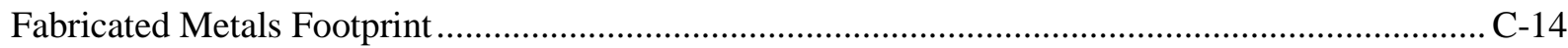

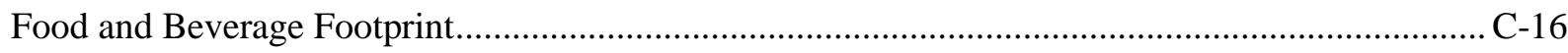

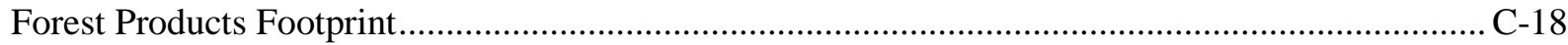

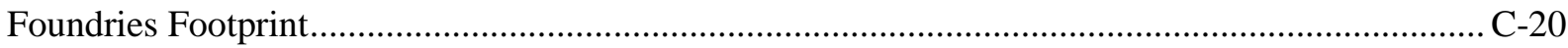

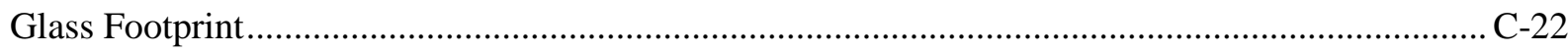

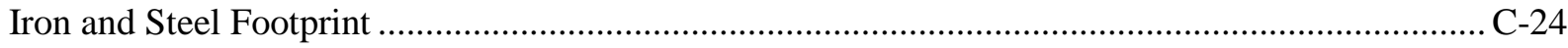

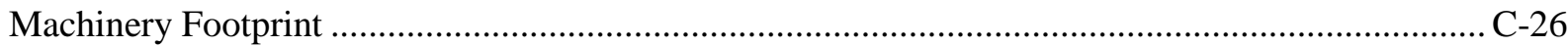

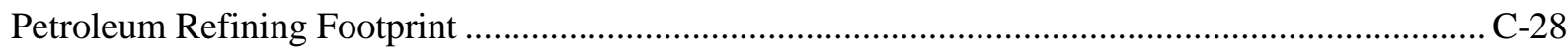

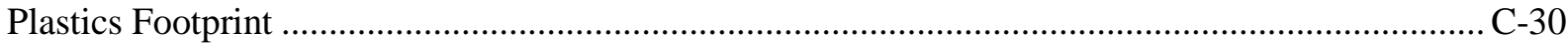

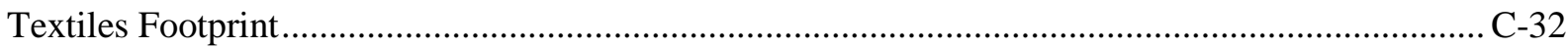

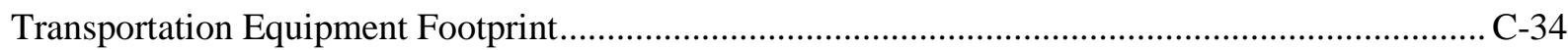




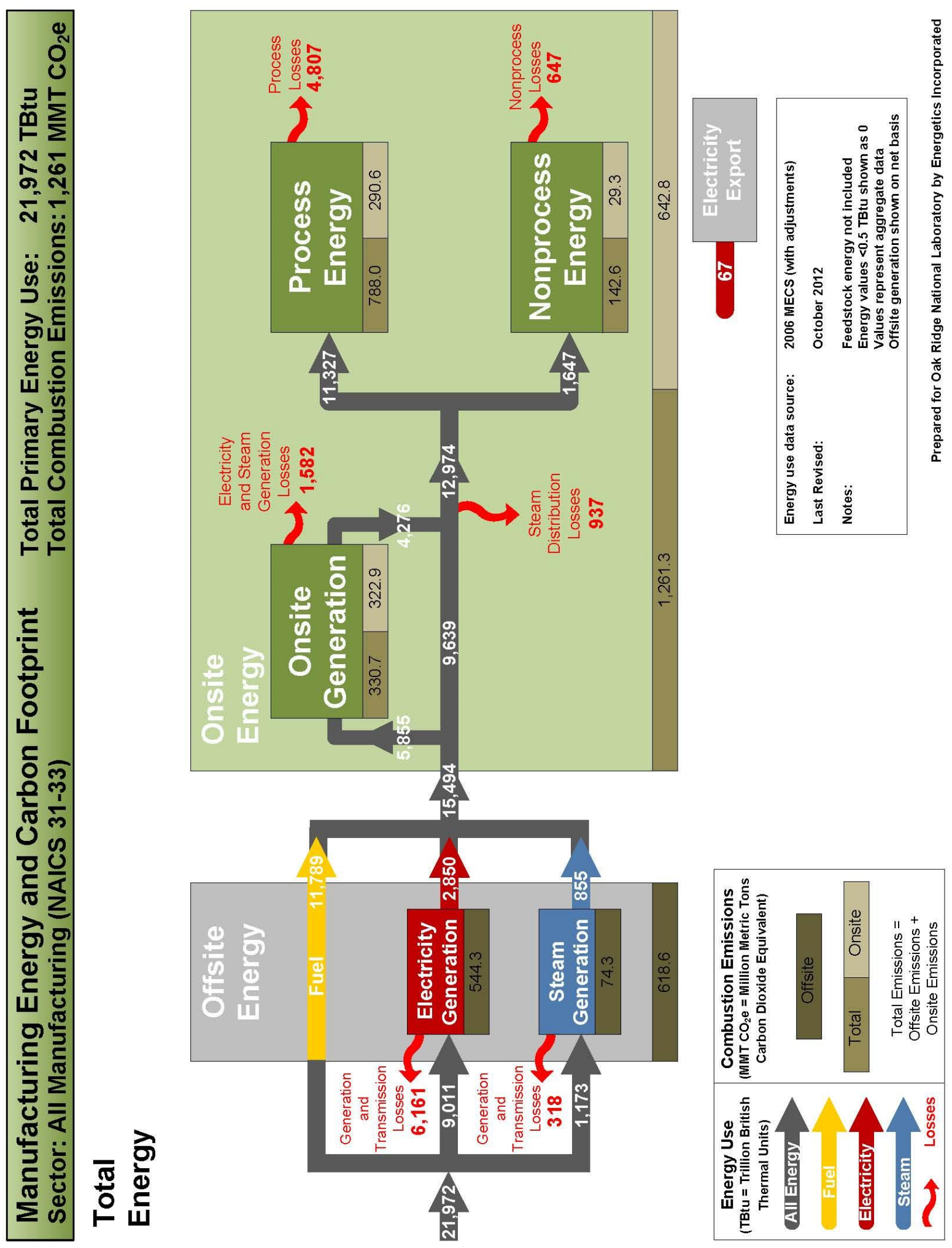




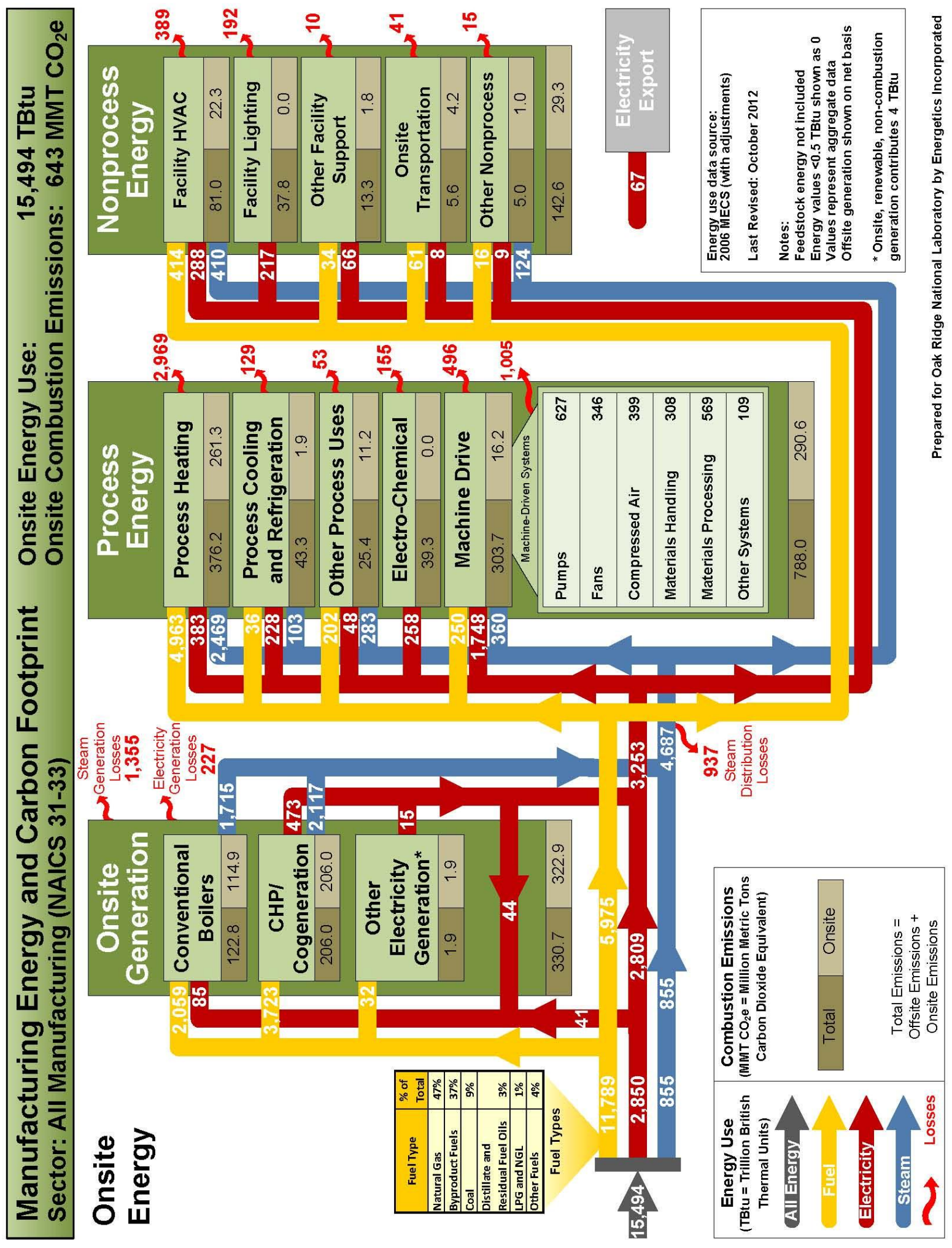




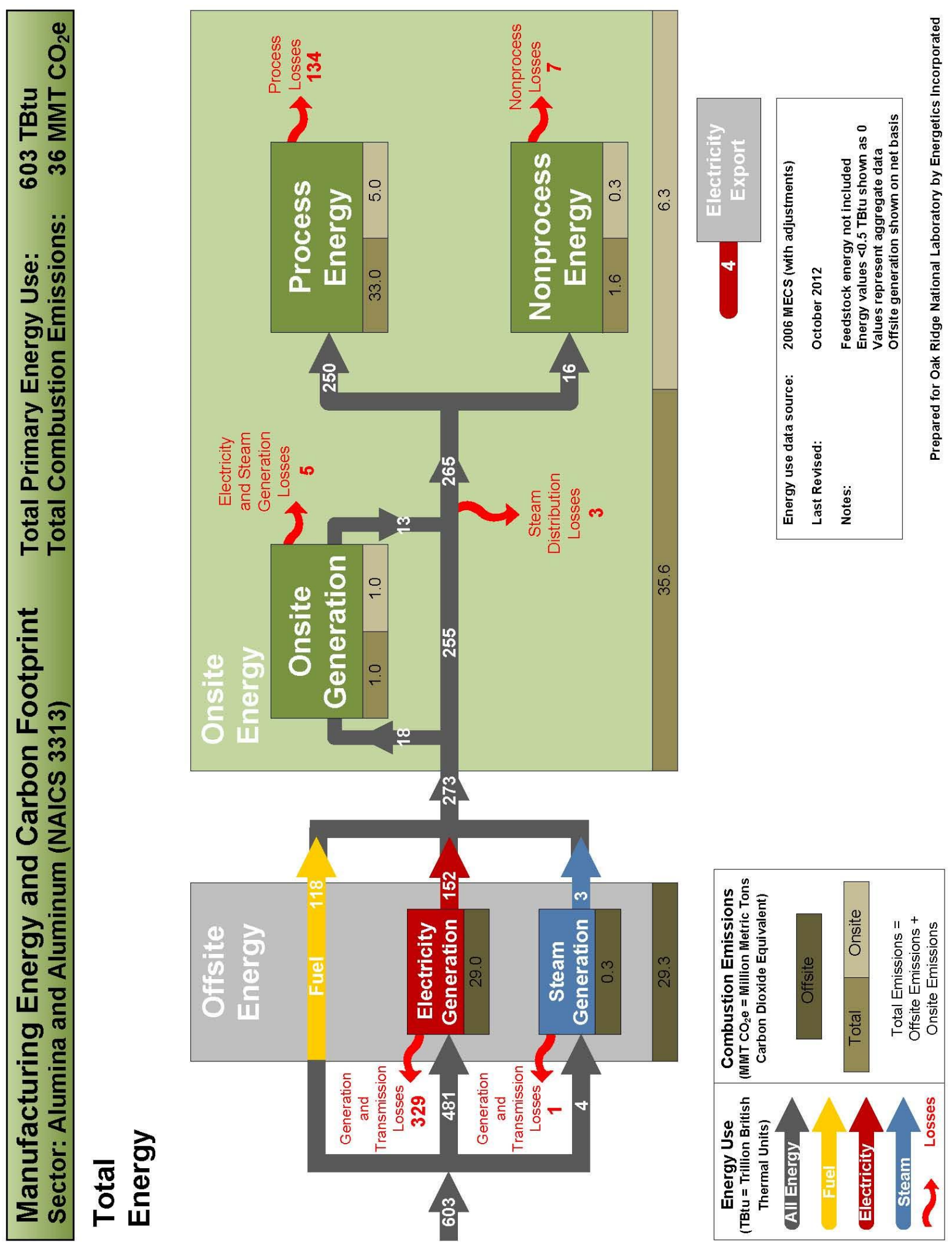




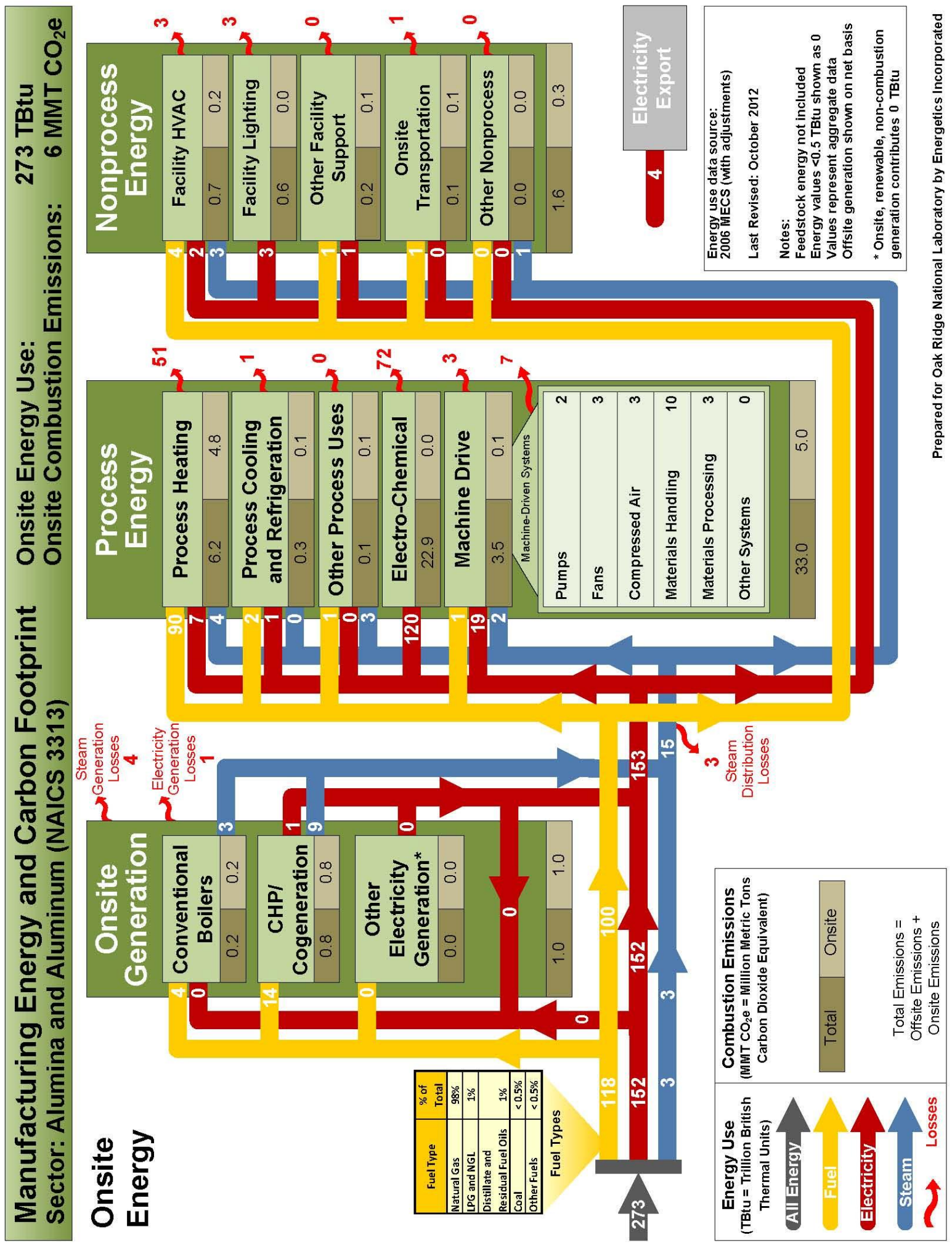




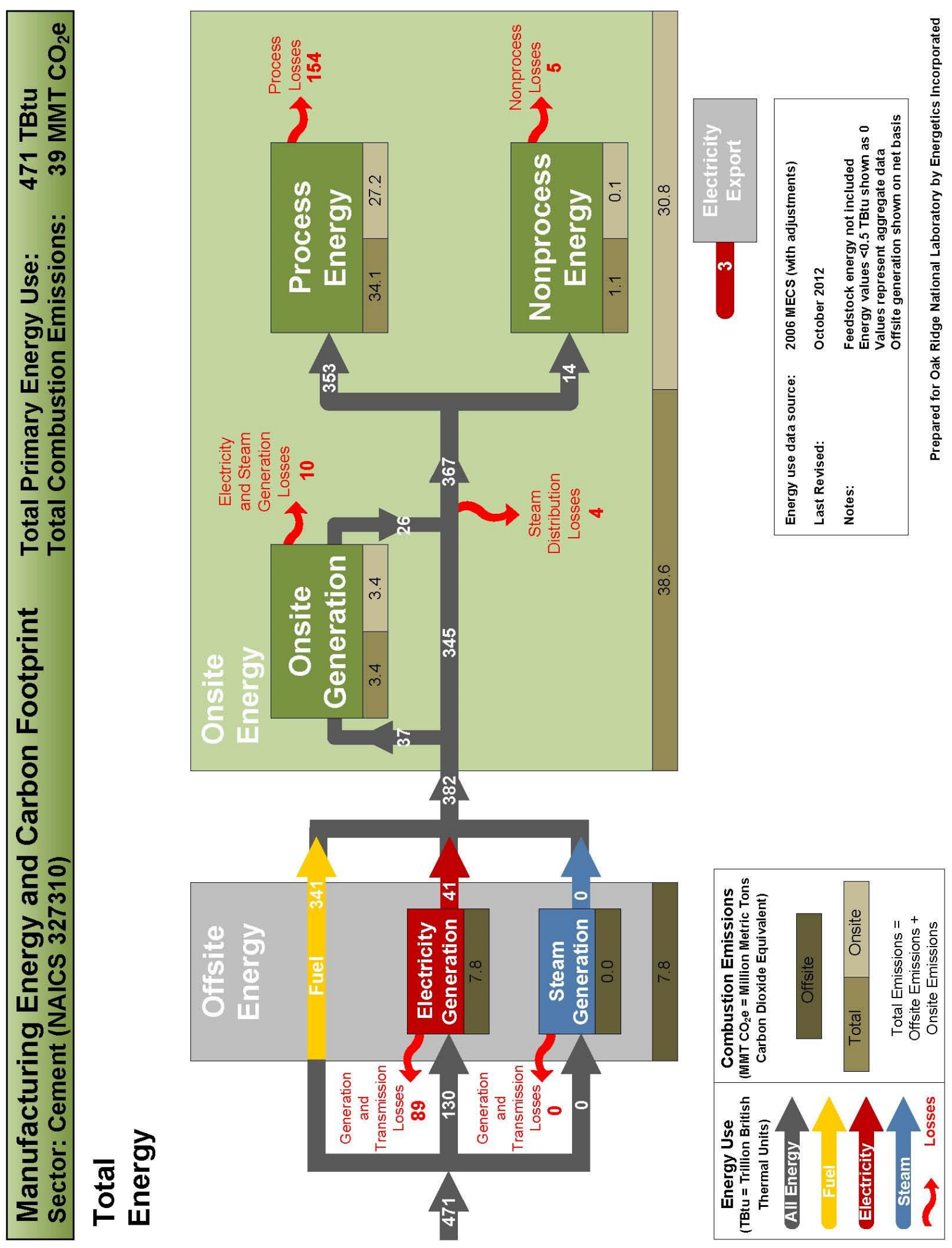




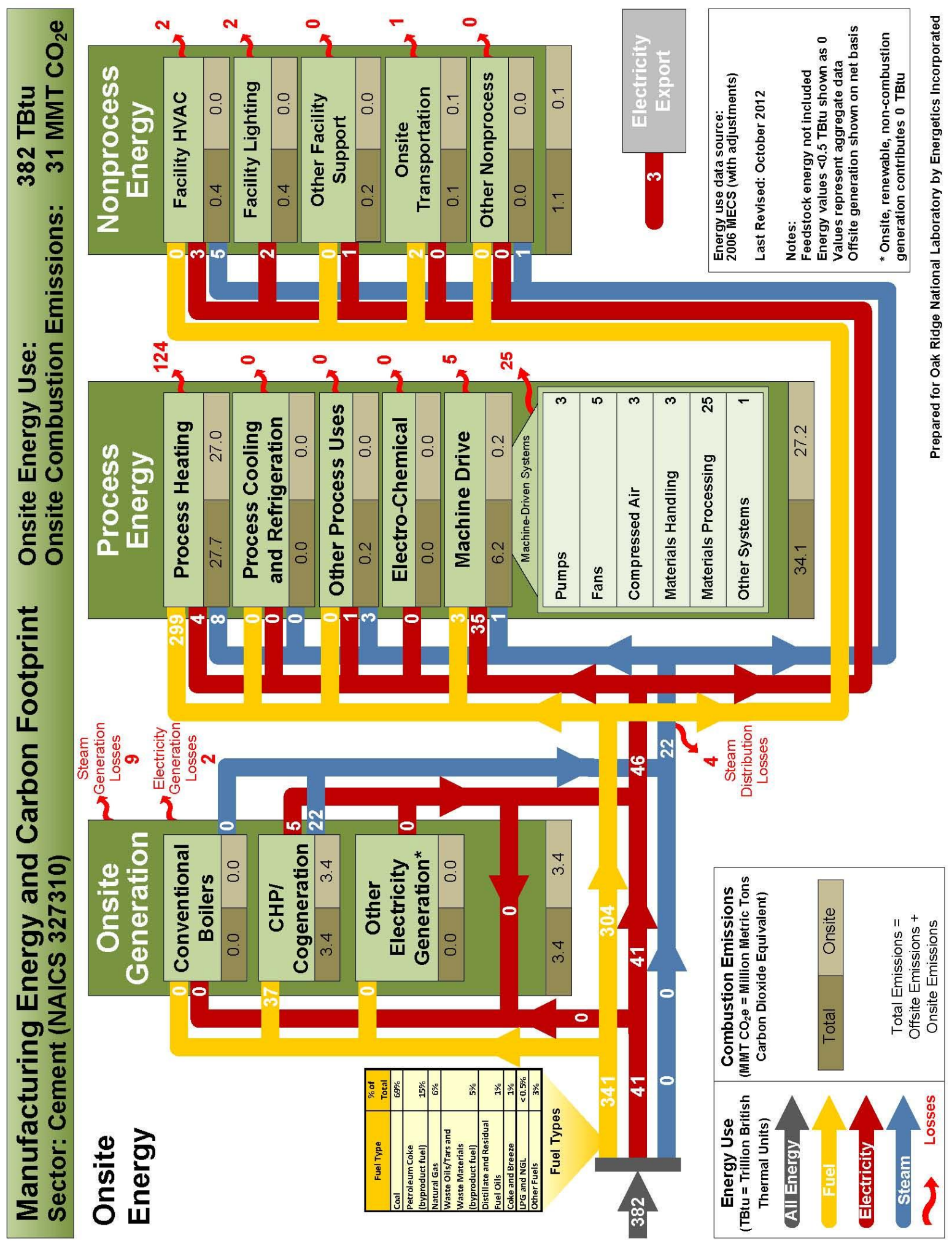




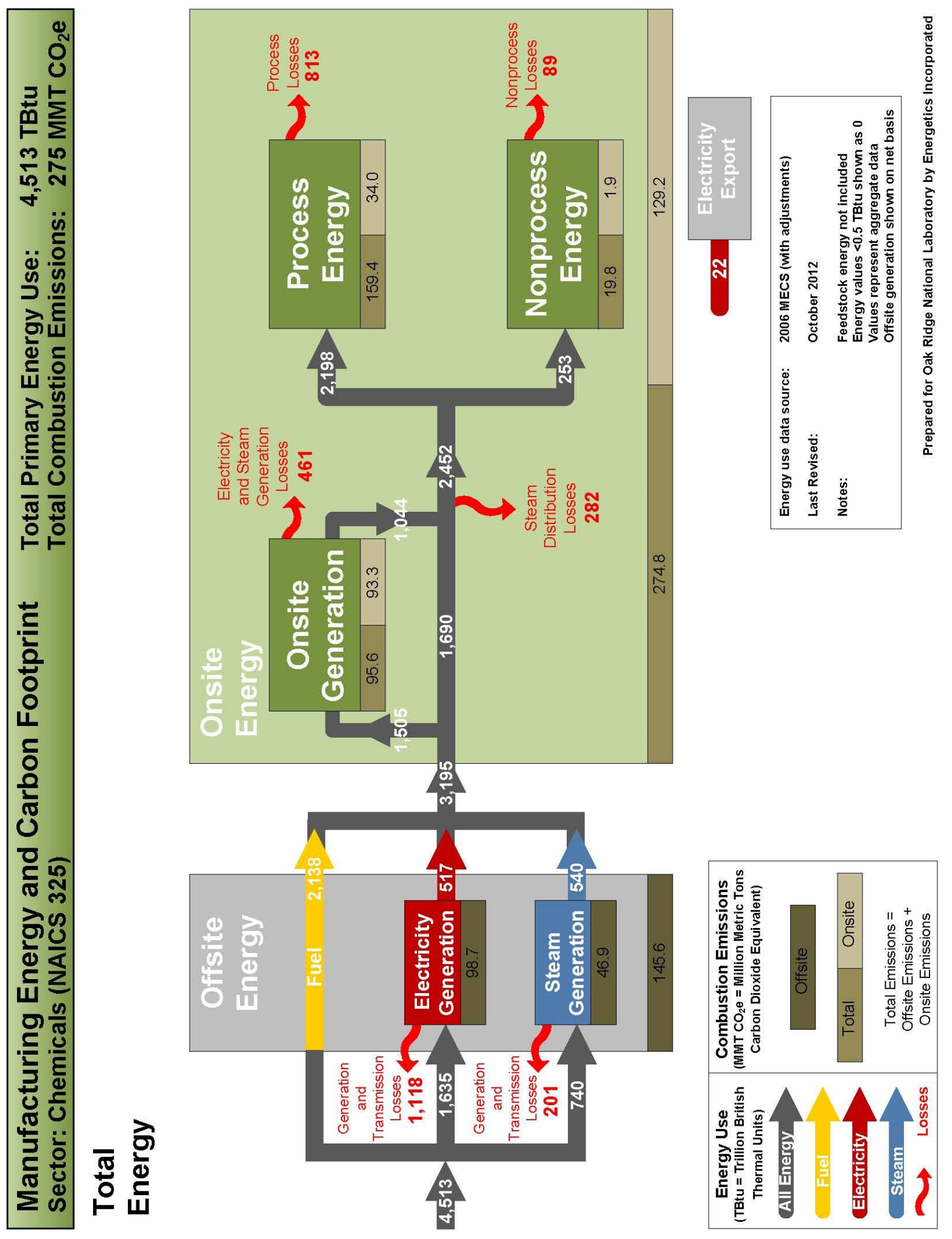




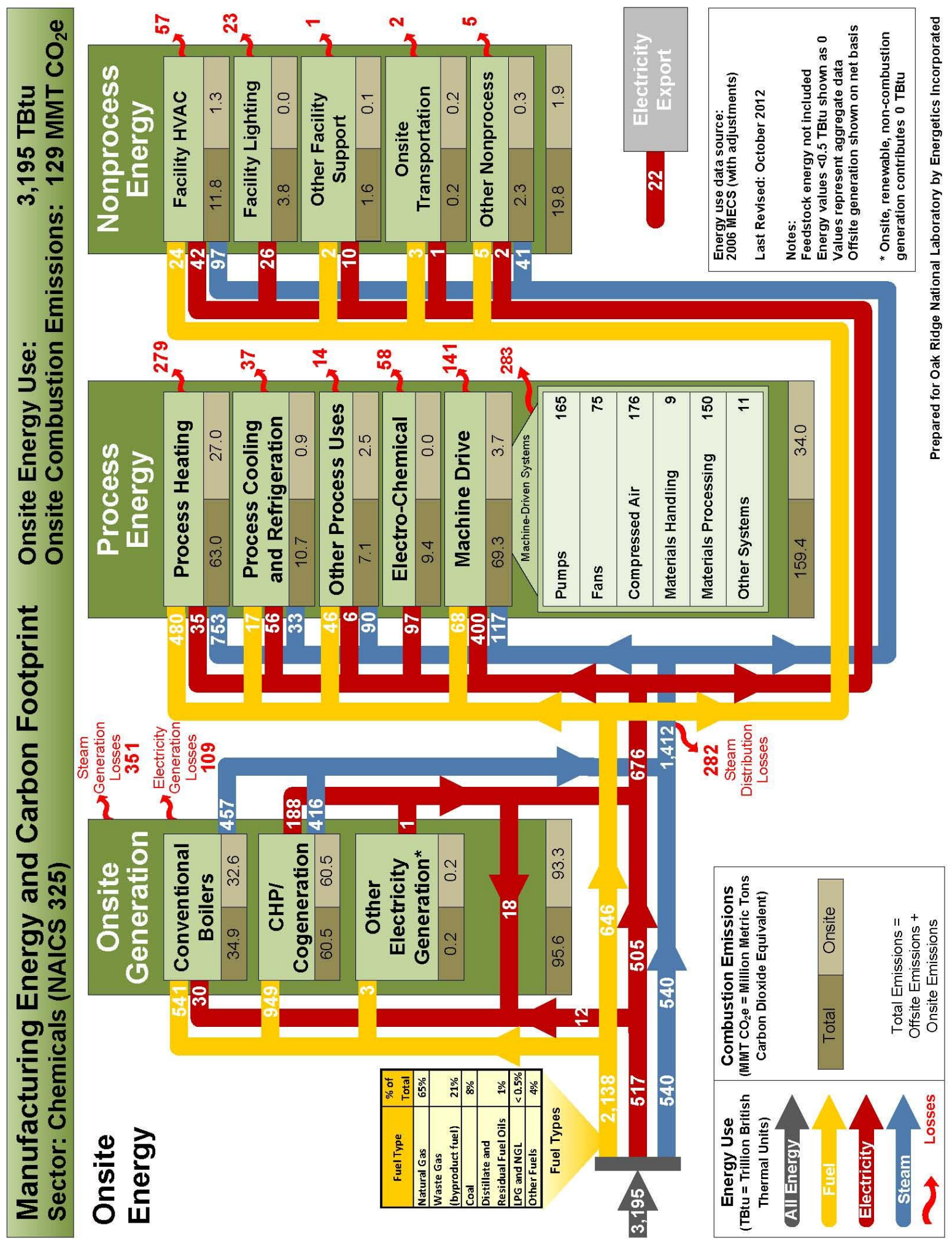



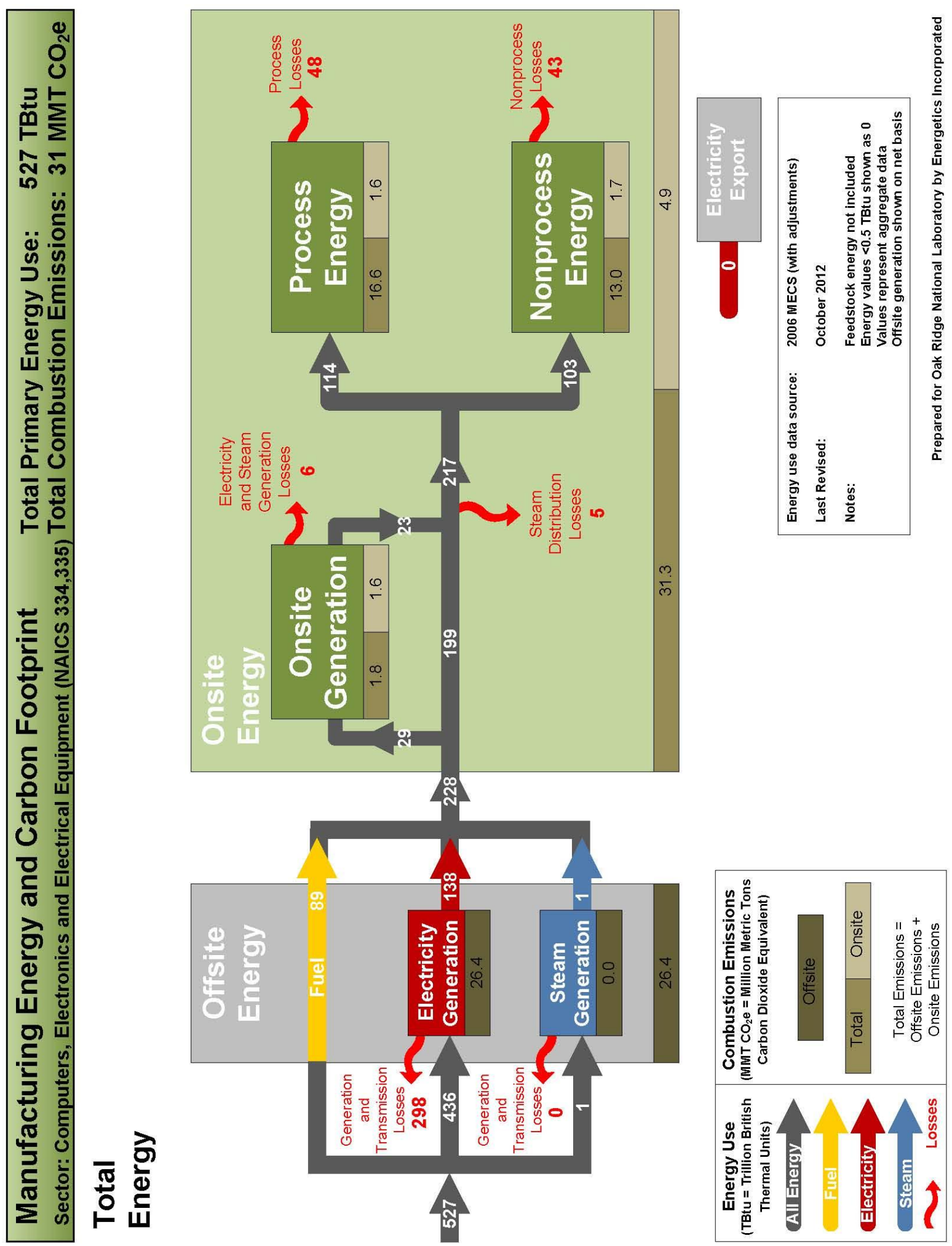


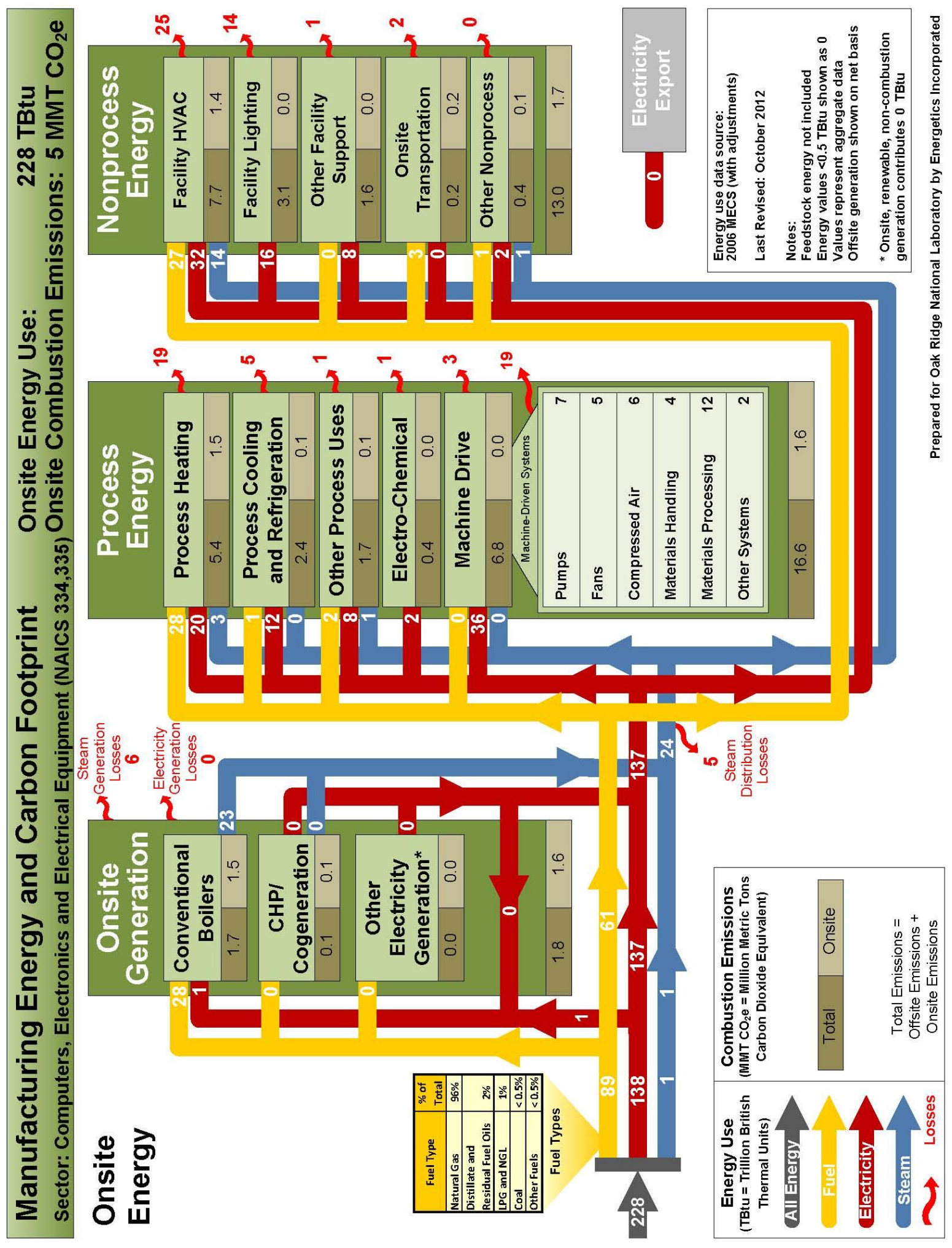




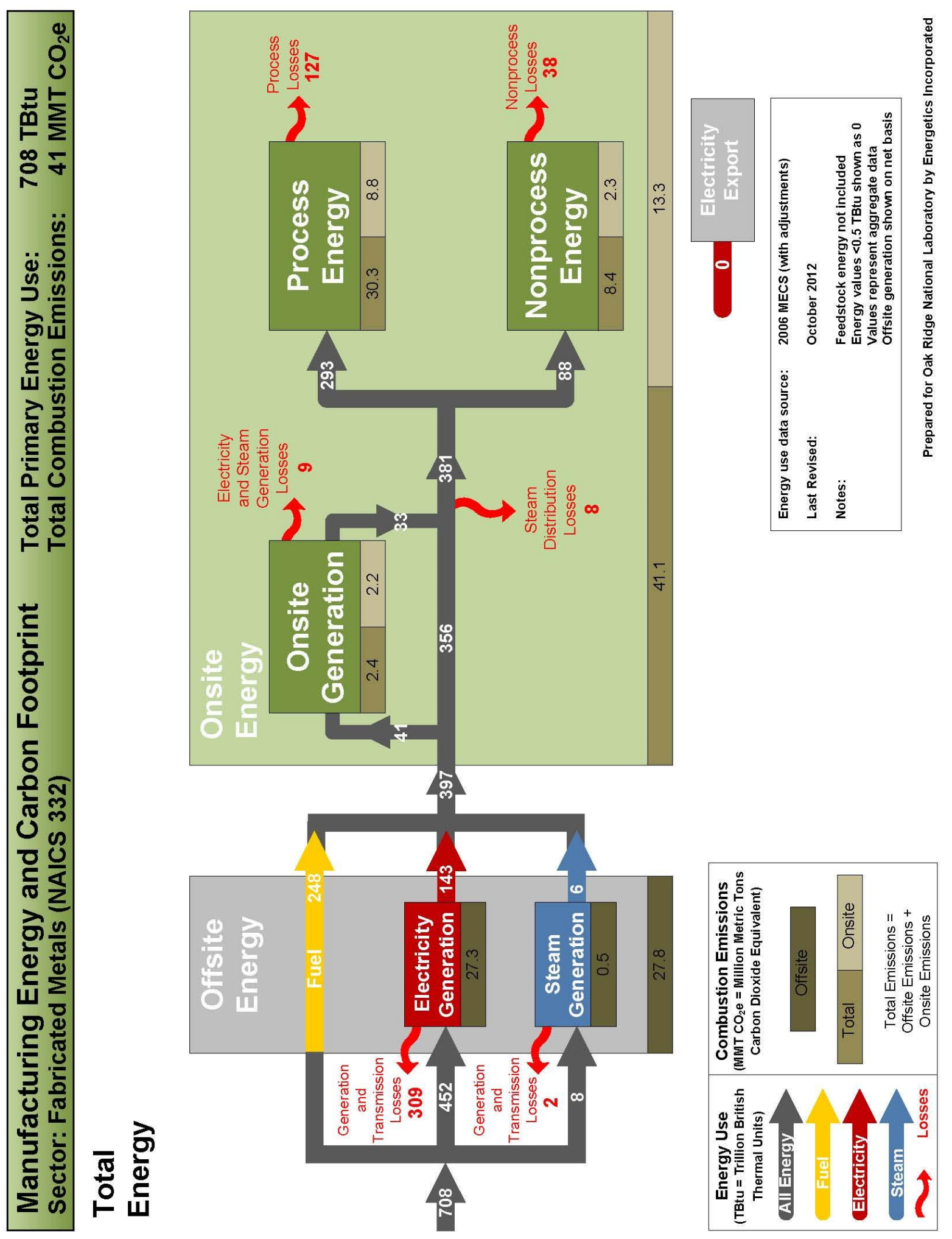




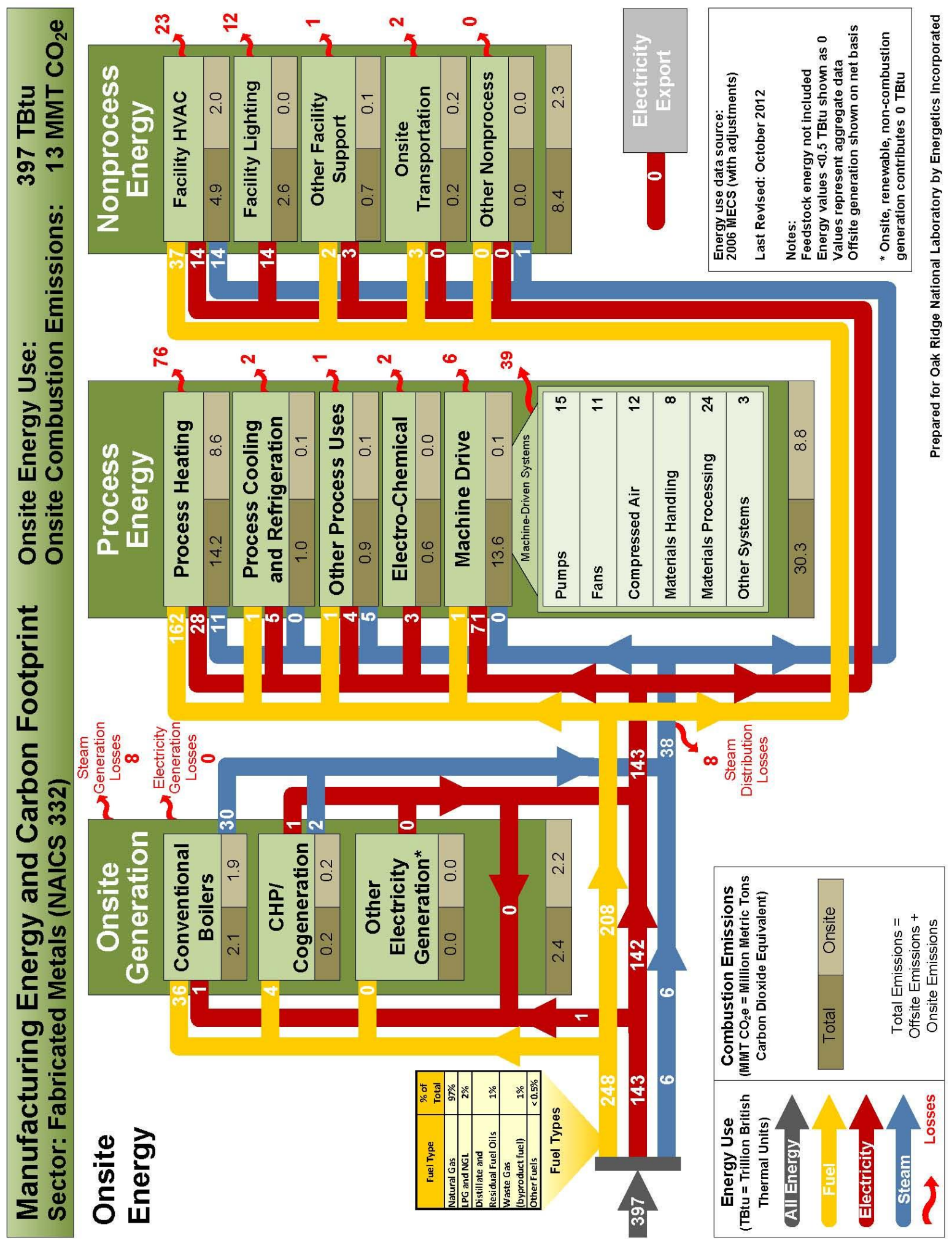




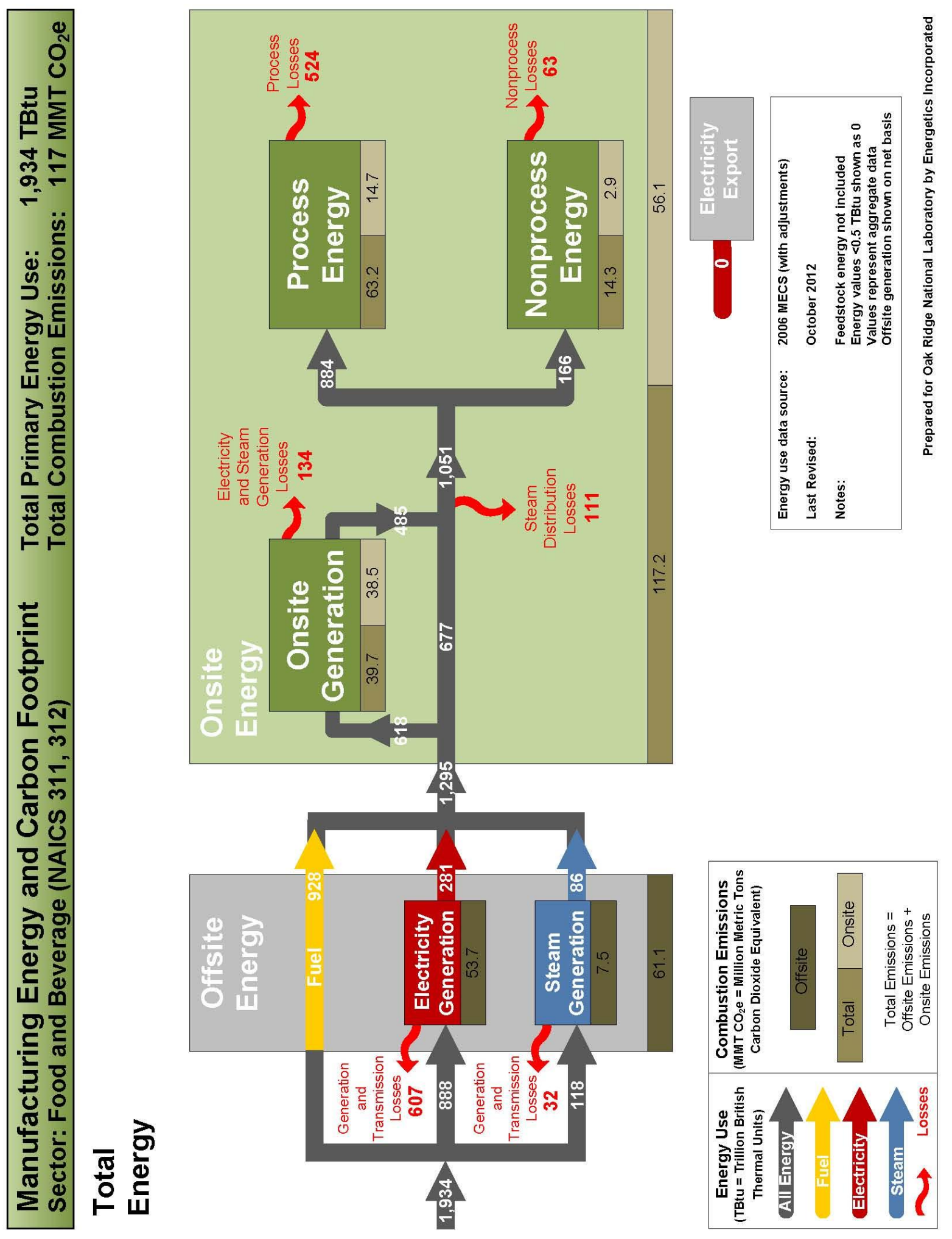




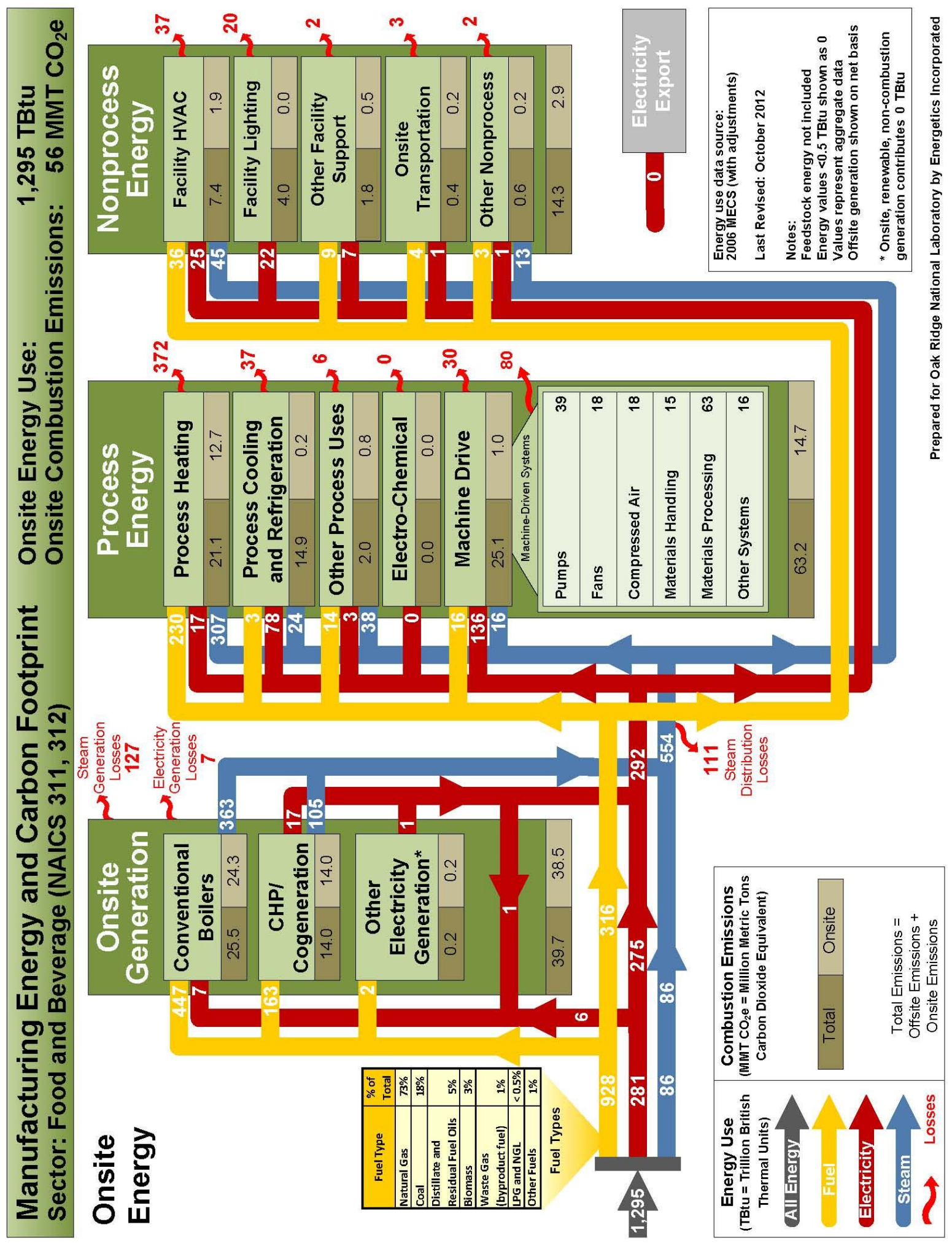




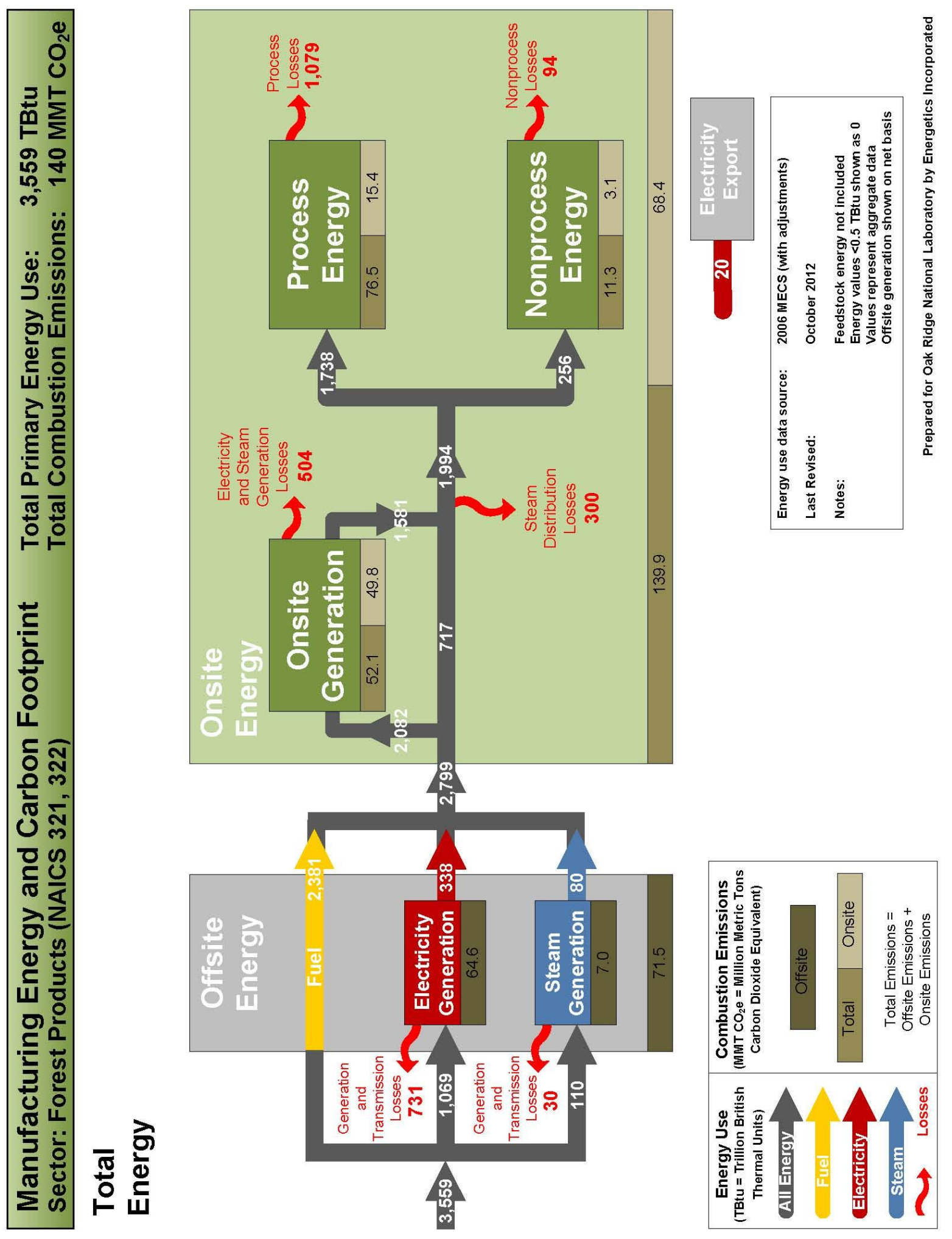




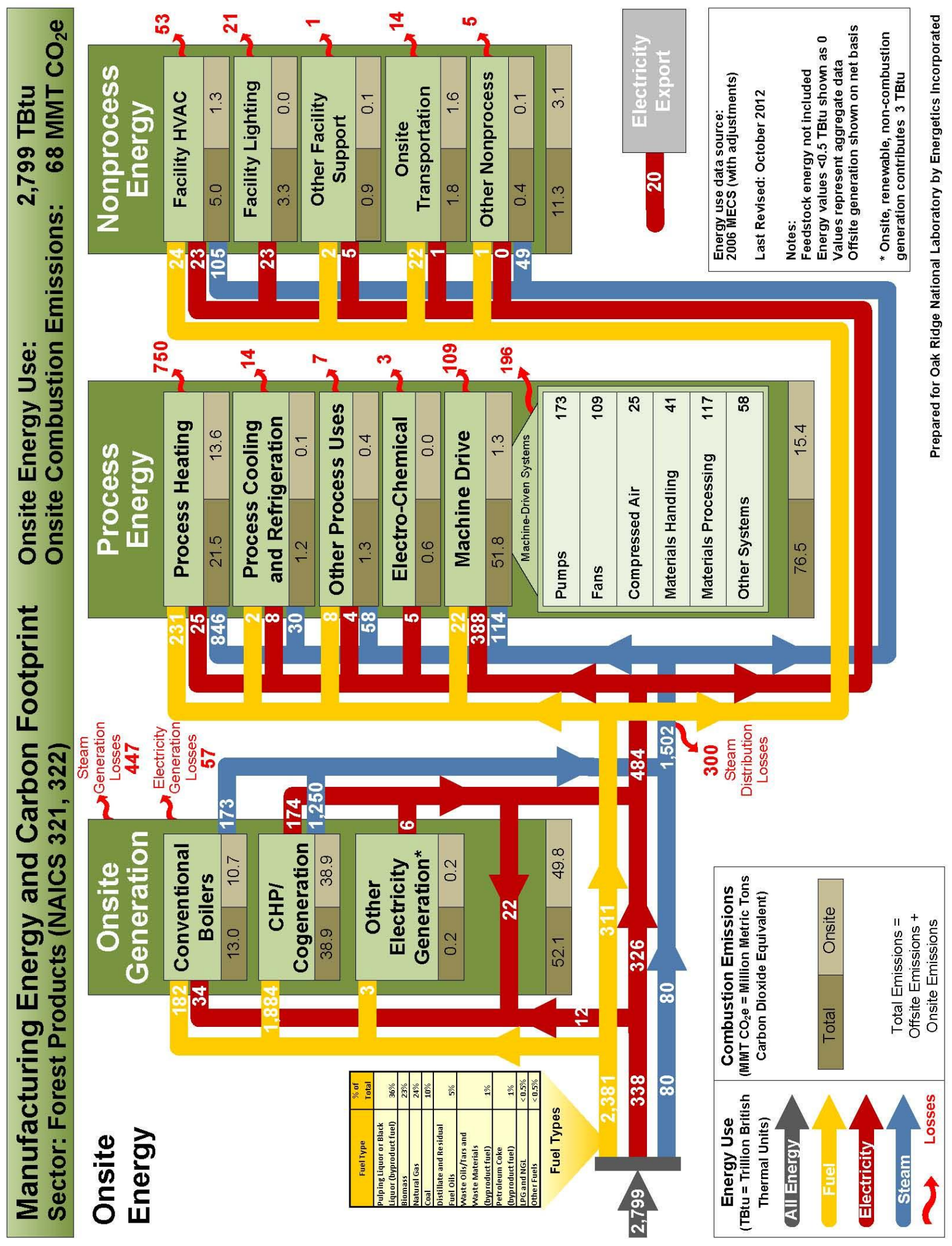




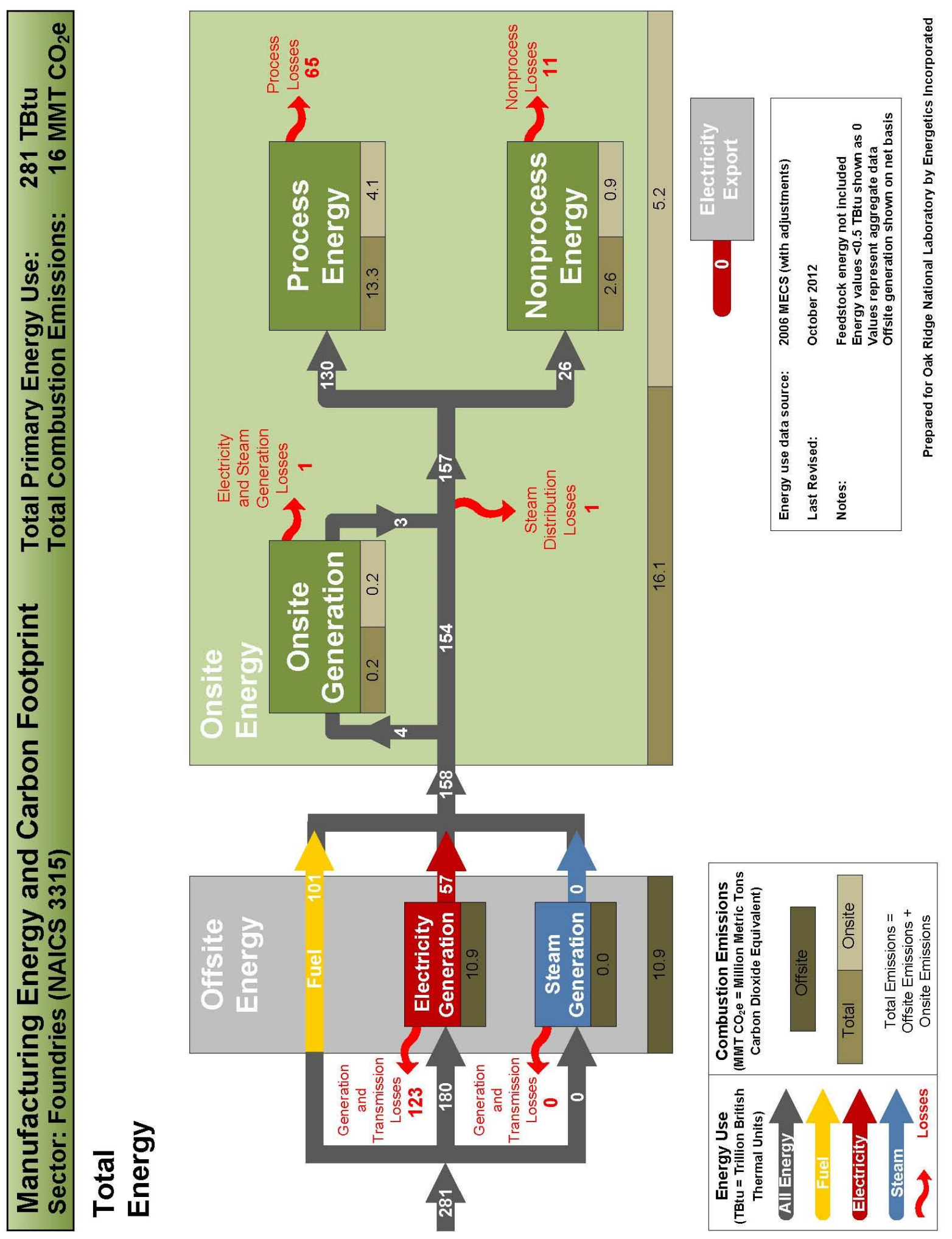




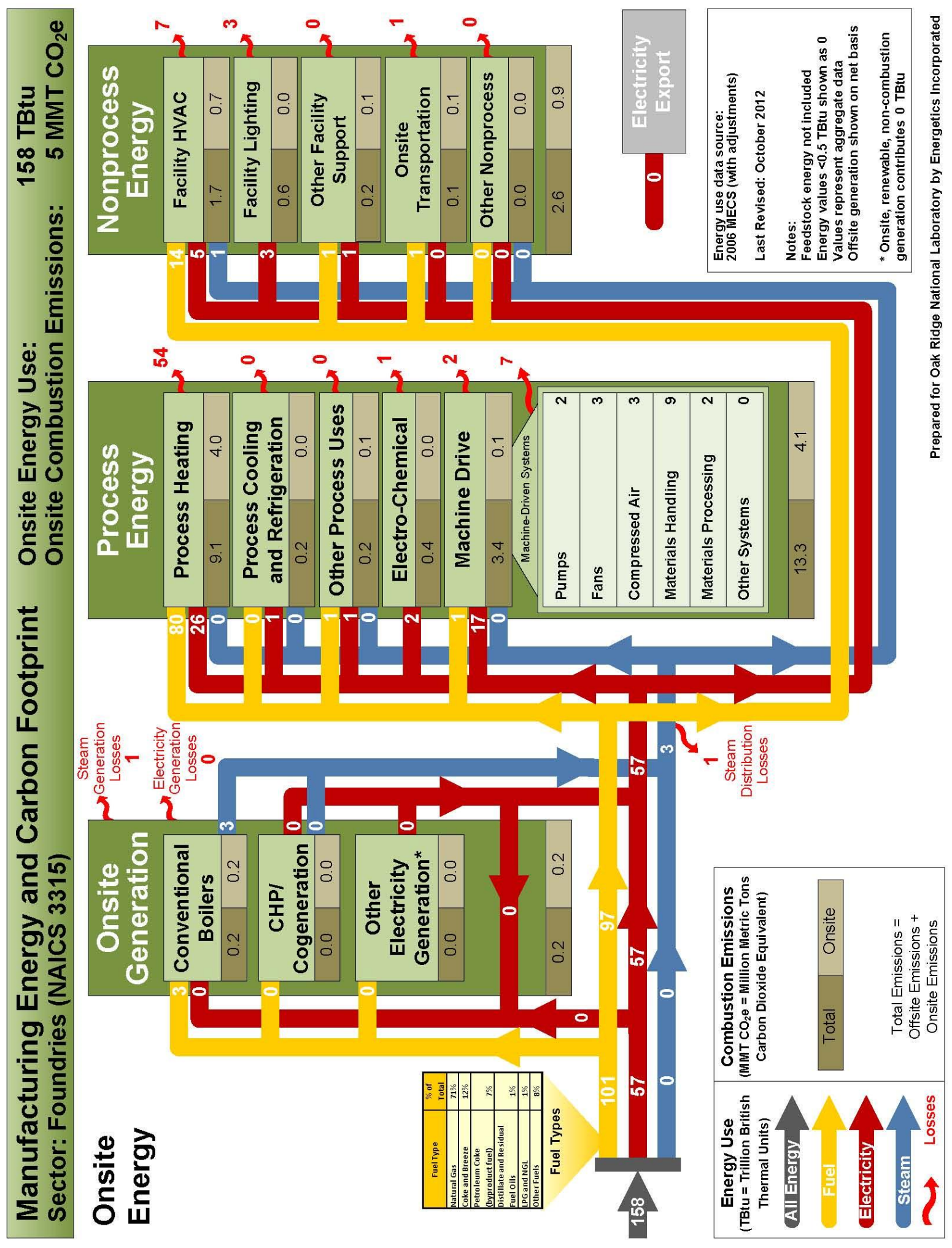




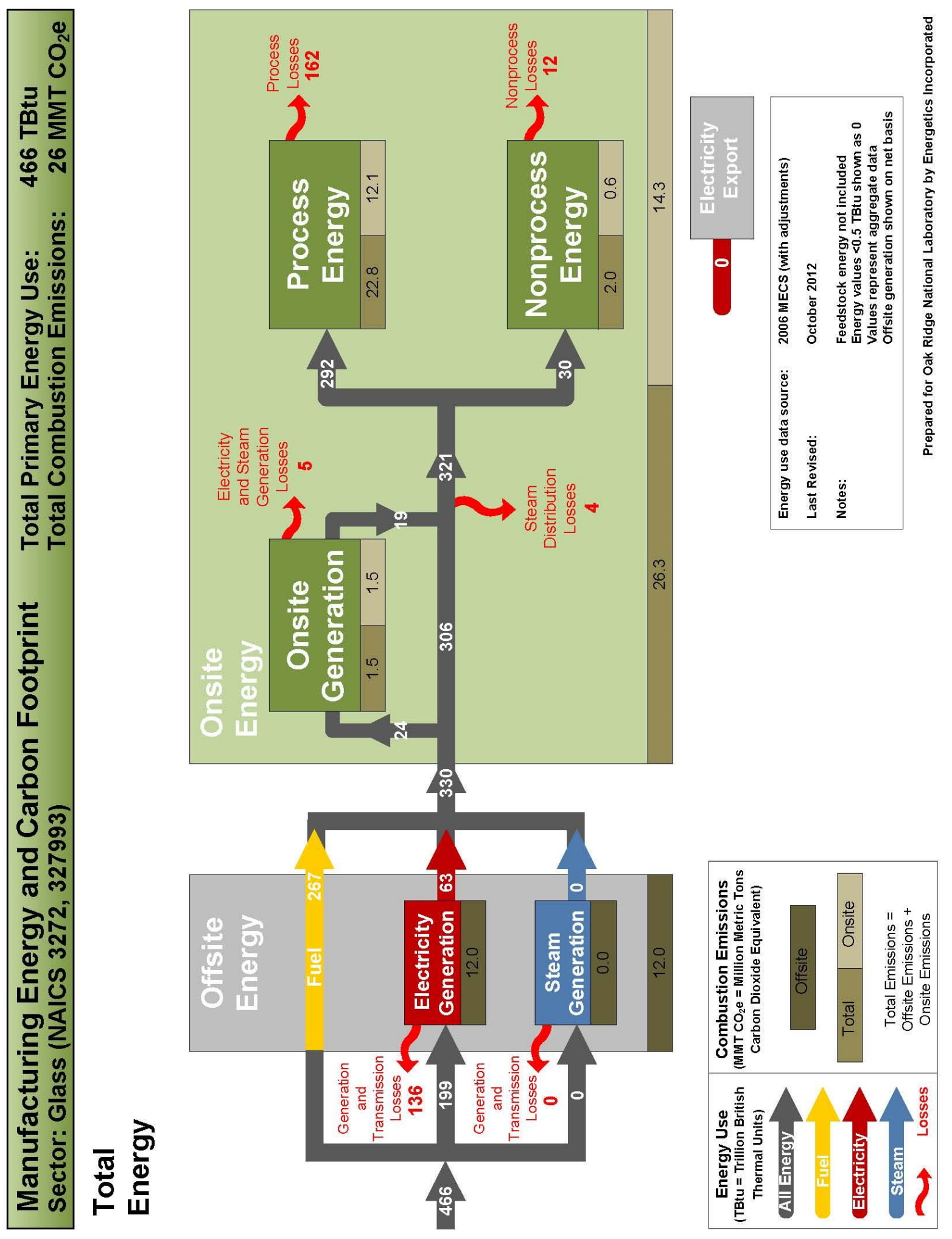




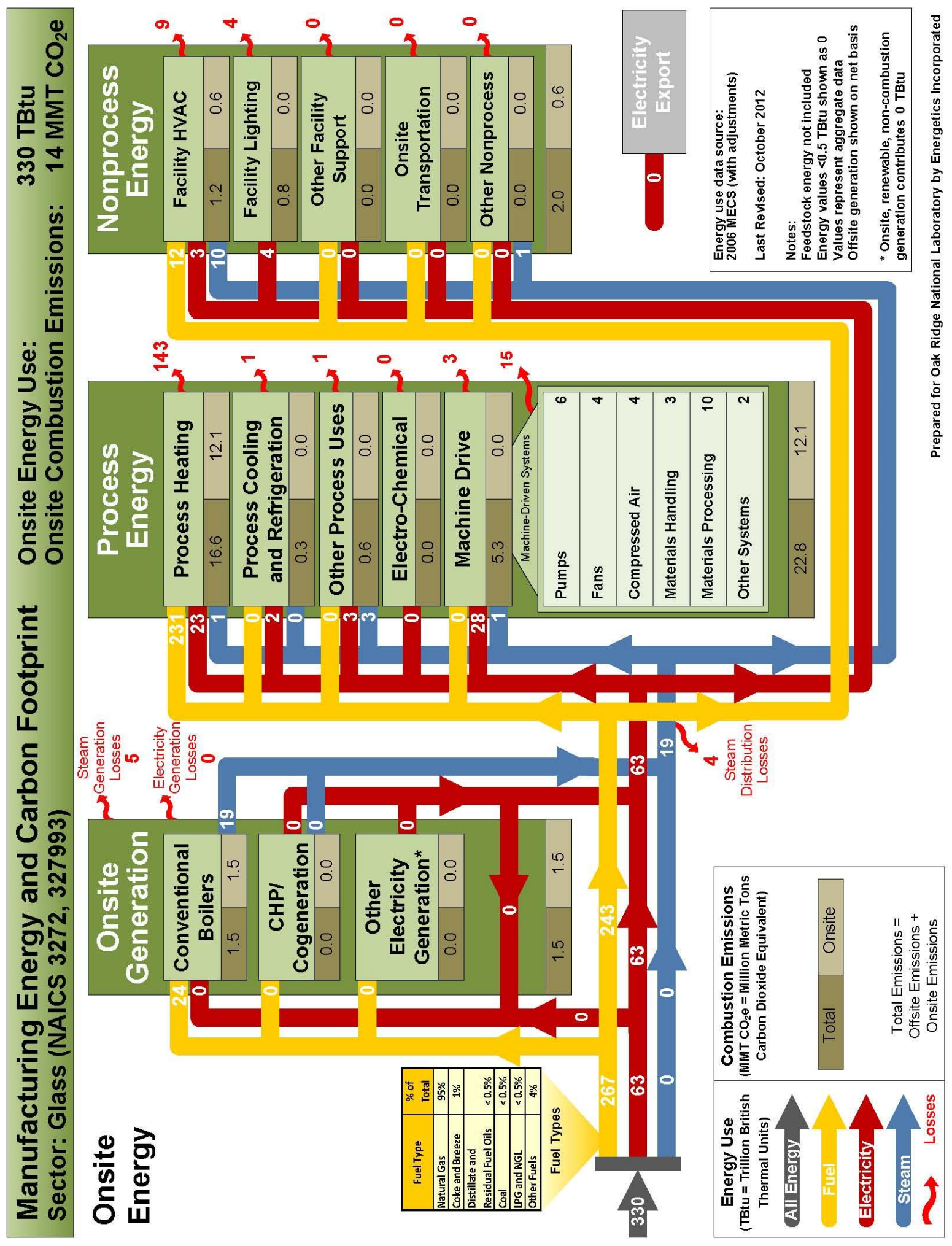




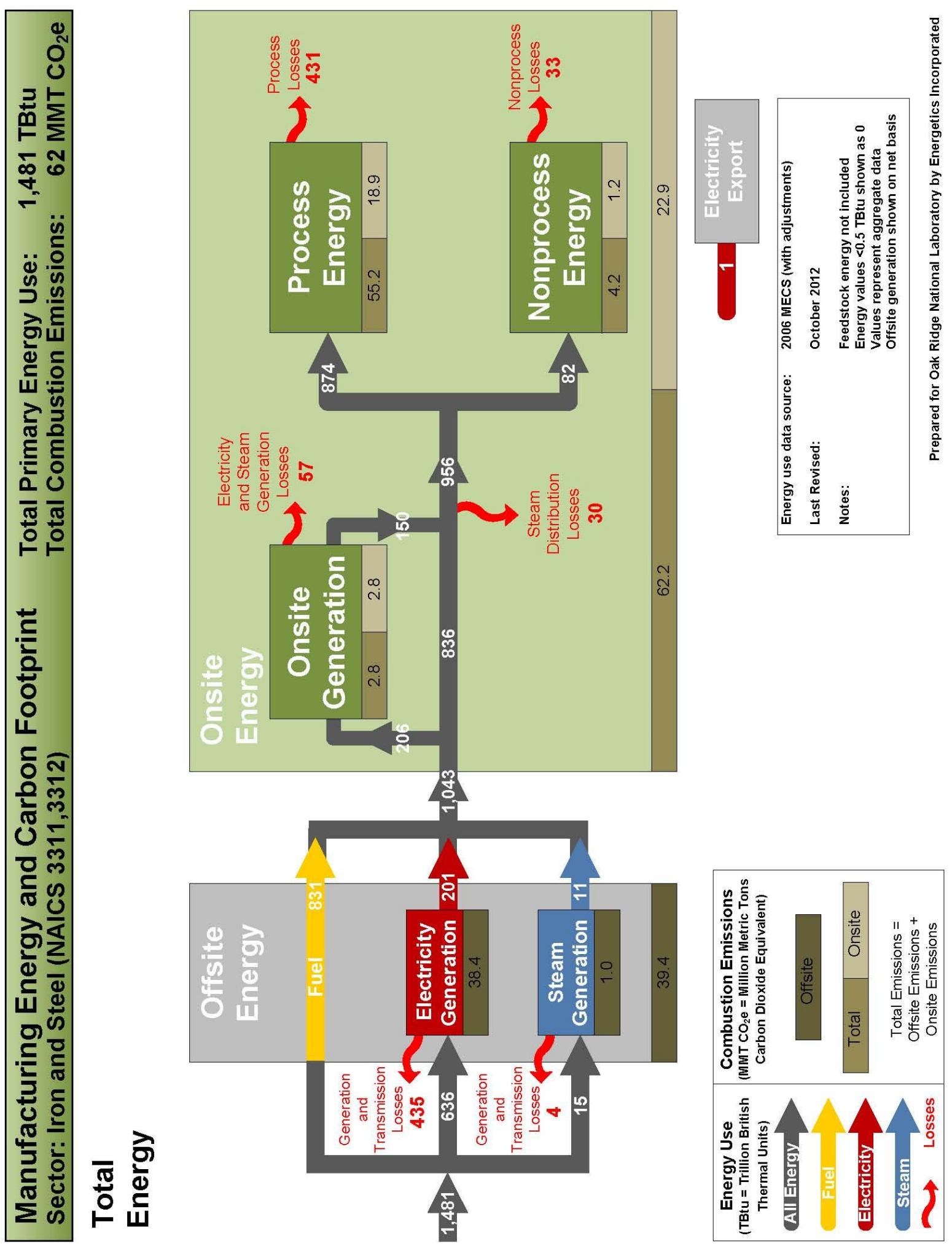




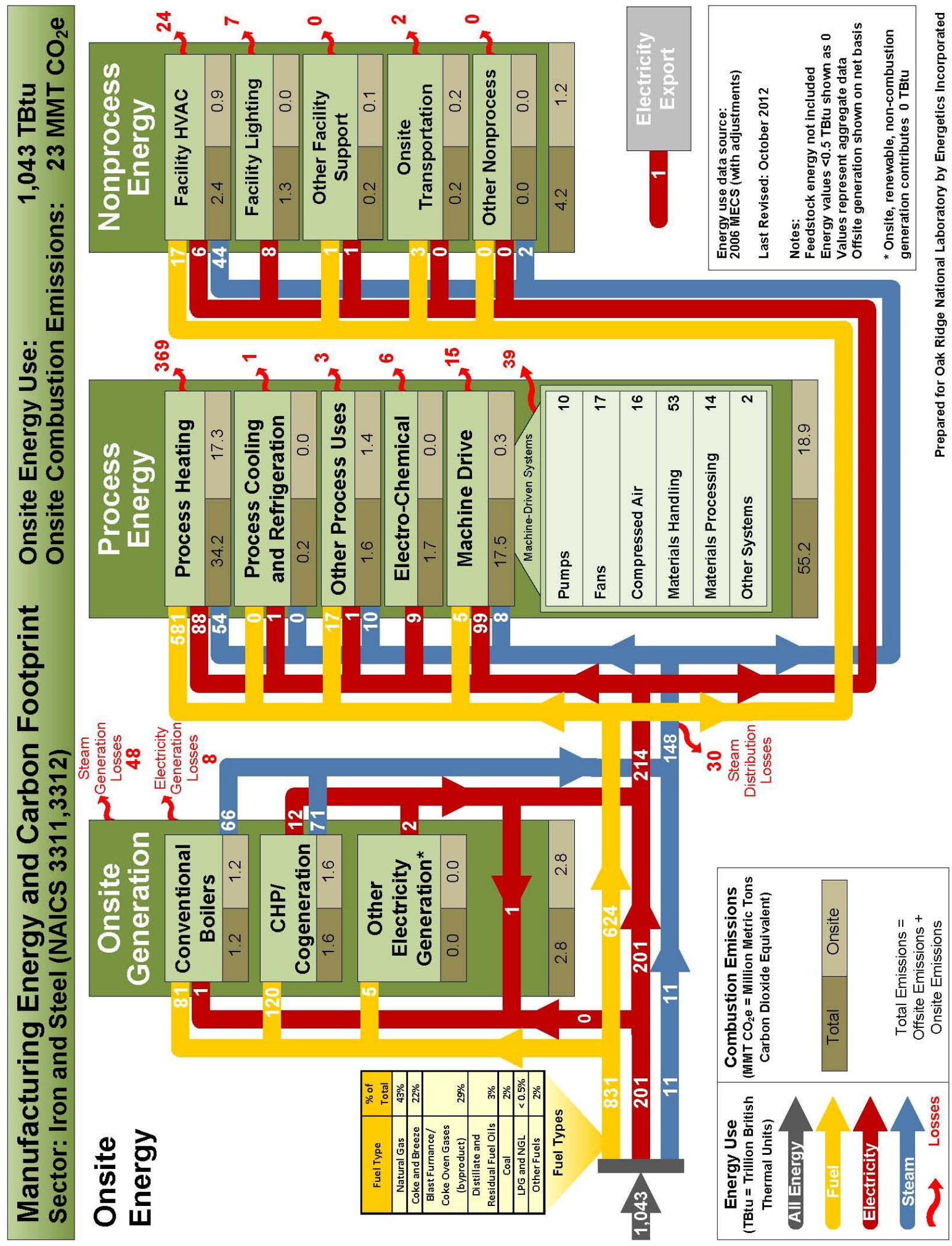




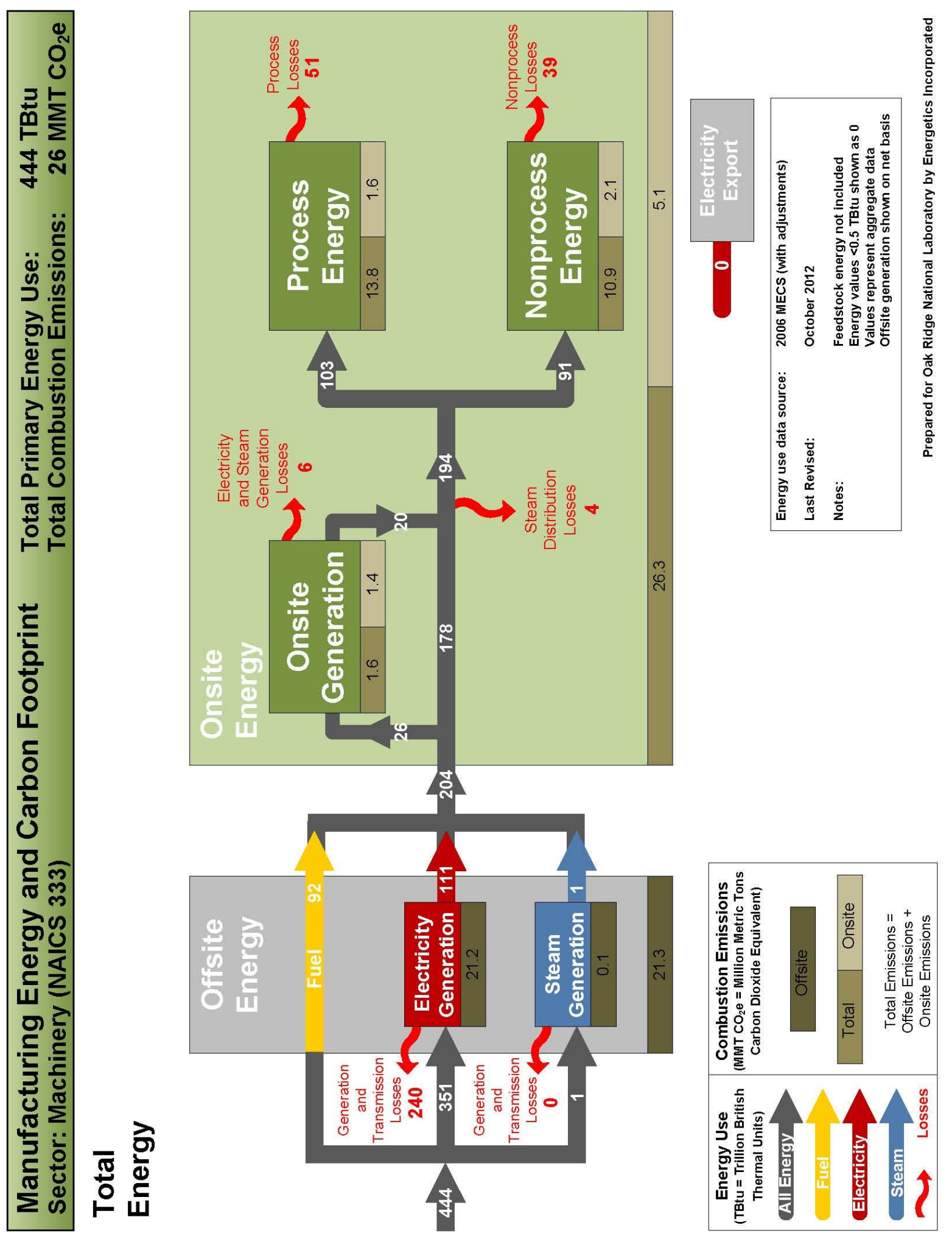




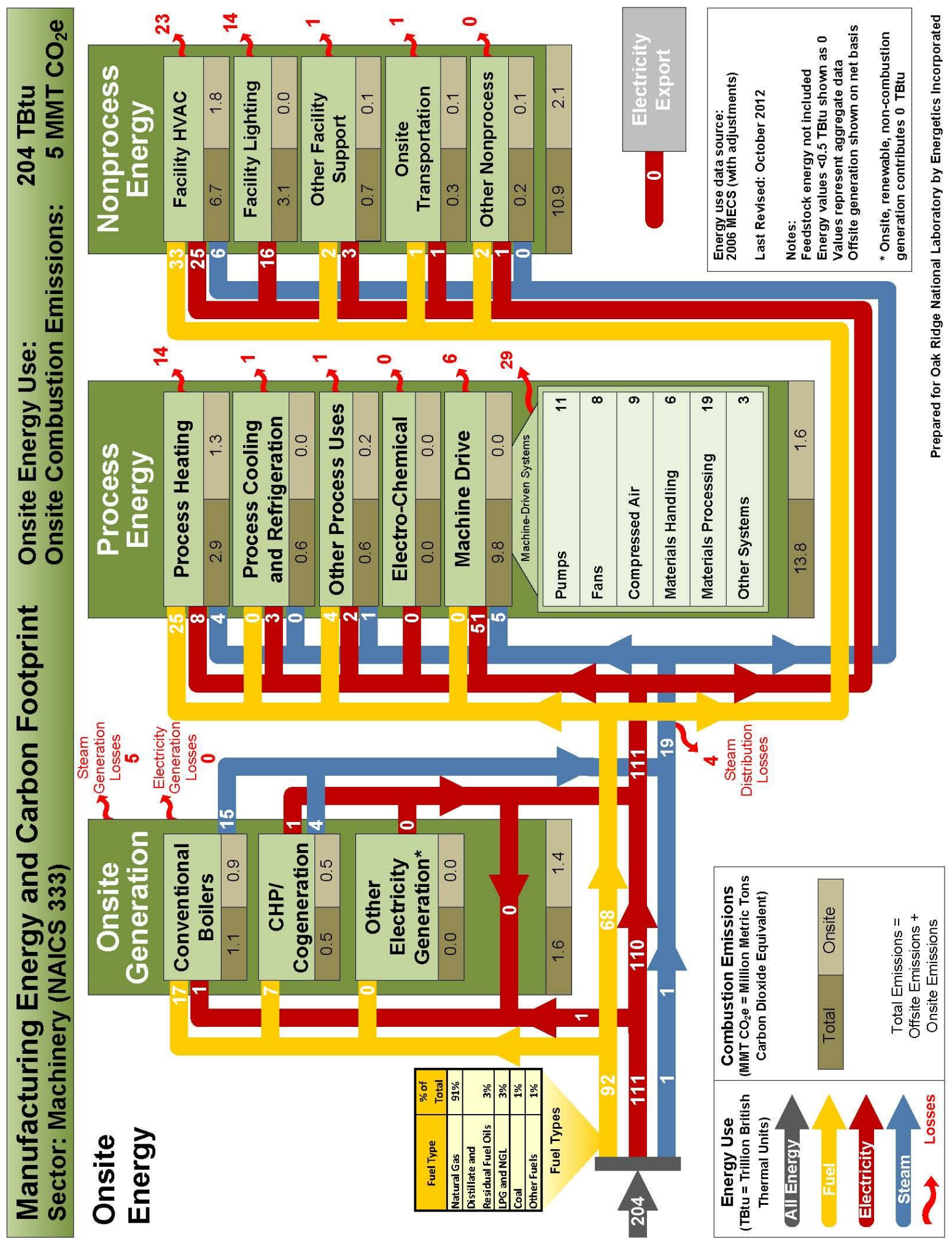




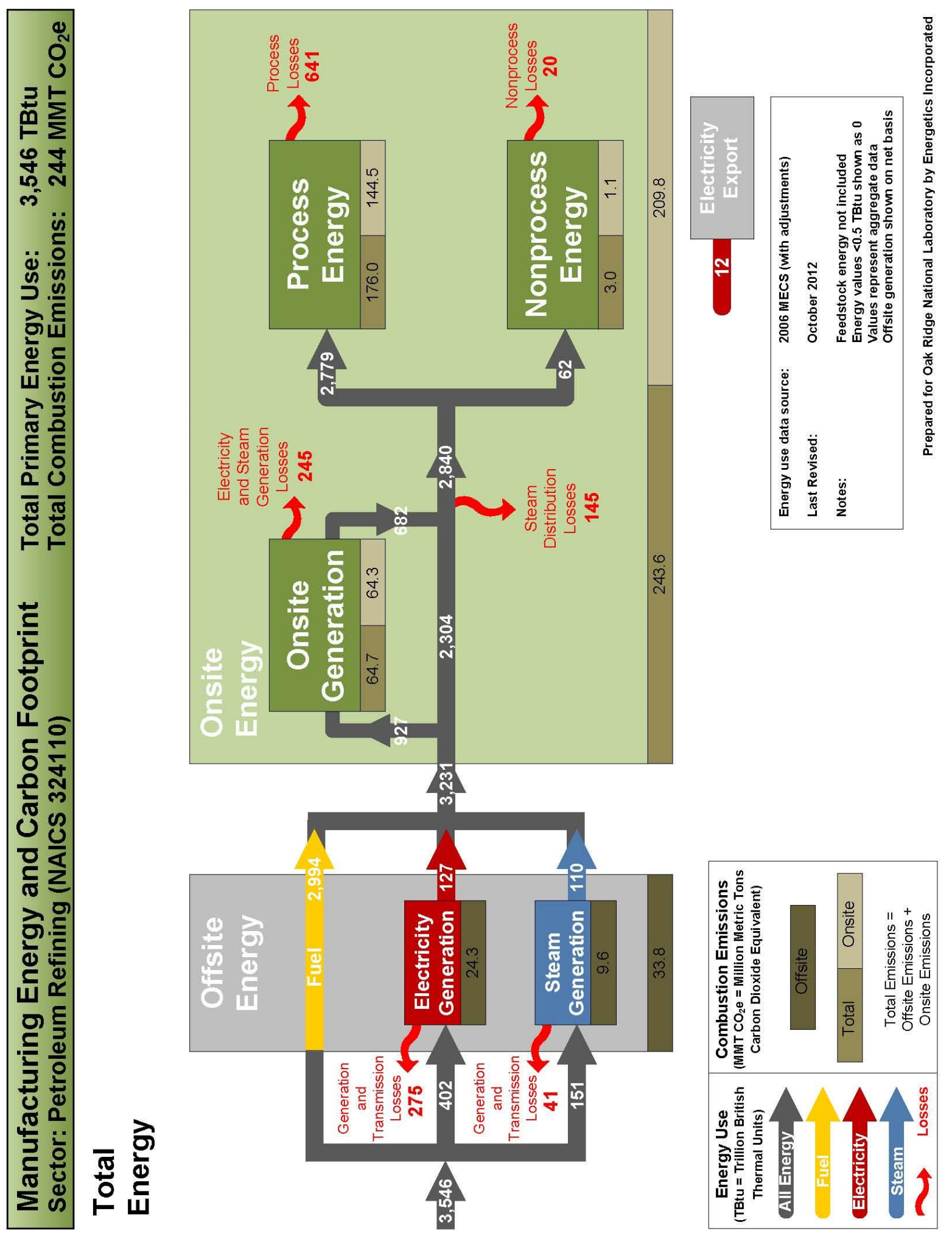




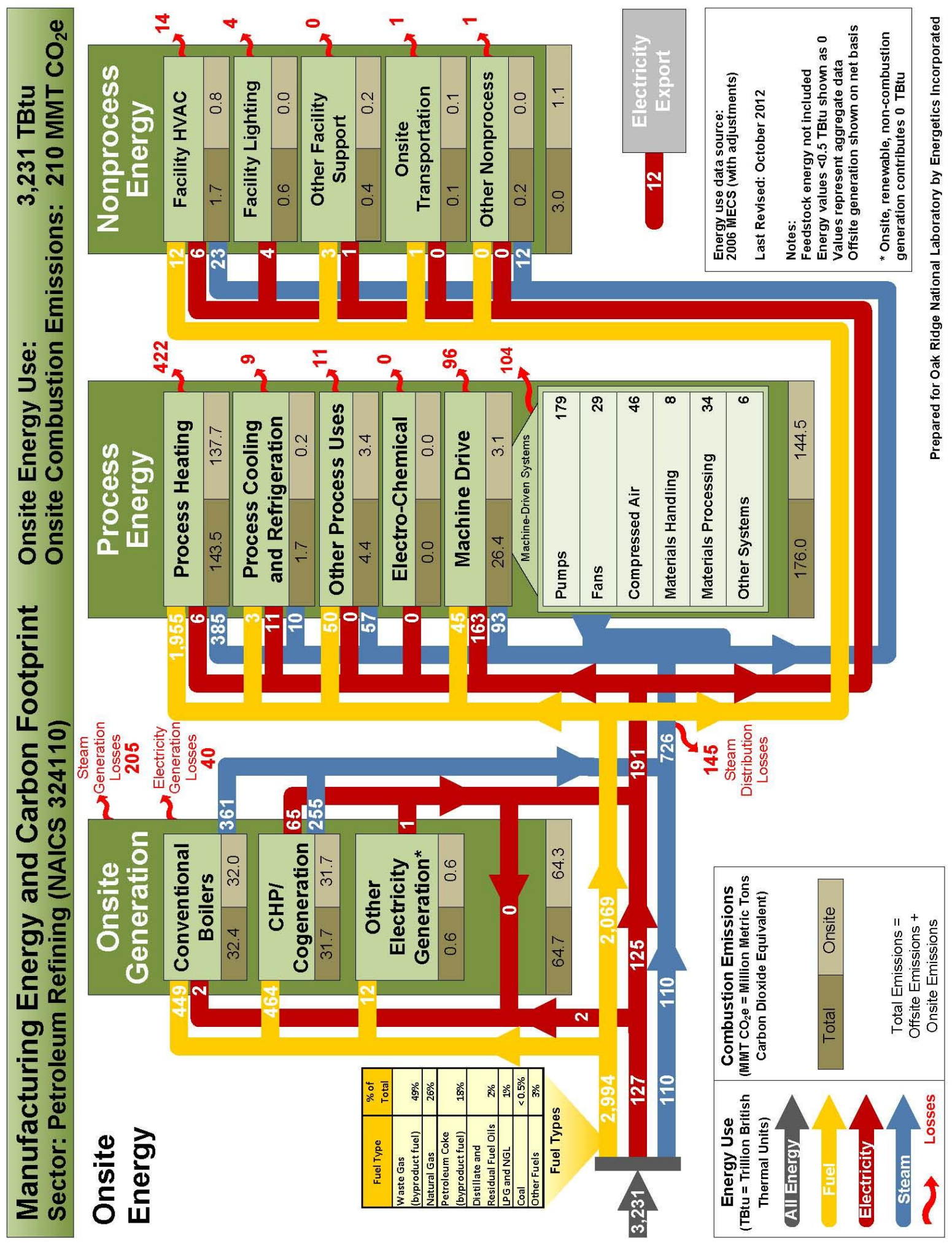




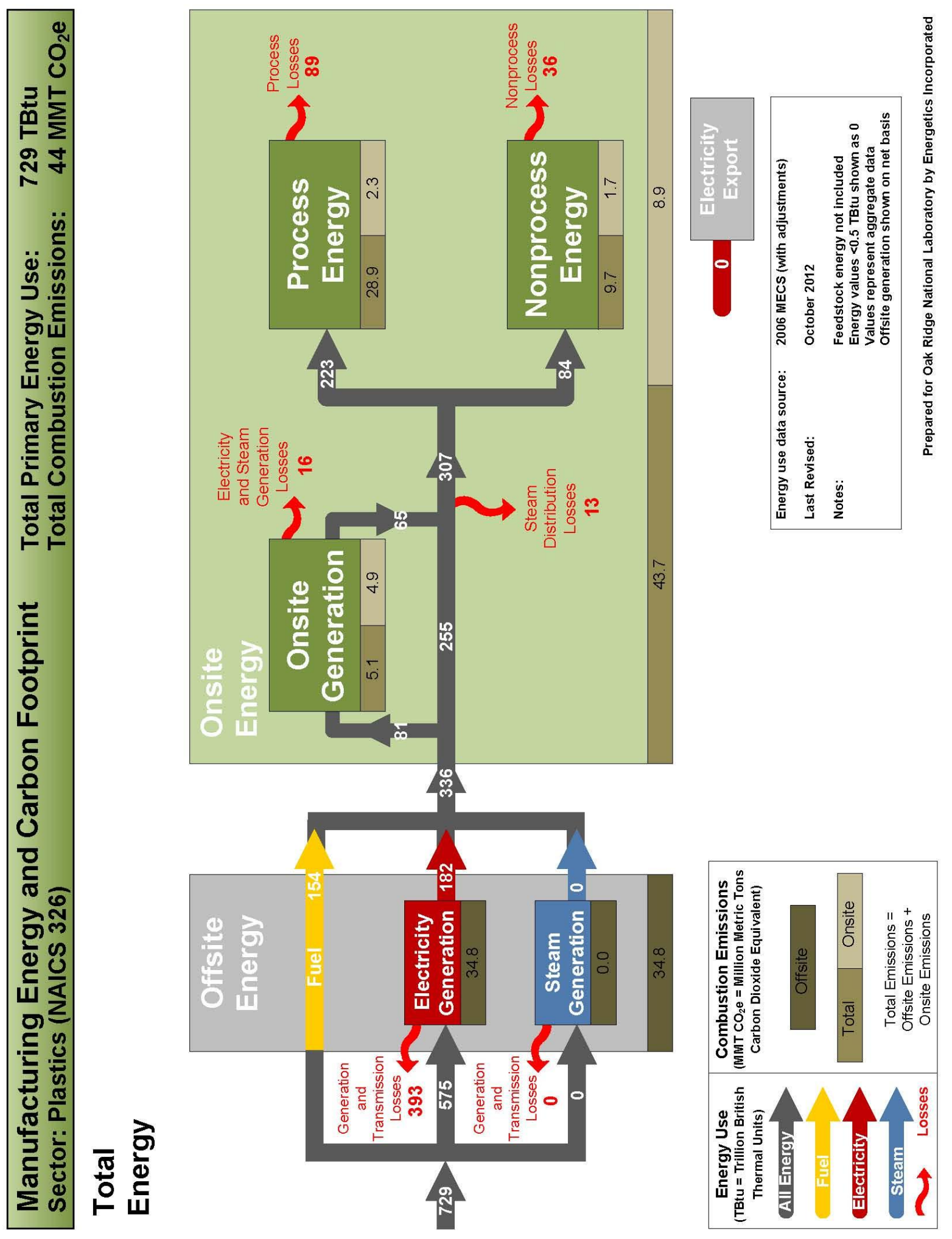




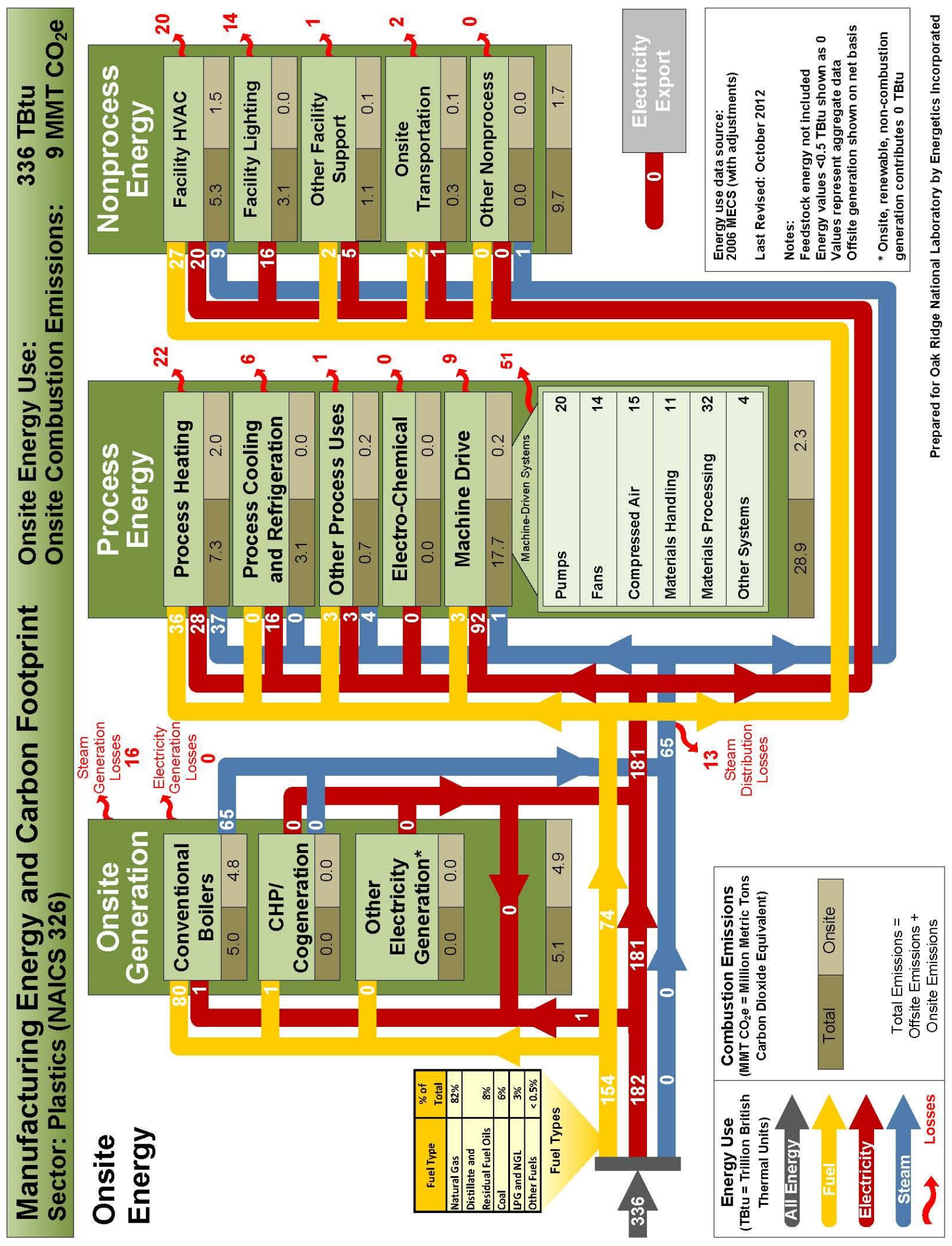




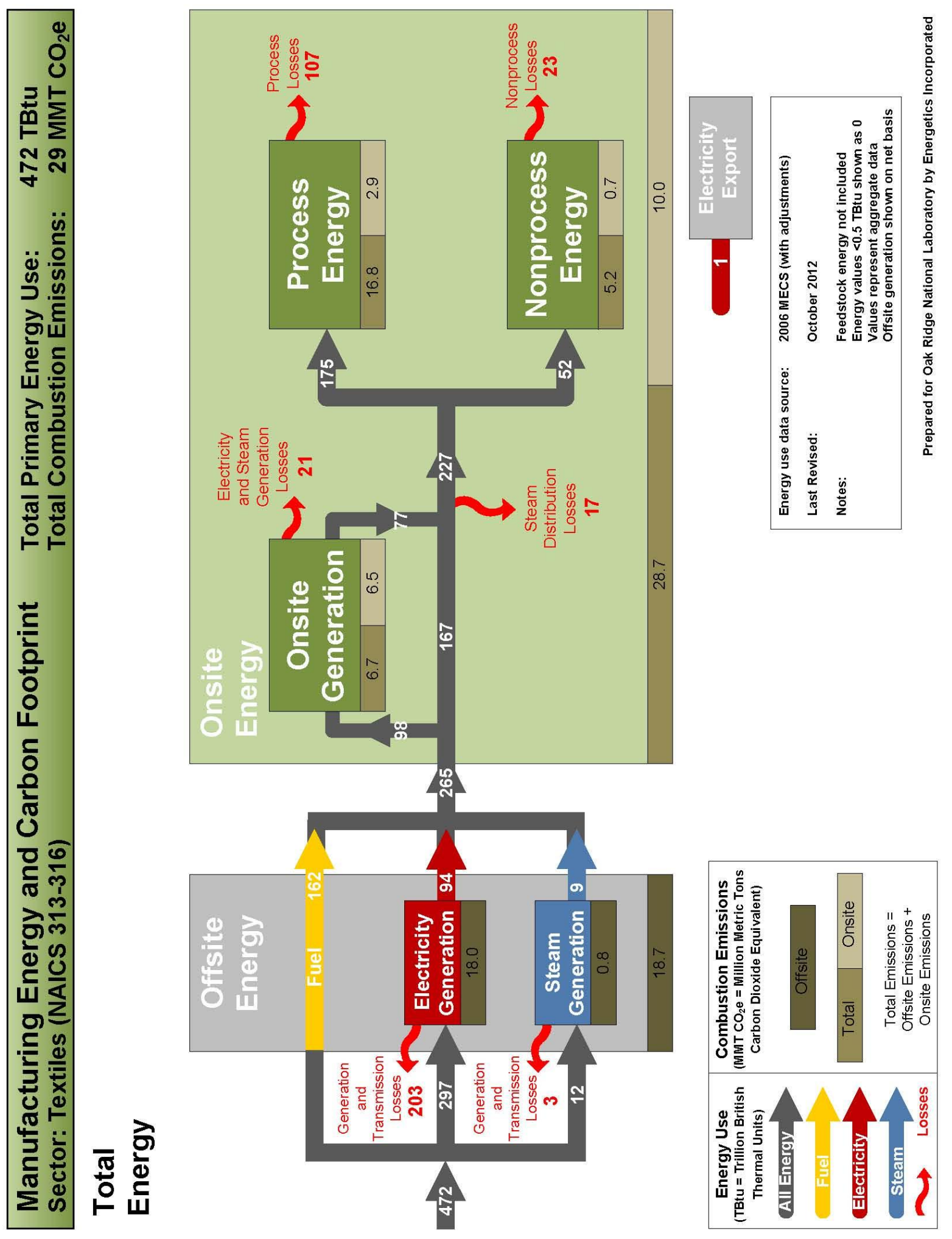




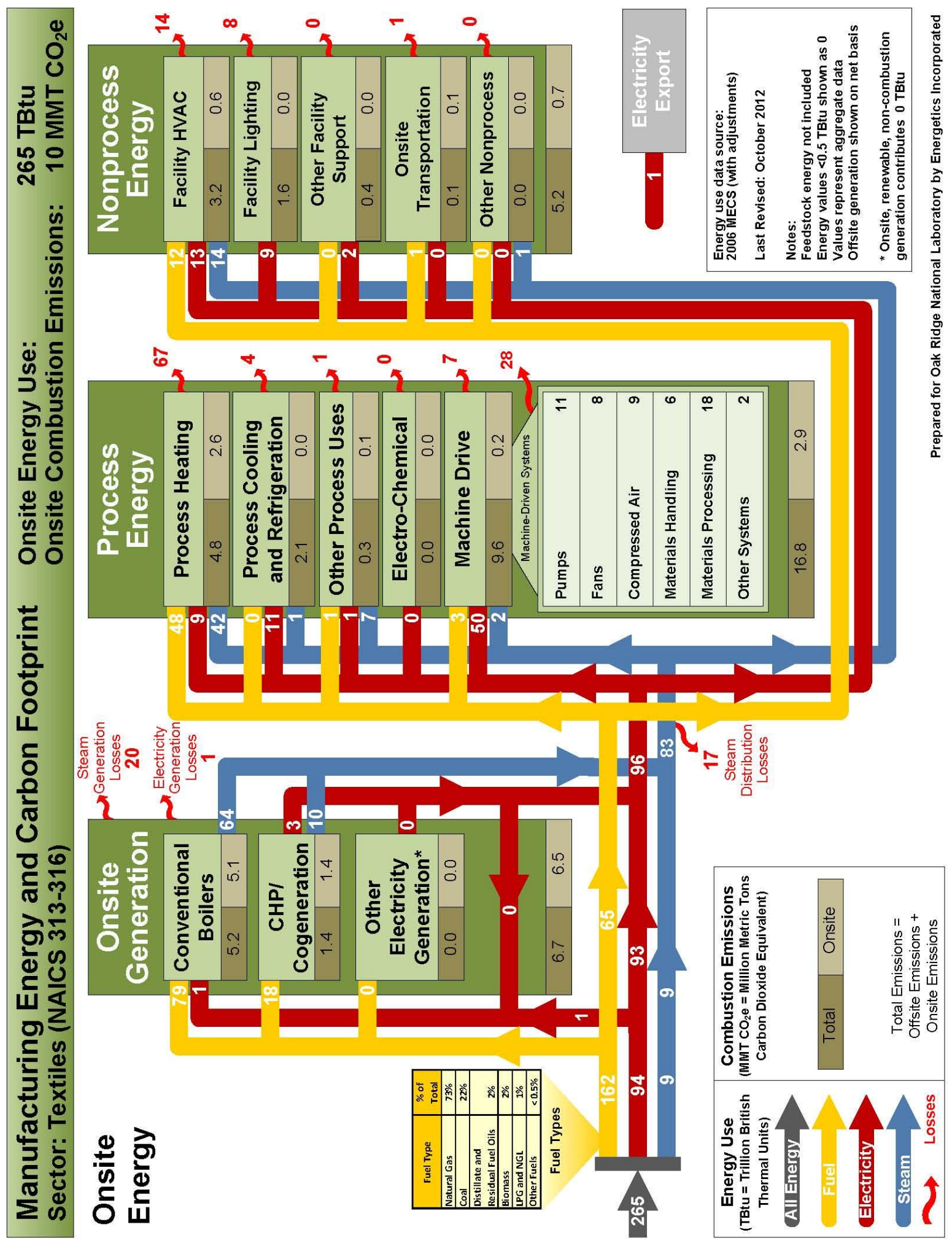




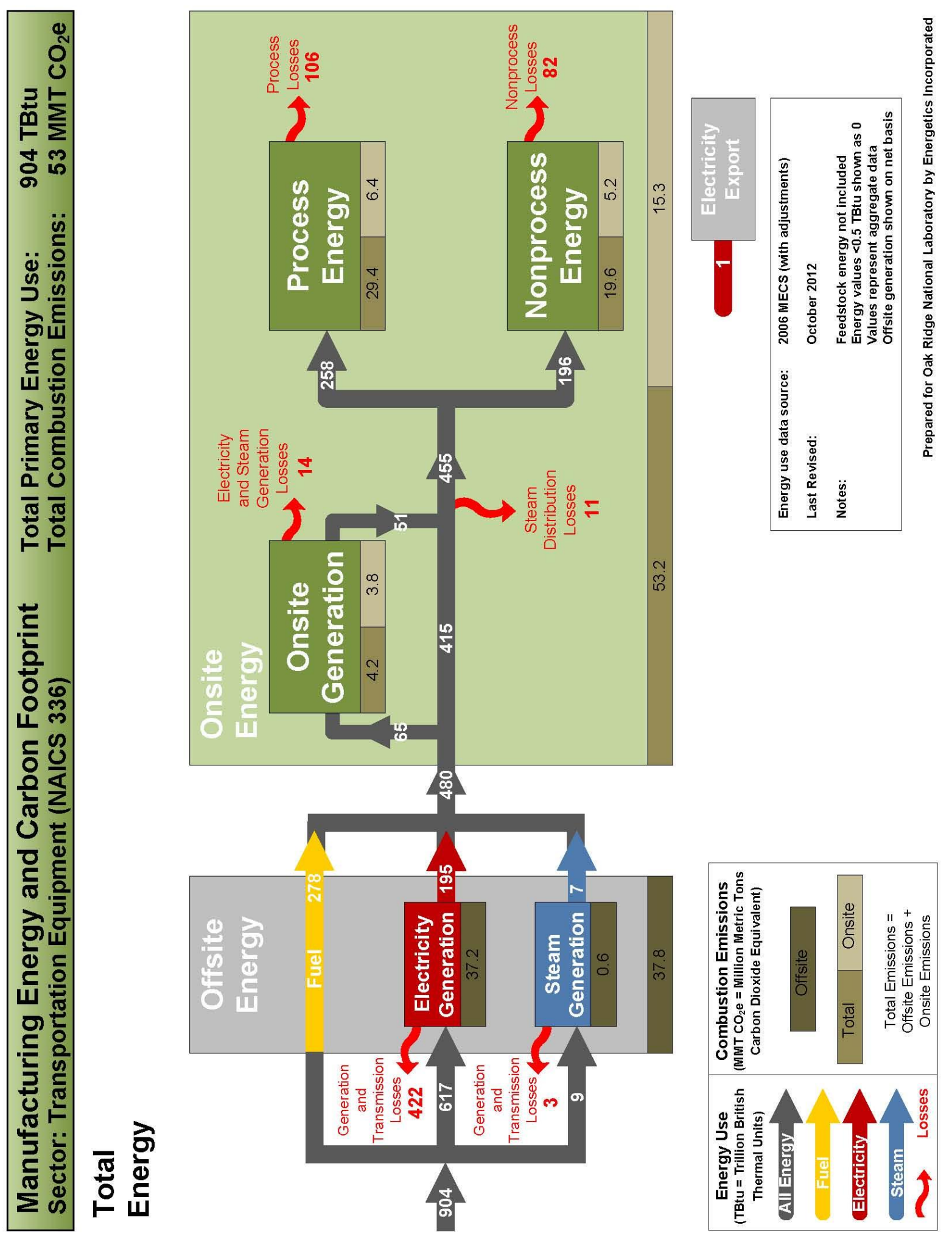




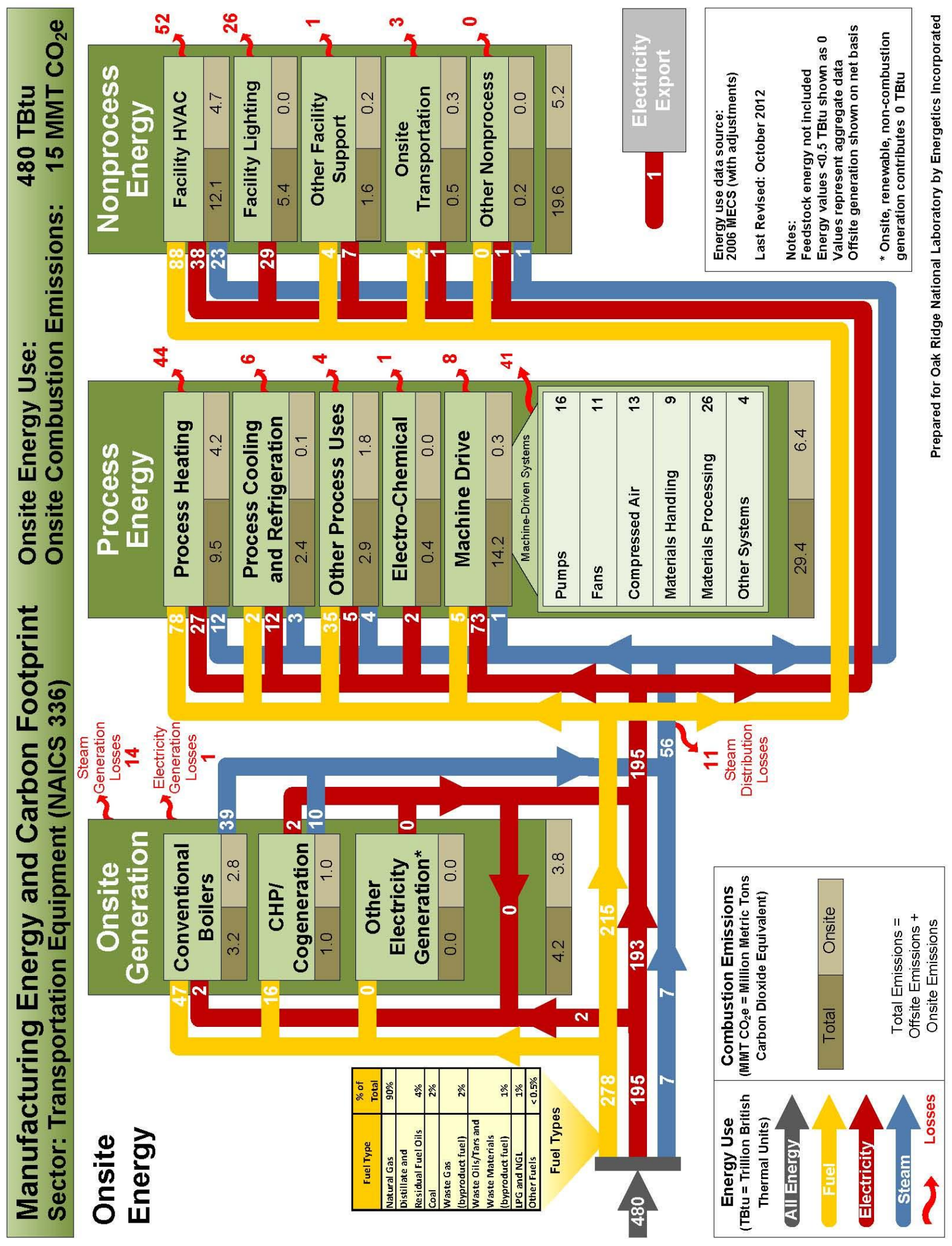


Appendix D

FOOTPRINT ASSUMPTIONS AND DATA ADJUSTMENTS 



\section{Appendix D. FOOTPRINT ASSUMPTIONS AND DATA ADJUSTMENTS}

The U.S. manufacturing energy use and greenhouse gas emissions analysis relies primarily on 2006 EIA Manufacturing Energy Consumption Survey (MECS) data, along with estimated loss assumptions for energy-consuming operations. Key efficiency and loss assumptions are provided in Tables D.1 to D.4. Greenhouse gas emission factors are provided in Table D.5. Data adjustments and assumptions were necessary in the analysis to address rounding errors, double-counting, withheld values, and to ascertain use of energy where end use was not reported. Further data adjustments were made to delineate the composition and use of the MECS "Other Fuels" category reported in MECS Tables 3.2 and 5.2. Adjustments and assumptions of necessary data were determined for each sector based on other EIA data sets, other published sources, and discussions with industry professionals and EIA staff.

Table D.1. Manufacturing energy footprint loss assumptions

\begin{tabular}{|c|c|}
\hline Energy system & Percent energy lost \\
\hline \multicolumn{2}{|c|}{ Energy generation, transmission, and distribution losses } \\
\hline Offsite generation & $\begin{array}{l}\text { Offsite electricity generation and transmission (grid) }-68.4 \% \\
\text { Offsite steam generation }-19 \% \\
\text { Offsite steam transmission }-10 \%\end{array}$ \\
\hline Onsite generation & $\begin{array}{l}\text { Onsite steam generation (conventional boiler) }-20 \% \\
\text { Onsite CHP/cogeneration }-24.4 \%-36.3 \% \text {, see Table D. } 2 \\
\text { Onsite steam distribution }-20 \%\end{array}$ \\
\hline \multicolumn{2}{|c|}{ Onsite process and nonprocess losses } \\
\hline Process energy & $\begin{array}{l}\text { Process heating }-18 \%-68 \% \text {, see Table D. } 3 \\
\text { Process cooling and refrigeration }-35 \% \\
\text { Electro-chemical }-60 \% \\
\text { Other processes }-10 \% \\
\text { Machine drive (shaft energy) - electric } 7 \% \text {, fuel } 60 \% \text {, steam } 50 \% \\
\text { Machine driven systems } \\
\quad \text { Pumps }-40 \% \\
\text { Fans }-40 \% \\
\text { Compressed air }-80 \% \\
\text { Materials handling - 5\% } \\
\text { Materials processing (e.g., grinders) }-90 \% \\
\text { Other systems }-5 \%\end{array}$ \\
\hline Nonprocess energy & $\begin{array}{l}\text { Facility HVAC }-35 \% \\
\text { Facility lighting }-88 \% \\
\text { Other facility support }-10 \% \\
\text { Onsite transportation }-60 \% \\
\text { Other nonprocesses }-10 \%\end{array}$ \\
\hline
\end{tabular}

Note: The values in this table are gross assumptions used to generate order-of-magnitude energy loss estimates. Energy generation and transmission loss assumptions are based on EIA data. Process and nonprocess loss assumptions are drawn from discussion with industry and process experts and have been substantiated where possible with review of relevant studies. In practice, these losses (energy generation, process, and nonprocess) are highly dependent on specific operating equipment and conditions and vary greatly within and across manufacturing sectors. 
Table D.2. CHP efficiency by sector

\begin{tabular}{|c|c|}
\hline Sector & $\begin{array}{c}\text { CHP } \\
\text { efficiency }\end{array}$ \\
\hline Chemicals & $63.7 \%$ \\
\hline Food and beverage & $74.5 \%$ \\
\hline Forest products & $75.6 \%$ \\
\hline Petroleum refining & $69.0 \%$ \\
\hline Iron and steel & $69.0 \%$ \\
\hline $\begin{array}{l}\text { All manufacturing weighted average } \\
\text { also used for the following sectors where there is insufficient data: } \\
\text { cement; textiles; transportation equipment; aluminum; machinery; fabricated metals; } \\
\text { plastics and rubber products; computers, electronics, and electrical equipment }{ }^{a} \text {; foundries } \\
{ }^{a} \text {; glass and fiberglass }{ }^{a} \text {. }\end{array}$ & $69.5 \%$ \\
\hline
\end{tabular}

Source: EIA (U.S. Energy Information Administration). 2006. "Form EIA-906, EIA-920, and EIA-923 Databases.” U.S. Department of Energy. http://www.eia.doe.gov/cneaf/electricity/page/eia906_920.html

${ }^{a}$ CHP energy use shown to be $0 \mathrm{TBtu}$, so CHP Efficiency is not applicable in the energy footprint.

Table D.3. Process heating loss assumptions by sector

\begin{tabular}{|l|c|}
\hline \multicolumn{1}{|c|}{ Sector } & $\begin{array}{c}\text { Percent of process } \\
\text { heating lost }\end{array}$ \\
\hline Chemicals; plastics and rubber products & $22 \%$ \\
\hline Food and beverage; textiles & $68 \%$ \\
\hline Forest products & $68 \%$ \\
\hline Petroleum refining & $18 \%$ \\
\hline Iron and steel; aluminum; foundries & $51 \%$ \\
\hline Glass & $56 \%$ \\
\hline Cement & $40 \%$ \\
\hline $\begin{array}{l}\text { All manufacturing average } \\
\text { (also used for the following sectors where there is insufficient data: transportation } \\
\text { equipment; } \text { machinery; fabricated metals; computers, electronics, and electrical } \\
\text { equipment.) }\end{array}$ & $38 \%$ \\
\hline
\end{tabular}

Sources: A Manufacturing Process Heating Energy Loss Working Group was formed in January 2012 in order to estimate energy losses from key process heating equipment for seven energy-intensive manufacturing sectors. Process heating energy loss, as defined in the energy footprint, is not a value that is readily available through literature search. As a result, the working group was formed to contribute to this important piece of the footprint analysis effort. Interviews with manufacturers, available plant assessment results, and relevant industrial studies were all considered in estimating process heating energy loss by manufacturing sector and subsector, shown in Table D.3 above. More methodology details are available in Appendix F. 
Table D.4. Steam allocation assumptions by sector

\begin{tabular}{|l|c|c|c|c|c|c|}
\hline \multicolumn{1}{|c|}{ Sector } & \multicolumn{7}{|c|}{ Steam end use allocation } \\
\cline { 2 - 7 } & $\begin{array}{c}\text { Process } \\
\text { heating }\end{array}$ & $\begin{array}{c}\text { Machine } \\
\text { drive }\end{array}$ & $\begin{array}{c}\text { Process } \\
\text { cooling/ } \\
\text { refrigeration }\end{array}$ & $\begin{array}{c}\text { Other } \\
\text { process uses }\end{array}$ & $\begin{array}{c}\text { Facility } \\
\text { HVAC }\end{array}$ & $\begin{array}{c}\text { Other } \\
\text { nonprocess } \\
\text { uses }\end{array}$ \\
\hline Alumina and aluminum & $31 \%$ & $13 \%$ & $0 \%$ & $27 \%$ & $21 \%$ & $7 \%$ \\
Cement & $45 \%$ & $6 \%$ & $1 \%$ & $16 \%$ & $27 \%$ & $6 \%$ \\
Chemicals & $67 \%$ & $10 \%$ & $3 \%$ & $8 \%$ & $9 \%$ & $4 \%$ \\
Computers, electronics and & $16 \%$ & $0 \%$ & $1 \%$ & $7 \%$ & $73 \%$ & $4 \%$ \\
electrical equipment & $35 \%$ & $1 \%$ & $1 \%$ & $16 \%$ & $46 \%$ & $2 \%$ \\
Fabricated metals & $69 \%$ & $4 \%$ & $5 \%$ & $8 \%$ & $10 \%$ & $3 \%$ \\
Food and beverage & $70 \%$ & $9 \%$ & $2 \%$ & $5 \%$ & $9 \%$ & $4 \%$ \\
Forest products & $13 \%$ & $15 \%$ & $0 \%$ & $9 \%$ & $60 \%$ & $3 \%$ \\
Foundries & $5 \%$ & $5 \%$ & $0 \%$ & $22 \%$ & $63 \%$ & $5 \%$ \\
Glass & $46 \%$ & $7 \%$ & $0 \%$ & $8 \%$ & $38 \%$ & $1 \%$ \\
Iron and steel & $24 \%$ & $29 \%$ & $1 \%$ & $7 \%$ & $37 \%$ & $1 \%$ \\
Machinery & $66 \%$ & $16 \%$ & $2 \%$ & $10 \%$ & $4 \%$ & $2 \%$ \\
Petroleum refining & $71 \%$ & $1 \%$ & $0 \%$ & $7 \%$ & $18 \%$ & $3 \%$ \\
Plastics & $63 \%$ & $2 \%$ & $2 \%$ & $10 \%$ & $21 \%$ & $2 \%$ \\
Textiles & $27 \%$ & $2 \%$ & $7 \%$ & $9 \%$ & $53 \%$ & $2 \%$ \\
Transportation equipment & $66 \%$ & $10 \%$ & $3 \%$ & $8 \%$ & $11 \%$ & $3 \%$ \\
\hline All manufacturing & & & $7 \%$ & \\
\hline
\end{tabular}

Sources: A Manufacturing Steam End Use Working Group was formed in 2011 in order to estimate the allocation of steam to process and nonprocess end uses across 15 manufacturing sectors. Comparative steam use by sector for the process and nonprocess end uses defined in the footprint is not a value that is readily available through literature search. As a result, the working group was formed to contribute to this important piece of the footprint analysis effort. The end use of steam for 15 manufacturing sectors was considered. An industry survey was issued by the working group to solicit industry expertise, and results from the survey were referenced in determining the final steam allocations by sector. Results from the peer review are shown in Table 4 above. Methodology details are available in Appendix E. 
Table D.5. Fuel GHG combustion emission factors ( $\mathrm{kg} \mathrm{CO}_{2} \mathrm{e}$ per million Btu)

\begin{tabular}{|l|c|c|c|c|c|}
\hline \multicolumn{1}{|c|}{ Fuel type } & $\mathbf{C O}_{2}$ & $\mathbf{C H}_{\mathbf{4}}$ & $\mathbf{N}_{\mathbf{2}} \mathbf{O}$ & Total GHG & Source \\
\hline Natural gas (pipeline weighted avg.) & 53.02 & 0.03 & 0.03 & 53.07 & {$[\mathrm{a}]$} \\
\hline Residual fuel oil (No. 5, No. 6) & 75.10 & 0.08 & 0.18 & 75.35 & {$[\mathrm{a}]$} \\
\hline Distillate fuel oil (No. 1, No. 2, No. 4) & 73.96 & 0.08 & 0.18 & 74.21 & {$[\mathrm{a}]$} \\
\hline LPG & 62.98 & 0.08 & 0.18 & 63.23 & {$[\mathrm{a}]$} \\
\hline Coal (industrial sector) & 93.91 & 0.28 & 0.48 & 94.66 & {$[\mathrm{a}]$} \\
\hline Coke (from coal) & 102.04 & 0.28 & 0.48 & 102.79 & {$[\mathrm{a}]$} \\
\hline Still gas & 66.72 & 0.08 & 0.18 & 66.97 & {$[\mathrm{a}]$} \\
\hline Petroleum coke & 102.41 & 0.08 & 0.18 & 102.66 & {$[\mathrm{a}]$} \\
\hline Other fuels & 74.49 & 0.08 & 0.18 & 74.74 & {$[\mathrm{a}]$} \\
\hline Wood and wood residuals & $93.80^{\mathrm{a}}$ & 0.80 & 1.25 & 2.05 & {$[\mathrm{a}]$} \\
\hline Agricultural byproducts & $118.17^{\mathrm{a}}$ & 0.80 & 1.25 & 2.05 & {$[\mathrm{a}]$} \\
\hline Pulping liquor/black liquor & $94.40^{\mathrm{a}}$ & 0.75 & 1.49 & 2.24 & {$[\mathrm{a}]$} \\
\hline Offsite steam generation & - & - & - & 86.85 & {$[\mathrm{~b}]$} \\
\hline Offsite electricity generation & 190.02 & 0.10 & 0.87 & 190.98 & {$[\mathrm{c}]$} \\
\hline
\end{tabular}

${ }^{a} \mathrm{CO}_{2}$ emissions from biomass fuel combustion (also known as biogenic $\mathrm{CO}_{2}$ ) are not included in the total emission factor because the uptake of $\mathrm{CO}_{2}$ during biomass growth results in zero net emissions over time. Sources:

[a] Federal Register/Vol. 74, No. 209/Friday, October 30, 2009/Part 98, Tables C-1, C-2, and AA-1 (EPA Mandatory Reporting Rules)

[b] EIA Voluntary Reporting of Greenhouse Gases, Appendix N, p 164, 2/13/2008

[c] EPA (U.S. Environmental Protection Agency). 2007. "Emissions and Generation Resource Integrated Database (eGRID), eGRID2007 Version 1.1.” U.S. Environmental Protection Agency. Last modified May 10. http://www.epa.gov/cleanenergy/egrid (adjusted to reflect transmission losses) 
Appendix E

ALLOCATION OF STEAM TO PROCESS AND NONPROCESS END USES 



\title{
Appendix E. ALLOCATION OF STEAM TO PROCESS AND NONPROCESS END USES MANUFACTURING ENERGY AND CARBON FOOTPRINT PEER REVIEW RESULTS
}

\author{
SABINE BRUESKE \\ ENERGETICS INCORPORATED \\ CAROLINE KRAMER \\ ENERGETICS INCORPORATED
}

\begin{abstract}
During 2011, the Manufacturing Steam End Use Working Group was formed to support analysis conducted for the United States Department of Energy Advanced Manufacturing Office (DOE/AMO). The working group provided industry peer review and contribution to the Manufacturing Energy and Carbon Footprints, an energy use analysis project conducted by Energetics Incorporated. Analysts and decision-makers utilize the energy footprints to better understand the distribution of energy use in manufacturing and the accompanying energy losses. The footprints provide a benchmark from which to justify the benefits of improving energy efficiency and for prioritizing opportunity analysis.

Comparative steam use by sector for the process and nonprocess end uses defined in the footprint is not readily available by sector through literature search. A peer review group was formed to contribute to this important piece of the footprint analysis. The end use of steam for 15 manufacturing sectors was considered. An industry survey was issued by the working group to solicit industry expertise, and results from the survey were referenced in determining the final steam allocations by sector. Results from the peer review have been incorporated into the energy footprint model and updated footprints have been republished on the DOE/AMO website.
\end{abstract}

\section{MANUFACTURING ENERGY USE FOOTPRINT ANALYSIS}

The Manufacturing Energy and Carbon Footprints serve as a map of manufacturing energy use and loss and associated greenhouse gas emissions for fuel, electricity, and steam use in the United States. Each footprint consists of two pages: one that provides an overview of the sector's total primary energy flow including offsite energy and losses (Fig. E.1) and one that provides a more detailed breakdown of the onsite energy by end use (Fig. E.2). Sixteen sector footprints have been published; detail on which sectors were studied is described later (see Table E.4).

The energy and carbon values portrayed in the footprint diagrams are the result of a complex analysis effort. Energy use statistics were primarily obtained from DOE, Energy Information Administration (EIA)-published 2006 Manufacturing Energy Consumption Survey (MECS) results. In order to complete an accurate balance of manufacturing energy use, some adjustments and assumptions were applied.

The topic of this paper (and the findings of the working group discussed herein) - the allocation of steam to process and nonprocess end uses - is a subset of the footprint analysis effort. After an extensive technical review of the footprints, two areas of analysis were identified as needing further industry peer review: estimation of steam allocation to process and nonprocess end uses and energy loss in process heating. The second peer review topic addressing energy loss in process heating end use is detailed in a separate white paper (see Appendix F). 


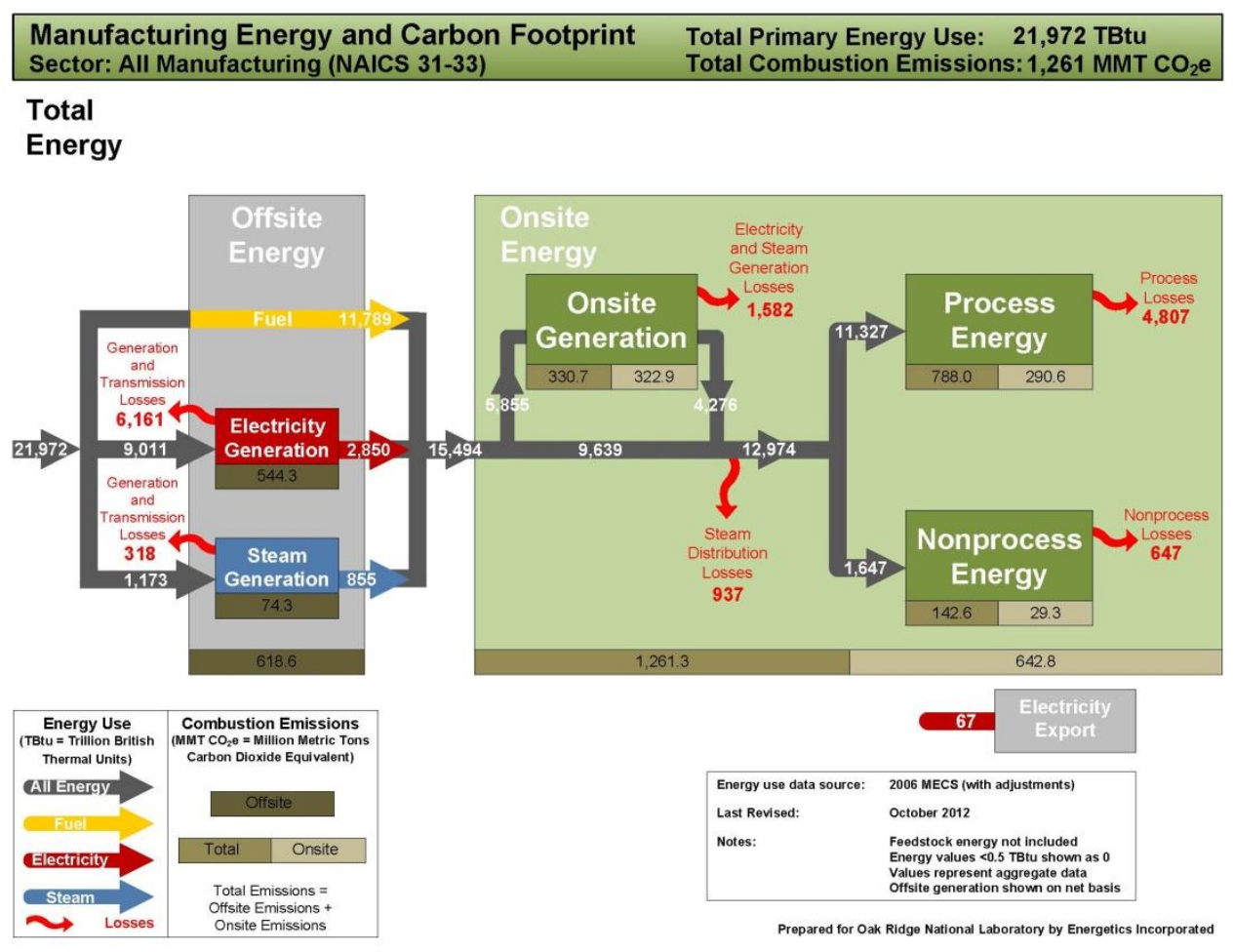

Fig. E.1. Manufacturing energy and carbon footprint for U.S. manufacturing - total energy

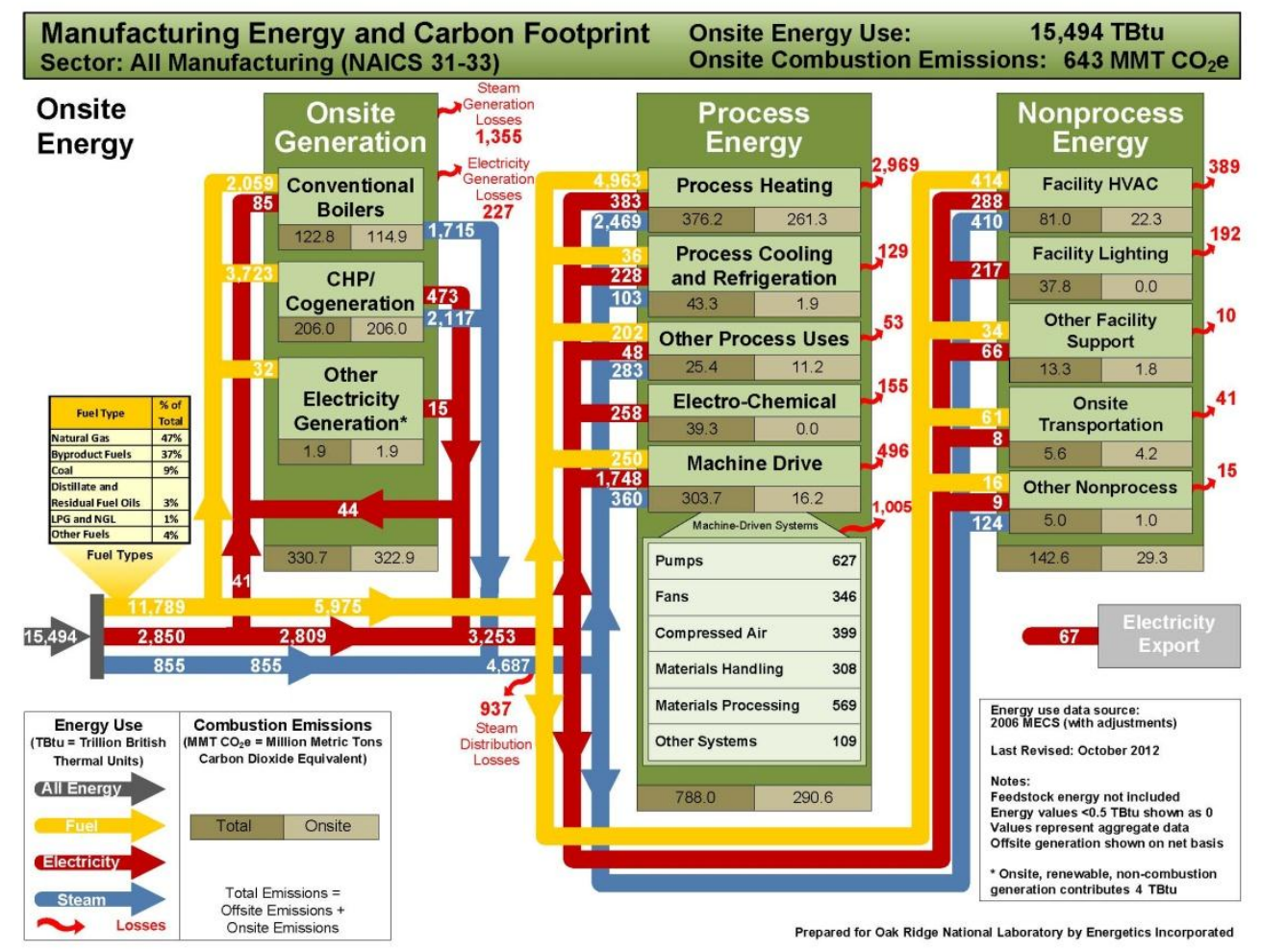

Fig. E.2. Manufacturing energy and carbon footprint for U.S. manufacturing - onsite energy 


\section{STEAM ALLOCATION PEER REVIEW}

The purpose of the Manufacturing Steam End Use Working Group was to provide industry peer review and contribution to a U.S. Department of Energy (DOE) manufacturing energy analysis project, the Manufacturing Energy and Carbon Footprints. The footprint analysis project was conducted by Energetics Incorporated under contract with Oak Ridge National Laboratory (ORNL) for the DOE Advanced Manufacturing Office (AMO).

A working group comprised of representatives from seven industrial organizations was convened in 2011 to perform a short-term, focused peer review effort. Organizations voluntarily participated in the working group meetings are shown in Table E.1.

Table E.1. Steam end use working group organizations

\begin{tabular}{|l|}
\hline Armstrong International \\
\hline Council of Industrial Boiler Owners (CIBO) \\
\hline Dow Chemical Company \\
\hline Energetics Incorporated \\
\hline U.S. Energy Information Administration (EIA) \\
\hline Kumana and Associates \\
\hline Oak Ridge National Laboratory \\
\hline Spirax Sarco \\
\hline
\end{tabular}

The steam end use values that were evaluated by the working group are highlighted in yellow in Fig. E.3. 


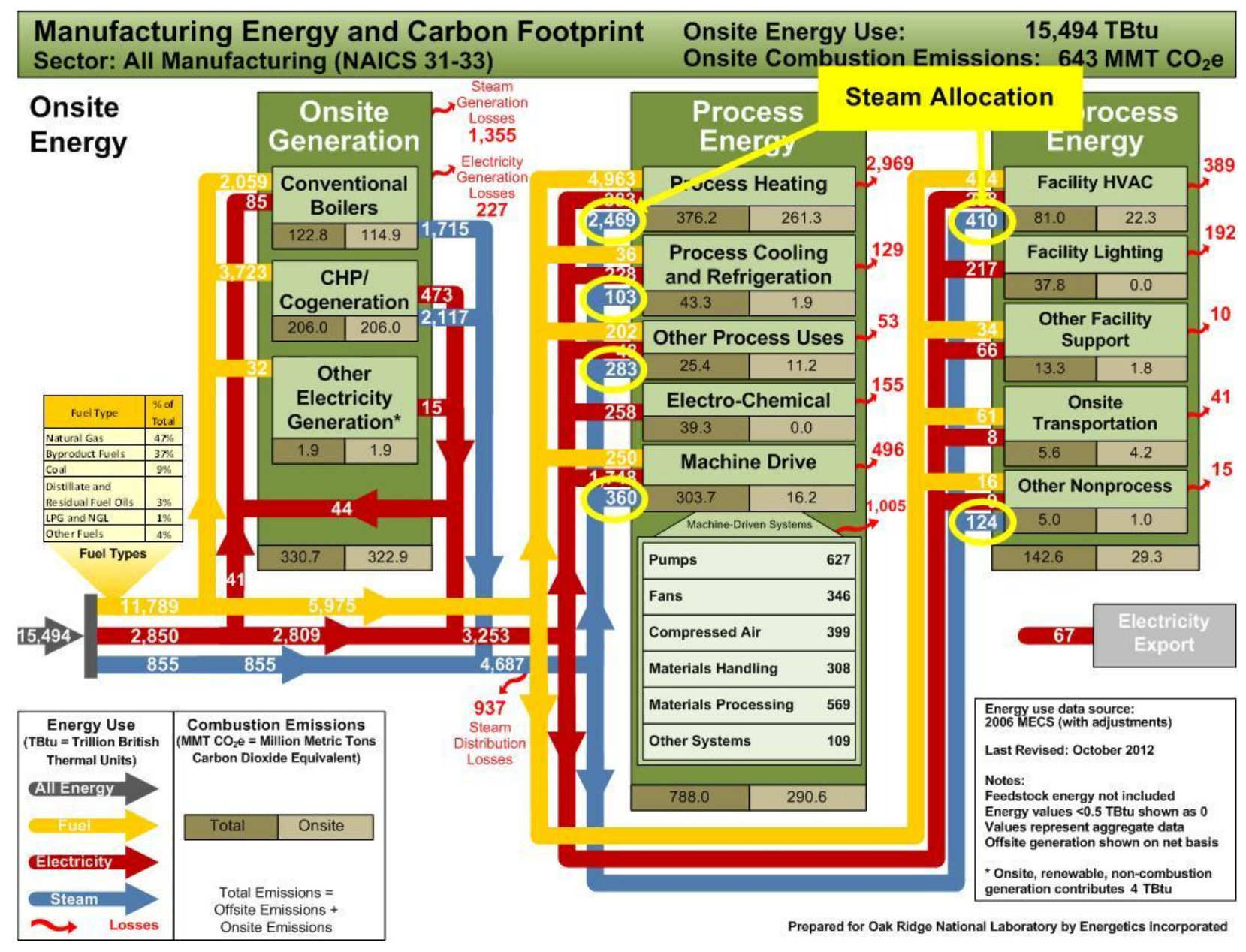

Fig. E.3. Steam end use values evaluated by steam working group

In the Manufacturing Energy and Carbon Footprints there are two sources for steam end use - offsite supply (purchased and transferred in) and onsite generation. Estimation of onsite utility steam generation is based upon the amount of energy used by and efficiency of steam-producing equipment (such as combined heat and power (CHP systems) and boilers). Calculations associated with steam supply and generation was not considered by the steam end use working group as these were outside the working group scope.

In the MECS data set, end use of fuel and electricity is reported by sector; steam end use, however, is not reported. For this reason, steam end use allocation must be assumed in the energy footprint model. The goal of the working group was to agree upon an acceptable approach for estimating steam allocation to six MECS-defined manufacturing process and nonprocess end uses: process heating, machine drive, process cooling and refrigeration, other process uses, facility heating, ventilation, and air conditioning (HVAC), and other nonprocess uses. Steam allocation results were needed for the following 15 individual sectors (listed in alphabetical order) and a weighted average of steam allocation for all of U.S. manufacturing: alumina and aluminum; cement; chemicals; computers, electronics, and electrical equipment; fabricated metals; food and beverage; forest products; foundries; glass; iron and steel; machinery; petroleum refining; plastics; textiles; and transportation equipment. 


\section{TIMELINE AND APPROACH}

The Manufacturing Steam End Use Working Group was a two month peer review effort. The working group met on four separate occasions in December 2011 and January 2012 and conducted additional analysis between meetings.

During the first meeting, the working group reviewed the topic and discussed methods of improving the original steam end use estimates. After considering various options, the working group agreed that the best approach to determining realistic sector-wide steam allocation results would be to allow steam experts the opportunity to provide their site-based knowledge. It was agreed that the survey contributors should be given the opportunity to provide input on all of the 15 sectors.

The Manufacturing Steam End Use Working Group conducted an online survey using the survey software SurveyMonkey. Survey results were kept anonymous and categorized by employer category only. Energetics Incorporated assisted the working group with creating the survey content and language. The survey was issued by a representative from Spirax Sarco on behalf of the whole working group and was distributed to over 225 recipients including industrial steam experts, qualified steam system evaluation specialists, steam equipment providers, and others. CIBO distributed the survey to its Energy and Technical Committees. A total of 67 industry individuals responded and provided input to the manufacturing steam end use survey. The distribution of survey respondents by their employer category can be seen in Fig. E-4.

\section{Survery Respondent Categories}

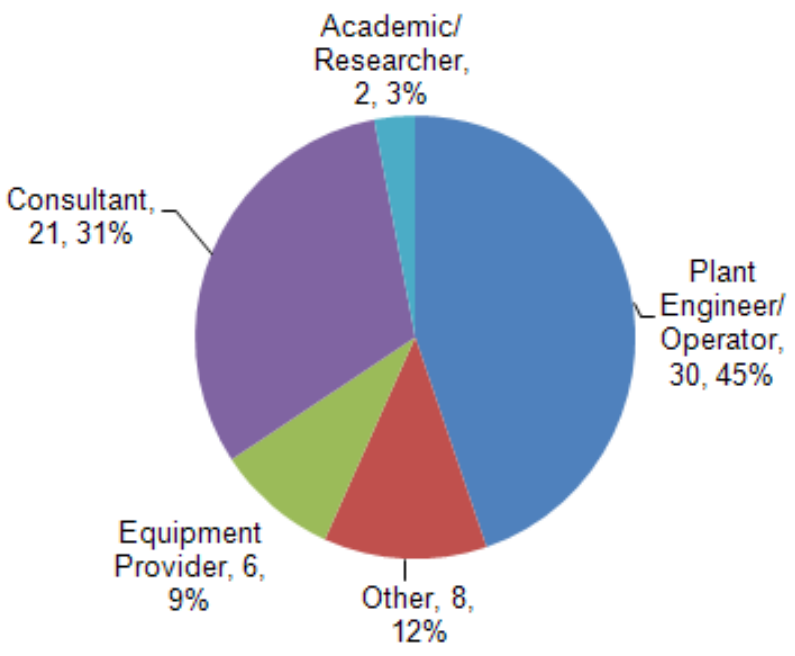

Fig. E.4. Survey respondents by employer category

Each survey participant had the opportunity to enter percentage steam use allocations across the six end use categories for 15 individual manufacturing sectors. Respondents were prompted to provide their sitebased level of knowledge (significant, moderate, minimal, or none) for each sector; respondents were not required to enter steam end use allocations for every sector.

During the third and fourth meetings, the working group reviewed the data from the survey and discussed any outstanding issues such as whether or not to weigh the responses based upon site-based knowledge level. Also, a few of the manufacturing sectors did not have as many respondents as was deemed 
necessary for accuracy so the working group agreed to re-open the survey for an additional week and elicit further requests for input in those sectors.

To account for the different levels of survey respondent self-indicated site-based knowledge, the working group agreed that the survey responses should be weighted as outlined in Table E-2.

Table E.2. Weighting of survey responses

\begin{tabular}{|l|c|}
\hline Respondent knowledge level & $\begin{array}{l}\text { Weight of } \\
\text { response }\end{array}$ \\
\hline Significant & 10 \\
\hline Moderate & 5 \\
\hline Minimal & 2 \\
\hline None & 0 \\
\hline
\end{tabular}

Working Group members agreed to eliminate the responses of participants who listed "none" as the sitebased level of knowledge on steam end use allocation in any particular sector in order to ensure the most accurate results. The total number of survey respondents (excluding those with a knowledge level of "none") for the 15 individual manufacturing sectors is shown in Fig. E.5.

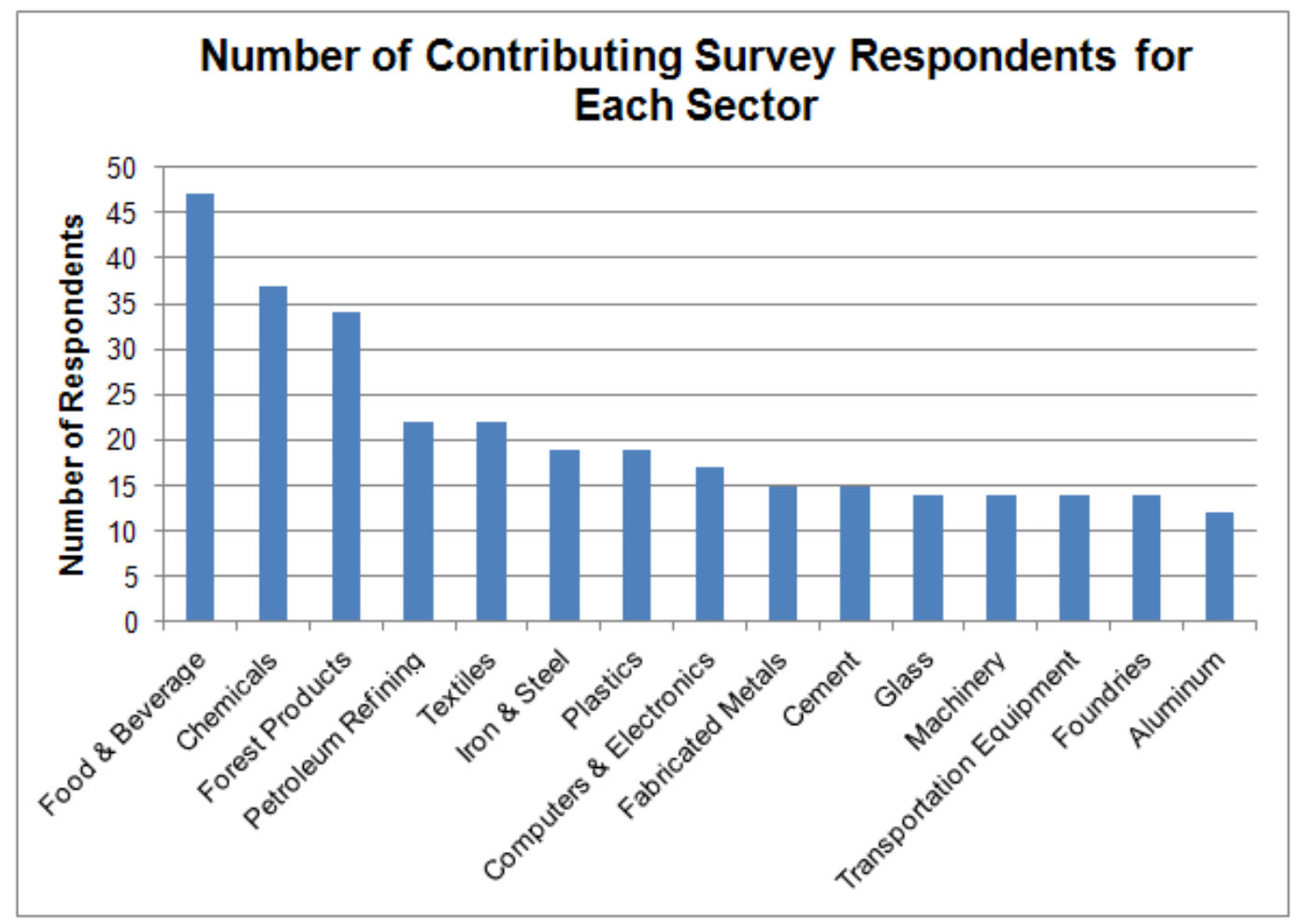

Fig. E.5. Number of survey respondents for 15 individual sectors

By the fourth and final meeting, the Manufacturing Steam End Use Working Group reached consensus on the results of steam allocation by sector. 


\section{RESULTS}

The Manufacturing Steam End Use Working Group used the results from the manufacturing steam end use survey to determine the final end use allocations of steam in the 15 individual manufacturing sectors as well as an average for all of U.S. manufacturing. A complete summary of the working group's final results of are given in Table E.3.

Table E.3. Results for steam allocation from the manufacturing steam end use working group

\begin{tabular}{|c|c|c|c|c|c|c|}
\hline \multirow[b]{2}{*}{ Sector } & \multicolumn{6}{|c|}{ Steam end use } \\
\hline & $\begin{array}{l}\text { Process } \\
\text { heating }\end{array}$ & $\begin{array}{l}\text { Machine } \\
\text { drive }\end{array}$ & $\begin{array}{c}\text { Process } \\
\text { cooling/ } \\
\text { refrigeration }\end{array}$ & $\begin{array}{c}\text { Other } \\
\text { process uses }\end{array}$ & $\begin{array}{l}\text { Facility } \\
\text { HVAC }\end{array}$ & $\begin{array}{c}\text { Other } \\
\text { nonprocess } \\
\text { uses }\end{array}$ \\
\hline All manufacturing & $66 \%$ & $10 \%$ & $3 \%$ & $8 \%$ & $11 \%$ & $3 \%$ \\
\hline Aluminum and alumina & $31 \%$ & $13 \%$ & $0 \%$ & $27 \%$ & $21 \%$ & $7 \%$ \\
\hline Cement & $45 \%$ & $6 \%$ & $1 \%$ & $16 \%$ & $27 \%$ & $6 \%$ \\
\hline Chemicals & $67 \%$ & $10 \%$ & $3 \%$ & $8 \%$ & $9 \%$ & $4 \%$ \\
\hline $\begin{array}{l}\text { Computers, electronics, and } \\
\text { electrical equipment }\end{array}$ & $16 \%$ & $0 \%$ & $1 \%$ & $7 \%$ & $73 \%$ & $4 \%$ \\
\hline Fabricated metals & $35 \%$ & $1 \%$ & $1 \%$ & $16 \%$ & $46 \%$ & $2 \%$ \\
\hline Food and beverage & $69 \%$ & $4 \%$ & $5 \%$ & $8 \%$ & $10 \%$ & $3 \%$ \\
\hline Forest products & $70 \%$ & $9 \%$ & $2 \%$ & $5 \%$ & $9 \%$ & $4 \%$ \\
\hline Foundries & $13 \%$ & $15 \%$ & $0 \%$ & $9 \%$ & $60 \%$ & $3 \%$ \\
\hline Glass & $5 \%$ & $5 \%$ & $0 \%$ & $22 \%$ & $63 \%$ & $5 \%$ \\
\hline Iron and steel & $46 \%$ & $7 \%$ & $0 \%$ & $8 \%$ & $38 \%$ & $1 \%$ \\
\hline Machinery & $24 \%$ & $29 \%$ & $1 \%$ & $7 \%$ & $37 \%$ & $1 \%$ \\
\hline Petroleum refining & $66 \%$ & $16 \%$ & $2 \%$ & $10 \%$ & $4 \%$ & $2 \%$ \\
\hline Plastics & $71 \%$ & $1 \%$ & $0 \%$ & $7 \%$ & $18 \%$ & $3 \%$ \\
\hline Textiles & $63 \%$ & $2 \%$ & $2 \%$ & $10 \%$ & $21 \%$ & $2 \%$ \\
\hline Transportation equipment & $27 \%$ & $2 \%$ & $7 \%$ & $9 \%$ & $53 \%$ & $2 \%$ \\
\hline
\end{tabular}

The six process and nonprocess end uses where steam is consumed are defined by EIA in the MECS survey as follows:

1. Process heating: the direct process end use in which energy is used to raise the temperature of substances involved in the manufacturing process (e.g., kilns, ovens, furnaces, strip heaters). Examples of process heating include the use of heat to melt scrap for electric-arc furnaces in steel-making, to separate components of crude oil in petroleum refining, to dry paint in automobile manufacturing, and to cook packaged foods.

2. Machine drive: the direct process end use in which thermal or electric energy is converted into mechanical energy and is used to power motor-driven systems, such as compressors, fans, pumps, and materials handling and processing equipment. Motors are found in almost every process in manufacturing. Therefore, when motors are found in equipment that is wholly contained in another end use (such as a compressor in process cooling and refrigeration), the energy is classified there rather than in machine drive. 
3. Process cooling and refrigeration: the direct process end use in which energy is used to lower the temperature of substances involved in the manufacturing process. Examples include freezing processed meats for later sale in the food industry and lowering the temperature of chemical feedstocks below ambient temperature for use in reactions in the chemicals industry.

4. Other process uses: the direct process end use that includes energy used for other direct process uses not falling under a specified process end use category. Examples include steam tracing, stripping, vacuum, purging, humidification, and fuel oil atomization.

5. Facility HVAC: the direct nonprocess end use that includes energy used to provide heating, ventilation, and air conditioning for building envelopes within the plant boundary.

6. Other nonprocess uses: the direct nonprocess end use that includes energy used for nonprocess uses other than the defined nonprocess energy categories. Examples include cleaning and hot water heating.

The all manufacturing steam end use allocation was calculated as a weighted average based upon the net steam and steam allocation for each sector. The values of net steam use for each sector are the sum of offsite steam (obtained from MECS 2006 data) and onsite steam (obtained using input fuel data and the estimated efficiencies of steam-producing equipment). Steam allocation for all U.S. manufacturing is heavily dependent on the sectors that have a higher net steam use. The forest products, chemicals, petroleum refining, and food and beverage sectors represent $88 \%$ of all manufacturing net steam use. The weighted average steam end use allocation for all of U.S. manufacturing as shown in Table E.3 was found to be $66 \%$ to process heating, $11 \%$ to facility HVAC, $10 \%$ to machine driven equipment, $8 \%$ to other process uses, $3 \%$ to process cooling and refrigeration, and $3 \%$ to other nonprocess uses.

\section{APPLICATION OF RESULTS}

The Manufacturing Steam End Use Working Group was created at the request of DOE and ORNL to obtain industry expert input that could be applied to the Manufacturing Energy and Carbon Footprints. The Manufacturing Energy and Carbon Footprints (published on the AMO website) serve as a useful reference for industrial energy use characteristics and allow for comparisons of energy consumption across and within sectors.

The 16 individual footprints map energy consumption, energy losses, and greenhouse gas emissions from fuel, electricity, and steam use for the respective sector. Manufacturing and energy footprints are available for the following individual manufacturing sectors (listed in alphabetical order): alumina and aluminum; cement; chemicals; computers, electronics, and electrical equipment; fabricated metals; food and beverage; forest products; foundries; glass; iron and steel; machinery; petroleum refining; plastics; textiles; and transportation equipment. The sectors are defined by North American Industrial Classification System (NAICS) code, as shown in Table E.4.

The net steam use for each of the 15 sectors can also be found in Table E.4. The net steam use by sector is calculated using 2006 MECS offsite steam numbers and input fuel data for conventional boilers and combined heat and power (CHP) systems (and associated assumptions of boiler and CHP efficiency) to calculate the total amount of steam produced in each industry. 
Table E.4. Manufacturing sector NAICS codes and net steam use

\begin{tabular}{|l|l|l|}
\hline \multicolumn{1}{|c|}{ Sector } & NAICS code & \multicolumn{1}{c|}{$\begin{array}{c}\text { Sector net steam* } \\
\text { (TBtu) }\end{array}$} \\
\hline All manufacturing & $31-33$ & 3,810 \\
\hline Aluminum and alumina & 3313 & 12 \\
\hline Cement & 327310 & 18 \\
\hline Chemicals & 325 & 1,134 \\
\hline Computers, electronics, and electrical equipment & $334-335$ & 19 \\
\hline $\begin{array}{l}\text { Fabricated metals } \\
\text { Food and beverage }\end{array}$ & 332 & 26 \\
\hline Forest products & $311-312$ & 443 \\
\hline Foundries & $321-322$ & 1,198 \\
\hline $\begin{array}{l}\text { Glass } \\
\text { Iron and steel }\end{array}$ & 3315 & 2 \\
\hline Machinery & 272,32799 & 15 \\
\hline Petroleum refining & $3311-3312$ & 118 \\
\hline Plastics & 333 & 15 \\
\hline Textiles & 324110 & 581 \\
\hline Transportation equipment & 326 & 52 \\
\hline $\begin{array}{l}* \text { The net steam use (in units of Trillion British Thermal Units } \\
\text { using EIA MECS offsite steam numbers and input fuel data for conventional boilers and combined heat and } \\
\text { power (CHP) systems (and associated assumptions of boiler and CHP efficiency) to calculate the total } \\
\text { amount of steam produced in each industry. EIA MECS does not allocate this steam to different end uses. }\end{array}$ \\
\hline
\end{tabular}

The Manufacturing Energy and Carbon Footprints have undergone multiple rounds of review in the finalization process including review and input from DOE AMO, ORNL, EIA, and representatives from various industry organizations and associations. The results from the Manufacturing Steam End Use Working Group have been incorporated in to the Energetics energy footprint model and updated energy footprints were posted on the DOE website.

The results from the Manufacturing Steam End Use Working Group have been significant in improving and updating the Manufacturing Energy and Carbon Footprints.

The final survey and working group results helped to refine the previous estimates for steam allocation by sector.

\section{CONCLUSION}

The final steam allocation results for all of U.S. manufacturing was based upon the results from the 15 individual sectors but was heavily weighted by the four sectors that represent $88 \%$ of all manufacturing net steam use: forest products $(31 \%)$, chemicals $(30 \%)$, petroleum refining $(15 \%)$, and food and beverage $(12 \%)$. Average steam allocation for all of U.S. manufacturing was largely process heating $(66 \%)$ as expected. However, facility HVAC (11\%) and machine drive (10\%) are also significant contributors to steam use in manufacturing.

This small, focused working group was successful in meeting the peer review objectives in the short timeframe allotted. The working group results improved the accuracy of the Manufacturing Energy and Carbon Footprints. The authors of this paper wish to express our gratitude for the leadership of the working group members in this effort and the contribution of all of those who responded to the survey. 

Appendix F

ESTIMATION OF PROCESS HEATING ENERGY LOSS 



\title{
Appendix F. ESTIMATION OF PROCESS HEATING ENERGY LOSS MANUFACTURING ENERGY AND CARBON FOOTPRINT PEER REVIEW RESULTS
}

\author{
SABINE BRUESKE \\ ENERGETICS INCORPORATED \\ SACHIN NIMBALKAR \\ OAK RIDGE NATIONAL LABORATORY
}

\begin{abstract}
$\underline{\text { ABSTRACT }}$
In January 2012, the Manufacturing Process Heating Energy Loss Working Group was formed to support analysis conducted for the U.S. Department of Energy (DOE) Advanced Manufacturing Office (AMO). The working group provided industry peer review and contribution to the Manufacturing Energy and Carbon Footprints, an energy use analysis tool developed by Energetics Incorporated. Analysts and decision-makers utilize the energy footprints to better understand the distribution of energy use in energyintensive industries and the accompanying energy losses; including, as described in this white paper, process heating losses. The footprints provide a benchmark from which to justify the benefits of improving energy efficiency and for prioritizing opportunity analysis.

The working group considered energy losses from key process heating equipment for seven energyintensive manufacturing sectors. Process heating energy loss, as defined in the energy footprint, is not a value that is readily available through literature search. A peer review group was formed to contribute to this important piece of the footprint analysis effort. Interviews with manufacturers, available plant assessment results, and relevant industrial studies were all considered in estimating process heating energy loss by manufacturing sector and subsector. Results from the peer review have been incorporated into the energy footprint model and updated footprints have been republished on the AMO website.
\end{abstract}

\section{MANUFACTURING ENERG USE FOOTPRINT ANALYSIS}

The Manufacturing Energy and Carbon Footprints serve as a map of manufacturing energy use and loss and associated greenhouse gas emissions for fuel, electricity, and steam use in the United States. Each footprint consists of two pages: one that provides an overview of the sector's total primary energy flow including offsite energy and associated generation and transmission losses (Fig. F.1) and one that provides a more detailed breakdown of the onsite energy by end use (Fig F.2). Sixteen sector footprints have been published; detail on which sectors were studied is discussed later (see Table F.5). The footprints are heavily referenced by private and public sector analysts and decision makers alike. They serve as a helpful reference in understanding the U.S. manufacturing energy use profile and are used in answering questions such as:
How much energy is consumed (source
vs. site)?
From where?
What are the associated carbon
emissions?
What form?
Where is it used?
How much is lost and where?

The energy and carbon values portrayed in the footprint diagrams are the result of a complex analysis effort. Energy use statistics were primarily obtained from the Energy Information Administration (EIA) 2006 Manufacturing Energy Consumption Survey (MECS) results. In order to complete an accurate balance of manufacturing energy use, some adjustments and assumptions were applied.

The topic of this paper (and the findings of the working group discussed herein) is a subset of the footprint analysis effort. After an extensive technical review of the footprints, two areas of analysis were identified as needing further industry peer review: estimation of steam allocation to process and nonprocess end uses and energy loss in process heating. The first peer review topic addressing steam allocation is detailed in a separate white paper (see Appendix E). 


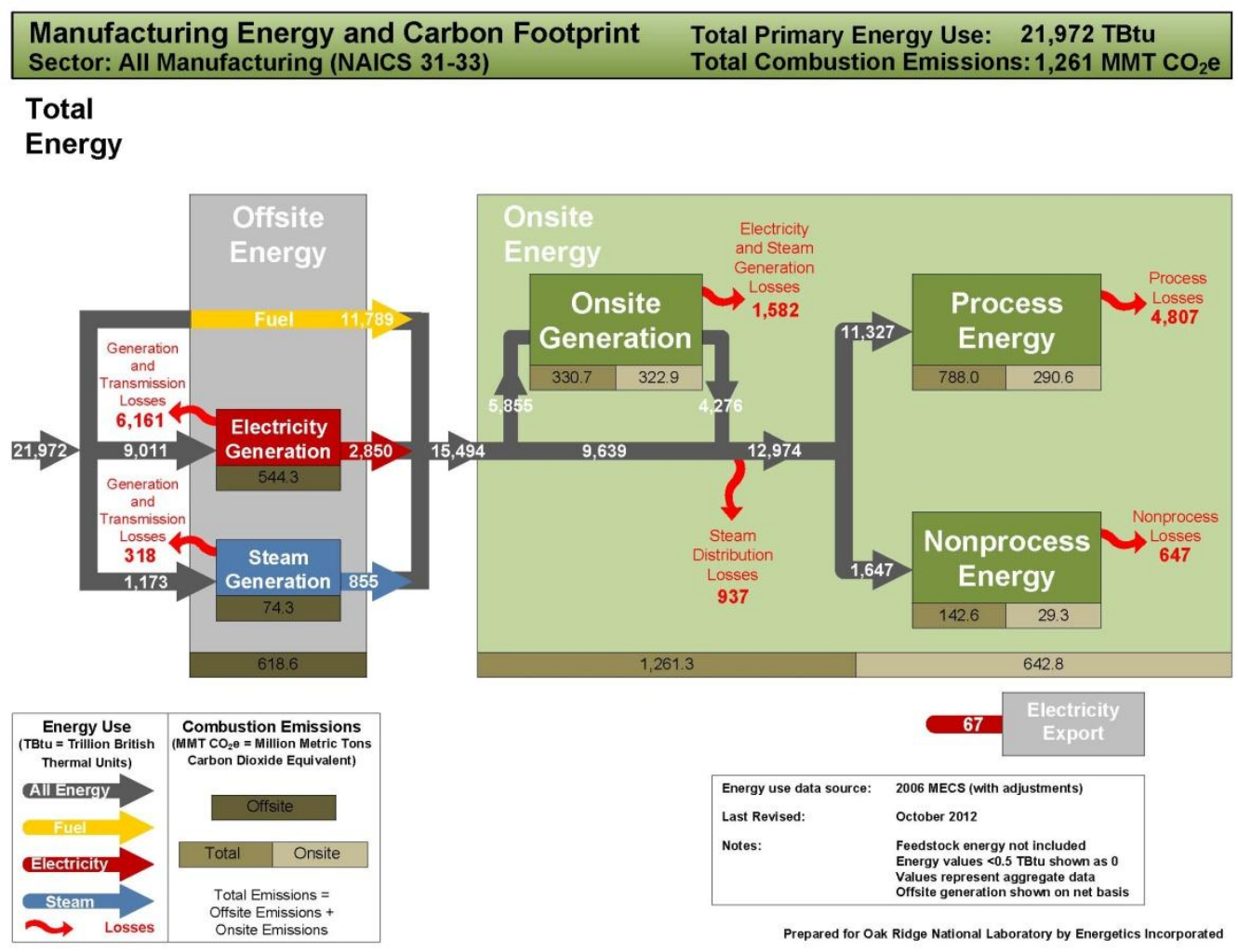

Fig. F.1. Manufacturing energy and carbon footprint for U.S. manufacturing - total energy

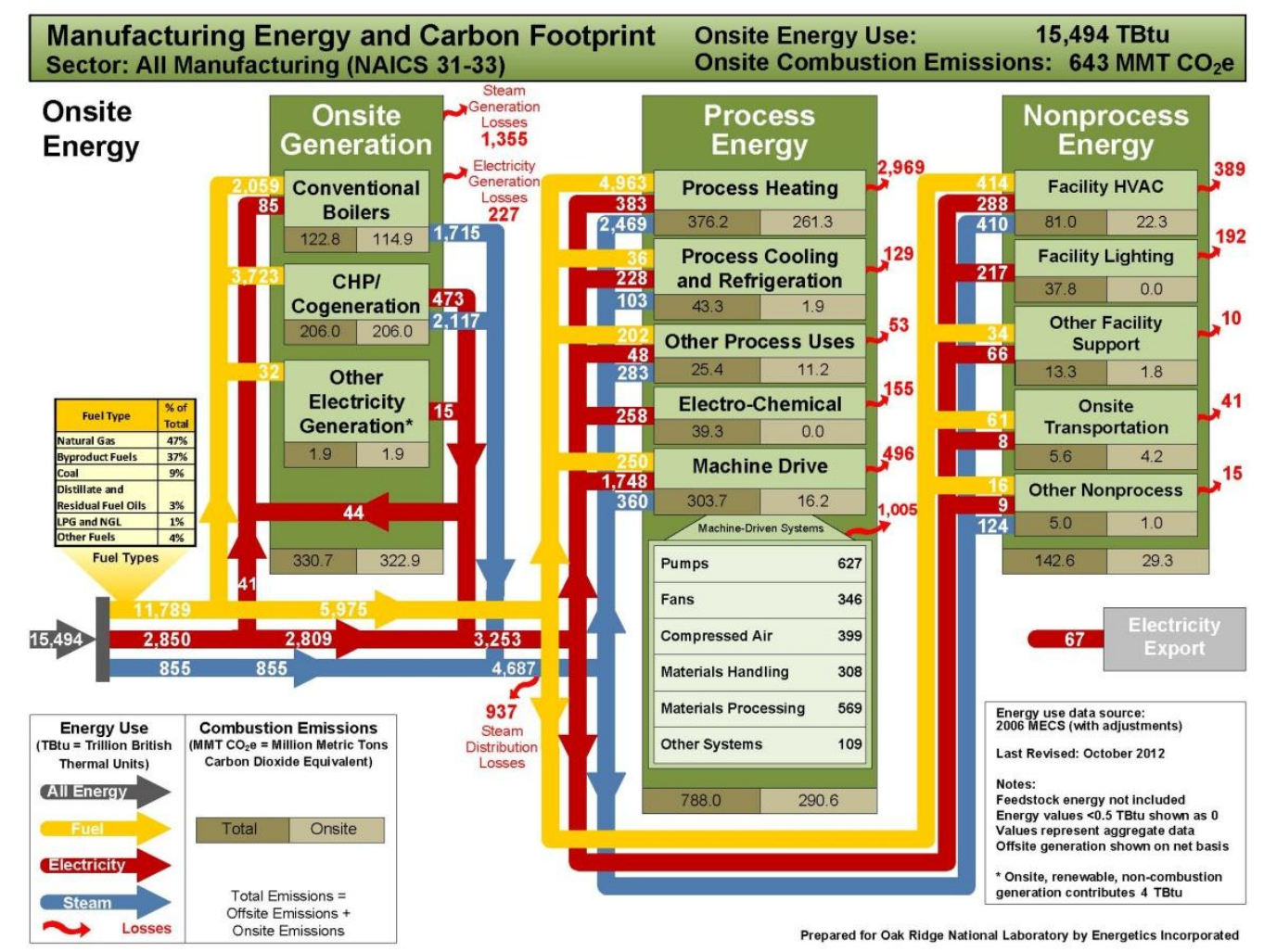

Fig. F.2. Manufacturing energy and carbon footprint for U.S. manufacturing - onsite energy 


\section{PROCESS HEATING ENERGY LOSS PEER REVIEW}

The purpose of the Manufacturing Process Heating Energy Loss Working Group was to provide industry peer review and contribution to an AMO manufacturing energy analysis project, the Manufacturing Energy and Carbon Footprints. The footprint analysis project was conducted by Energetics Incorporated under contract with Oak Ridge National Laboratory (ORNL) for AMO.

A working group was convened in January 2012 to perform a short-term, focused peer review effort. Organizations that voluntarily participated in at least one of the working group meetings are listed below in Table F.1.

Table F.1. Process heating energy loss working group organizations

\begin{tabular}{|c|c|}
\hline Advanced Energy * & Eclipse, Inc. \\
\hline Alcoa Inc. * & Energetics Incorporated $*, \wedge$ \\
\hline Alzeta Corporation * & U.S. Energy Information Administration * \\
\hline Briggs and Stratton Corporation $*, \wedge$ & Fives North American Combustion, Inc. \\
\hline CHT Analytics $*, \wedge$ & Hauck Manufacturing Company * \\
\hline Diamond Engineering * & Invensys Eurotherm $*, \wedge$ \\
\hline The Dow Chemical Company * & Karl Dungs Inc. * \\
\hline Duke Energy Corporation $*, \wedge$ & Lawrence Berkeley National Laboratory * \\
\hline $\mathrm{E} 3 \mathrm{M}$, Inc. $*, \wedge$ & Oak Ridge National Laboratory $*, \wedge$ \\
\hline Emerging Technology Application Center & Southern Company $*, \wedge$ \\
\hline \multicolumn{2}{|c|}{$\begin{array}{l}\text { Organizations that participated in more than one working group meeting are noted with }(*) \text { symbol in the list, } \\
\text { organizations that participated in the final consensus meeting are noted with }\left({ }^{\wedge}\right) \text { symbol in the list. }\end{array}$} \\
\hline
\end{tabular}

Organizations that participated in more than one working group meeting are noted with $(*)$ symbol in the list, organizations that participated in the final consensus meeting are noted with ^ ${ }^{\wedge}$ symbol in the list. The process heating energy loss value that was evaluated by the working group is highlighted in yellow Fig. F.3 (2,969 TBtu for All Manufacturing). 


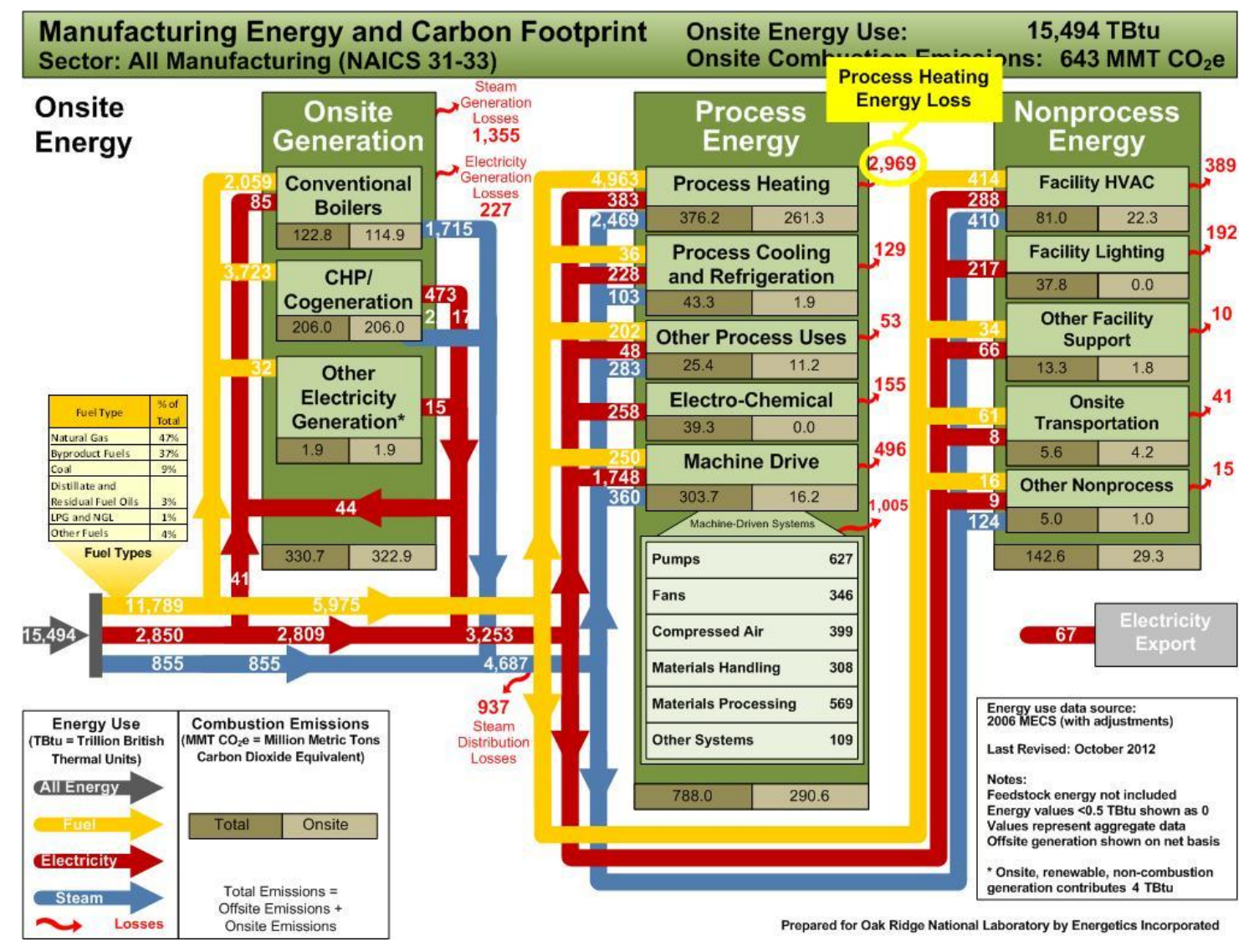

Fig. F.3. Process heating energy loss value evaluated by the process heating working group

Process heating is defined by EIA in the MECS survey as follows:

Process heating: the direct process end use in which energy is used to raise the temperature of substances involved in the manufacturing process (e.g., kilns, ovens, furnaces, strip heaters). Examples of process heating include the use of heat to melt scrap for electric-arc furnaces in steelmaking, to separate components of crude oil in petroleum refining, to dry paint in automobile manufacturing, and to cook packaged foods.

The term direct end use in the definition deserves explanation, as there were questions on this subject from working group participants. An obvious assumption is that the term Process Heating includes boilers, which is not the case.

The onsite energy footprint shows both indirect and direct end use of energy. Indirect energy use is shown on the footprint as Onsite Generation, this is primarily fuel used for boilers and combined heat and power (CHP) units. The indirect energy input is converted to steam and power to be used onsite. Direct energy, on the other hand, refers to process and nonprocess end uses such as process heating, machine drive, and lighting. The working group was tasked to consider energy losses from direct process heating end use only.

In the MECS data set, direct process heating end use of fuel and electricity is reported by sector; steam end use, however, is not reported. A steam working group was formed to help with estimating steam allocation to process and nonprocess end uses. Process heating energy use (fuel, electricity, and steam) is known for each of the manufacturing sectors studied. The goal of the working group was to agree upon an acceptable approach for estimating energy loss from (or heat loss) from this end use. Process heating energy loss can appear in different forms, including: input losses such as incomplete combustion, system losses such as radiation and convection losses, and exhaust or vent losses. 
Process heating energy loss results were needed for the following fifteen individual footprint sectors (listed in alphabetical order) and a weighted average of process heating energy loss for all of U.S. manufacturing: alumina and aluminum; cement; chemicals; computers, electronics, and electrical equipment; fabricated metals; food and beverage; forest products; foundries; glass; iron and steel; machinery; petroleum refining; plastics; textiles; and transportation equipment.

\section{TIMELINE AND APPROACH}

The Manufacturing Process Heating Energy Loss Working Group was a seven month peer review effort. The working group met on three separate occasions between January 2012 and August 2012 and conducted additional analysis between meetings.

During the first meeting in January 2012, the working group reviewed the topic and discussed methods already considered for estimating process heating energy loss. These prior analysis approaches are briefly summarized in Table F.2.

\section{Table F.2. Alternative analysis approaches considered by Energetics}

\begin{tabular}{|c|c|}
\hline Source & Brief description \\
\hline Early version of the energy footprint & $\begin{array}{l}\text { System losses estimated to be } 15 \% \text { for all sectors; } \\
\text { exhaust loss not estimated. }\end{array}$ \\
\hline $\begin{array}{l}\text { Waste Heat Recovery: Technology and } \\
\text { Opportunities in U.S. Industry, BCS, } \\
2009\end{array}$ & $\begin{array}{l}\text { System losses estimated to be } 15 \% \text { for all sectors; } \\
\text { process heating key equipment and exhaust loss } \\
\text { estimates derived from BCS report. }\end{array}$ \\
\hline $\begin{array}{l}\text { Energy and Environmental Profile... } \\
\text { Petroleum Refining Industry, Pulp and } \\
\text { Paper Industry, Aluminum Industry, } \\
\text { Energetics, 2007, 2005, } 1997\end{array}$ & $\begin{array}{l}\text { System losses estimated to be } 15 \% \text { for all sectors; } \\
\text { process heating key equipment from profile reports; } \\
\text { exhaust loss from other sources including draft exhaust } \\
\text { model. }\end{array}$ \\
\hline $\begin{array}{l}1992 \text { Industrial Process Heat Energy } \\
\text { Analysis, Gerhardt, et al., EEA, } 1992\end{array}$ & $\begin{array}{l}\text { System losses estimated to be } 15 \% \text {; process heat key } \\
\text { equipment from } 1992 \text { report; exhaust loss not estimated. }\end{array}$ \\
\hline $\begin{array}{l}\text { Energy Analysis of } 108 \text { Industrial } \\
\text { Processes, Brown et al., } 1985\end{array}$ & $\begin{array}{l}\text { System losses, process heat key equipment, and exhaust } \\
\text { loss from } 108 \text { processes compiled in to a spreadsheet } \\
\text { model. }\end{array}$ \\
\hline
\end{tabular}

After a quick review of Energetics' prior research on this subject, it was agreed by the working group that the reference book Energy Analysis of 108 Industrial Processes was the most comprehensive data source for the scope of analysis. After the first working group meeting the following Rules of Engagement were agreed upon by the group:

Group title: Manufacturing Process Heating Energy Loss Working Group

Group focus: Review and contribute to the process heating energy loss estimates by sector that will appear in the AMO Manufacturing Energy and Carbon Footprints.

Original data source for process heating energy balance model:

Energy Analysis of 108 Industrial Processes (108 Processes), 1985, based on 1976 Census, (year of data $=$ approximately 1980)

Group Agreement: The group recognized that 108 Processes was approximately 30 years out of date. The group recognized that 108 Processes is being used as a baseline for process heating energy balance analysis, and that resulting process heating energy loss figures will be reviewed by industry experts and 
adjusted as necessary to account for industry advancements (in terms of energy efficient technologies and waste heat recovery equipment) and other inaccuracies.

The working group agreed that results would be finalized through consensus of the group.

At the time of the second working group meeting in February 2012, the results from a spreadsheet model based on 108 Industrial Processes data were presented to the group. Some adjustments were made to the results to account for process efficiency gain in the 30-plus years since publication of the report. Process heating loss from the 108 Processes model was found to range from $27 \%$ to $88 \%$, with weighted average for All Manufacturing of $58 \%$.

At the conclusion of the second working group meeting the group agreed that the spreadsheet model was the best that could be done with the data available. However, a common perception held that the results of the spreadsheet model could be improved upon. Concerns with the results included:

The process energy data from 108 Processes is for a typical individual plant. When multiple subsectors are averaged in the model there is no accounting for production differences, they are weighted equally. Inclusion of production data was thought to be too time consuming.

The process energy data in the reference is for all process energy end uses, not just process heating. Assumptions were made as to which process steps constituted process heating end use.

It was unclear whether energy recovery was accurately accounted for in the spreadsheet model.

Feedstock considerations - in some cases it was not clear whether fuel use included feedstock energy Properly accounting for energy released in exothermic reactions was not always possible

In a small group discussion it was agreed that the best approach to determining realistic sector-wide process heating energy loss results would be to speak with manufacturers directly and build an estimate from the ground up, rather than trying to modify a model with questionable results. It was agreed that a range of subsector estimates would add greater substantiation to the sector-wide estimate.

In the period from March through August 2012 representatives from Energetics Incorporated and ORNL met with a number of plant operation managers and energy managers both by phone and in person to explain the analysis and solicit plant-based estimates of process heating energy loss. Estimates in various forms of completeness were obtained from the manufacturing organizations in Table F.3.

Table F.3. Contributing manufacturing organizations

\begin{tabular}{|l|l|l|l|l|}
\hline ArcelorMittal & $\begin{array}{l}\text { Carus } \\
\text { Corporation }\end{array}$ & Darigold & Davisco Foods & $\begin{array}{l}\text { Del Mar Food } \\
\text { Products }\end{array}$ \\
\hline $\begin{array}{l}\text { Didion Dry } \\
\text { Corn Milling }\end{array}$ & Foster Farms & $\begin{array}{l}\text { Hilmar Cheese } \\
\text { Company }\end{array}$ & Phillips 66 & Saint Gobain \\
\hline Shell & Spreckels Sugar & Tenova Core & $\begin{array}{l}\text { former employee- Kimberly Clark } \\
\text { and Georgia Pacific }\end{array}$ \\
\hline
\end{tabular}

To guide conversation during these meetings a simple energy balance spreadsheet tool was developed detailing key processing heating equipment by manufacturing subsector (e.g., furnace, dryer, melter, oven, evaporator, etc.). Since process heating equipment varies greatly by sector and by plant, a simplified energy balance was suggested to make it easier to gather energy loss estimates uniformly. Arvind Thekdi, a process heating expert assisting Energetics with the footprint analysis, provided oversight in developing the process heating energy balance approach. Figure F.4 and Table F.4 were produced with Arvind's guidance and were used in explaining the energy balance approach to others. Similar process heating energy balance methodology is referenced in other DOE publications and tools (Process Heating System Performance: A Sourcebook for Industry, February 2008, and Process Heating Assessment and Survey Tool, PHAST version 3.0, November 2010). 
Stated simply, for a given amount of fuel, steam or electricity energy input, energy losses can occur either in energy input, in system or box losses, or as exhaust or vent losses. Remaining energy input is retained in the form of process heat. Table F.4 gives more detail on the broad energy balance areas shown in Fig. F.4.

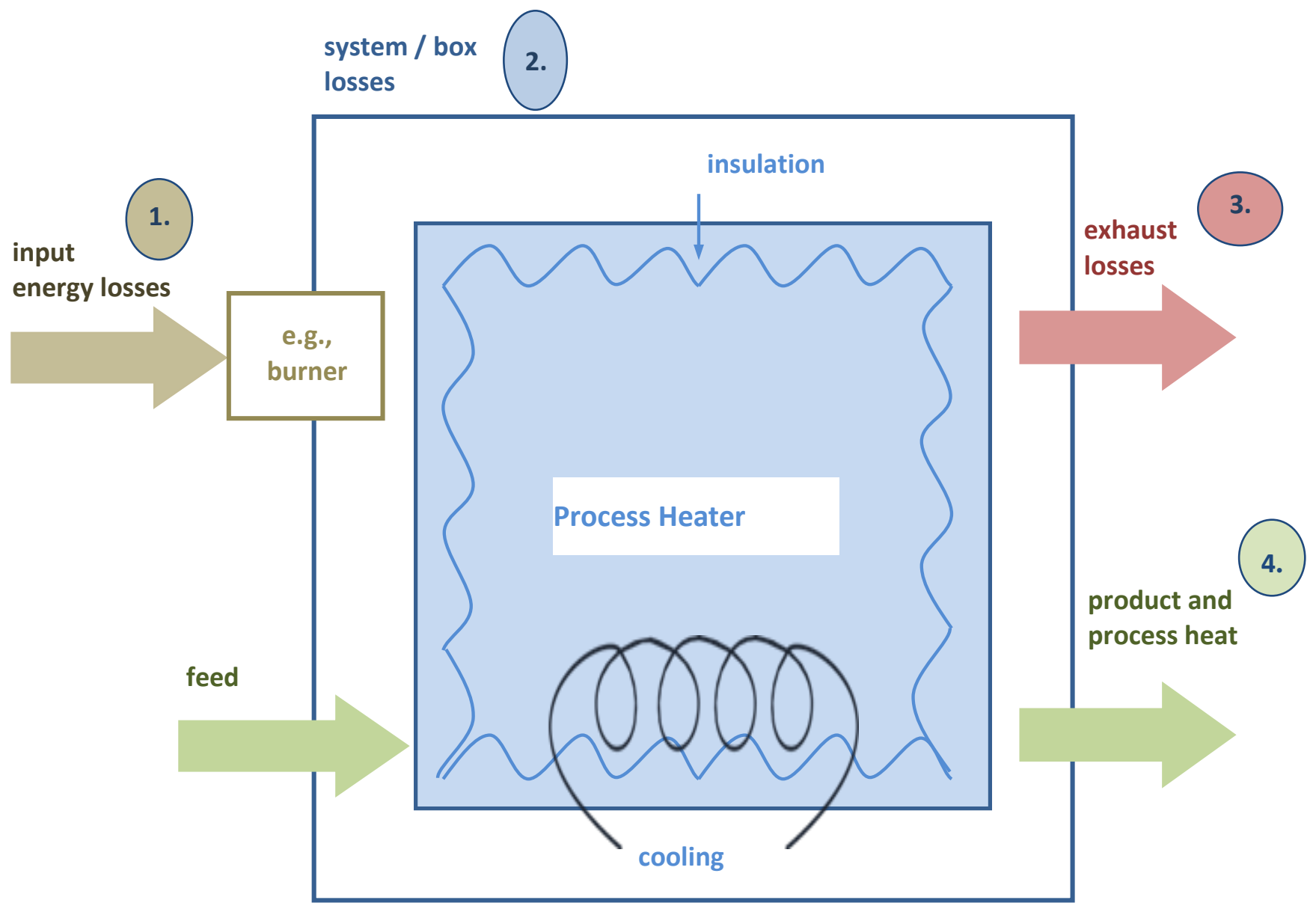

Fig. F.4. Simplified process heating equipment energy balance (as derived from Improving Process Heating System Performance: A Sourcebook for Industry, Figure 2, Page 13)

Table F.4. Simplified process heating energy balance loss areas explained

\begin{tabular}{|c|c|c|c|}
\hline \multicolumn{2}{|c|}{ Energy use and loss area } & Energy use and loss area description & Explanation \\
\hline & $\begin{array}{l}\text { Input energy } \\
\text { losses }\end{array}$ & $\begin{array}{l}\text { Input fuel and feed losses, e.g., incomplete } \\
\text { combustion losses }\end{array}$ & $\begin{array}{l}\text { Compared to other Energy Use and Loss } \\
\text { Areas, input/combustion losses are } \\
\text { considered insignificant for commonly used } \\
\text { fuels (natural gas and fuel oils) }\end{array}$ \\
\hline & $\begin{array}{l}\text { System/box } \\
\text { losses }\end{array}$ & $\begin{array}{l}\text { Radiation and convection losses, wall, } \\
\text { door and insulation losses, opening losses, } \\
\text { cooling losses, conveyor losses, furnace } \\
\text { heat storage and load conveyor losses (all } \\
\text { losses except heat going to the product and } \\
\text { heat content of the exhaust gases) }\end{array}$ & $\begin{array}{l}\text { System losses vary widely depending on } \\
\text { size, age, and application. System losses are } \\
\text { estimated to range between } 5 \text { and } 25 \% \text { of } \\
\text { energy input in process heating applications. }\end{array}$ \\
\hline & Exhaust losses & Flue (exhaust heat) losses & $\begin{array}{l}\text { Exhaust losses vary widely depending on the } \\
\text { process conditions - temperature, loading } \\
\text { conditions and equipment design (such as } \\
\text { use of recuperators). Exhaust losses are } \\
\text { estimated to range between } 25 \text { and } 55 \% \text { in } \\
\text { process heating applications. }\end{array}$ \\
\hline & $\begin{array}{l}\text { Product and } \\
\text { process heat }\end{array}$ & $\begin{array}{l}\text { Product and process heat requirement } \\
\text { includes sensible and phase change heat, } \\
\text { and heat of reaction }\end{array}$ & $\begin{array}{l}\text { Product and process heat requirement } \\
\text { represents the balance of total input energy } \\
\text { after losses are accounted for }\end{array}$ \\
\hline
\end{tabular}


The energy system boundary was a challenge to define in some cases. Generally speaking, if energy is retained in the product stream and there is further processing of the product (i.e., the energy value is utilized or lost in downstream end use) the process heating equipment energy loss will be less than $100 \%$. How much energy is lost, and where, is estimated in the spreadsheet model. In cases where there is no retained energy value in the product stream, energy loss is assumed to be $100 \%$. For example, in container glass conditioning and annealing, process heating losses are assumed to be $100 \%$. Product enters the forehearth at approximately 2400 degrees Fahrenheit and exits at 2000 degrees Fahrenheit. In conversations with glass plant engineers it was agreed that the energy input, normally in the form of natural gas fired burners in this case, is "lost" via system losses (e.g., refractory losses) or exhaust losses.

In addition to process heating loss estimates from meetings with plant engineers, various data sources were consulted to add detail to the spreadsheet model. U.S. DOE Save Energy Now Assessment data was referenced, and a number of technical studies were cited in support of some sector estimates.

A third and final working group meeting was held in August 2012. During this meeting the results of the simplified energy balance approach were shared with the working group and sources were discussed. Working group representatives in attendance at this third meeting reached consensus on the approach and results presented. The results from the simplified energy balance approach were thought to be more realistic than the results obtained initially from the 108 processes model.

Based on comments and questions from working group participants during the third working group meeting, four follow up topics were identified for further study: exhaust losses in petroleum refining, dryer losses in forest products and food and beverage, efficiency gains in electric arc furnaces, and glass annealing losses. These follow-up topics were addressed shortly after the meeting and updated results were distributed to the working group.

\section{RESULTS}

Process heating loss estimates were derived for seven manufacturing sectors, representing $84 \%$ of manufacturing process heating energy use: petroleum refining, chemicals, forest products, iron and steel, food and beverage, cement, and glass. Based on the weighted average of the seven sectors, average process heating loss for all of U.S. manufacturing was calculated to be $38 \%$.

With the remaining sectors accounting for just $16 \%$ of process heating energy use and timing and budget constraints, the remaining sectors were not studied with the same level of detail. However, to provide estimates for process heating losses in all footprint sectors, the results from the seven sectors that were studied were applied to the remaining eight sectors as follows:

All Manufacturing average - applied to fabricated metals, transportation equipment, computers and electronics, and machinery

Iron and Steel - applied to foundries and aluminum

Chemicals - applied to plastics and rubber

Food and Beverage - applied to textiles

The process heating energy loss results for all sectors are summarized in Table F.5. The sectors are defined by North American Industrial Classification System (NAICS) code. Process heating energy use is also shown in Table F.5, along with the contributing percent of total process heating energy use. Process heating energy is shown in terms of trillion British Thermal Units (TBtu) and is the sum of fuel, electricity and steam energy for the sector as a whole in the United States. The first seven sectors in Table F.5 consume $84 \%$ of manufacturing process heating energy use. 
Table F.5. Results for process heating energy loss from the manufacturing process heating energy loss working group

\begin{tabular}{|c|c|c|c|c|}
\hline Manufacturing sector & NAICS code & $\begin{array}{l}\text { Process } \\
\text { heating } \\
\text { energy loss } \\
\text { estimate }\end{array}$ & $\begin{array}{c}\text { Process } \\
\text { heating } \\
\text { energy use } \\
\text { (TBtu) }\end{array}$ & $\begin{array}{l}\text { Percent of total U.S. } \\
\text { manufacturing process } \\
\text { heating energy use }\end{array}$ \\
\hline Petroleum refining & 324110 & $18 \%$ & 2,346 & $30 \%$ \\
\hline Chemicals & 325 & $22 \%$ & 1,268 & $16 \%$ \\
\hline Forest products & $321-322$ & $68 \%$ & 1,102 & $14 \%$ \\
\hline Iron and steel & $3311-3312$ & $51 \%$ & 723 & $9 \%$ \\
\hline Food and beverage & $311-312$ & $68 \%$ & 555 & $7 \%$ \\
\hline Cement & 327310 & $40 \%$ & 311 & $4 \%$ \\
\hline Glass & 3272,327993 & $56 \%$ & 255 & $3 \%$ \\
\hline Fabricated metals & 332 & $38 \%$ & 201 & $3 \%$ \\
\hline Transportation equipment & 336 & $38 \%$ & 117 & $1 \%$ \\
\hline Foundries & 3315 & $51 \%$ & 106 & $1 \%$ \\
\hline Plastics and rubber & 326 & $22 \%$ & 101 & $1 \%$ \\
\hline Textiles & $313-316$ & $68 \%$ & 100 & $1 \%$ \\
\hline Alumina and aluminum & 3313 & $51 \%$ & 100 & $1 \%$ \\
\hline $\begin{array}{l}\text { Computers, electronics, and } \\
\text { electrical equipment }\end{array}$ & $334-335$ & $38 \%$ & 51 & $1 \%$ \\
\hline Machinery & 333 & $38 \%$ & 37 & $<0.5 \%$ \\
\hline All manufacturing & $31-33$ & $38 \%$ & 7,814 & $100 \%$ \\
\hline
\end{tabular}

A list of the sources consulted for the seven sectors is provided in Table F.6. The Save Energy Now Assessments do not correspond to the manufacturers listed in Table F.6. The assessments were selected at random based on applicable NAICS code; company information was kept confidential

Table F.6. Sources consulted in estimating process heating energy loss

\begin{tabular}{|c|c|c|c|}
\hline Manufacturing sector & Manufacturing meetings & $\begin{array}{l}\text { DOE's Save } \\
\text { Energy Now } \\
\text { Assessments }\end{array}$ & Technical studies \\
\hline Petroleum refining & $\begin{array}{l}\text { Phillips 66, Shell, CHT } \\
\text { Analytics }\end{array}$ & 4 assessments & N/A \\
\hline Chemicals & Carus Corporation & 0 & Ref 1 \\
\hline Forest products & $\begin{array}{l}\text { Former employee of } \\
\text { Kimberly Clark and Georgia } \\
\text { Pacific, Dick Reese and } \\
\text { Associates, E3M }\end{array}$ & 0 & $\begin{array}{l}\operatorname{Ref} 2, \operatorname{Ref} 3, \\
\operatorname{Ref} 4\end{array}$ \\
\hline Iron and steel & $\begin{array}{l}\text { ArcelorMittal, Tenova Core, } \\
\text { E3M }\end{array}$ & 1 assessment & $\operatorname{Ref} 5, \operatorname{Ref} 6$ \\
\hline Food and beverage & $\begin{array}{l}\text { Davisco Foods, Darigold, } \\
\text { Spreckels Sugar, Foster } \\
\text { Farms, Didion, Del Mar Food } \\
\text { Products, Hilmar Cheese } \\
\text { Company }\end{array}$ & 1 assessment & $\operatorname{Ref} 7, \operatorname{Ref} 8$ \\
\hline Cement & & 0 & $\operatorname{Ref} 9, \operatorname{Ref} 10$ \\
\hline Glass & Saint Gobain & 4 assessments & $\begin{array}{l}\text { Ref } 11, \operatorname{Ref} 12 \\
\operatorname{Ref} 13, \operatorname{Ref} 14\end{array}$ \\
\hline
\end{tabular}




\section{APPLICATION OF RESULTS}

The results from the Manufacturing Process Heating Energy Loss Working Group have been significant in improving and updating the Manufacturing Energy and Carbon Footprints. The inclusion of process heating energy loss estimates in the footprints allows for estimation of overall generation and end uses losses in the report. This data will also help AMO staff evaluate opportunities to reduce, recycle, and recover waste heat from process heating equipment.

The Manufacturing Energy and Carbon Footprints have undergone multiple rounds of review in the finalization process including review and input from AMO, ORNL, EIA, and representatives from various industry organizations and associations. The results from the Manufacturing Process Heating Energy Loss Working Group and the Steam End use Working Group have been incorporated in to the Energetics energy footprint model and updated energy footprints have been posted on the AMO website.

\section{CONCLUSION}

The Manufacturing Energy and Carbon Footprints (published on the AMO website) serve as a useful reference for industrial energy use characteristics and allow for comparisons of energy consumption across and within sectors. The Manufacturing Process Heating Energy Loss Working Group was created at the request of DOE and ORNL to obtain industry expert input that could be applied to the Manufacturing Energy and Carbon Footprints.

This small, focused working group was successful in meeting the peer review objectives in the timeframe allotted. The working group results improved the accuracy of the Manufacturing Energy and Carbon Footprints. The authors of this paper would like to express their gratitude to the working group members and to the manufacturers that were consulted in this effort. Their efforts were voluntary and greatly appreciated.

\section{REFERENCES}

Reference 1 - Energy Analysis of 108 Industrial Processes, Brown et al, 1985

Reference 2 - Available and Emerging Technologies for Reducing Greenhouse Gas Emissions from Pulp and Paper Manufacturing Industry, EPA, Oct 2010

Reference 3 - Energy Efficiency Improvement and Cost Saving Opportunities for the Pulp and Paper Industry, Kramer, Klaas Jan et al., Oct 2009

Reference 4 - Waste Heat Potentials in the Drying Section of the Paper Machine in UMKA Cardboard Mill, THERMAL SCIENCE, Jankes et. al, 2011

Reference 5 - Study on Reheat Furnace Warm Charging, Alkadi, 2001

Reference 6 - Energy and Materials Flows in the Iron and Steel Industry, ANL, 1983

Reference 7 - Debunking RTO Operating Cost Sales Rhetoric, Cycle Therm

Reference 8 -Energy Efficiency Improvement and Cost Saving Opportunities for the Corn Wet Milling Industry, An ENERGY STAR Guide for Energy and Plant Managers, LBNL, 2003

Reference 9 - Energy Technology Policy and Performance Analysis a Cement Industry Perspective. European Journal of Scientific Research, Ramesh, A. et al. 2012.

Reference 10 - Energy Auditing and Recovery for Dry Type Cement Rotary Kiln Systems - A Case Study, Energy Conversion and Management, Engin, Tahsin and Vedat Ari. 2005.

Reference 11 - Energy balances of glass furnaces: Parameters determining energy consumption of glass melt process, 67th conference on Glass Problems, Beerkens, Ruud. 2007.

Reference 12 - Mathematical Modeling of a Cupola Furnace, Technical University of Denmark, Reference 13 - Methodology for the free allocation of emission allowances in the EU ETS post 2012, Sector report for the mineral wool industry, Ecofys, Nov 2009.

Reference 14 - Masters Thesis, Chalmers University of Technology Sweden, Bergek, 2011. 

